

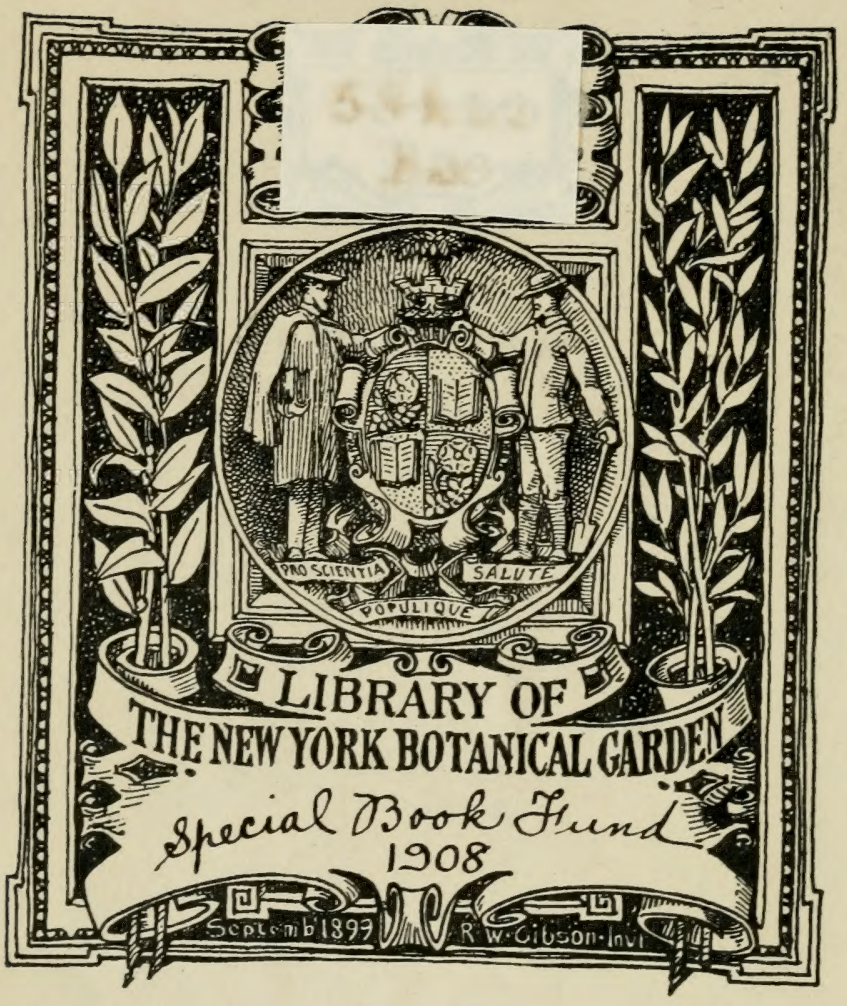








\section{DIE FAMILIE}

DER

\section{BROMELIACEEN.}

IACH IHREM HABITUELLEN CIARAKTER

BEA B BE ITET

MIT BESONDERER BERÜCKSICHTIGUNG

D E R A N A A S A

J. G. BEER.

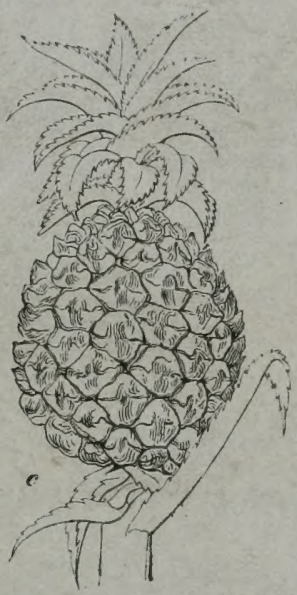

W 1 EN.

T E N D L E R \& C O M P.

M. DCCC. LVII.
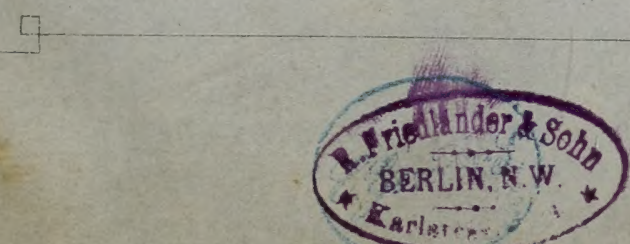



\section{DIE FAMILIE}

DER

\section{B R O M E L I A C E E N.}




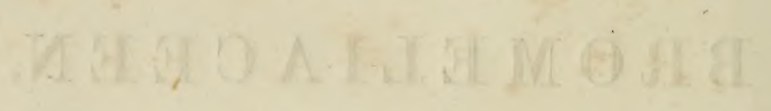




\section{DIE FAMILIE}

DER

\section{B R 0 M E L I A C E E N.}

NACH IHREM HABITUELLEN CHARAKTER BEARBEITET

3IT BESONDERER BERÜCKSICHTIGUNG

DER A N A A S A

VON

$$
\text { J. G. B }
$$

BESITZER UER K. K. ÖST. GOLDENEN GELEIIRTEN-MEDAILLE, LND DER KÜN. PREUSS. GROSSEN GOLDENEN MEDAILLE FÜR WISEENSCHAFT.

\section{LMRARY}

NEW YORK

BOTANICAL

UARDEN.

\section{WIEN.}

T E N D L E R \& $\mathrm{C}$ O M P.

M. DCCC, LVII. 


$$
\begin{aligned}
& . A 1 \\
& B H
\end{aligned}
$$

Druck ron I. C. Zamarski in Wien. 


\section{Li in l e it ung.}

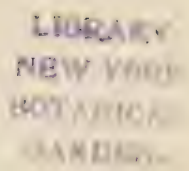

Seit dem Erscheinen meines Werkes „Praktische Studien an der Familie der Orehideen" - ward mir Gelegenheit in Berlin, durch die Güte meines verehrten Freundes, des Herrn Direktor Klotzseh, meine Studien für die vorliegende Arbeit zu vollenden.

Die Bromeliaceen bilden eine der interessantesten und die verschiedensten Formen enthaltende Pflanzenfamilie. So schwierig die Bearbeitung derselben im Anfange sich zeigte, - wie oft ich mich bei meinen vielfachen Studien darüber förmlich verlassen und in ein Labyrinth von verschiedenen Begriffen gerathen sah, erkannte ich doch bald, dass Fleiss und Ausdauer zu einem allerdings beachtenswerthen Ziele führen dürften.

Um nicht stets eine grosse Anzahl von Büchern vor mir zu haben, blieb mir nur ein Weg, nämlich alle Abbildungen von Bromeliaceen, diesich in der botanischen Literatur finden, sorgfälig zu copiren. Hierdurch gelangte ich in den Besitz eines wahrhaft nützlichen Materials; ich studirte nebenbei alle lebenden Pflanzen dieser Familie, welche mir 
zugänglich waren. Nach ihnen sind die Eintheilung sowohl als die Beschreibungen entstanden. TVer die Verwirrung kennt, welche die Feder hier angestiftet hatte, - der wird mich gewiss entschuldigen, wenn ich getragt habe, von Begränzung dieser Pflanzenfumilie bis zur Beschreilung der letzten Species, -- nur aus eigener Anschauung zu schöpfen.

Wenn man die älteren und alten botanischen Werke durchsieht, - so muss es auffallen, dass z. B. die so schönen Formen vom Genus Billbergia fast gar nicht alggebildet wurden. Erst in unserer Zeit haben, besonders die periodischen Gartenschriften, diese herrlichen Gebilde häufiger gebracht, - - was natülich den Reisenden der letzteren Jahre zu danken ist. Anderseits überrascht der Formenreichthum in den älteren Werken, zumal es zur Seltenheit gehört, eine Pflanze öfter abgebildet zu finclen.

So trifft man in den Werken des 16. Jahrhunderts wohl nur erst die Ananassa sativa abgebildet und auch beschrieben; hier ist aber auch die Verschiedenheit der Varictäten, welche zu den $A b$ bildungen gewählt wurden, -- sehr auffallend, indem jeder dieser alten Autoren eine andere Pflanzenform vor sich hatte. Bei „Ananassa" findet sich in diesem Buche das hierauf Bezügliche sorgsam gesammelt. Fast gleichzeitig ward Tillandsia usneoides, Lin. gut beschrieben und hiiufig abgebildet; es ist dies ebenfalls auffullend, indem diese Pflanzenformen doch gar keine Reize bieten und nur geringen Nutzen schaffen. Erst später ging man an die Aufgabe, die grossen Formen der Bromelien abzubilden und zu beschreiben, aber angereiht findet man wieder die kleinen niedlichen Formen von Diaphoranthema. Beer (wie Tillandsia virescens. R. et Par.), welche ausschliesslich nur. Peru und Chili zu bewohnen scheinen.

Unserer Zeit war es vorbehalten, eine Menge Werke zu fürdern, welche einen reichen Schatz von Bromeliaceen licferten. Aber hier finden sich wieder die bedauerlichsten Missgriffe: - ieh darf nur an die Flora Fluminensis ron $A$ ra b erinnern! Andere knstbare Werke, wie La Bonite, Atlas botanique par Ga ud i ehaud, 
dann La Coquille par Duperrez, entbehren, wie die zuerst genannte, - aller Beschreibung!

Bei meinem Wege der Betrachtung, - wo die Gesammtgestalt der Gewächse zur Geltung kommt, - sind solche Werke, auch ohne Beschreibung und guter Diagnose, dennoch vollkommen brauchbar, indem ohnehin auf die innere Organisation der Blüthe keine Rücksicht genommen wird.

Erst die letztere Zeit brachte Brongniard, de Vriese, Charles L e maire, Carl Ko ch u. a. m. auf den Gedanken, einige dieser Pflanzenformen nach dem Gesammtwerthe des Bliithenstandes in Genera auszuscheiden, und so entstanden die gut bezeichnenden Benennungen, wie: Eehinostachys, Macrochordium, Disteganthus, Platystachys. Anderseits sieht man aber hierdurch, wie nöthig und wohlthätig gut bezeichnende Benennungen für Genera und Species sind, - und wie verwerflich die Sucht, Namen von Personen, welche man ehren will, den Pflanzenformen zu geben.

Bei der Ordung der Bromeliaceen beginne ich mit der Begräuzung der Familie. Die dann zunächst folgende Ordnung der Hauptabtheilungen und der Sippen ist ganz kurz gefosst, und ich glaube, dass diese, - wenn der Suchende die Familie der Bromeliaceen nur einigermassen kennt, -- genügen dürfte, um gleich hierauf zur Bestimmung des Genus zu schreiten. Um aber meine Arbeit den herrschenden Begriffen nach Möglichkeit zu nühern, habe ich die Schema ausführlicher behandelt, und hiermit mich bestrebt, von jeder Form ein ganzes Bild zu entwerfen.

Diese Arbeit soll, wie ich hoffe, den Beweis liefern, dass rerschiedene IVege zur Erkenntniss von Pflanzen führen; vielleicht wird hicdurch der praktischen Anschauung ein nenes nützliches Feld angebahnt werden. Ich bin vollkommen iberzeugt, dass viele monocotyle Gewiichsfamilien auf meine Weise, die Merkmale festzuhalten, - gut erkenntlich zu bearheiten sind, immer 
aber wird die Gestalt der Gewächse die Grundlage bilden müssen.

Nach Beendigung dieser vorliegenden Arbeit habe ich begonnen, Material für eine „Denderologia“ zu sammeln. Dieser riesigen Aufgabe gehe ich mit Freuden entgegen, indem nun Wald und Flur mir ihre geheimen Blïtter öffnen sollen, um daraus die Gesetze der Wachsthumsverhältnisse zu studiren und, - wenn möglich! - in eine geordnete Reihenfolge zu bringen.

Wien am 1. Januar 1856.

\section{Der Verfasser.}




\title{
BRONELLCEAE.
}

\author{
Lindley.
}

\section{Ordnung der Bromeliaceen.}

Begränzung der Familic. Die Bromelinceen bewohnen ausschliesslich Amerika.

Staudort. Auf lebenden und todten Bäumen, selten auf der Erde, auch zwischen Fels, - oder im Sande; - dann an sonnigen, freien Stellen.

Die Pllanze. Blät ter immer einfach, strahlenförmig oder kelchhildend dicht beisammen stehend. Oft sügezähnig und stachelspitzig.

B 1 üthenstand end- oder seitenständig, meistens aufrecht und oft durch die Laubblätter der Endknospe, oder durch Hochblätter lebhaft gefürbt.

Blüthe, immer Zwitterblüthler. Drei hinfällige Kronenblätter. Drei bleibende, mit der Frucht (Kapsel, Beere) verwachsene Kelchblitter. Sechs Staubblïtter, ein Griffel. 


\section{IRauptabtheilung.}

B l üt he nstand: Endstän d i g. BROMELIEAE.

\section{Unterabtheilung.}

Bliithenschaft mit Laubbliattern besetzt.

\section{Phylantheae.}

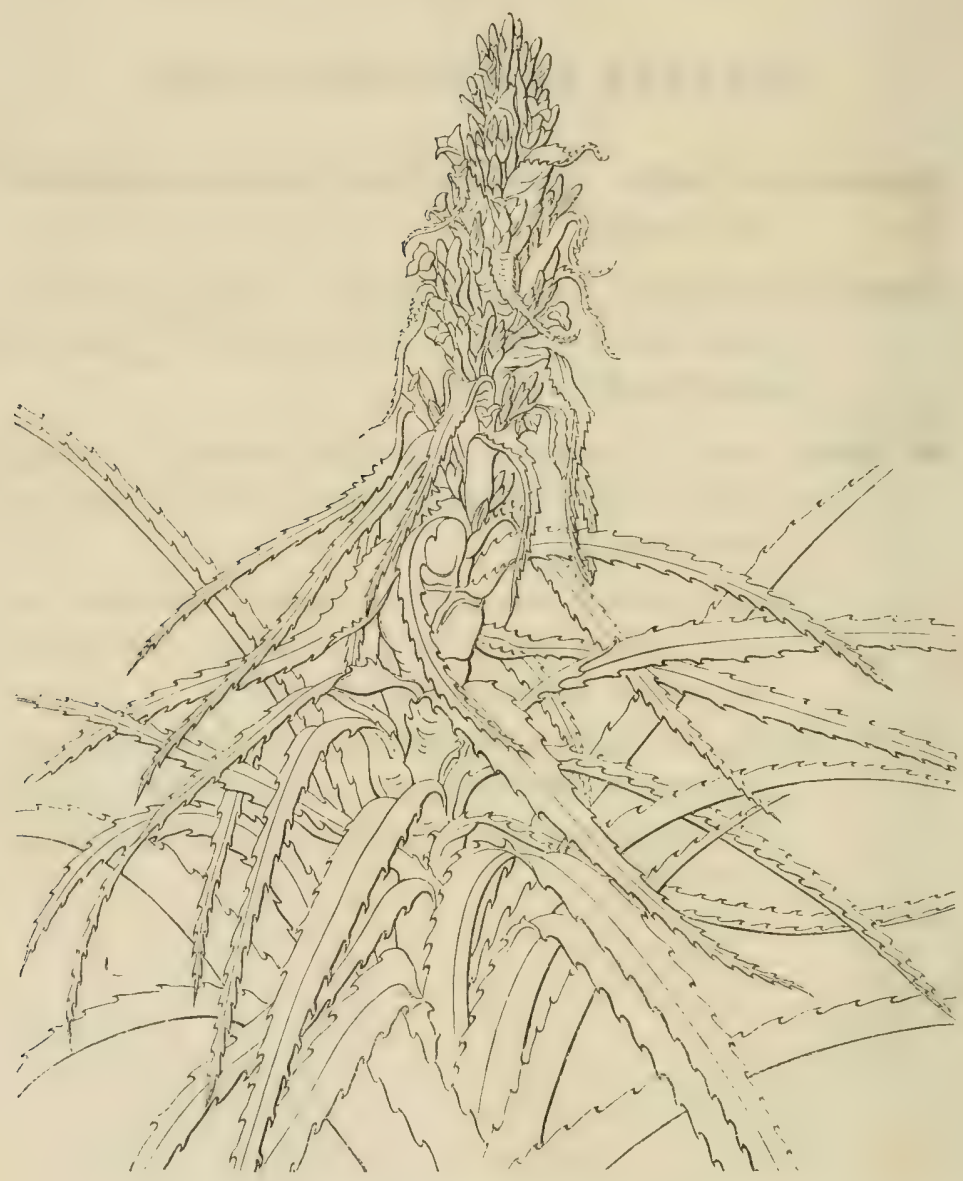

Fig. I. Agallostachys antiacanthus. Beer. 
1. Sippe. Eubromeliue.

Blüthenstand in Nitte der Herzbläter, gedrängt kopfförmig, oder locker büschelförmig, durch deutlich entfernte Laubblätter geschieden.

2. Sippe. Anaplophytue.

Pflanze an allen Theilen unbewehrt.

3. Sippe. Phlomostachyae.

Blüthenstand durch aufrecht stehende Bracteen, -. walzig --keulenförmig gebildet.

4. Sippe. Pitcainniac.

Blüthenknospen lang zugespitzt. Fruchtkuoten deutlich lyramidal, dreikantig.

5. Sippe. Hohenbergiae.

Blüthenstand rundlicht, bewehrt, an langem Stiele and cincm Laubblattkranze aufsitzend.

6. Sippe. Nidulariae.

Blüthen zwischen den Herzblättern vertheilt sitzend.

1. Sippe. Ptatystachiae.

Blüthen ausschliesslich zweizeilig gestellt. 


\section{Unterabtheilung.}

Blüthenschaft nur mit Bracteen (Hochblättern) besetzt.

\section{Lepidantheae.}

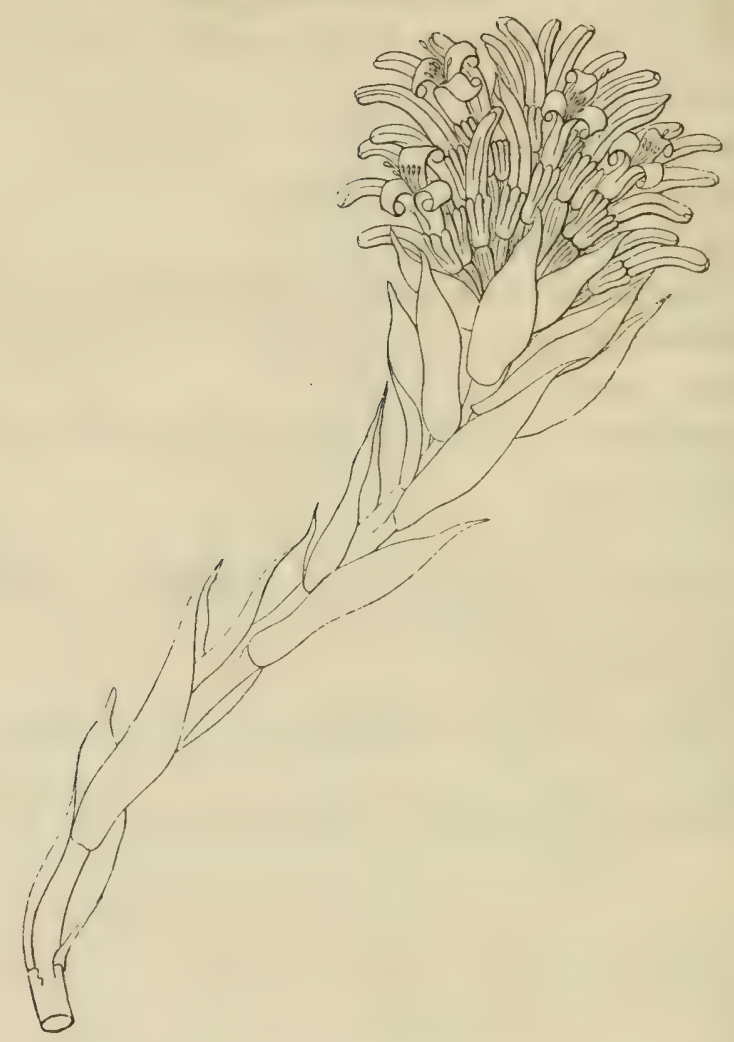

Fig. II. Billbergia fastuosa. Beer. 
1. Sippe. Vrieseae.

Blüthen ausschliesslich zweizeilig gestellt.

2. Sippe. Tussaciae.

Blüthen sparrig, Fruchtlknoten eiförmig, - glänzend, bis zur Hälfte von einer dicht anliegenden Bractee umhüllt.

3. Sippe. Guzmanniae.

Blüthenstand durch aufrechte Deckblätter, verlängert — walzenförmig gebildet.

4. Sippe. Lamprococcae.

Beeren glänzend, eiförmig oder kugelig, mit kaum sichtbaren Deckblättchen.

5. Sippe. Billbergiae.

Blüthenstand kopfförmig oder überhängend locker, traubenförmig. Kronenblätter zurückgeschlagen oder eingerollt. Hochblätter (Bracteen) weich, lebhaft roth gefärbt.

6. Sippe. Hoplophytae.

Blüthen locker, - unregelmässig am Blüthenstande vertheilt. Kelchzipfel stachelspitzig. Blumenkrone aufrecht.

\%. Sippe. Puyae.

Blüthenstand mit regelmässig verkümmernden Blüthen an den Enden.

8. Sippe. Macrochordiae.

Blüthenstand durch regelmässige und dicht aneinander stehende Fruchtknoten walzenförmig gebildet. Blüthen schwärzlicht von Farbe. 


\section{IHauptabtheilung.}

Blüthenstand mit einem Laubschopf gekrönt. ANANASSAEAE.

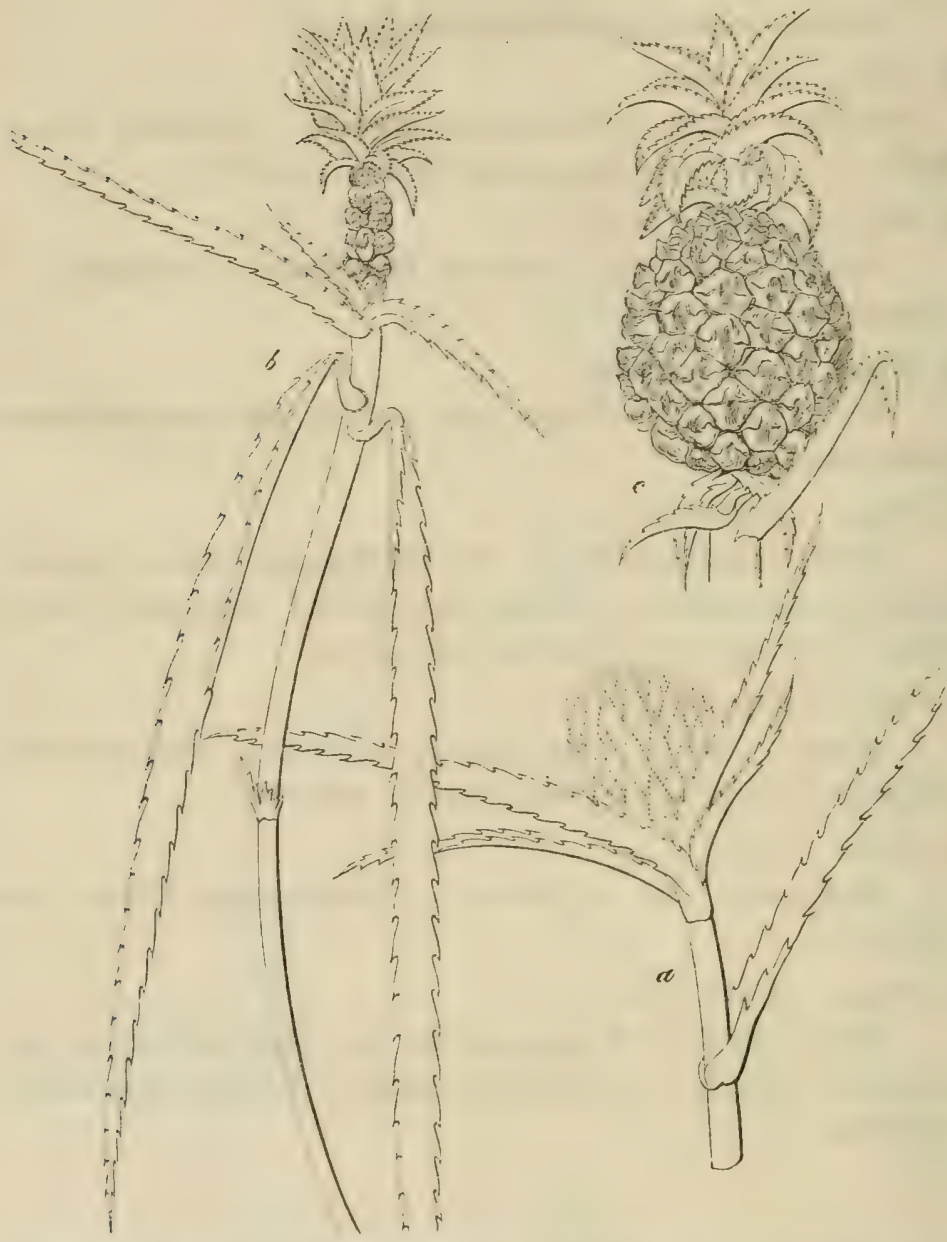

Fig. III. a. Blüthenstand der wilden Ananassa. - b. Fruclıtstand derselben. - c. Frucht der Ananassa sativa. Lind l. 


\section{1ill. 面aubtabtheilung.}

B l ï thenstand: S e itenständig. DIAPHORANTHEMEAE.

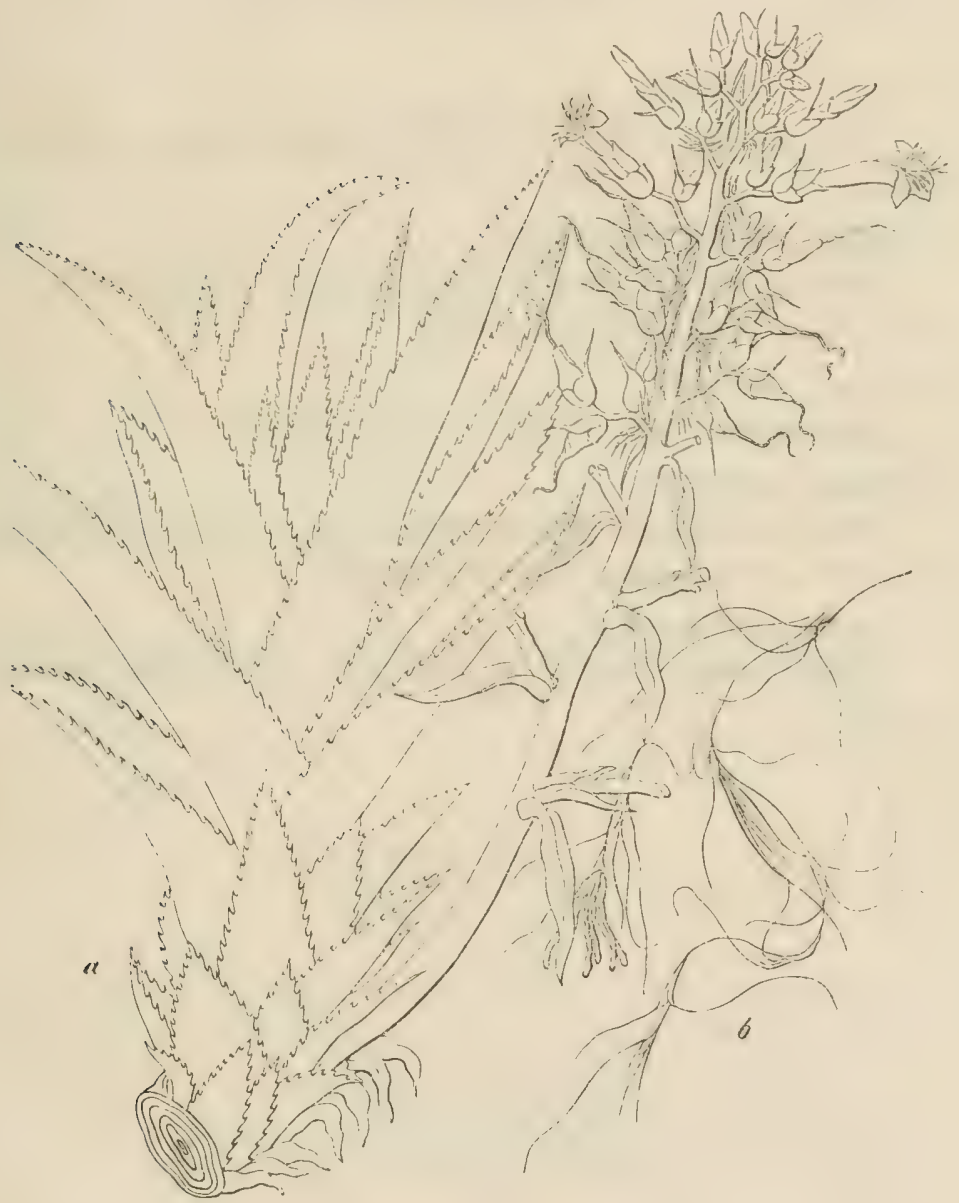

Fig. IV. a. Aeclmea paniculata. R. et Pav, - b. Tillandsia usincoides. Linné. 
1. Sippe. Tillandsiae.

Blüthen einzeln; Stamm und Aeste fädlich, dünn, schlaff herabhängend.

2. Sippe. Diaphoranthemeae.

Blüthen von aufrechten Bracteen umgeben. Blïthen nicht beständig ein-, zwei-, auch mehrblüthig.

3. Sippe. Dickyae.

Kronenblätter am Scheitel ein Dreieck bildend.

4. Sippe. Aechmeae.

Blüthen zahlreich verkümmernd. Bractee den Fruchtknoten umhüllend, seitlich, lang und starr gegrant.

5. Sippe. Disteganthae.

Blüthenstände eiförmig, grundstündig. Laubblätter deutlich gestielt. 


\section{Schema der Haupt- und Unterabtheilungen.}

I. Gesammtblüthenstand: aus der Endknospe der Hauptaxe sich entwickelnd, in keinen Laubschopf auswachsend. Frïchte: unter sich frei.

\section{Ilauptabtheilung.} BROMELIEAE.

1. Blüthenschaft seiner ganzen Länge nach mit den sich mit ihm zugleich erhebenden laubigen Herzblättern der Endknospe besetzt.

\section{Unterabtheilung, Phylantheae.}

2. Blüthenschaft seiner ganzen Länge nach mit deckblattartigen Hochblïttern (Bracteen) aus dem Laubherzen sich erhebend.

\section{Unterabtheilung, Lepidantheae.}

II. Gesammtblüthenstand: aus der Endknospe der Hauptaxe sich entwickelnd, in einen laubigen Blattschopf auswachsend. Früchte unter sich zu einer fleischigen Sammelfrucht verwachsend.

\section{Hauptabtheilung.}

ANANASSAEAE.

III. Gesammtblüthenstand: achselständig. Endknospe der Hauptund gleichwerthigen Nebenaxen: laubtragend, nie blühend.

\section{IIanptabtheilung.}

DIAPHORANTHEMEAE. 


\section{Schema der Sippen.}

\section{Iauptabtheilung.}

BROMELIEAE.

\section{Unterabtheilung. Phylantheae.}

Sämmtliche Blüthen strenge zweizeilig an ihren Spindeln angereiht.

Sippe \%. Platystachyae.

Sämmtliche Blüthen um ihre Spindeln drei- oder mehrreihig geordnet.

2. Blüthenspindel dünn, biegsam und aufrecht. Blüthenknospe lang zugespitzt. Fruchtknoten deutlich pyramidal-dreikantig. Niederblätter am Grunde der blïhenden Hauptaxe oder am Schössling sich findend; von den Laubblättern verschieden, meistens scharf bewehrt, holzig, und in einen langen scharfen Dornenfortsatz auslaufend. Sippe 4. Pitcairniae.

Niederblätter von den Laubblättern nicht wesentlich verschieden, nie in einen langen holzigen Dornenfortsatz auslaufend.

3. Deutlich entwickelter Blüthenschaft, eine gedrüngte walzenförmige, verlïngerte einfache Aehre, durch mächtig entwickelte, breite, geschindelte, farbige, aufrechte Deckblätter gebildet.

Sippe 3. Phlomóstachyae.

Blüthenstand keine lange walzige, breit beschupte Aehre bildend.

4. Blïthenstand locker, steif aufrecht. Pflanze an allen Theilen unbewehrt. Laubblätter lang zugespitzt, durch die eingerollten Laubblattrïinder rinnig oder piriemenförmig gestaltet, matt silberglänzend, oder pergamentartig glatt.

Sippe 2. Anoplophytae.

Laubbätter starr, an den Rändern oft bewehrt; die Bliithen zwvischen den Herzblättern sitzend. 
5. Blithen einzeln, - in Reihen, oder kop ffö rmig büschelig zusammengedrängt, in den Achseln der sie weit überragenden Herzblätter sitzend. Sippe 6. Nidulariae.

Blüthenschaft deutlich entwickelt, oder, wenn sehr verkürzt, - eine mächtige, endständige, einfache, kopfförmige Aehre tragend. Laubblätter starr, scharf bewehrt.

6.

6. Blüthenschaft mit gedrängt oder deutlich entfernt stehenden, an den Rïndern meist dornig bervehrten Laubblïttern besetzt.

Sippe 1. Eubromeliae.

Blïthenschaft sehr verlïngert, stielrund, düm biegsam, mit wenigen, sehr entfernt stehenden, meist verkürzten, an den Ründern dornig bewehrten Blättern besetzt; die obersten stärker entwickelt, unter der sitzenden Aehre zu einer langen und breiten laubblattartigen griuen Hülle zusammengedräingt.

Sippe 5. Hohenbergiae. 


\section{Schema der Gattungen.}

\section{Ilauptabtheilung.}

\section{BROMELIEAE.}

\section{Unterabtheilung. Phylantheae.}

1. Sippe. Eubromeliae.

Laubblätter steif, immer scharf dornenzähnig. Herzblätter zur Blüthezeit lebhaft roth oder braun sich färbend.

Kronenblätter dünnlı̈utig, deutlich fiedernervig. Lockere einfache oder ruthenförmige verzweigte Aehre. Deckblätter und Kelchzipfel unbewehrt. Encholirium.

Kronenblätter derbe, anscheinend nervenlos. Deckblätter oft bewehrt, - Kelchzipfel oft stachelspitz.

2. Kopfförmige gedrungene Aehre, welche von den Laubblättern überragt wird.

Bromelia.

Büschelig oder traubig zusammengesetzter, steif aufrechter Blüthenstand. Schaft mit deutlich entfernt stehenden Laubblättern besetzt. Agallostachys.

2. Sippe. Anoplophytae.

Blüthenstand locker aufrecht. Kronenblätter länger als der Kelch. Anoplophytum.

3. Sippe. Phlomostachiae.

Blüthenstand steif aufrecht, eine einfache walzenförmige Achre bildend.

Maishlätterartige Belaubung. Blumenkrone rachenförmig.

Phlomostachys.

Laubblätter fein sägezähnig und stachelspitz. Deckblätter bei den Bliithen steif, an den Rändern gefaltet, fein sägezähnig. Kronenblätter gleichmässig aufrecht.

Quesnelia. 


\section{Sippe. Pitcairniae.}

Laubblätter zahlreich, schlaff, schmal, selten scharf gewimpert, nie stachelspitzig, vom Grunde aus abstehend, oft mit weissem oder braunem kleiigem Ueberzuge auf den Blattflachen versehen. Sehr selten; mit rein weisser, lang zottiger WVolle dicht bekleidet.

Kronenblätter zweilippig, - rachenförmig geschindelt.

Staubfaden und Griffel sichtbar, -- herabgeneigt.

Pitcairnia.

Kronenblätter schneckenlinig zurückgerollt. Staubblätter und Griffel gerade, - weit vorgestreckt.

Cochliopetalum.

Kronenblätter steif aufrecht. Blumenkrone regelmässig. Staubblätter und Griffel aufrecht, kürzer als die Kronenblätter.

Orthopetalum.

5. Sippe. Hohenbergiae.

Blïthenschaft mit mehreren scharf bewehrten Laubblättern gekrönt, aus deren Mitte sich der bewehrte, steif aufrechte Blüthenstand rundlich erhebt.

Hohenbergia.

6. Sippe. Nidulariae.

Blüthen zwischen den Herzblättern vertheilt, - sitzend.

Laubblätter weich und dïnn, auf der Aussenseite gewöhnlich mit sehr feinen, scharf begränzten Längslinien geziert. Blüthen einzeln zwischen den Herzblättern sitzend, kaum sichtbar. Herzblätter zur Blüthezeit sich roth und gelb färbend.

Caraguata.

Laubblätter steif, pfriemenförmig zugespitzt, mit weiss kleiigem und fein warzigem Ueberzuge versehen. Blithen frei, lang vorgestreckt, röhrenförmig, einzeln zwischen den Blättern sitzend. Die Spitzen der Herzblätter zur Blüthezeit sich matt blutroth färbend.

Pityrophyllum.

Beer, Bromeliaceen. 
Laubblätter glatt, bewehrt. Die Blüthen in geordneten Reihen zwischen den Blattachseln und den Herzblättern sitzend. Blüthen stumpf spitz, kaum geöffnet. Herzblätter zur Blüthezeit lebhaft hochroth gefärbt.

\section{Nidularium.}

Laubblätter stark wellig, steif, mit breit wulstiger Mittelrippe, durch kleiigen Ueberzug, mit Querbinden oder feinen Punkten geziert. Blüthen weiss, - gehäuft, anscheinend gipfelständig, fast fleischig, mit welligem, flattrigem Saume.

Chryptanthus.

7. Sippe. Platystachiae.

Blüthenstand oder dessen Zweige rein zweizeilig.

Laubblätter lederartig, mit gedehnter Spitze, oft mit weisslichtem Anfluge dicht bekleidet. Deckblütter an den Aehren der Länge nach mehr oder minder flach zusammengedrückt.

Platystachys. 


\section{Schema der Sippen.}

\section{Ilauptabtheilung. \\ BROMELIEAE.}

\section{Unterabtheilung. Lepidantheae.}

Sämmtliche Blüthen strenge zweizeilig an ihre Spindel angereiht.

Sippe 1. Vrieseae.

Sämmtliche Blüthen in drei oder mehreren Zeilen um ihre Spindel gestellt.

2. Aehre einfach cylindrisel, mit sehr dicht zusammengedrängten Blüthen. Blumenkrone gleich nach dem Oeffnen sich schwärzlich färbend.

Sippe 8. Macrochordiae.

Blüthen, die Oberflïche der gemeinsamen Spindel nie vollkommen bedeckend. Blumenkrone sich nicht schwärzlich verfärbend.

3. Blüthenstand verzweigt. Kronenblätter aufrecht. Kelchzipfel stets stachelspitzig. Deck- und Laubblitter meistens scharf bewehrt.

Sippe 6. Hoplophytae.

Kelchzipfel, Deck- und Stützblätter nie bewvehrt. 4.

4. Blüthen gegen das Ende der Haupt- und Zweigspindel des Blüthenstandes regelmässig verkümmernd. Die Deckblättchen bleibend. Sippe 7. Puyae.

Ende der Haupt- und Zweigspindel des Blüthenstandes nie regelmässig verkümmernd.

5. Walzenförmige verlängerte einfache, mit breiten geschindelten, die Blüthe fast überragenden Deckblättern, besetzte Aehre. Laubblätter glatt. Blumenkrone regelmässig und aufrecht stehend.

Sippe 3. Guzmanniae.

Blüthenstandspindel sehr dünn, verzweigt, oft überhängend.

Die sparrigen Blithen in den Achseln der dicht anliegenden, 
den eiförmigen Fruchtknoten über die Hälfte der Länge umfassenden Deckblättern, - gleich weit entfernt stehend. Sippe 2. Tussaciae.

Glänzende eiförmige, oder kugelige, gewöhnlich schön gefürbte Beerenfrüchte, Blüthen unansehnlich, sammt dem ganzen Blüthenstande, den Laub- und den winzigen Deckblättchen; glatt, - unbewehrt.

Sippe 4. Lamprococcae.

Blüthensiand steif aufrecht, oder zierlich überhïngend. Deckblättchen häufig fehlend. Blumenkrone den Kelch weit überragend. Saum der Ersteren entweder einfach zurückgeschlagen, oder mehrfach schneckenlinig eingerollt. Fruchtknoten, Stielchen und Schaft wollig oder mehlig bekleidet. Hochblätter weich, gewöhnlich prachtvoll roth gefärbt. Laubblätter scharf bewehrt.

Sippe 5. Billbergiae. 


\section{Schema der Gattungen.}

\section{Hauptabtheilung.}

BROMELIEAE.

\section{Unterabtheilung. Lepidantheae.}

1. Sippe. Vrieseae.

Blüthenstand oder dessen Zweige rein zweizeilig.

Laubblïtter beiderseits glänzend, dünn, fust durchsichtig, gleich breit, mit stumpfen Enden. Pflanze ganz unbewehrt. Deckblätter an den Aehren der Lănge nach mehr oder minder flach zusanmengedrückt. Vriesea.

2. Sippe. Tussaciae.

Laubb]ätter weich, lederartig ganzrandig, stumpf-spitz endend, oft sehr zierlich farbig gefleckt und bemalt. Bracteen, Fruchtknoten und Kelchzipfel gleichmässig trüb grün, oder anders gefurbt, - glänzend glatt. Der ganze Blüthenstand schmảchtig.

Tussacia.

3. Sippe. Guzmanniae.

Blüthenstand steif aufrecht, eine walzenförmige, lebhaft mehrfarbige Aehre bildend. Pflanze ganz unbewehrt. Deckblätter schwach gewölbt.

Gusmannia.

4. Sippe. Lamprococcae.

Blüthenspindel fleischig, biegsam, häufig vielästig, mit hin und her gebogenen Spindelchen. Pflanze ganz unbewehrt. Laubblätter glänzend.

5. Sippe. Billbergiae.

Lamprococcus.

Laubblätter kelchbildend, am Grunde dicht zusammen stehend, steif, scharf bewehrt, mit den Enden zierlich ausgebreitet; lebhaft grün, oft mit weisslichten Querbinden versehen. Kelchzipfel fleischig, sammt den Fruchtknoten weiss filzig oder mehlig bestäubt.

Billbergia. 
6. Sippe. Hoplophytae.

Laubblätter sehr steif, sügezähnig. Fruchtknoten sammt den kurzen Kelchzipfeln eiförmig. Blumenkrone aufrecht, wenig geöffnet. Befruchtungsorgane gar nicht sichtbar. Hoplophytum.

Kelch mehrfach schraubenförmig zusammengedreht. Fruchtknoten klein, an langen Stielchen hängend. Blüthenstand stark verzweigt, entschieden überhängend, mit eiförmigen, scharf bewelirten Hochblättern der ganzen Länge nach besetzt. Laubblïtter gleich breit, seharf sïgezähnig und stachelspitz. Eingedrehter Rand der Kelchzipfel, zart, häutig, glatt. Aeusserer Rand verdickt, vielnervig, in eine Dornspitze auslaufend, - sehief. Streptocalyx.

\%. Sippe. Puyae.

Hochblätter hinfïllig, schlaff. Pflanze baumartig.

Laubblätter bewehrt, schmal, mit langgedehnter, weicher, hellbrauner Spitze endigend, im zierlichen Bogen nach allen Richtungen überhängend. Blüthenschaft steif aufrecht, stark verzweigt. Kronenblätter aufrecht, bauchig, geöffnet.

Pruya.

8. Sippe. Macrochordiae.

Blüthenstandspindel sammt Deckblättchen dicht, weiss wollig, ganz unbewehrt. Kelchzipfel rund fleischig; meistens unbewehrt. Kronenblätter gerade, - abstehend.

Macrochordium.

Blüthenstandspindel sammtDeckblättchen brüunlich filzig, letztere lang und starr gegrant. Kelchzipfel mit aufwärts gebogener Dornspitze. Kronenblätter gerade abstehend.

\section{Echinostachys.}

Blüthenstandspindel sammt Deckblättchen glänzend, - glatt; letztere breit umfassend, - lang und starr gegrant. Kelchzipfel mit aufrechter Dornspitze bewehrt, die Blumenkrone überragend.

Chevaliera. 


\section{Schema der Sippen.}

\section{IIauptabtheilung. \\ DIAPHORANTHEMEAE.}

Stamm und Aeste herabhängend, verschlungen, fädlich, mit seh. entfernt stehenden Blättchen. Blüthe einzeln aus einer Scheide hervortretend.

1. Sippe. Tillandsiae.

Stämme aufrecht, mit am Grunde zusammengedrängten Blättern. Blüthenschaft steif aufrecht, nie constant ein-, sondern mehrblüthig.

2. Sippe. Diaphoranthemeae.

Sümmtliche Blüthen vollkommen entwickelt. Blumenkrone am Scheitel abgestutzt, entschieden dreieckig.

3. Sippe. Dycliae.

Bliithenstand erscheint am Stamme unter den Laubblittern; er trïgt zahlreiche verkümmernde, in lange starre Grane ungewandelte Blüthen. Deckblätter der entwickelten Blüthe mit den Ränderı den Fruchtknoten ungreifend, seitlich lang und scharf gegrant.

4. Sippe. Aechmeae.

Grundständiger, niederliegender, eine gedrungene eiförmige, stiellose, walzige Aehre bildender Blüthenstand.

5. Sippe. Distegantheae. 


\section{Schema der Gattungen.}

\section{Hauptabtheilung.}

\section{DIAPHORANTHEMEAE.}

1. Sippe. Tillandsiae.

Laubblätter schmal lineal oder fadenförmig. Blüthenblätter länger als die Kelchzipfel, rund und ausgebreitet zurückgebogen. Scheidenblatt bei der Blithe diitenartig, den Fruchtknoten ganz umhüllend. Tillandsia.

2. Sippe. Diaphoranthemae.

Blüthenspindel von geschindelten spitzen Bracteen am Blüthenstande, dicht umgeben. Blüthe aufrecht, zwischen den Deckblättern wenig vorstehend.

Diaphoranthema.

3. Sippe. Dyckiae.

Vielblumige, steif aufrechte, lockere, oft verzweigte Achre. Schaft lang, Stiel rund, sparsam mit kleinen, trockenhäutigen Hochblättern besetzt.

Dyclia.

4. Sippe Aechmeae.

Schaft steif aufrecht, stielrund, mit wenigen abstehenden, scharf bewehrten Blättern besetzt. Kelch und Kronenzipfel unbewehrt, ersterer schraubig gedreht. Deckblitter der entwickelten Blüthen lederartig, die verkïmmernden zusammengerollt, die verkümmernde Blïthe dicht umsehliessend, um vieles kleiner und schmäler. Die scharfe Grane jedoch -.. vollkommen ausgebildet.

Aechmea.

5. Sippe. Disteganthae.

Kronenblïtter weit geöffnet, gerade abstehend. Kelchzipfel stachelspitzig. Blüthenstand eingehüllt in geschindelte, bewehrte, herzförmige Deckblitter. Laubblitter deutlich gestielt.

Disteganthus. 


\section{Repräsentanten der Gattungen.}

Genus Encholirium. - Encholirium Augustae. K. Preuss. Garten-Verh. 1846. Br. XVIII.

" Bromeli a. - Brom. longifolia. Rud. Paxt. Fl. Gard. II. t. 65.

"Agallostachys. - Brom. sylvestris. Bot. Register t. 2392.

"Anoplophytum - Till. stricta. Sol. Bot. Magazin t. 1529.

" Phlomostachys. \& Puya Allensteinii. Bot.Mag. t. 4309.

"Quesnelia. - Quesnelia rufa. Gaud. Bonite t. 54.

"Pitcairnia. - Piteairnia ringens. Icones pl. H. Berol, t. 25.

"Cochliopetalum. - Pitcairnia stamminea. Loddiges

Bot. Cab. t. 722.

"Orthopetalum. - Pitcairnia lanuginosa. R. et P. Flora

Per. et Chilensis t. 258.

" Hohenbergia. - Hohenbergia strobilacea (Acanthostachys strob.). Icones pl. H. Berolinensis t 9.

" Caraguata. Caraguata lingulata. Annales de Gand. III.

" Pityrophyllum. - Tillandsia ionantha. Pl. Flore van

Hontte. t. 1000.

" N idul a ri um. - Nidul. fulgens. Jardin Fleuriste 1V. t. 411.

" Cryptanthus. - 'Tillandsia acaulis. Bot. Reg. t. $115 \%$.

"Platystachys. - Tillandsia setacea. Bot. Mag. t. 2375.

"Vriesea. - Vriesea speciosa. Bot. Mag. t. 4382.

$"$ Guzmannia. - Guzmannia tricolor. Annales de Gaud.III.

"Tussacia. - Tussacia vittelina. Icones pl. Berolin. t. 40.

"Billbergia. - Billbergia pyramidalis. Bot. Mag. tab. 1732, auch Billbergia farinosa. Bot. Mag. tab. 2686.

" Hoplophytum. - Billbergia fusciata. Bot. Reg. t. 1130, auch Aechmea mucroni flora. Bot. Mag. 4832.

"Streptocalix. - Wien. Mus. Sp. Amazonas, Ega. Poeppig.

"Puy a. - Pourretia coarctata. R. etP. Gaudichaud Bonite t. 41. 
Genus La m prococcus, - Aechmea fulgens dis. Bot. Mag. t. 4293.

, Ma croc h ordi u m. - Billb. tinetoria. Annales de Gand.III. 56.

"Echinostachys. - Echinostachys Pinellianus. Hort.

"Chevaliera. - Chevaliera ornata. Gaud. Bonite t. 61.

"Ananassa Lindl.

" Tillandsia. - Till. usneoides. Lamarque Encyclop. t. 224.

" Diaphoranthema. - Tillandsia recurvata. R. et $P$. Flora. P. et Chil. t. 271.

"Dyckia. - Dyckia rariflora. Bot. Mag. 3449.

"A echmea. - Aechmea paniculata. R. et P. Flora Per. et Chilensis t. 264.

" Disteganthus. - Disteganthus basi-lateralis. Flore van Houtte III. 


\title{
Beschreibung der Arten.
}

\section{ENCHOLIRIUM Martius.}

\author{
Ench. A ugustae R. Schomburgk.
}

Berliner Gartenbau - Verhandlungen vom Jahre 1846 albgebildet.

Die trockenen Exemplare des liönigl. preuss. Museums No. 1021, welche $\mathrm{R}$. Schomburgk am Roreima im englischen Guiana sammelte, und nach welchen die Benennung und Abbildung geschah, bilden, mit der Zeichnung verglichen, aulfallende Unterschiede, indem an den Original-Exemplaren die Laubblätter, welche sich mit dem Blïthenstande crheben, vollkommen jenen gleichen, welche den Stamm umgeben; sie sind nämlich aufrecht spitz zulaufend und stehen fast in gleicher Höhe mit dem ganzen Blüthenstande. Die Abbildung hingegen zeigt Bracteen, welche gestreift, kurz, stumpf spitz erscheinen. Diese irrige Zeichnung der oberen Laubblätter ist auffallend. -

Die Pflanze sammt dem Blüthenstande zwischen 1 und $1 \frac{1}{2}$ ' hoch, die unteren Laubblätter schwach sägezähnig, und zeigen einen Mittelnerv; sie sind bei 8"lang, am Rande etwas wellig und unordentlich auf- und abwärts gerichtet. Der Schaft erhebt sich steif gerade, ist

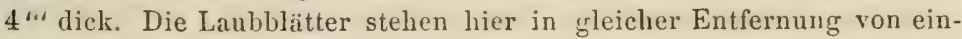
ander, und zwar steif aufrecht. Hier verlicren sich die Sägezähne allmälig, auch die Blattläche wird schmal, spitz. Der Bliithenstand bildet eine etwas geneigte Aehre und ist, da die Blüthen am Ende desselluen sehr nahe beisammen stehen, gegen oben keulenförmig gebildet. Bei jeder Blüthe steht eine 2" lange lanzett-eiförmige Bractee. Die ganze Pflanze ist bis auf die schön rothbraun gefürlten Blïthen - lebhaft grün und weich behaart. Blüthenstielchen $3 / 4$ " lang. Kelchzipfel 7." lang, lanzettförmig, anliegend. Blüthen flatterig, - offen, Kronenblätter am Rande etwas wellig, weich, fiedernervig. Genitalien nur wenig kürzer als die Kronenblätter, in der Blüthe tief hinein sichtbar. Diese herrliche Species ist eine zicrliche Erscheinung, welche durch die so seltsame Fürbung der Blüthen reizend genannt werderı kann.

Ench. Garreli Beer.

Garrelia encholirioides. Gaudichaud. Bnnite. Atlas botanique tab. 115.

Pflanze, Laubblätter und Blüthenstand aufrecht; Blätter an Grunde stark umfassend, sehr steif, scharf sägezähnig und stachelspitz; sie sind 
kaum 1' lang, in der Mitte $1 / 2$ " breit. Die Laubblätter am Schaft sind sparsam vertheilt, mit der Spitze herabgebogen. Der Blïthenstand ist stark verzweigt, jeder Zweig über 1' lang. Blüthen einzeln sparrig stehend, mit einer kleinen anliegenden Bractee verselen. Blüthen fest auf'sitzend. Kelchipipfel tiel eingeschlitzt, anliegend, 4"' lang. Kronenblätter weit geöffnet. Genitalien sichtbar. Der ganze Blüthenstand, mit Ausnahme der Kronenblätter, mit weichen Haaren bekleillet. Das herrliche, kostbare Werk L a Bonite hat ebenfalls gar keine Beschreibung der Pflanzen, obwohl die Abbildungen mit dem grössten Aufwande besorgt wurden. Ueber die Färbung der Pflanze sowie der Blüthen ist nichts bekannt.

\section{BROMELIA Plımier.}

Brom. h u milis Linné.

Jacquin's Icones plantarum rariorum I. tab. 60.

Stamm kaum 6" hoch, Laubblätter scharf bewelırt, strahlenförmig abstehend, am Grunde holzbraun, sonst lelhaft dunkelgrün, über 1' lang, 1" breit. Seitensprossen am mittleren Theile des Stammes hervorbrechend, anfangs aufstrebend, dann gegen die Erde gesenkt, um sich festzuwurzeln. Wenn die Planze den Blüthenstand treibt, färben sich die Herzblätter vom Grunde ans bis zurHälfte der Länge, oder die innersten selbst ganz - lebhaft blutroth. Blüthenstand sitzend, Blüthe dunkelblau und wie geschlossen, am Grunde in einem weisslichten Filze gebettet. Die Genitalien viel kürzer als die aufrechten Kronenzipfel. Der Stamm erscheint zur Blüthezeit mässig verdickt.

Merkmal der Species: Die rothgefärbten Laubblätter legen sich an den Blüthenstand an und stehen mit gleicher Höhe der Blüthen plötzlich gerade ab.

Die wollig umkleideten, kaum vorragenden Blüthen.

\section{Brom. Karatas Jaequin.}

Jacquin. Plant. hort. bot. Vindobonensis t. 31. Jacquin Select. strip. Americanorum Historia tab. 178. Fig. 26 (Caraguata acanga). Kerner. Hortus semper virens tab. 109. Hernandez. Rerum med. n. Hispaniae Thesaurus XV. Seite 272. Mexocotl (Fruchtstand). Morison. Hist. 2. p. 218, 8. 4, t. 22. Fig. 7. (Fruchtstand.)

Pflanze stengellos zierlich. Blätter zahlreich, alle wurzelständig, piriemlich lineal, stachelspitz, dornig gewimpert, anfrecht, weniger starr als bei anderen Species von Bromelia, daher oberhalb meist zurückgebogen, öfter über manneshoch. Blüthen geruchlos, bei 3 "lang. Kelch und Fruchtknoten mit rother. Wolle bekleidet, die Krone rosenfarbig. Frucht eiförmig, 3" lang, vicle ( - 2 bis 300) zugleich. in der Mitte der 
dann etwas mehr abstehenden Blätter sitzend, bilden eine halbkugelförmige Scheibe, mit dem Durchmesser von $1 / 2$ '. Diese enthalten unter einer lederartigen und gelblichen Rinde ein weisses, saftiges Fleisch von süss-sanerem Geschmacke, in welchem sehr viele kahle, fast rundliche und braune Samen liegen. Abgeschält gefällt das Fleisch dem Gaumen nicht übel.

J a c quin.

Standort: Bergwälder an Baumstämmen. Cuba, Martinique.

M erkmal der Species: Der flachrunde Blüthenstand.

Die geschlossenen, dunkel weinrothen, alle fast gleich hoch stehenden Bliithen.

Die weit abstehenden, röthlich lederfarbenen, breiten, einen Kranz um den Blüthenstand bildenden, längslinigen Blätter zunächst den Blüthen.

Der knollig verdickte, kurze, reich beblätterte Stamm.

\section{Brom. concentrica Beer.}

Tillandsia concentrica Arrab. Flora Flumiuensis III, tab. 133.

Da bei den Abbildungen der Flora Fluminensis keine Beschreibung sich findet, ist nur Muthmassliches über Färbung u. s. w. zu sagen.

Der Form des Blüthenstandes nach gleicht dieses Prachtgebilde der Brom. Karatas, obwohl n u r hi er eine Aehnlichkeit sich findet.

Laubblätter zungenförmig, flach ausgebreitet, 3 " breit, bei 6 " lang, sägezähnig, wahrscheinlich auf grünem Grunde mit unregelmässigen, runden, bis 1 "grossen rothen Flecken geziert. Die sehr regelmässig stehenden Blüthen bilden einen kreisrunden, von den Laubblättern begränzten Blïthenstand. Jede Blüthe trägt ihre Bractee, welche mit derselben gleiche Höhe hat.

Der Stamm dieser herrlichen Pflanze kriecht an den Bäumen hinan, und lässt die entblätterten Strünke zurïck. Jedenfalls ist diese Planze eines der wünschenswerthesten Gewächse für unsere Sammlungen.

Merkmal der Species: Die platt abstehenden Laubblätter, welche in schöner Vertheilung eine Schüsselform darstellen.

Die - wahrscheinlich - lebLaft roth gefleckten Laubblätter.

\section{Brom. Carolinae Beer.}

Billbergia Caroline van Houtte. Nidularium sp. Hort. Guzmannia picta? Hort.

Ich habe diese schöne Pflanze, welche in Berlin und Hamburg sich ziemlich verbreitet findet, als Billb. Caroline von van $\mathrm{H}$ ou t te erhalten.

Diese schöne Species, so wie alle, welche der Gattung Bromelia angehören, verändern Stellung und Färbung der inneren Laubblätter, 
so wie die Pflanzen sich zum Blühen vorbereiten. Vor dieser Epoche hat die Pflanze die Laubblätter alle steif aufgerichtet, und gleichfarbig, von der Spitze bis zur halben Länge lebhaft hellgrün. Das Blatt ist am Grunde ganz umfassend, dann bauchig $2 \frac{1}{2}$ " breit, bis zu $4^{\prime \prime}$ der ganzen Länge, mit weichem Rande weisslicht glänzend, grün; von hier an bildet dasselbe eine tiefe Rinne, welche endlich verflacht, und das zungenförmige Blattendigt miteiner etwas gedrehten $2^{\prime \prime \prime}$ langen weichen Spitze. Die Laubfläche beträgt in der Mitte $2 y_{2}$ " und ist $1 y_{4}$ Schuh lang. Die zahlreichen Laubblätter sind alle ziemlich gleich lang, vor der Blüthezeit steif aufrecht. Endlich, weun die Blïthezeit herannaht, werden die Spitzen der inneren Laubblätter lebhaft blutroth gefärbt; diese Färbung schreitet rasch vor, - dergestalt, dass im Zeitraume von mehreren Tagen der innere Kranz derselben bis auf den Grund sehr schön roth gefärbt erscheint; in dieser Zeit legen sich aber die Laubblätter wagerecht und es tritt nun in Mitte der Laubblätter der diclıt geschlossene, glänzend hellgrüne, kopfförmige Blüthenstand hervor. Dieser erhebt sich nur sehr wenig und ist immer von den Laubblättern weit überragt. Die stumpf pfriemenförmigen Blüthenknospen sind alle gegen das Centrum gerichtet. Die Blüthen entwickeln sich einzeln, aufgerichtet $1 /{ }^{\prime \prime}$ lang, die Zipfel wenig geöfnet, - lebhaft blau. Die Genitalien sind um vieles kürzer als die Kronenblätter. Der Bläthenstand ist $1 y_{4}$ " breit, dicht begränzt von den umfassenden, glänzend rothen Laubblättern. Bei genaverer Untersuchung zeigt sich, dass jede Bliithe eine flattrige, schmutzig hellgrüne, bei 1 " lange, fast $1 / 2$ " breite Bractee trägt; der Fruchtknoten ist fast weiss, die Kelchzipfel aber etwas fleischig, weich spitz, von sehr lebhaft grüner Färbung. Im Verblühen krümmen sich die Kronenblätter ganz zusammen und bilden einen blauen Knäuel in Mitte der steif aufrechten Kelchzipfel.

Die Pflanze hat in Blüthe einen Iurchmesser von $2 \frac{1}{2}$ Schuh; sie ist durch die nun strahlenförmig abstehenden, so verschieden gefärbten Laubblätter eine wahre Zierde jeder Sammlung.

\section{Brom. tristis Beer.}

\section{Billbergia purpurea van Houtte.}

Diese kleine unscheinbare Pflanze gehört zur Gruppe der Bromelia Karatas. Laubblätter am Grunde etwas bauchig, verschieden an Länge, - die längsten 14" lang, 1' breit, am Rande mit sehr entfernt stehenden, kaum bemerkbaren Sägezähnen besetzt, stumpf spitz endigend. Kehrseite der Laubblätter vom Grunde aus schmutzig purpurfarbig, wie marmorirt; dann der ganzen Länge nach mit schwach sichtbaren Querstreifen geziert. In Mitte der Laubulätter sitzt der runde, wenig erhabene, 
1 $\frac{1}{2} "$ Durchmesser haltende Blüthenstand. Blüthen zahlreich, dicht beisammenstehend. Kelchzipfel dunkel purpur, fast schwarz, mit eingerollten Rändern und sehr spitzen, aber nicht scharfen Enden. Jede Blüthe trägt eine schmale aufrechte, kaum $1 / 2$ " lange purpurfarbige Bractee, welche aber am Blüthenstande, umgeben von den Laubblättern, - gar nicht sichtbar sind. Kronenblätter blau, aufrecht ausgebreitet, am Grunde in weiss übergehend.

Aussenseite der Laubblätter trüb grasgrün; jenc, zunächst dem Blüthenstande, ziemlich lebhaft purpurfarbig, wie marmorirt und gefleckt.

Brom. cruenta Graham.

Billbergia cruenta Hook. Botanical Magazine t. 2892.

Pflanze lebhaft lichtgrün. Die unteren Laubblätter mit schwach sichtbaren, weisslichten Querbinden geziert. Alle Laubblätter sägezähnig und stachelspitz, am Grunde den Stamm ganz umfassend; jene, welche zunächst am Blüthenstande stelıen, sind von der Spitze bis 1" breit in die Blattfäche hinein, rein begränzt, lebhaft blutroth gefärbt. Blüthenstand licht erbsengrün, mit steif aufrechten Bracteen von gleicher Farbe zwischen den Bliithen besetzt. Kelchzipfel aufrecht, schmutzig gelb. Kronenblätter eine aufrechte Röhre bildend. Kronenblattzipfel flach ausgebreitet, hier lebhaft lila, mit lichtem verwaschenem Rande, die Rölıre rein weiss. Als Knospe lebhaft weinroth. Genitalien kürzer als die Blumenröhre, Staubbeutel goldgelb.

Merkmal der Species: Der ganz grüne Blüthenstand.

Die weisse Blüthenröhre.

Die blutrothen Enden der Laubblätter.

Brom.: carnea Hort.

Bromelia longifolia Rudge, Paxton Flower Garden II, tab. 65.

Pflanze kaum 1' hoch, hell blau grün gefärbt. Laubblätter 2 ' lang, scharf sägezähnig und schwach stachelspitz. Blüthenstand fast zwischen den Laubblättern sitzend. Laubblätter an denselben und den aufrechten Bracteen, welche die Blïthen dachziegelförmig reichlich umgeben, - hell schmutzig lila, weinroth gefärbt, im Grunde lebhaft fenerroth. Blüthen sehr nahe, kopfförmig zusammenstehend, alle aufrecht, hell roth-lila gefärbt. Griffel weit vorragend, blau purpurfarbig. Staubfäden aufrecht, wenig vorragend, schmutzig goldgelb. (Die Bromelia carnea der Pariser Gärten ist wahrscheinlich diese von Lindley beschriebene und abgebildete Pflanze.)

Diese Bromelia longifolia ist auffallend verschieden von $\mathrm{B}$. longifolia $R$ udge. Lindley weist daranf hin, dass er nicht ganz sicher 
ist, die echte B. long. Rudge vor sich zu haben, jndem er die so sehr versclijiedene Blattlänge selbst bemerkt. - Die Basis der Lanbblätter scheint ebenfalls verschieden, indem bei $\mathrm{Rudg}$ e jedes Laubblatt breit umfassend endet, was bei der Ablildung von Lindley wenigstens nicht genau sichtbar ist. Es ward daher nöthig, dieser Species den Namen Bromelia carnea Hort. zu geben, um beide Formen auseinander zu halten.

Merkmal der Species: Die dicht kopfö̈rmig zusammenstehenden, ganz lila-farbenen Blüthen. Genitalien vorragend. Laubblätter strahlenförmig abstehend, 2 Fuss lang.

Brom. longifolia Rudge.

Rudge, Plantarum Guianae, tab. 49.

Blätter sehr lang, allmälig verschmälert stachelspitz und sägezähnig. Aehre sitzend zapfenförmig. Blätter alle wurzelständig, sehr dicht reitend, lineal verschmälert, gestreift, zugespitzt, von der Länge von 4 bis 5 Schuhen. Der Schaft viel kürzer als die Blätter. Die Aehre ganz bekleidet mit lanzettförmigen Bracteen, die gekerbt gewimpert. an der Basis breiter und purpurfarbig sind. Achren einzeln, gedrängt, länglich, der Längendurchmesser 3 ". Die Aehrchen 5 - bis 6 blüthig. Kelch bis zum Fruchtknoten getheilt. Die Blättchen eiförmig, coneav, zusammengeneigt, an der Basis und in der Mitte dicker, an der Spitze stachelspitz. Krone: keine. Staubgefässe 6; 3 daron sind länger. Staubbeutel waren bei der hier beschriebenen Species schon abgefallen. Pistil: Fruchtknoten rundlich. Stempel von der Länge der Staubgefässe, Narbe 3 spaltig.

Rudge.

Mrerkmal der Species: Blüthenstand eiförmig. Bracteen zwischen den Bliithen. Laubblätter am Blüthenstande aufrecht, am Grunde stark umfassend, dann kaum $1 / 2$ Zoll breit, 4 bis 5 Schuh lang.

Brom. la nuginosa Beer.

Pourretia lanuginosa Ruitz et Pavon. Flora Peruviana et Chilensis, tab. 256.

Eine sehr schöne aufrechte Pflanze, deren 8 "lange Laubblätter, $1 / 2$ " breit, am Grunde nicht ganz umfassend, mit stark entwickeltem Mittelnerv, kräftigen gleichmässigen Sägezähnen und - am allmälig spitzen Ende - - schwach stachelspitz sind. Blattläche ausgebreitet. Stamm bei $5^{\prime \prime \prime}$ dick, gegen den Blüthenstand nur wenig an Dicke abnehmend. Bliithenstand thyrsusförmig, unverzweigt, $4 \frac{1}{2}$ " hoch, 3 " breit. Blïthen und Bracteen steif aufrecht, letztere dachziegelförmig gestellt. Fruchtknoten und Kelchzipfel 1 $1 \frac{1}{4}$ "hoch, letztere stumpf spitz, wenig 
geschlitzt, dicht an den weit geöfneten, $1 / 2$ " breit, über $1^{\prime \prime}$ langen, mit stark entwickeliem Hittelnerv versehenen, am stumpfen Ende etyas zuriickgebogenen Kronenblüttern, - anliegend. Genitalien länger als die Kronenblätter, steif, gerade, weit vorragend. Griffel um $5^{\prime \prime \prime}$ lïnger als die Staubbentel.

Es folgt hier die Beschreibung von Ruitz et Pavon.

Pflanze: Blüthenstand eine sehr grosse, straussförmige Aehre. Laubulätter sägezähnig, stachelspitzig, schwertfürnig. Kelche wollig, Krone dunkel grünlich gefärbt.

Stamm rund anfgerichtet, einfach, von der Höhe von 2 Ellen, an der Basis durch Blattspuren schuppenartig bekleidet und verdickt.

Bläter dicht dachziegelförmig, schwertiörmig gerinnt, kahl, am Grunde wollig, mit Stachelspitze, und die unteren Sïgezähne zurïckgedreht, die iibrigen alle eingedreht.

Blïthen eine sehr grosse, straussförmige, endständige Aehre bildend und sich dachziegelförmig deckend, die Bracteen deutlich entfernt von einander. Bracteen eiförmig zugespitzt, ausserıalb wollig, aufgerichtet, an der Spitze endlich zurückgedreht. Keleh 3theilig, ansserhalb wollig, aschfarben, die Zipfel an der Frucht um das Doppelte kiuzer. Blumenblätter 3, grïnlich, unterhalb in Form einer Röhre zusammengewunden, oberhalb offen zurïckgeschlagen, im Verwelken von Purpurfarbe, mit den Staubgefüssen und dem Pistil spiralig eingedreht.

Peru u. s. w., an Hügeln und in Hainen, an Felsen, gewöhnlich Carpals genannt. Sept., Oct., Nov. Der Blüthenstand enthält kristallhellen Guimmi.

$\mathrm{Ruitz}$ et $\mathrm{Pavon}$.

Brom. arvens is Arrab.

Flora Fluminensis III, tab. 114.

Eine sehr grosse Planze, deren tiefrinnige, stark umfassende, bei 4" breite, fein sägezähnige und stumpfe Spitze, aufrechte zahlreiche Laubblätter, dem Gewächse ein sehr liräftiges Anschen verleihen müssen. Schon der Unstand, dass der Blüthenschaft bei $1 \frac{1}{2}$ " dick und nur bei 1 Schuh hoch ist, zeigt von dem robusten Baue der ganzen Pllanze. Der Bliithenstand selbst ist 5" hoch und 3 " breit, stumpf eiförmig von Gestalt. Von den wenig vorstehenden Blüthen trägt jede eine aufrechte, schmal zungenförmige, fein sägezähnigge Bractee. Ueber die Färbung le’s ganzen Gewïichses ist nichts bekannt; doch hat der Bliithenstand einige Aehnlichkeit mit Bromelia longifolia.

Brom. sylvestris Arrab.

Flora Fluminensis III, tab. 113.

ist nicht Bromelia sylvestris Willdenow!

Beer, Bromeliaceen. 
Pflanze sammt Blüthenstand ungefähr 1 Schuh hoch. Laubblätter tiefrinņig, am Grunde wenig umfassend, gleichmässig breit und mit scharf hackigen Zähnen bewaffnet. Blüthenschaft über 5 " hoch und $3 /{ }^{2}$ " breit, ganz mit aufrecht stehenden schmalen, fein sägezähnigen Bracteen besetzt. Blithen kanm vorragend. Kelchzipfel etwas gegen aussen gebogen.

Dies ist ebenfalls eine Form, welche de $\mathrm{m} \mathrm{Bl}$ ü thenstande $\mathrm{nach}$ an Bromelia longifolia erinnert.

\section{Brom. c om ata Beer.}

Tillandsia comata Arrab. Flora Fluminensis III, tab. 140.

Die Laubblätter sind glatt, fast gleich breit, gleichmässig sägezähnig, kaum stachelspitz. Der Wuchs der Pflanze schlank, die unteren Laubblätter nur halb so lang als jene zunächst dem Blüthenstande, welche über 1 Schuh Lünge erreichen. Der Blüthenstand ist gedrückt eirund, $3^{\prime \prime}$ hoch und $2 "$ breit, durch zahlreiche, steif aufrechte, $1 / 4$ "breite geschindelte Bracteen gebildet. Bliithen nicht sichtbar. Von der Färbung der Pflanze ist nichts bekannt.

\section{Brom. pyramidata Beer.}

Pourretia pyramidata R. et Pav. Flora Peruviana et Chilensis, tab. 257.

Pflanze: Die Aehre pyramidal. Blätter schwertförmig, am Rande purpurfarbig, sägezähnig. Blumenkrone gelblich grün.

Stamm einfach, eine Elle lang, rund, bis zur Mitte mit Blättern bedeckt. Die Blätter dicht, dachziegelförmig, schwertförmig, rinnig, dunkelgrün, am Rande purpurfarbig, kahl, mit Sägezähnen, welche sämmtlich eingedrelıt sind. Die Blü the in einer gedrungen pyramidenförmigen Aehre angeordnet, mit ziemlich entfernt stehenden Bracteen besetzt. Die Bracteen eiförmig zugespitzt, concave stachelig, am Rande röthlich. Kelch kahl, grün, 3theilig, die Zipfel eiförmig, spitz, concav, angedrückt, unterständig, bleibend und unmerklich dreiseitig. Blumenblätter 3, eiförmig, länglich, gleich gross, bis über die Mitte in sich selbst eingerollt, von Farbe gelblich grün. Staubfäden pfriemenförmig kahl, beinahe von der Länge der Blumenblätter. Staubbeutel lineal aufsitzend. Peru, Gebirge, bei Chinhao u. s. w. auf Felsen. Blüht Juli bis October.

Ruitz et Pavon.

Pflanze sammt dem Blüthenstande nach $\mathrm{R}$ uitz $u$. Pavon $3^{\prime}$ lang. Die Laubblätter bilden einen dicht gedrängt stehenden, strahlenförmigen Büschel.

Der 3" hohe Blüthenstand trägt aufrecht stehende steife, scharf bewehrte Bracteen, welche vor dem Aufblühen der Blume die Knospe weit überragen. Beim Oeffnen der grossen 2 " langen Blüthe senkt sich die 
Bractee, welche nur von der Blïthe überragt wird, sammt dieser hrrab, welche nun hängend erscheint. Die Genitalien sind sichtbar, die Blumenkronenblätterzipfel flach und zurïckgeschlagen. Die Kelchlappen sind tief geschlitzt und lanzettförmig spitz.

\section{Brom. ignea Beer.}

Trew et Ehret, Plantae selectae, tab. 51. - Lamarque Encyclopädie, tab. 223.

Grösse der Pflanze unbestimmt. Laubblätter wie bei Ananassa sativa, schön griun, steif, gleichmässig gegen die Spitze verschmälert, gleichförmig sägezähnig und derb stachelspiłz. Die Laubblätter zunächst. dem Blüthenstande sind auf der Aussenfläche schmutzig lilafarbig, die Inneutläche aber prachtroll feuerroth. Die Blüthen stehen in einem Bïschel beisammen. Die Kelche sind lebhaft grün, die ausgebreiteten Blumenkronenblätter schön blau rosa. Genitalien nicht zu sehen. Die gefärbten Laubblätter, welche in bedeutender Anzahl den Schaft zieren, werden gegen das Ende, wo die Blïthen stehen, immer kürzer, so zwar, dass das erste farbige Laubblatt am Schafte über 1 Schuh Länge, das letzte aber nur 1 Zoll Länge erreicht. Dit ganze Erscheinung der Ptlanze ist prachtroll, und bei dieser Species dehnt sich die Hauptachse schon bedeutend in die Länge. Leider scheint diese herrliche Species noch nicht lebend in Europa eingefïhrt zu sein, obwohl unter der Masse von unbenannten Species, welche in den Gärten nun schon gesammelt sind, sich auch diese Pllanze befinden kann.

\section{AGALLOSTACHYS Beer.}

Agall. sylvestris Beer.

Bromelia sylvestris Willd. Botanical Magazine tab. 2392. - Sertum botanicum P. C. van Geel.

Diese prachtvolle Pfianze wurde rom botanischen Garten bei Berlin durch den Director F. Otto im Jahre 1823 uach England geschickt, und zwar mit dem obigen Namen. Diese Species sieht vor der Blüthe der Bromelia fastuosa Lindley recht ähnlich. Die sehr grosse Pflanze trägt über $3^{\prime}$ lange Laubblätter, welche auf der Kehrseite hellgrủn, auf der Oberfäche aber lebhaft dunkelgrün gefärbt sind. Die Laubblätter sind regelmässig scharf sägezähnig und enden ohne Stachelspitze. Wenn die Herzblätter sich mit der Endknospe erheben, fürben sie sich lebhaft roth; die Unterfäche dieser Blätter färbt sich aber lebhaft rosenfarbig. Der säulenförmige, pyramidale, steif aufrechte Blüthenstand erreicht eine Höhe von $3^{\prime}$ und 2" Durchmesser; er ist der ganzen Länge nach mit hellrothen Laubblättern besetzt, welche gegen das obere Ende, 
endlich scheidig umfassend, hier mit dunkler rothen Punkten und olne Zähne an den Blatträndern erseheinen. In den Achseln dieser Laubblätter sitzen die Bliithen büschelförmig beisammen. Kelch, Schaft und Frucht (einzelne eiförnige Früchte) sind hell blau grün und mit dunkler grünem Filze bekleidet. Blumenkronenblätter lebhaft roth, etwas zuriickgeschlagen. Genitalien aus der Blumenröhre kaum vorragend, jede Blüthe trägt eine kleine schmale, licht lederbraune Bractee.

MI rkmal der Species: Blüthenbüschel in Reihen geordnet.

Agall. fastuosa Beer.

Bromelia fastuosa Lindl. Collectanea tab. I. - Kerner, Hortus sempervirens, tab. 745.

Diese herrliche Pflanze unterscheidet sich im nicht blühenden Zustande von Agallostachys sylvestris durch einen gedrungeneren Wuchs, durch breitere, etwas kurze Laubblätter, welche in eine schwache Stachelspitze endigen; dann in Blüthe aber durch einen mehr verzweigten, freieren, wahrhaft pyramidalen Blïthenstand. Laubblätter längs des ganzen Bliithenstandes gleichförmig, am Grunde nicht scheidig umfassend; über die Hïlfte der Länge des prachtvollen, mehr als 1 1/2 Schuh hohen Blüthenstandes finden sich keine Laubblätter mehr, sondern die Zweige desselben tragen nur eine kurze, ebenso wie die Laubblätter lebhaft feurig blutrothe Färbung. Die zahlreichen Bliithenäste sind 4 Zoll lang und so wie der Schaft licht olivengriin. Fruchtknoten und Kelchzipfel ganz frei, lebhaft grün. Kronenblatter weit vorgestreckt, hell rosa, und blutroth hemalt. Genitalien nicht sichtbar. Der Schaft, Zweige und Fruchtknoten schmutzig grün, filzig bekleidet. Eine gut gehaltene l'flanze beschreibt mit ihren abstehendeu Laubblättern einen Unkreis von 12 .

Agall. P ing u in Beer.

B romelia Pinguin Linné. Jacquin. Historia select. pag. 91. - Redouté. Liliacees tab. 396. - Tussac, Flore des Antilles IV, tab. 22, - Dictionnaire de sciences naturelles, tab. 49. - J. Dillenii, Hortus Elthamensis II, tab. 211. (Ananas sauvage. Bromelia pyramidata acaulis nigris Blumier.)

Blätter dornig gewimpert, stachelspitz. Endständige Tranbe. Kelch einblättrig, tief dreispaltig, ausserhalb fast zottig, an den Fruchtknoten sitzend hinfällig. Die Zipfel lanzettlich lineal, zugespitzt gerinnt, aufrecht sehr lang. Krone dreiblättrig, lineal länglich, spitz, concav, etwas länger als der Kelch, mit dem Grunde der Kelchrühre angewachsen, Spitzen abstehend, sonst aufrecht und umfassend. Nektarium keines. Staubgefässe 6. Staubräden pfriemlich aufrecht, um die Hälfte kürzer als der Kelch, durch breite Basen unter sich und mit der Kelchröhre und den Kronenblättern verwachsen. Antheren lineal, an der Basis pfeilförmig, 
aufiecht, von der Långe des Kelches. Pistil: Fruchtlnoten lïnglich, schwach, dreiseitig, gross, filzig, unterständig. Grifiel pliciemlich, dreiseitig, dick, von der Lünge der Stanbfäden, aufrecht. Narbe dreispaltig, stumpf. Beere fast eiförmig, einficherig, fleischig, nit lederartiger Hülle. Same wenig, fast eiförmig, stumpf, eingebettet.

Laubblätter 5 bis $6^{\prime}$ lang, scharf dornzähnig und starr aufrecht; wenn der Blïthenschaft sich zu entwickeln beginnt, selbst auch frïher schon, werden die Laubblätter zunächst der Endknospe dunkelroth. Blüthenschaft 2 bis $3^{\prime}$ lang, mit weissem Filze bekleidet und mit zahlreichen, bei $2^{\prime \prime}$ langen Blïthen besetzt, deren Fruchtkmoten und Kelch ebenfalls weiss filzig bekleidet sind. Kronenblätter hellroth. Die gelblichen, ubber 1" langen Frïchte entwickeln sich schnell nach der Blïchezeit, und sind reif von unangenchm saurem Geschmacke; sie enthalten einigen braunen Samen.

Jamaica und Cartagena.

J a c quin.

Indem ich auf obige Beschreibung Jacquin's hinweise, erlaube ich mir nur zu sagen, dass die Laubblätter zwischen den zahlreichen Blïthenzweigen bis ans Ende des Blithenstandes vertheilt sind. Ihre Farbe ist ein mattes, helles Rothbraun. Die Bliithen bilden eine dicht gedrängte Pyramide, welche den Schaft, der am Grunde $2^{\prime \prime}$ dick ist, fast gïnzlich verdecken. Auch diese Species ist eines der prachtvollsten Gewächse. Als gute Abbildung kam jedoch nur jene des Redouté (Liliacees) an* geführt werden, indem bei den anderen hier noch angeführten Abbildungen die Blattbildung nicht getreu gezeichnet ist.

\section{Agall. antiacantha Beer.}

Bromelia antiacantha Bértoloni. Novi Comentarii Acad. scient. Instituti Bononiensis Tom VII, tab. 12. - Bromelia sceptrum Fenzl. Paradisus Vindobonensis

Ich habe die Beschreibung obiger Bromelia von Bertoloni genau durchgelesen. Nachdem Dr. Echard Fenzl mir anch seine Beschreibung giitigst mittheilte, fand ich nach Rücksprache mit demselben nicht mehr nöthig, selbe hier zuzuziehen, inflem Bertoloni's Brom. anthiacantha vollkommen mit Bromelia sceptrum Fenzl ubereinstimmt.

Diese Pllanze ist wohl die Königin unter den Bromeliaceen! Die herrliche, grosse, kräftige Planze hat $2^{\prime \prime}$ breite, bei $5^{\prime}$ lange, steif anfrechte, wenig ïberhängende, scharf bewehrte, mit einem schwachen Mittelnerv versehene Laubbiatter. Die jungen Sprosse brechen wie lange, schmalc Keulen aus dem Mutterstamm hervor. Die Pflanze sammt dem Bliithenschaft erreicht die Höhe von 6'. Der Bliithenstand mit den lebhaft blutroth gefärbten Laubblättern der Endknospe besetzt, beträgt $4^{\prime}$ Höhe. Der Schaft ist bei $2^{\prime \prime}$ dick. Schon fast $1^{\prime}$ unter dem ersten 
Blïthenbiischel werden die hellrothen Laubulïtter am Grunde bauchig umfassend und hier grünlich weiss, bis endlich bei den Blüthen selbst das Laubblatt nur mehr am spitzen Ende lebhaft roth, dann aber rein begränzt, lebhaft weiss ins Grünliche spielend, am Grunde aber wellig und bauchig gestaltet die Blïthen umgiebt; am obersten Theile verlicrt sich die rothe Blattfäche gänzlicl, und es bleiben nur die weissen umfassenden scheidenartigen Blätter îbrig. Kelch. Stielchen, Zweige, Schaft und untere Blatttheile sind weiss filzig belikeidet. Die Blüthenkrone ist blau lila schattirt, die Genitalien nicht sichtbar. Es ist mir kcine Pflanze aus irgend einer Familie bekannt, welche einen so grossartigen Effekt hervorbrächte, als diese Species von Agallostachys! Die Farben stehen hier rein und keck beisammen, - aber diese stolzc Pflanze lässt lange warten, bis sie zur Blïthe gelangt. Jedenlalls sind die blülıbaren Pllanzen mindestens 20 Jahre alt.

\section{Agall. variegat a Beer.}

Bromelia variegata Arruda da Camara. Dissertat. Plantas que dao linho u. s. w. Rio Janeiro 1810.

Arruda beschreibt die Pfanze wie folgt: „Laubblätter 3 bis $6^{\prime}$ lang, scharf sägezähnig, von anssen mit verwaschenen Querbinden geziert, innere Seite grün. Schaft $2^{\prime}$ lang, hin und her gebogen, fast spiralig gedreht. Die Achre einfach, die Stielchen kurz. Bracteen bei den Bläthen klein. Die Bliithen purpurbläulich von Farbe. Blumenblätter autrecht, länglich mit stumpfen Enden, an der Basis mit Nektarschuppen. Die Staubläden liegen in einer Rinne des Blumenblattes. Die Frucht ist eine ovale, etwas zugespitzte, wenig kantige, - genabelte Beere, von der Grösse einer Olive. Nach einem lebenden Exemplare im kais. Pilanzengarten zu Schönbrunn zu urtheilen, welches den Namen „Bromelia linifera" trägt und von welchem Herr Direktor Schot t mir frenndlich mittheilte, dass diese Pflanze vielleicht die Bromelia variegata sein dürfte, - wäre noch zu Arruda's Beschreibung anzuhängen, dass die Pllanze einen bei $4^{\prime}$ hohen dünnen Stamm bildet, an dem die Laubblätter in gleicher Entfernung vertheilt stehen. Die Ränder der Blätter haben eine röthliche Färbung; dies giebt der Pflanze ein kränkliches Ansehen. Allein mit Gewissheit lässt sich hier nicht entscheiden, indem es eben so wahrscheinlich ist, dass die Bromelia linifera in Schönbrunn eine gute Species sein kann.

Agall. chrysantha Beer.

Bromelia chrysantha Jacq. Hortus Schcienbrunniensis, tab. 55.

Pflanze sehr gross. Laubblätter zahlreich, in Mitte steif aufrecht, unten ubergebogen, hier eine tiefe Rinne bildend, welche sich allmäligr 
verfacht, sehr steif, am Grunde wenig umfassend, auf der Aussenfläche lebhaft gelbgrün, Innenseite mit dünnen Längsstreifen geziert, weisslich grün. Sägezähne sehr scharf, alle gegen aufwärts gebogen, holzbraun, die Blätter enden ohne Stachelspitze; sie sind von verschiedener Länge, die meisten aber $2 \frac{1}{2}$ ' lang und $1 \frac{1}{2}$ " breit. Der Blithenstand erhebt sich aus einem dichten Büschel in Mitte aufrechter Laubblätter, welche am Ende holzbraun bemalt sind, er ist von den steif aufrechten Laubblättern um vieles überragt. Derselbe ist $1^{\prime}$ lang mit aufrechten, $3^{\prime \prime}$ langen Zweigen dicht besetzt und bildet eine Kegelform. Die Laubblïtter der Zweige, sowie die Bracteen bei jeder einzelnen Blüthe, sind auf matt schmutzig hellgelbem Grunde mit lederbrannen Längsstreifen geziert; erstere über $2^{\prime \prime}$ lang, aufrecht abstehend, scharf sägezähnig, die letzteren verkehrt herzförmig, unbewehrt, weich, anliegend. Stiel, Sticlchen, Fruchtknoten und die an den Rändern etwas welligen, tief geschlitzten, bauchig anliegenden Kelchzipfel, - sämmtlich schr hell gellgrïn, mit Olivengrün reichlich bemalt. Die Frucht wird zur Reifezeit ganz goldgelb, ist geniessbar, sehr süss, olıne einen ananassartigen Geschmack zu besitzen, Kronenblätter lebhaft goldgelb mit röthlichem Anfuge glänzend, glatt, ganz flach ausgebreitet, stumpf spitz endend, 1/2 " breit, ${ }^{3 / 4}$ " lang, im Verblühen etwas gedreht. Die Knospe eben so gefärbt. Die Blätter sichtbar über einander liegend. Genitalien nicht sichtbar.

Agall. Comm eliniana Beer.

Bromelia Commeliniana de Vriese. Description et Figures de Plantes nouvelles et rares 1847.

\section{ANOPLOPHYTUM Beer.}

Anopl. strietum Beer.

Tillandsia stricta Soland. Botanical Magazine t. 1529. - Sertum botanicum van Geel. Rossi Catalogus Modoetiensis, tab. 3.

Pflanze kaum 7" hoch. Laubblätter pfriemenförmig, 3" lang, etwas plattgedrückt, auf hellgriinem Grunde, mit weiss kleiigem Ueberzuge, am Grunde umfassend, die Blattränder aufgebogen, nach allen Richtungen strahlenförmig abstehend. Die Laubblätter am Schafte aufrecht, am Grunde des Blüthenstandes verbreitert, hier schön roth bemalt, gegen die Blattspitze grün gefürbt: bei den oberen Blüthen verliert sich die Laubblattspitze ganzlich und erscheint als dachziegelförmig gestaltete, aufrechte, anliegende, schön roth bemalte Bractee. Der Schaft ist grün purpurfarbig, wie angehaucht, und zwischen den unteren Blüthen sichtbar. Blïthen einzeln aufrecht, wenig geöffnet, dunkelblau. Pie Genitalien sind nicht sichtbar. Kelch roth bemalt, die Kelchzipfel fast an- 
liegend. Bis zur halben Entwicklung sind die Bläthen von den Bracteen bedeckt.

Merkmal der Species: Der kleiige Ueberzug der Laubblätter.

Die dachziegelförmig gestalteten, hell rosa mit dunkelroth bemalten Bracteen.

\section{Anopl. rubidum Beer.}

Tillandsia rubida Lindl. Botanical Register, 1842, tab. 63.

Pflanze lebhaft grün, kaum 4 $\frac{1}{2}$ " hoch. Laubblätter lederartig, dicklich, am Grunde stark umfassend, hier tief rinnig mit aufwärts gebogenen Rändern, unregelmässig nach allen Richtungen stehend. Schaft und Laubblätter an demselben lebhaft blutroth, letz.tere mit grïnen Blattenden. Blüthenstand $1 \frac{1}{2}$ "lang, etwas verlüngert halbkugelförmig. Blüthen alle zugleich geöffnet, ganz frei abstehend. Blüthenkronenblätter rund, zurückgeschlagen, lebhaft blutroth. Die Genitalien sind nicht sichtbar. Kelch licht lederfarbig, bis auf den Grund sichtbar.

Die Laubblätter finden sich längs des ganzen Blüthenstandes; sie stehen hier wagerecht ab, sind am Grunde bauchig, umfassend, und tragen bei sonst lebhaft rother Färbung alle grïne Laubblattspitzen. Dieses selı zierliche Pflainzchen findet sich in mehreren Sammlungen lebend.

Merkmal der Species: Die lederbraunen Kelche.

\section{Anopl. roseum Beer.}

Tillandsia rosea Lindley, Botanical Register, tab 1357.

Pflanze 4 $\frac{1}{2}$ "hoch, sehr hellbläulich grün. Laubblätter $3 \frac{1}{2}$ "lang, $3^{\prime \prime \prime}$ breit, an den Rändern behaart. Schaft steif aufrecht, sammt den Lanbblättern, welche er trägt, hell gelblich grïn gefürbt. Bliithenstand eiförmig, 1 1 $\frac{1}{2}$ " hoch, durch regelmüssig gestaltete, anfrechte, stumpf spitze, am Grunde herzförmige, hier umfassende, lebhaft blutrothe, ins rosafarbene übergehende Bracteen gebildet. Die Blüthen sind von den Bracteen ganz bedeckt. Dies ist ein sehr zierliches, aber auch seltenes Pflänzchen.

Merlimal der Species: Der eiförmige Blüthenstand.

Die ganz bedeckten Blüthen.

Anopl. aëranthos Beer.

Pourretia aëranthos Rossi. Catalogus Mot etiensis tab. 2. - Herbier General des Ama. teurs V, tab. 304.

Pflanze sehr klein, kaum von Till. dianthoidea (Anoplophytum dianth.) zu unterscheiden. Laubblätter weisslich grün, mit schwach 
kleigem Anfluge. Bliithen blau. Bracteen purpurröthlich. Das aufrechte Pflänzchen 5" hoch. Bracteen kahnförmig, etwas abstehend, 1" lang. Bliithen aufrecht, auggebreitet, nahe beisammen stehend. Laubblitter am Grunde tiefrinuig, herabgebogen, und antrecht spitz endend. Die lüngsten $2 y_{2} "$ lang, 4 "' breit; sie bilden einen kleinen aufrechten Büschel.

\section{Anopl. dianthoideum Beer.}

Tiliandsia dinnthoidea Rossi. Catalogus Motoetiensis, tab 1. - Herbier General des Amateurs, tab, 304. - Gartenflora von Regel, Mai 1854. Academia Neapolitana, 5. t. 1

Pflanze 4" hoch, hell bräunlich grün (wie ein Spross unserer Gartennelke). Die Lanbblätter tief rinnig, unregelmässig beisammenstehend. Blüthenstand $1 \frac{1}{2} "$ hoch, durch die lebhatt rosatarben aufrechten, lanzettförmigen Bractcen, deren jerle Blïthe eine besitzt, und dann durch die gleichzeitig offenen, schönen dunkelblanen Blïthen ein sehr lieblich erscheinendes Pfänchen. Die Blumenkronenblätter sind ausgebreitet, die Genitalien nicht sichtbar.

Merkmal der Species: Die gleichzeitig geöffneten, dunkelblanen Bliithen.

Anopl. bicolor Beer.

Tillandsia bicolor Ad. Bring. La Coquille, Voyage par Duperrey, tab. 36

Die beblätterte Pflanze ist $8 \%_{2} "$ hoch. Laubblätter steif aufrecht, sehr spitz endend, am Gruncle stark umfassend, $4 \frac{1}{2}$ " lang. Bliithenschaft aulrecht, Blïthenstand armblüthig, Blïthen aufrecht. Die Laubblätter am Blïthenstande scheidenartig umfassend, gestreift, am Ende mit einem Blattzipfel versehen. Da auch bei diesem französischen Prachtwerke ,1 la Coquille" gar keine Beschreibung der Pflanze sich befindet, so ist auch ïber die Farbe des Blüthenstandes u. s. w. nichts zu sagen.

\section{Anopl. pulchellum Beer.}

Tillandsia pulchella Lindl. Exotic Flora, tab. 154.

(Tillandsia pulchra Hoocker?)

Dieses zierliche Pfl̈̈nzchen ähnelt dem Blüthenstande nach der Tillandsia dian thoidea (Anoplophy tum dianthoideum); allein die Laubblätter sind durchaus verschieden. Anoplophytum pulchellum bildet einen dichten Büschel: sehr zahlreiche, bei 6" lange, aber nur 1 “" breite Laubbliitter, welche alle aufrecht stchend und am Grunde etwas umfassend sind. Bliuhenstand aufrecht, und auffallend krätig gegen die zarten Laub. blätter. Bractenartige Laubb]ätter bei den Blüthen, lebhaft weinroth, mit grïner Blattspitze. Blüthenkrone aufrecht, rein weiss. Genitalien nicht sichtbar.

Merkmal der Species: Die rein weissen Blïthen. 


\section{Anopl. lineare Beer.}

Tillandsia linearis Arrab. Flora Fluminensis III, tab. 128.

Laubblätter bei 18 "lang und nur $2^{\prime \prime \prime}$ breit, steif anfrecht. Blüthenschaft steif aufrecht, Blüthenstand armblüthig. (Es ist nur eine Blüthe gezeichnet.) Blüthenkronenblätter ganz ausgebreitet, $1 / 2$ " breit, $3 / 4$ "lang, herzförmig. Wahrscheinlich ist die ganze Pflanze mit weich haarigem Filze bekleidet. Beschreibung fehlt.

\section{Anopl. Duratii Beer.}

Phytarrhiza Duratii Visiani. Memoire de Visiani, 1854.

Stamm nur 2 " hoch. Laubblätter wenige, am Grunde tief rinnig, dann flach pfriemlich verwachsen, stumpfspitz endend, bei $3^{\prime \prime}$ lang und auch kürzer, herabgebogen und abstehend, weisslich grün, fleischig. Schaft dünn, aufrecht, mit Blüttern dicht besetzt; Blüthenstand sammt ersteren $10^{\prime \prime}$ lang, verzweigt, dieser aufrecht, vielblüthig, von einem aufrechten Blatte gestützt. Bracteen bei der Blïthe, kürzer als der Fruchtknoten, schmal spitz endend, hier abstehend. Fruchtknoten und schmale, spit\%e, tief geschlitzte Kelchzipfel 3/4 lang, hell grïn mit matt hell weinroth reichlich bemalt. Kronenblätter ganz ausgebreitet, sehr wellig flattrig, am Rande fiedernervig, hell bläulich, röthlich, zusammen 3/4" breit. Genitalien nicht sichtbar.

\section{Anopl. strobilanthum Beer.}

Bonapartea strobilantha Ruitz et Pavon. Flora Peruviana ef $\mathrm{Chilensis,} \mathrm{tab.263.}$

Pflanze: Schwertförmige Blätter, welche kürzer sind als der Halm, Aehre einfach und zarfenförmig. Der Halm aufrecht, rund, gregliedert, fest, gestreift, kahl, unterhalb beblättert, oberhalb beschuppt, von der Länge von 2 bis $3{ }^{\prime}$. Blätter dachziegelförmig, sclıwertförnig syiı, dicht gestreift, oberhalb kahl, unterhalb purpurglänzend, mit fahlgelben, wie kleienartigen Punkten besetzt, und mit eingebogenen Rändern, Stengel umfassend, unterhalb dutenförmig, scheidig umfassend, die Schuppen den Stengel bekleidend, länglich lanzettlich, dutenförmig, angedrückt, gestreift, ausserhalb purpurfarbig mit kleienartigen Schïppchen besetzt.

Die Aelre einzeln, endständig, eiförmig, zapfenförmig. Blüthen mehrere, dachziegelförmig, sitzeıd, überall durch Deckblätter gesondert.

Bracteen eiförmig, mit kurzer Spitze, der obere Rand purpurfarbig, gestreift, einige in der Mitte liegende eingedrückt, die äısseren aber spitz. Kelch länglich, dreiseitig, lederartig trocken, häutig, dreifiedrig. Die Kelchzipfel unter sich zusammengerollt, mit schief stehenden Eirschnitten. Blumenblätter drei, weiss länglich, eiförmig abstehend, mit linealen 
Nägrchn versehen und röhrenförmig znsammengerollt. Staubgefässe 6 , ffriemenförmig. Stanlbeutel gelb. Kapsel dreiseitig, fahlgelb, durch den Relch umhïllt.

Standort: Haine, Anden, Peru, auf Bäumen und in Wäldern bei Chicoblaya. Blitthezeit Januar und Februar.

Ruitz und Pavon.

Pflanze sammt Blüthenstand $2 \frac{1}{2}$ ' hoch. Laubblätter 5 , ganz aufrecht, das längste $1^{\prime}$ lang, in der Mitte fast $1^{\prime \prime}$ breit. Diese Pflanze hat viele Aehnlichkeit mit Bromelia blanda Schott (Brasilien), obwohl ich nicht vollkommen hiervon iiberzengt bin, da im Wiener Herbarium nur Bruchstücke der Pllanze und ganze Blüthenstände sich befinden. Der fast kugelrunde, $1 \frac{1}{2}$ " im Durchmesser laltende Blüthenstand zeigt wohl an der Abbildung runde, ulen last eiförmige Bracteen bei den Blithen, wohingegen bei Schott's Pflanze dicselben lanzettlörmig spitz sind; allein die Blumenkronenform hat grosse Aehnlichkeit. Da nicht immer selbst scheinbar guten Abbildungen zu trauen ist, - so bleibt jedenfalls Schott's Pflanze, da hievon keine Beschreibung vorhanden - fraglich.

II erkmal der Species: Der kugelförmige Blüthenstand.

Anopl. flexuosum var. pallidum Beer.

Tillandsia flexuosa var. pallida. Botanical Register tab. 749.

Pflanze sammt Bliithenstand $1 \frac{1}{2}{ }^{\prime}$ hoch. Laubblätter am Grunde 1)auchig breit, stark umfassend, rinnenförmig, ron der Ditte der Länge angefangen kaum $1^{\prime \prime}$ breit, allmälig spitz endend. Laubblätter hell lläulich grün, Blattenden schmutzig weinroth. Blüthenschaft, Blüthenstand, Bracteen und Kelche lebhaft grasgrün, mit Purpuriarbe leicht bemalt. Blumenkrone aufrecht stehend, über 1" lang, schmutzig weiss, in Verblühen sammt den Genitalien aschgrau werdend. Griffel kürzer als die Blüthenkronenblätter, hellgrün. Staubfäden länger als die Blumen• krone, von Farbe hellgelb. Bracteen bei den einzelnen Blüthen kürzer, wie der Kelch, - anliegend. Blüthenstand verzweigt.

Merkmal der S pecies: Seitenzweige, welche die Eudblüthenknospe weit überragen.

Anopl. vittatum Beer.

Tillandsia vittata. Linden in Brüssel.

Dieser Species wurde von Herrn Linden in Brüssel, dem die Gärten eine Menge der schönsten Orchideen und Bromeliaceen verdanken, der Name "vittata" gegeben. Einige schmutzig roth braune, unregelmässige Linien an den $3 /, "$ langen Bracteen, welche sich bei jerler Blithe befinden, mögen die Ursache der Benennung sein. Die 
Gesammterscheinung ist aber sehr zierlich, und obwohl auch die Kronenblätter nur fahl gelblich von Farbe sind, - ist doch die Pflanze der Kultur werth; allein den Species-Namen verdient sie gewiss nicht. Meinem Vorsatze getreu bleibend, ändere ich anch diesen Special - Namen nicht, obwohl jedenfulls Schade ist, dass dieser so gut bezeichnende Name nun vergeben ist, da in der Folge blühende Bromeliaceen zu benennen sein werden, welche die Benennung ,vittata" vollsommen rechtfertigen wïrden.

Beschreibung der Pflanze: Laubblätter am Grunde umfassend, hier tiefrimnig, dann gleichmässig schmäler werdend bis zum stumpf spitzen Ende, $1 \frac{1}{2}$ 'lang, in Mitte der Laublänge etwas über $1^{\prime \prime}$ breit. Die Laubblätter bilden einen zierlich überhängenden Büschel, aus deren Mitte sich ein reichlich gleichartig beblätterter, sammt dem Blüthenstande 2 ' langer, kräftiger, zierlich geneigter Schaft erhebt. Die Blüthen stehen an fast wagerechten Seitenzweigen dicht beisammen; an jedem Zweige ist nur immer eine Blüthe geöffnet, deren Kronenblätter steif aufrecht, abgerundet, $1 \frac{1}{4}{ }^{\prime \prime}$ lang, die kürzeren gelluen Staubbentel und den etwas längeren grünen Griffel weit überragen. Die Blumeuls ronenblätter sind gelblich und so durchsichtig, dass die gelben Staubbentel durchscheinen. Der Bliithenschaft ist selbst zwischen dem Blïthenbüschel noch 3“" dick, rund, glänzend grïn. Ueber die Hälfte der Länge des Blïthenschaftes stehen die Laubblätter an demselben weit ab, dann aber sind sie fest anliegend. Zwischen den Verzweigungen des Bliithenstandes wird das Laubblatt aber an dem Blüthenzweige wagrecht herabgebogen. Jede Bliithe trägt eine fest anliegende, bei 3/4" lange, glatte, matt rothe, unregehmässig gestreifte Bractee. Der Fruchtinoten sammt den Kelchzipfeln, welche letztere an den Kronenblättern fest anliegen, ist etwas bauchig rund, glänzend, grün, in der Mitte $4^{\prime \prime \prime}$ breit und etwas ïber $1^{\prime \prime}$ lang. Vom Blüthenstielchen ist gar nichts zu sehen. Die Blüthen entwickeln sich eine nach der andern, dauern nur einen Tag und hängen dann missfarl,jg an den nun ganz geschlossenen Kelchzipfeln, so zwar, dass der Fruchtknoten oben stumpf spitz erscheint. Die noch unentwickelten Blüthen stehen in einem dichten Büschel am Ende des Zweiges, - wie auch an der Hauptachse. Der Zwischenraum von einem Seitenzweige des Blütheıstandes zum nächstfolgenden ist ziemlich gleichmässig, und beträgt ungefähr über $1^{\prime \prime}$.

\section{Anopl. gu i a nense Beer.}

Cottendorfia Guianensis Klotzseh, Berliner königl. Herbarium No. 1564.

Ich verdanke die Mittheilung dieser seltenen Pflanze dem verehrten Herrn Dr. Klotzsch. Die Aufnahme in die Beschreibungen fand ich 
um so mehr am Platze, als ich von Cottendorfia wohl in Römer, $\mathrm{Sch}$ h ltes die Beschreibung land, - jedoch die Pflanze selbst nur im Berliner Herbar zu Gesichte bekam. Es dürften aber für die Folge doch lebende Pllanzen in die Sammlungen eingefïhrt werden, da Cottendorfia florida Schult. fil. von Martius in Brasilien gefunden und diese Form jedenfalls einen grossen Bezirk bewohnt.

Cottendorfia ist eine ganz unbewehrte, aufrechte Form, mit ganzrandigen, steif aufrechten, am Grunde stark umfassenden, dann pfriemlich zusammengerollten, schmalen, bei $1^{\prime}$ langen, stumpf endenden, mit wolligem Anfluge bekleideten Laubblattern. Der Schaft erhebt sich steif anfrecht, kaum federkicldick, rund, und ist sammt dem sparrig verästelten, bis $8^{\prime \prime}$ langen Bliithenstande über $2^{\prime}$ hoch. Die Blüthchen stehen einzeln an 1“" langen Sticlchen wagrecht ab. Die Kronenbläter aufrecht, bei $3^{\prime \prime \prime}$ lang. Kelchlappen sehr tief geschlitzt, über $2^{\prime \prime \prime}$ lang. Blüthe wahrscheinlich weiss. Genitalien kürzer als die Kronenblätter. Eine sehr schmächtige Pllanze, deren Stamm im frischen Zustande kaum $4^{\prime \prime \prime}$ dick sein mag.

(Standort: am oberen Corentyn. Englisch-Guyana.

Robr. Schom burgk.)

\section{PHLOMOS'TACHYS Beer.}

\section{Phlom. Altensteini Beer.}

Puya Altensteinii L. Kl. et Otto. Icones plantarum Berolin., tab. 1. - Annales de Gand. II, tab. 59. - Flore van Houtte II, 1816. - Pitcairnia undulatifolia Hook. Botanical Magnzine tab. 4241 .

(Pitcairnia Allensteinii. Scheidw.)

Diese schon sehr verbreitete Pflanze findet sich in den Cordilleras Columbiens, zwischen la Gara und Caracas. Die fast zweizeilig stehenden, am Grunde stark umfassenden, bei 3' langen und $3^{\prime \prime}$ breiten Laubblätter hängen von der Mitte der Länge an schlaff über. Die Laubblätter am Bliithenstande gehen vom Grasgriin in lebhaftes Roth iiber, je näher sie dem Bliithenstande stehen. Der Blüthenstand ist über 6" hoch, lebhaft fenerroth; durch die steif aufrechten Bracteen, welche sich dachziegelförmig decken, sind auch die Kelchzipfel ganz bedeckt, und es ist nur dic aufrechte, weisse, im Verblülıen gelbliche, röhrenförmige, oben etwas unregelmässig ausgebreitete Blumenkrone, welche $1 y_{2}$ " $z$ wischen den rothen Bracteen vorsieht, - sichtbar. Griffel weit vorragend. Pistil gedrelit, goldgelb. Staubfäden von gleicher Länge wie die Kronenblätter. Der Bliithenstand bildet eine einfache dichte Aehre von grosser Sehönheit. 
Phlom. Altensteinii var. gigantea Beer.

Puya Altensteinii var. gigantea Hook. Botanical Magazine tab. 4309. - Flore van Houtte III. $253,254$.

Diese prachtvolle Pflanze ist über alle Beschreibung schön! Ich glaube, dass diese und die Agallostachys antiacantha (Brom. Sceptrum Fenzl) wohl die herrlichsten Gebilde dieser an schönen und seltsamen Formen so überreichen Familie sind.

Es ist eine wahrhaft gigante Varietät von Puya Altensteinii, indem hier der Blüthenstand allein bei $1 \frac{1}{2}{ }^{\prime}$ Länge erreicht. Aber nebst dem ist die ganze Erscheinung der Planze in vieler Hinsicht sehr verschieden. Hauptmerkmale zur Unterscheidung sind einmal das dichte Zusammenstehen der Blüthen, dann die kürzeren, am stumpfen Ende grünlich bemalten Bracteen; ferner, dass die Laubblätter am Rande wenig wellig, die Blattfläche aber platt ausgebreitet erscheint, und schliesslich die wirklich reitenden, wenig umfassenden Laubblätter. Leider ist diese Prachtpflanze noch sehr wenig verbreitet. Da dieses Gewächs in allen seinen Blattheilen um mindestens zweinal grösser ist, wie Phlomost. Altensteinii, so ist sie auch oìne Blüthe eine sehr schöne Blattplanze.

Phlom. densiflora Beer.

Puya mäidifolia Planch. et Linden. Flore van Houtte, tab. 915. - Annales de Gand. V, tab. 289. (Pitcairnia mäizaifolia und Pit. mäidifolia Hort.) - Pite. densifiora Brong.

Der Name ,maisblätterartig" ist nicht gut gewählt, da diese Blattform bei allen guten Species von Phlom, einen Hauptcharakter bildet.

Die Pflanze bildet wenige, am Grunde stielrunde, dann umfassende, $1^{1} \frac{1}{2}$ ' lange, $2^{\prime \prime}$ breite, etwas gefaltete, mit einem starken Mittelnerv versehene Laubblätter. Der Stamm ist am Grunde etwas zwiebelartig aufgetrieben; aus der Mitte der wenigen Laubblätter erheben sich die Herzblätter, und bei 6"Höhe wird der blass weinrothe, etwas behaarte Schaft sichtbar, welcher den sehr zierlichen, lebhalt blutroth gefärbten Blüthenstand trägt. Schaft und Blütlıenstand sind $1 \frac{1}{2} \cdot$ hoch. Die aufrechten, sich regelmässig deckenden, lebhalt blutrothen, grün spitzen Bracteen stehen mit der Spitze etwas gegen aufwärts. Der Fruchtknoten und die Kelchzipfel, welche letztere etwas abstehen, sind lebhaft glänzend grün und grösstentheils zwischen den Bracteen vorragend. Kronenblätter weiss, $1 \frac{1}{2}{ }^{\prime \prime}$ lang, nach aussen abstehend, die Zipfel ausgebreitet. Staubbeutel sichtbar, goldgelb. Narbe etwas vorragend, gedreht, goldgelb.

Phlom. sulphurea Beer.

Puya sulphurea Hort. Herrenhausen. Botanical Magazine tab. 4696.

Diese zierliche Species hat die Gestalt und Grösse der Phlom. Altensteinii, jedoch ist die Gestalt des Blüthenstandes nicht so gedrungen, 
mehr gedehnt, fast 1' lang. Die Bracteen stehen aufrecht, anliegend, mit den Zipfeln mässig nach innen gebogen, von Farbe lebhaft hellbraun, grün besäumt und mit grüner Spitze. Blüthenkrone anliegend, aufrecht, unregelmässig geöffnet, hell grünlich gelb. Genitalien kürzer, wie die Kronenblätter, aufrecht. Staubbeutel steif aufreclit. Pistil grün, etwas länger, wie die Staubfäden, am Ende gedreht. Blüthen im Verblühen lebhafter gelb werdend.

\section{Phlom. gigantea Beer.}

\section{Neumannia gigantea Brong}

Laubblätter am Grunde umfassend, reitend, $6^{4}$ lang, $1^{3} / 4$ bis $2^{\prime \prime}$ breit, hell grün, am Rande wellig, überhängend. Blüthenschaft bei $7^{*}$ hoch, $1^{\prime \prime}$ dick. Blïthenstand 1' lang, ersterer hell schmutzig grün, leicht filzig bekleidet. Bracteen aın stumpf spitz verlaufenden Bliithenstande, aufrecht, etwas flatterig, sehr licht, schmutzig chocoladefarben. Blüthen weiss, 3 " lang, gegen aussen gebogen, sehr schnell verblühend, im Ver. blühen licht lederfarbig. Genitalien kürzer wie die Blımenkronenblätter. Blumenkrone etwas rachenförmig. Der Species-Name ,gigantea" ist hier sehr bezeichnend, indem diese Pflanze, wenn sie genug Raum findet, um sich vollkommen auszubilden, jedenfalls eine schöne Blattpflanze genannt werden muss.

\section{Phlom. imbricata Beer. \\ Neumannia imbricata, Brong.}

Gesammtgestalt der Pflanze der Phlom. Altensteinii sehr ähnlich; nur ist diese Form in allen Theilen kleiner. Ganze Pflanze, mit Ausnahme der schmutzig licht gelben Blumenkrone, - trüb hell grün. Die Bracteen am Blïthenstande etwas flatterig. Blïthen schmutzig weiss grün.

\section{Phlom. Funkiana Beer. \\ Puya Funkiana. Linden?}

Diese schöne Pflanze bildet ihrem Blüthenstande nach eine Ueber. gangsform zu dem Genus Pitcairnia, indem sie der Pitcairnia bracteata ziemlich nahe steht. Allein die Laubblitter, dann der steif aufrechte, kräftige, sehr gedrungene Blüthenstand stellt sie auch eben so nahe an Phlom., wohin gegen die dem ganzen Blüthenstaude entlang dicht stehenden, ganz sichtbaren Blïthenknospen und die kleinen, nur bis zu den Kelchzipfeln reichenden grünen Bracteen, diese Species einer PitcairniaForm (Unterabtheilung a.) sehr nahe bringt. Die Pflanze ist nirgend ab- 
gebildet; ich fand selbe in Schönbrunn, mit obigem Special-Namen, in kräftiger Vegetation und Blüthe.

Die Tracht der Pllanze ganz wie Phlom. Altensteinii. Laubblätter am Rande stark wellig, über $2^{\prime \prime}$ breit und bei $2^{\prime}$ lang, lebhaft dunkelgrün. Blüthenstand steif aufrecht. Schaft etwas filzig, $-3^{\prime \prime \prime}$ dick. Ersterer 8" hoch, spitz endend. Blïthenknospen bis zum Gipfel des Blüthenstandes entwickelt, lebhaft goldgelb. Blumenkrone röhrenförmig, 2" lang, an der Spitze wenig geöffinet. Genitalien kürzer, wie die Kronenblätter. Bracteen flatterig, matt grün, lanzettförmig, kaum 1"lang. Beim Verblïhen senkt sich derFruchtknoten sammt der noch fast frischen Blumenkrone nach abwärts; nun sind auch die 2 " langen, matt griinen Blüthenstielchen sichtbar.

\section{Phlom. atro-rubens Beer.}

Puya sp. Chirique Vulkan (Mejiko) Warszewitz.

Diese sehr schöne Species erhielt ich aus dem Garten des Herrn $\mathrm{N}$ a u e $\mathrm{n}$ in Berlin unter dem Namen Puya sp. Wárszewitz Chirique Vulkan (Mejiko). Diese Pflanze ist so rerschieden in Farbe und Bau des Blüthenstandes, dass sie verdient, in jeder guten Pflanzensammlung aufgenommen zu werden.

Laubblätter-am Grunde umfassend, damn vertieft sich die Blattspreite dergestalt, dass das Blatt nur eine Rinne bildet; bei $4 \frac{1}{2}$ " Länge entwickelt sich die Blattspreite schnell, das Blatt ist dann $2^{\prime \prime}$ breit, am Rande stark wellig und $1 \frac{1}{2}^{\prime}$ lang; in Mitte des Blattbüschels erhebt sich der Blüthenstand, mit den aufrechten Laubblättern der Endknospe besetzt. Er' ist $1^{\prime}$ hoch, $21_{2}^{\prime \prime}$ breit und fast gleichmässig dick. Die Bracteen sind am Grunde stark umfassend, dann lanzettförmig, sehr spitz endend; am breitesten Theile am Grunde $1 \frac{1 / 2}{2}$ breit und variiren in der Länge von $2 \frac{1}{4}$ bis $2^{3} /_{1} "$. Die Bracteen sind lebhaft glänzend, sehr dunkel rubinroth und haben alle die langen spitzen Enden zierlich nach aulwärts gebogen, und zwar dergestalt, dass die Hälfte der Länge der Bracteen frei absteht; dieser Theil der Bracteen ist am dunkelsten, - fast schwarz gefärbt. Die lebhaft hellgelben, zwischen den Bracteen vorstehenden aufrechten, rachenförmig geöffneten Blïthen entwickeln sich alle zienılich gleichzeitig, aber die Blüthen entwickeln sich am oberen Ende des Bliithenstandes zuerst; daun folgen die anderen in Schnelle nach. Die lebhaft orange - gefärbten Staubbeutel stehen aufrecht zwischen den Kronenblättern und werden von diesen überragt. Die seltsam schönen, dunkelfarbigen Bracteen und die zahlreichen, lebhalt hellgelben Blïthen gereichen dieser Species zur grossen Zierde. 


\title{
Phlom. (?) regularis Beer. (Fossil.) \\ Palaeoxyris regularis Brong.
}

Brongni ard vergleicht diese Formen mit den lebenden Xyrideen oder Restiaceen. Sternberg reiht selbe den Restiaceen an.

Es sind Palaeoxyris regularis Brong. und Palaeoxyris Münsterii Prssl. u. m. a. bekannt. Die Restiaceen, welche ich besah, zeichnen sich alle durch einzelne Blätter bei jedem Knoten des Stengels aus; diese stehen aber immer so entfernt von einander, dass sie sich nie erreichen; bei Palaeoxyris hingegen sind sie sehr nahe stehend und decken sich gegenseitig. Bemerkenswerth ist auch die noch sichtbare lebhafte rothe Fürbung des Blïthenstandes und der Laubblätter am Stengel, wesshalb diese Pflanze grosse Aehnlichlreit mit den bekannten lebenden Formen von Phlom. Altensteinii u. s. w. hat.

Schliesslich mag noch bemerkt sein, dass unter den Restiaceen die Gattung Elegia die meiste Aehnlichkeit mit der fossilen Form bietet.

\section{QUESNELIA Gaudichaud.}

\author{
Quesn. rufa Gaudichaud. \\ Bonite, Atlas botanique tab. 54 . \\ Billbergia Quesneliana Brong. Flore van Houtte 1855, tab. 1028.
}

Diese seltene baumartige Pflanze erreicht eine Höhe von 18 bis $20^{\prime}$; bei $6^{\prime}$ Höhe bringt die Pflanze den ersten Blüthenstand, dann folgen die Seitenzweige, wo immer der erst erscheinende die anderen überwächst und hierdurch das Gewächs an Höhe zunimmt. Die abgeblühten Aeste werden endlich dürr und lassen am Stamm deutliche Merkmale zurück. Der ganze Stamm ist mit Wurzeln dicht bekleidet, die wie bei den Baumfarren, aber bei Quesnelia nur theilweise mit dem Stamme selbst verwachsen. Dieses herrliche ornamentale Gewächs befindet sich im Garten zu Schönbrunn in wahrhaft prachtvollen Exemplaren, und dort hatte ich Gelegenheit, die Pflanze zu studiren. Es ist von diesem Genus nur eine Species bekannt; ich fand weder im Wiener noch im Berliner Herbar getrocknete Pflanzen hiervon. Gaudichaud hat eine treffliche Abbildung, welche sehr genau wiedergegeben ist, in dem prachtvollen Werke "La Bonite," das eine Menge neuer, seltsamer Formen dieser Familie enthält. Die Abbildungen sind hier mit vollem Vertrauen zu benützen, so zwar, dass eine Beschreibung der abgebildeten Pflanzen in diesem Falle weniger vermisst wird. Ein Mangel ist es freilich in so ferne, als man dort tiber die Färbung der Pflanzen gar keine Aufklärung erhält! - 
Pflanze baumartig. Stamm von den abfallenden Blättern schuppig, bis 4" dick. Lanbblätter am Grunde tief rimnig mit aufrecht stehenden Blattrindern, hier unbewehrt. Die Blattläche ansgebreitet, allmälig scharf stachelspitz und am Blattende etwas zusammengerollt, der ganzen Länge nach sehr gleichmässign, f'ein scharf sägezühnig. Länge $2^{\prime}$ bis $3^{\prime}$ und $2^{\prime \prime}$ breit. Obwohl jedes Laubblatt bis auf den Grund sichtbar, ist doch der Stamm ganz von denselben bedeckt. Der starke Blïthenschaft von $1 / 2$ " Dicke ist reich beblättert; hier sind die Laubblätter aufrecht, zunächst dem Blüthenstande bei $1 / 2$ ' lang, schwach stachelspitz und schmutzig lichtroth gefürbt. Der Blüthenstand steckt gewissermassen zwischen den letzten Laubblättern, - er ist bei $9^{\prime \prime}$ lang und $3^{\prime \prime}$ dick, eine stumpfe Kegelform bildend. Bracteen steif aufrecht, fast holzig, am Rande wie gefältelt, hier scharf sägezähnig; gegen das schwach stachelspitze Ende verlieren sich die Fältchen und anch die Sägezähne. Der Mittel theil der Bracteen ist mit Längsstreifen geziert. Eine grosse Menge solcher sehr regelmässig gestalteter und sich deckender Bracteen erinnert an einen Tamnenzapfen. Die Bracteen sind über $2^{\prime \prime}$ lang, 3/4 "breit und es stehen bei 16 in einer Reihenfolge; sie sind alle gleichmässig lebhaft blutroth gescheckt, mit weisslichen Rändern; bei der Bracteenspitze ragen die drei aufrechten Blumenkronenblätter nur $4^{\prime \prime \prime}$ vor; sie sind lebhaft blau, am Grunde weiss. Die Genitalien sind kürzer wie die Blumenblätter; Stanbbentel gegen den gedrehten Griffel (Narbe) zusammengeneigt, gelb. Fruchtknoten und die runden, anliegenden Kelehzipfel etwas weiss wollig bekleidet.

Die Abbildung in van $\mathrm{H}$ o $u$ t te 's Flore ist nach einer kümmerlichen Pflanze gezeichnet; alle Theile am Bliithenstande sind übrigens getreu wiedergegeben.

\section{PITCAIRNIA Heretier.}

\section{Unterabtheilung.}

Deckblättchen länger als Fruchtknoten und Kelchzipfel.

Pitc. bracteata. Ait.

Botanical Magazine tab. $2 \$ 13$. - Pitcairnia latifolia Herbier general des Amaleurs. IV ab. 223. - Redouté Liliacees II, tab. 73.

Lanbblätter an Grunde löffelförmig umfassend, hier allein sägezühnig, lebhaft grasgrün; auf der Innenseite sehr licht weissgrün, $1 \frac{1}{2}{ }^{\prime}$ lang, $3 / 4$ " breit, mit stark entwickeltem Mittelnerv, an Rande wenig wellig; der umfassende Blattheil 2" breit, 1" lang, sägezähnig. Schaft 
aufrecht, sammt dem 3 $\frac{1}{2}$ " langen Blithenstande 9" lang. Bracteen bei den Blüthen schmutzig hellgrïn, $1 \frac{1}{2}$ " lang, unten bauchig - dann lanzettförmig stumpf endend, aufrecht, fast keulenförmig zusammenstehend. Kelchzipfel von den Bracteen bedeckt. Blüthen unordentlich beisammenstehend, flatterig, schmutzig weinroth. Staubfiden und Griffel weiss, Staubbeutel goldgelb. Kronenblätter $1^{\prime \prime}$ lang. Genitalien kiirzer als die Kronenblätter.

I erkmal dieser Species: Die gebogenen, 1 " langen, sägezähnigen Blattenden.

\section{Pite. bracteata var. Gireaudiana Beer. Pitcairnia Gireatudiana Ditrich.}

Vorblätter grïnlich hell braun, Widerhacken dunkel holzbraun, scharf. Blattende holzartig. Laubblïter zahlreich, gleichmässig ausgebreitet, am oberen Theile ïberhängend, bei '2' lang, nahe an $1^{\prime \prime}$ breit, am Grunde an den Blattrïuderı 2 bis '2\%, lang, scharf sägezïhnig, dann - ganz unbeweht, allnülig sehr spitz, aber weich endend; am Rande etwas wellig; Mittelrinne gut ausgebildet. Oberflïche der Laubblätter lebhaft, glïnzend griin. Unterflïche gleichmässig, bedeckt mit weisslichem Filze, der leicht wegzuwischen ist. Laubblätter am Bliithenschaft, Bracteen, Stiel und Stielchen gleichmässig hellgrin. Bliithenlnospe rund, lang, stumpf spitz, gegen aussen gebogen. Bliithenkrone selı flatterig. Das oberste Kronenblatt entschielen und allein aufwirrts gebogen. Knospe und geöfrnete Blüthe hell, lebhaft, fleischroth; am Grunde grïnlich verwaschen. Staubfüden aus der Jlüthe mordentlich heraush ängend, kürzer als die Kronenblätter. Stanbbeutel leblaft orangengelb. Staubfäden hellgrün. Griffel hellgrün, aufrecht, etwas iibergebogen; so lang als die Kronenblätter.

Hauptmerkmal: Ein steif aufgerichtetes Dlumenblatt.

Pite. iridiflora Hort. Lond.

Laubblätter $4^{\prime \prime \prime}$ breit, $2^{\prime} 10^{\prime \prime}$ lang. Vorblätterbüschel am Spross und am Bliithensehatt, am ersteren zahlreich, 1/2" breit, schwach hackig gezahnt; die vertrockneten Blätter rollen sich ein, letztere schwach hackig gezahnt, wenig steif, aufrecht.

Schaft und Blüthenstand 6 " hoch. Die Blüthen stehen dicht beisammen. Bracteen bei jeder Blüthe steif aufrecht, etwas mehlig bestäubt, bei $1 \frac{1}{1 / 2} "$ lang, hellgriin. Fruchtknoten und Kelchzipfel bei $1 \frac{1 / 2}{1 / 2}$ lang. Kronenblätter 2" lang, wenig geöfinet, rachenförmig; diese drei Theile lebhaft ziegelroth. Genitalien so lang wie die Blumenblätter. Staubfäden 
in einem Büschel zusammenstehend, weiss. Staubbeutel aufrecht, goldgelb. Narbe weinroth, so lang wie die Staubfäden.

Schönbrunn. Mai.

Pitc. sulphurea Andrews.

Inotanist's Repository tab. 249. - Pitcairnia bracteata var. sulphurea Hook. Botanical Magazine tab. 1416.

Ich finde mich bewogen, die Pitcairnia bracteata var. sulphurea Hook. einzuziehen, da selbe mit Pitcairnia sulphurea Andrews vollkommen gleich ist.

Stattliche schöne Pflanze, mit wenigen glänzenden glatten, schön grünen, über $11_{2}^{\prime}$ ' langen, $1^{\prime \prime}$ breiten gleichrandigen Laubblättern. Schaft und Blüthenstand aufrecht; mit Ausnahme der lebhaft schwefelgelben Kronenblätter - licht blaugrün.

Blüthenstand sehr schön, $9^{\prime \prime}$ lang, $3^{\prime \prime}$ breit. Blüthen sehr zahlreich, als Knospen etwas nach aussen gebogen. Kronenblätter $2^{\prime \prime}$ lang, flatterig, rachenförmig. Genitalien kürzer als die Kronenblätter. Griffel und Pistil lebhaft grïn.

Wenn man die beiden oben genannten Abbildungen zusammenhält, so erscheint wohl ein Unterschied in der Tracht, indem bei Hooker's Abbildung die Bracteen die Blüthen mehr dominiren; allein dieses scheint nur daher zu rühren, dass die Pflanze Andrew's, als sie ab. gebildet wurde, alle Blüthen mehr entwickelt hatte, als jene Pflanze, welche Hooker abbilden liess.

\section{Pite. macrocalyx Hooker.}

Botanical Magazine tab. 4705.

Eine sehr schöne stattliche Pflanze, die einen reichen Büschel lebhaft grün gefärbter Laubblätter treibt. Laubblätter $3 \frac{1}{2}{ }^{\prime}$ lang, $2^{\prime \prime}$ breit, ganzrandig, vom Grunde aus " "lang, eine Röhre bildend, im Grunde wenig umfassend, mit schwach entwickeltem Mittelnerv. Schaft, Bracteen und Blüthenstielchen licht gelbgrün, ersterer weiss wollig. Fruchtknoten und Kelchzipfel lebhaft orangefarbig, ganz frei. Blüthen über $2^{\prime \prime}$ lang, rein weiss mit Schwefrlgelb an der Spitze reichlich bemalt, rachenschildförmig. Genitalien länger als die Kronenblütter. Staubfäden gelb. Pistil schön blaugrün. Die Bractee, welche von der Blüthe wagrecht herabgedrückt wird, ist $1 \frac{1}{2}$ " lang, schifförmig, an den Fruchtknoten anliegend; beim Verblühen senkt sich der Fruchtknoten nach abwärts und die Kelchzipfel schliessen sich an die verwelkte Blüthe innig an. 


\section{Pite. asterotricha Poepp et Endl.}

Nova Genera Plantarum Poeppig et Endlicher tab. 158.

Blätter schwertförmig, stachelspitz, unterhalb weiss filzig. Stengel rispig mit aufrechten Zweigen; die Bliithen traubig, einseitwendig; die deltoidischen Bracteen überragen die Blüthenstielchen, und die äusseren Zipfel der Blïthenhülle sind dicht filzig kleienartig, die inneren Zipfel an der Basis nackt. Standort in Peru an sehr warmen Abhängen der Vor-Anden beim Landgute Cassapi. Bliithezeit November.

Beschreibung: Stengel zahlreich, steif aufrecht, rund, kahl, purpurfarbig, oft fast $6^{\prime}$ lang. Die wurzelständigen Blätter aufstrebend zuriickgebogen, abstehend, an der Basis verbreitet, sternförmig gestellt, schwertförmig, allmälig verschmälert, am Rande zurückgebogen, mit vorwärts gerichteten Stacheln besetzt, die rund, sehr spitz, rauh, glänzend und kastanienfarbig sind, $2^{\prime}$ lang, in der Mitte schmaler als 1", unterhalb mit weissem kleienartigen Filze bedeckt, oberhalb glänzend, kahl. Die stengelständigen Blätter, den untersten Theil desselben schmiickend, fast abwechselnd stehend und schmaler als die wurzelständigen Blïtter: an der Basis verbreitert und Stengel umfassend, mit grösseren Stacheln, flach. Die Rispe von der halben Länge des Stengels, einfach, mit 1' langen Zweigen, die aufstrebend, nur an der Spitze Blüthen tragend, zusammengedrückt oder unmerklich eckig, mit dichtem fahlgelben Filze bekleidet; die Bracteen an der Basis der Zweige Stengel umfassend, breit eiförmig deltoidisch, lang gespitzt, mit dornigen, ungleichen, gebogenen und häutigen Dornen besetzt, ausserhalb mit kurzem kastanienfarbigen Filze bedeckt. Die Bliithen traubig, einseitwendig, schön, und wohl von allen Species dieses Genus am grössten.

Die Blïthenstielchen rund, filzig, fast gleich der halbstengelumfassenden Bractee, die breit eiförmig deltoidisch, spitz, aufrecht, convex und ausserhalb filzig ist; die Deckblättchen des Blüthenkopfes stumpfer und länger als die Blïthenstielchen. Die äussere Blüthenlü̈lle bis zur Basis sechstheilig, mit aufrechten, an der Spitze kaum abstehenden linealen Zipfeln, die zugleich mit convexer Basis eiförmig, am Rücken gerinnt, mit dichtem fahlgelben Filze bekleidet und 18" lang sind. Die innere Blïthenhïlle fast gekriinmt, um das Doppelte länger als die äussere; die Zipfel zusammengeneigt, niemals zurückgebogen, nach dem Aufblühen spiralig eingerollt, lineal, an der änssersten Spitze ein wenig verbreitert, nervig, an der Basis unter sich zusammengerollt und dort nackt, kahl und hell licht purpurn. Staubgefässe 6, kürzer als die innere Blüthenhïlle, gleich lang aufrecht, frei, 3 davon an der Basis der inneren Zipfel leicht angewachsen; die 3 anderen den äussern Zipfeln gegenüber- 
gestellt. Staubfäden fadenförmig rund, weiss. Staubbentel lineal, beiderseits stumpr, ïber dem Grunde angeheftet; 2fächerig, die Fächer cylindrisch der Länge nach aufspringend. Blüthenstaub kugelig glatt, fahlgelb. Eierstock halb oberständig eiförmig, kegelförmig, in Vergleich zur. Blüthe klein, 3fächerig, viellinig. Griffel endständig, steif aufrecht, von gleicher Länge mit den Staubgefïssen und der Blüthenhülle, fadenförmig rund. Narben 3, in Cylinderform spiralig eingedreht, lineal, anf einer Seite mit einem häutigen, welligen Rande versehen, spitz. Kapsel eiförmig, spitz, 3furchig, papierartig, lrahl, unterhalb 3fächerig, an der Spitze wandspaltig, 3klappig, die Klappen einwärts aufspringend, vielsamig. Samen zahlreich, dem randständigen Samenträger eingefügt, gegenläufig, kleingrubig, kastanienbraun, in eine kurze, grannenartige Spitze verlängert.

Poepp. et Endlicher.

\section{Pite. ferruginea Ruitz et Pavon.}

Flora Peruviana et Chilensis 1II, pag. 36.

Pflanze: Schaft rispig, die Rispe weitschweifig sparrig. Blätter schwertförmig, stachelig. Blïthen riickwärts sichelförmig (rachenförmig). Krone sehwach purpurfarbig.

Sprossen sehr viele, gehäuft, abstehend.

Schaft einfach, unverzweigt aufstrebend, rund, 2 Ellen (4') lang. Bläter gegenseitig anliegend, zerstreut, schvertörmig, lang, schmal. Die Ränder mit Stacheln besctzt, die Rispe endständig, sehr gross, zusammengesetzt aus zerstreuten besoncleren hispen. Bracteen halb stengelunfassend, eilanzettförmig, spitz, gestreift, ausserhalb wollig roth. Blüthenstiele rundlich kahl. Blithenstielchen rund, wollig, am oberen Ende zuriickgebogen, eimbliithig, unterstützt durch eiförmige concave, dreimal kürzere, gestreilte, halb stengelumfassende und wolligeBracteen. Die Blüthen überhängend, rückwärts sichellörmig (rachenförmig). Kelch ausserhalb wollig, roth, 3theilig, halb unterständig bleibend. Zipfel lanzett-piriemenförmig, eingedriickt, von der Breite eines Daumens, rückwärts sichelförmig.

Kronenblätter schwach purpurlarbig, an der Basis nackt, d. i. ohne Schuppen, - 2 bis $3^{\prime \prime}$ breit, lineal sichelförmig, unter sich eingerollt, gestreilt, aderig, dem Fruchtboden eingetïgt, kahl, in Vervelken sich spiralig einrollend.

Staubfäden 6, halb pfriemenförmig̨, zusammengedrïckt, wenig kuirzer als die Krone, dem Fruchtboden eingefügt. Staubbeutel lineal pfeilförmig, 2fächerig, lang und fust aufliegend; die abgeblïhten spiralig. Die Fruchtknoten mit unterständigem Grunde, oberständig, eiförmig, kahl. 
Pistil von der Länge der Staubäden, fadenförmig und rreiseitig. Narben 3, länglich, lineal, flach; am entgegengesetzten Rande pfriemenförmig gekerbt, unter siclı spiralig eingerollt. Kapsel pyramidenförmig, dreiseitig, dreifurchig, mit leicht grefurchten Ecken, dreifacherig un dreiklappig. Die Klappen eiförmig, spitz, innerhalb durch einen zarten Nerv gezeichnet, mit einwärts gekrïmınten Rändern, welche die Scheidewände bilden. Samen zahlreich, den Rändern der Klappen beiderseits eingebettet, länglich, an beiden Enden in eine zarte Granne auslanfend. Die Fruchtböden randständig, häutig.

Standort Peru, auf sandigen Hïgeln um Lima, am Amancaes u. s. w. Blüthezeit Mai, Juni.

Abbildung und die ausgezeichnele gesammelte Pflanzenspecies hahen wir im Schiffbruche W. Petri Alcantharensis verloren.

Ruitz et Pavon.

\section{Pite. fulgens Desne.}

Eine sehr schöne stattliche Species! - Vorhlatthiischel griu, steif, scharf bewehrt. Laubblätter auf der Unterfäche weiss filzig, ganzrandjo, hier schwach wellig, iiber $1^{\prime \prime}$ breit und $2^{\prime}$ lang. Schalt aussergewöhnlich stark, steif aufrecht, gleichmässig ïber $1 / 2$ " dick, schmutzig weinroth, schwach weiss filzig bekleidet. Laublyäter an demselben au Grunde ganz umfassend, hier einen Vulst hildend, schmutzig weinroth, gegen das Ende hellgriin. Blüthenstand durch Deckblätter verlängerl, eiförmigg, hei $2 "$ Durchmesser und 4" Hühe. Das Ende des Blïthenstandes l,ilden zathlreiche, dicht ïber einander liegende Deckblïtter. Bliithen aufrecht, um etwas länger als die Deckblitter. Kronenblätter wenig geäfnet, hell scharlachroth. Genitalien kiirzer als die Kronenblätter. Stanbblitter orangetaruig; Griffel etwas länger als diese; weiss mit etwas rother Bemalung. Die ganze Pflanze sammt Blïthenstand erreicht eine Höhe ron $2^{\prime}$ und ist jedenfalls ein selr erfrenlicher Zuwachs zu dieser ohnehin so reichen Gattung.

Blïthezeit Herbst und Winter.

\section{Unterabtheilung.}

Deckb]ättchen selten länger als die Blïthenstielchen.

Pitc. ringens Klotzsch.

Jcones plantarum. Hort. Berolinensis tab. 25. - Pitc. albucaefolia Schrader. Blumenbachia t. 3. - Pitc. Iatifolia Hort. Herrenhusanus t. 3.

Laubblätter vom Grunde aus aufrecht, hier stark umfassend und sägezühnig, dann schnell schmal werdend, mit tiefer Mittelrinne, glatt, 
lichtgrün glänzend, der obere Blattheil zierlich iibergebogen, hier schmal stumpf spitz. Blüthenschaft, Bracteen, Blüthenstielchen und Fruchtknoten lebhaft hellgrün, mit Purpur reichlich bemalt. Bracteen bei jeder Blüthe steif aufrecht, lanzettförmig, 3/4 "lang, $3^{\prime \prime \prime}$ breit. Kelchzipfel tief geschlitzt, anliegend, spitz endend, bei 1"lang, licht weinroth. Kronenblätter etwas flatterig, rachenförmig zusammenstehend, das hintere Blatt abstehend, alle stumpf spitz und lebhaft blutroth gefärbt. Staubbeutel in eine Reihe geordnet, etwas länger als die herabgeneigten Kronenblattzipfel, - goldgelb. Griffel und Narbe länger als die Staubbeutel, hellroth. Pistil ein Knöpfchen bildend, ebenfalls hellroth. Die Knospen pfriemenförmig spitz endend, gegen aufwärts gebogen.

Pitc. punicea Hort.

Laubblattbüschel rasenbildend. Laubblätter $1^{\prime}$ lang, 1/2" breit, am Grunde eine tiefe Röhre bildend, hier etwas umfassend, dann schmäler werdend, endlich schwach mittelnervig, am unbewehrten Rande etwas wellig, spitz zulaufend. Aussenfläche sehr dunkelgrün mit einigen lichteren ganz feinen Längslinien. Kehrseite mit weisslichem Anfluge und vielen Längsstreifen. Blüthenstand und Schaft 11/4' lang. Bluithenstand 11" hoch, unverzweigt. Blïthen alle aufwärts stehend; sie bilden einen obeliskförmigen prachtvollen Bliithenstrauss. Bracteen bei jeder Bliithe abstehend, griin, $1 / 2$ " lang. Blüthenschaft und -Stielchen lebhaft dunkelweinroth gefärbt und stark weiss, wie mehlig bestäubt. Fruchtknoten und etwas abstehende, ziemlich tief geschlitzte Kelchzipfel am Grunde schmutzig weinroth, gegen die Lappen hin grünlich verwaschen gefärbt und mehlig bestaubt. Kronenblätter aufrecht, lose zusammenstehend, Jebhaft blutroth, 2" lang, am Grunde 4"' breit, am Ende etwas rachenförmig geöffnet. Genitalien länger als die Kronenblätter, nahe zusammenstehend, vorragend hellgelb. Blüthenknospe pfriemlich gegen aufwärts gebogen, bis zur ersten Entwicklung lebhaft blutroth gefärbt.

Blïthen sehr zahlreich, alle gleichförmig nahe zusammenstehend.

Pitc. albucaefolia Schrad.

Blumenbachia. Schrader tab. 2, pag. 24.

Ist eine sehr schöne Pflanze, durch zahlreiche Laubblätter und zierlichen Blïthenstand ausgezeichnet. Laubblätter bis $1 \frac{1}{2}$ ' lang, $1 / 2$ " breit, bis zur Hälfte der Länge aufrecht stehend, dann ïberhängend glattrandig, nur am Grunde mit einigen Sägezähnen besetzt. Auf der Oberfläche lebhaft grün, auf der ganzen Unterfläche weisslich filzig bekleidet. Der Schaft ist dünn, erhebt sich gerade und ist sammt dem nicht verzweigten Blüthenstande $13^{3}{ }^{\prime}$ hoch. Letzterer ist $6 "$ lang. Die licht- 
grünen, etwas filzigen Bracteen sind abstehend und $3 / 1$ "lang. Die Bliithenstielchen bis auf den Grund sichtbar. Kelchzipfel weit geschlitzt, schmal. Blumenkrone zart, 1" lang, durchsichtig, selır weit rachenförmig geöffnet, lebhaft scharlachroth. Genitalien so lang wie die Blumenblätter, gelb. Die Endlsnospen stehen dicht beisammen. Blüthen sehr zahlreich, eine Pyramide bildend. Der ganze Blithenstand ist lejcht filzig bekleidet und mit Rostbraun wie angehaucht.

\section{Pitc. bromelia efolia Ait. Lotanical Mag. tab. 824.}

Eine Pflanze, welehe den Namen , bromeliaefolia" trägt, setzt jedenfalls rorans, dass die Laubblätter steif und gleich mässig scharf bew ehrt sind. Redouté und Kerner haben ebenfalls Pitcairnien abgebildet, welche den Namen „bromeliaefolia" tragen; aber wenn die drei Abbildungen znsammen verglichen werden, dann zeigt sich, dass hier zwei ganz gut unterscheidbare Formen mit e in em Namen belegt wurden. Dieses hat mich veranlasst, Pitc. brom. Redouté und Pite. brom. Kerners H. semp. zu vereinen und als Pitc. Redoutéana zu beschreiben. Die grossen Unterschierle in den Blattzuständen und dem Blïthenstande sind aus beiden Beschreibungen leicht ersichtlich.

Pitc. bromeliaefolia hat steif aufrechte, schmal spitz endende scharf und gleichmässig sägezihnige Laubblätter; welche am Grunde stark umfassend sind. Die Aussenflächte ist schmutzig grasgrïin; auf der Innterfläche um vieles bleicher. Der ganze Schaft sammt dem Bliithenstande und den Blüthenstielchen ist lebhaft weinroth, glatt, glänzend. Blüthen auf - und abwärts stehent. Kelchzipfel und Fruchtknoten schmutzig weinroth, 1" "lang. Kronenblitter spitz endend, zu einer Röhre vereint, am Ende kaum geöffnet. Genitalien so lang als die Kronenblätter. Blïthenstand reichblumig, nicht verzweigt.

\section{Pitc. Redoutéana Beer.}

Pitcairnia bromeliaefolia. Redouté Liliacees II, t. 75. - Pitcairnia bromeliaefolia Kerner, Hortus sempervirens tab. 46.

Laubblätter weich, am Rande wellenförmig; zierlich überhängend. flatterig, mit langen, schlaffen, spitzen Enden; die äusseren an Grunde bis 3 " Länge, mit weichen Sägezähnen besetzt, dann aber, wie die inneren Laubblätter, ganz weich und unregelmässig weit abstehend. Schaft von unten auf schmutzig grüin, dann in schnutzig weinrotlx übergehend; eben so gefürbt sind die Stielchen, Fruchtknoten und Kelchzipfel. Kronenblätter lebhaft bläulich roth, weit geöffnet, entschieden rachenförmig; Genitalien um vieles kürzer als jene. Laubblätter und 
Stützblättchen bei jeder Bliithe hell griin, mit roth reichlich bemalt. Kelchzipfel und Fruchtknoten kaum 1" lang, - letzterer 1/3 "Durchmesser. Kronenblätter $2 "$ lang. Bliithen sparig am unverzweigten Bliithenstande.

\section{Pitc. distacaia Beer.}

Tillandsia distacaia Arrab. Flora Fluminensis tab. 141.

Die Zeichnung dieser Pflanze ist gewiss auffallend willkürlich! Die Kronenblïtter und der Fruchtknoten zeigen wohl eine Pitcairnia; es ist aber ein zweizeiliger Blüthenstand gezeichnet, welcher mir bei dieser Gattung noch nicht rorgekommen. Die unteren Laubbläter sind glattrandig, die oberen drei aber bei $1 \frac{1}{2}$ "lang und 1 " breit, gleichmässig sägezähnig, wie eine Bromelia. Alle Blätter stehen steif aufrecht. Der Schaft ist etwas überhängend. Da lieine Beschreihungen zu den Abbildungen erschienen sind, - ist auch über Färbung u. s. w. nichts bekannt.

Pitc. e chinata Hooker.

Botanical Magazine tab. 4709.

Eine seltsam schöne Pflanze, die selbst ohne Blüthe, wegen ihres kräftigen Wuchses und der reichen Bebliitterung einer Dracaena gleicht. Pflanze aufrecht mit etwas iiberhängeuden Blättern, diese scharf sägezähnig und schwach stachelspitz, am Grunde rinnenförmig, wenig umfassend, hier schmutzig lederfurbig, damn lebhaft grïn. Die Blätter sind 2 ' 5" lang und 2 " breit; sie haben eine schwache Hittelrippe und einige Lüngsstreifen. Schaft zur Grösse der Pllanze - schwach, schmutzig gelh, etwas filzig bekleidet, zwischen den sparrigen Blüthen in Grün ïbergehend. Blüthensticlchen frei, 9" lang, griinlich von Farbe. Bracteen bei jecler Blïthe iiber $1^{\prime \prime}$ lang, bauchig lauzettlich, hellgelb. Fruchtknoten und Kelchlappen $2^{\prime \prime}$ lang, ersterer tief weinroth, in goldgell, iibergehend, dann rein goldgelb. Dieser Theil der Pflanze ist sehr merkwürdig, indem er überall mit dicken, bis $2^{\prime \prime}$ langen, keulenförmigen Drïsenhaaren besetzt ist. Kronenblätter $1 \frac{1 / 2}{2}$ lang, röhrenförmig, wenig geöfnet, gelblich weiss. Genitalien kaum sichtbar. Stanbbeutel kürzer als die Kronenblätter, lebhaft gelb. Die nicht zahlreichen Blüithen stehen unordentlich, bald hinauf-, bald herabgeneigt; sehr schön und eigenthümlich sind die Blüthen bei halber Entwicklung.

\section{Pite. flammea Lindl.}

\section{Botanical Register tab. 1092.}

Pflanze ganz unbewehrt. Laubblätter am Grunde stark rinnenförmig, fast reitend, $1 \frac{1}{2}{ }^{\prime}$ lang, $1^{\prime \prime}$ breit, am Grunde etwas fleischig, dann glänzend glatt. Innere Fläche licht blaugriin aussen lebhaft, dunkelgrïn. 
Diese Pllanze scheiut leine schardhackigen Vorlubatterluischel zu treiben. Schaft steif aufrecht, grïn, nit rüthlichem Anfluge; Bracteen bei den Blüithen eben so gefürbt und etwas länger als die $1 / 2$ "langen, lebhaft rothen Blïthenstielchen. Fruchtinoten und Kelehlappen feurig roth. Blïthen alle aufrecht, zahlreich, nahe zusammensteheud, sehr schön blutroth. Die Kronenblïter stehen, eine Rïhre bildend, beisammen, sind am Ende rachenförnig geöhnet. Staubläden rein weiss, Staubbentel gelb. Griffel etwas vorragend. Pistil rund, feurig, lichtroth.

\section{Pite. furfuracea Hort.}

Jacquin. Privat-Bibliothek Sr. M. des Kaisers. - Pitcairnia latifolia Bot. Mag. tab. 856. Bot. Mag. tab. 2657.

Wir haben hier die aufallende Erscheinmug, eine Species mit zwei Namen in einem Werlie ahgebildet zu sehen, namlich Pitc. furfuracea und Pite. latifolia, beide in Botanical Magazine. Die Abbildung in der Flore et Pomone ist nicht zu beriicksichtigen, indem dieselbe nur einen Umriss der Pflanze darstellt. Hingegen sind die unter Jaequin's per. sönlicher Leitung und mit seincr eigenhändigen Bestimmung für S. II. den verstorbenen Kaiser Franz durch sehr geschickte Hünde in gross Folio - ja selbst auf Pergament gemalten Pflanzen, ein wahrer Schatz, welcher leider so wenig benuitzt wird! Ich werde noch öfter Gelegenheit haben, dieser werthvollen Sammlung zu gedenken. Da die im kaiserlichen Garten gezeichnete Pite. furfuricea ein prachtroll ausgebildetes Exemplar gewesen, - so werle jeh diese Pllanze zu meiner Beschreilung wählen, indem dieselbe auch in meiner Sammlung noch nicht so vollkommen blühte.

Pflanze einen kurzen, unten blattlosen Stamm bildend. Laubblätter zierlich iiberhängend, schwach sägezähnig, an Grunde eine Rinne bildend. Lier wenig umfassend, $1^{\prime}$ lang, $3 / 4$ " breit. Aussenfläche lebhaft griin, Lnterfläche hellgrïı. Schaft filzigr, wie behaart, griin, mit Purpur reichlich bemalt, sammt dem Bliithenstande $21_{2}^{\prime}$ lang, sehr kräftig. Blïthenstand schwach verzweigt, $10 "$ lang. Blithen unordentlich zusammenstehend. Blïthenknospen an der Spitze des Blïthenstandes dicht gedrängt zusammenstehend, lebhaft grün mit roth bemalt. Fruchtknoten und Kelchzipfel leblıaft gelb, in blutroth iibergehend. Bracteen bei jeder Bliithe, etwas länger als die gelblichen Bliithenstielchen, am Grunde bläulich, dann schmutzig weiss und endlich an der Spitze lederbraun; auch hier zeigt sjch die filzige Belileirlung. Kronenblätter stumpf spitz, tiel' geschlitzt rachenförmig, schmutzig verwaschen weinroth bis bhtroth. Genitalien kürzer als die Kronenblätter, etwas vorhängend. Staul, beutel gelb. 


\section{Pitc. Ja cks o n i i Hooker.}

Botanical Magazine tab. 1510.

Planze sammt dem Schaft und Bliithenstande 1 $1 / 2$ ' hoch. Laubblätter alle nahe zusammenstehend, aufrecht, $1^{\prime}$ lang, zierlich am Ende übergebogen, schwach sägezähnig, spitz endend, mit entschieden hervortretendem Mittelnerv. Pflanze lebhaft blaugrün. Schaft etwas filzig bekleidet, hell gelbgrün mit röthlichem Anfluge. Blïthenstielchen, Kelchzipfel, Fruchtknoten und Kronenblïtter lebhaft blutroth, theilweise ins Gelbe übergehend. Blüthenstielchen ganz frei, 1/, "lang. Fruchtknoten und Kelchzipfel $3 / 2$ " lang. Kronenblätter iiber $2^{\prime \prime}$ lang. Bracteen nur $y_{4} "$ lang und sehr schmal. Der Bliithenstand trägt bis zur kleinsten Knospe die lebhaft rothe Färbung. Staubfäden so lang wie die Kronenblätter. Staubbeutel nahe zusammenstehend, steif aufrecht, goldgelb. Griffel weit vorragend, goldgelb, roth bemalt.

\section{Pitc. in tegrifoli a Gawl.}

Botanical Mag. tab. 1462. Pitcairnia furfuracea, Annales de Flore et Pomone. - Pitcairnia graminifolia Hort. Blumenbachia von Schrader.

Laubblätter weich, schlaff, hell schmutzig grasgrün, auf der Unterfläche hell blaugrün, mit mehreren Längsstreifen versehen; $1 \frac{11}{2}{ }^{\prime}$ lang, g'" breit, ganz unbewehrt. Bliithenstand aufrecht, verzweigt. Schaft, Blïthenstielchen und Bracteen bei jeder Bliithe haben eine licht braunrothe Färbung. Fruchtknoten und Kelchzipfel verwaschen gelb, in lebhaft blutroth iibergehend. Kronenblätter lebhaft blutroth, eine dünne Röhre bildend, am Ende kaum unregelmässig geöfnnet, etwas gedreht. Staubbentel und Griffel gelb gefärbt, letzterer etwas aus der Röhre vorragend. Die Knospen stehen alle aufrecht sehr dicht beisammen und haben gegen die Spitze des Blüthenstandes cine licht grüne Fürbung; dieser ist 9" hoch; die Bracteen ${ }^{3 / 4}$ "; Fruchtknoten und Kelchzipfel 1"; die Blumenröhre $3 / 4$ ".

\section{Pite. la evis Beer.}

Tillandsia laevis. Arrab. Flora Fluminensis tab, 126.

Laubblätter eine tiefe Rinne bildend, unbewehrt, wahrscheinlich über 3" lang und 1" breit. Stamm verdickt, mit den Resten der abgefallenen Laubblätter hesetzt. Blätter fast zweizeilig. Bläthenschaft wollig, gerade, sammt dem Blüthenstande bei $2 \frac{1}{2}{ }^{\prime}$ lang. Blüthenstand 6" hoch, durch das nahe Zusammenstehen der wagerecht alsstehenden zahlreichen Blüthen pyramidal geformt. Bracteen bei den Blüthen $3 / 4 "$ lang. Fruchtknoten und Kelchzipfel 1 " lang. Kronenblätter eine 
dünne, etwas bauchige Röhre bildend, am Ende rachenförmig geöffnet. Genitalien etwas vorhängend. Färbung nicht bekannt.

\section{Pite. latifolia Jacquin.}

Privat-Bibliothek Sr. M. des Kaisers.

Laubblätter zahlreich, schlaff hïngend, $1 \frac{1}{2}{ }^{\prime} \operatorname{lang}, 1 \frac{1}{2}{ }^{\prime \prime}$ breit, gleichmässig schwach sägezähnig. Blïthenstand und Schaft $1 \frac{1}{1}{ }^{\prime}$ 'lang, zierlich gebogen, letzterer hell weinroth. Bracteen bei den Blïthen hell grü, schmal, spitz, 1/2" lang. Fruchtknoten und Kelchzipfel lebhaft orangefurbig. Kelchzipfel über 1" lang, spitz zulaufend. Blumenkrone auffallend gross. Einzelnes Blatt $1 / 2$ " breit, $2 \% / 2$ "lang. Die Blumenlulutter stehen sehr unordentlich beisanmen und sind bis zu den Kelchzipfeln offen, so zwar, dass man die Staubfiden bis aut den Grund sehen kann. Diese sind so lang wie die Blumenblätter und lehnen sich, in eine Reihe geordnet, an dieselben; letztere sind aussen fleischfarben, innen aber feurig blutroth mit gelb bemalt. Der ganze Bliithenstand hat ein sehr flattriges Ansehen, und es erscheint auch beachtenswerth, dass die Bliithen sich nicht der Reihenfolge nach öfnen, indem in Mitte der abgeblühten Blumen sich auch Blüthenknospen befinden.

Pite. longifolia Hookei.

Botanical Magazine tab. 4775.

Diese Species bildei einen aufrechten, 3" hohen, 1" dicken, braunen, holzigen Stamm. Die Laubblätter sitzen an Scheiden, welche schwach gestreift und stark unfassend den Stamm ungeben. Die Blattspreite ist an der Blattscheide $4^{\prime \prime \prime}$ ureit, verbreitert sich dann aber schnell, so zwar, dass dasselbe bei einer Länge von $3^{\prime} \mathrm{im}$ Mitte $1 \frac{1}{2}{ }^{\prime \prime}$ Breite erreicht. Die Blattspreite ist fein sägezähnig. Die Sprossen erscheinen am alten Stamm, und zwar mehrere Zoll ober der Erde. Der Schaft erhebt sich aufrecht, sehr dünn, und ist, so wie die Fruchtknoten, Kelchzipfel, Blüthenstielchen und Bracteen lebhaft grasgrïn gefürbt und filzig bekleidet. Der Blüthenstand ist 9" lang, vielmals verzweigt. Die Blïthen alle, sammt den Stielchen steif aufrecht stehend. Kelchzipfel sehr tief geschlitzt, lanzettförmig, schmal, spitz endend, wesshalb auch die $2^{\prime \prime}$ langen, lebhaft blutrothen Bliithen fast bis auf den Grund sichtbar sind. Die Kronenblätter bilden eine dünne, gedrehte Röhre; die spitzen Zipfel aber stehen alle gleichmässig gegen aussen gebogen; aus den rachenförmigen Blumenblättern stehen die bedeutend kiirzeren gelben Staubbeutel steif hervor.

Der ganze Blüthenstand bildet eine eigenthümlich eckige Erscheinung. 


\section{Pite. paniculata Ruitz et Pavon. \\ Flora Peruviana et Chilensis CCLX.}

Pflanze: Der Schaft rispig, die Bispe zusammengesetzt. Blätter sägezähnig und stachelspitz, schwertförmig, bestäubt. Blumenkrone carminroth.

Schaft aufrecht, rund, abwärts geneigt, bestäubt, weiss, etwas länger als die Blätter und einfach.

Blätter an einander liegend, 2 Ellen lang, a usserhalb bestäubt, weisslich grau, von der Mitte bis zur Spitze herabgebogen, abstehend, schwertförmig, schmal; die Ränder der Blätter sägezähnig und unterhalb. verdünnt; die Vorblätter waffenlos.

Rispe endstiindig, sehrr gross und doppelt zusammengesetzt. Blüthenstiele abwechselnd, die unteren etwas weiter entfernt, mit lanzett pfriemenfürmiger, concaver, gestreifter und immer umstellter (umfassender) Bractee umgeben. Die seitlichen Blüthenstiele zerstrent durch eiförmige, concave und häutige Bracteen unterstiitzt.

Das Bliithenstielchen einblüthig, unterstiitzt durch kleine eifürmige und spitze Bracteen.

Der Kelch dreitheilig, die Zipfel angedriekt, dreimal so lang als die Krone, halb unterständig, bestäubt, weiss.

Kronenblätter drei, hochroth, lanzettförmig, aufrecht, oberhalb rü ckwärts g ebogen, abstehend, unterwärts zusammengerollt, verwelkend bleibend.

Sechs Staubficten, fadenförmig, von der Länge der Kronenblätter, aufrecht. Staubbeutel pfeilförmig, schmal, gelb. Fruchtlnoten pyramidenförmig, schwach dreiseitig, halb oberständig.

Pistil fadenförmig, so lang als die Staubgefässe.

Narben drei, divergirend, abstehend.

Kapsel pyramidenförmig, eingehïllt durch Kelch und Blumenblätter, schwach dreiseitig, dreifurchig, dreifücherig und dreiklappig. Samen zahlreich, länglich, beiderseits mit pfriemenförmiger Spitze.

Anden, Abhänge bei Chinchao n. s. w., auf Felsen. Juli, August.

Ruitz et Pavon.

Wahrscheinlich ist Pitcairnia longitolia Hooker (Botan. Mrag. 4775) und diese Pflanze eine Species, obwohl sich einige Unterschiede in der Beschreibung finden.

\section{Pite. muscosa Martius.}

Botanical Magazine tab. 4770. - Piteairnia leiolema Hort.

Diese Species dürfte wohl die kleinste unter den Pitearnien sein. Es gibt noch eine Pflanze, welche Pite. leiolema genannt wird, - die 
sich aber in so geringem Grarle von Pite. muscosa unterscheidet, dass sie füglich hierher gezogen werden kum. Das Pflänzchen bildet einen

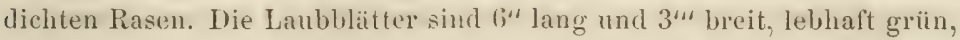
auf der Unterfläche licht blaugriin, manchmal am Rande gewimpert, aber ganz wehrlos. Schaft, Bracteen und Endknospen hell gelbgriin, mit weiss filzigem Ueberzuge. Fruchtknoten und Kelchzipfel 1" lang, lebhaft blutroth. Kronenblätter $1 \frac{1}{2}$ " lang, hell roth gefärbt mit gelblichem Anfluge. Staubfäden weiss. Stanbbeutel gell). Griffel weiss, beide kürzer als die Blüthenkrone. Der Blïthenstand ist 4" hoch, die Blüthen alle steif aufrecht.

\section{Pite. Beyealema Hort.}

Scliönbrunner Garten.

Diese Species ist in allen Theilen grösser als Pitc. muscosa, aber doch noch eine der kleinsten aus dieser reichen Gattung. Ptlanze dichte Rasen bildend. Laubblätter sehr zahlreich, 10" lang, $4^{\prime \prime \prime}$ breit; Unterfläche weiss, - Oberfläche hellgrủn, rom Grunde aus eine tiefe Röhre bildend, hier an Ende schmutzig weiss, durchsichtig, an den Rändern fein, weich gewimpert. Schaft und Blüthenstand - welch' letzterer für sich 6" misst - 22" lang, mit leicht abwischbarem, weisslichem Filze bekleidet. Kronenblïter eine schlanke, dinne. 2 "lange Rïhre bildend, von prachtvoll scharlachrother Farbe. Kelchzipfel tief geschlitzt, fast stumpf endend, 1" lang, matt scharlachroth, an den durchsichtigen Pändern gelblich bemalt. Bracteen bei den Bliithen, etwas lïnger als die Bliithenstielchen; beide weiss filzig bekleidet. Schaft schmutzig lunkelgrün, auf der Lichtseite purpurfarben bemalt.

\section{Pitc. nubigen a Plan. et Linden.}

Flore de Serres van Houtte, tab. 847.

Eine sehr gute neue Species, mit pyramidalem Blüthenstande. Laubblätter etwas faltig, gestreift, am Grunde verschmälert, hier 4“" breit, in der Mitte $1^{\prime \prime}$ breit, wellig spitz endend, ganz unbewehrt, $1 \frac{1}{2}{ }^{\prime}$ lang. Blüthenstielehen 3/,"lang, sammt den abstehenden, über 1 "' breiten und $1 / 2$ " langen lanzettförmigen Bracteen bei jeder Blüthe, wie auch die nahe zusammenstehenden Endlinospen des Blüthenstandes grasgrün mit rüthlichem Anfluge. Fruchtknoten und Kelehzipfel, welche sehr tief geschlitzt und abstehend spitz verlaufen, an den Spitzen wein'oth, dann schmutzig orangengelo verwachsen gefärbt. Kronenblätter bis auf den Grund gegen vorne offeu, riickwärts nahe zusammenstehend, aufrecht, 2" lang; 5"' breit, au Rande wellig, rachenförmig; lebhaft hoch rosa, 
mit blutroth gestreift und breit bemalt. Staubfäden und -Beutel gerade aufrecht zusammenstehend; Grifiel etwas länger als erstere, beide hell goldgelb, bis auf den Grund sichtbar, kürzer wie die Kronenblätter.

Blüthen sehr zahlreich, alle aufrecht, rund, pyramidal zusammenstehend. Blüthenstand unverzweigt, über 8 " hoch.

\section{Pite. angustifolia Willdenow.}

Redouté Liliacees II, tab. 76.

Die Pflanze bildet einen Büschel hackiger Vorblätter, aus denen sich die gleich breiten, gleichmässig abstehend sägezähnigen, etwas fleischigen, hellgrünen Laubhlätter zierlich aufrecht erheben. Laubblätter am Grunde wenig umfassend, dann 1/2" breit, 11/4" lang, gleichmässig rinnenförmig, schlaff spitz endend. Die Sägezähne stehen ziemlich regelmässig, $1 / 2$ " von einander, sind an der Spitze braun und sehr fest. Die Unterfliche der Blätter ist wie weisslich linirt und selbst etwas filzig. Der Blüthenschaft ist dïnn, steif, und mit dem Blüthenstande ïber $2^{\prime}$ lang, lebhaft gelbgriü. Der Blüthenstand einfach verzweigt, gelblich; die grünen Bracteen bei jeder Blüthe $1 / 4$ " lang und etwas abstehend. Fruchtknoten rund; Kelchzipfel aufrecht anliegend; Blüthenstielchen ganz sichtbar, sämmtlich gelb-roth gefärbt. Blüthen nach verschiedenen Richtungen stehend. Kronenblätter über 1 $1 \frac{1}{2}$ " lang, am Grunde schmal röhrenförmig, dann rachenförmig ausgebreitet, lebhaft gleichmässig blutroth gelürbt. Staubbeutel hell goldgelb, kürzer wie die Kronenblïtter. Griffel und Pistil röthlich, iiber die Blumenkrone weit vorragend. Die Blüthen stehen sparrig vertheilt.

\section{Pite. tomentos a Dietrich.}

Pitcairnia angustifolia B. Aiton. Botanical Magazine tab. 1547.

Diese Pflanze ist dergestalt verschieden von Pitcairnia angustifolia Willd., dass ich mich veranlasst finde, den Species-Namen "Pitcairnia tomentosa" beizubehalten.

Laubblätter steif aufrecht, wie ein Ananassablatt, gleichförmig mit kleinen aufwärts stehenden Sägezilhnen bewafinet, am Ende stachelspitz, matt grün. Auf der Unterfläche hell filzig weissgrün, mit dunkler grünen Längsmakeln geziert. Mittelrinne nur am Grunde der wenig umfassenden Laubblätter. Blüthenstand unverzweigt. Schaft und Bracteen bei den Blüthen, weisslich filzig. Blüthenstielchen und Fruchthnoten gelblich grün. Kelchzipfel feuerroth tief bemalt. Kronenblätter schön orangengelb mit blutroth bemalt, 2 "lang; Zipfel breit, weit rachenförmig geöffnet. Blüthenknospe etwas gedreht, stumpf spitz. Endknospen am Blüthenstande sehr nahe zusammenstehend, hellgrün gefärbt. Genitalien 
kürzer wie die Blumenblätter, sichtbar, der Grifiel länger, beide lebhaft hellgelb. Die Bliithen werden im Verblühen lederfarbig, die ganze Pflanze hat ein derbes Ansehen.

\section{Pite. su a v e olens Lindl.}

Botanical Register, tab. 1069.

Laubblätter mit stark entwickelter, scheinbar doppelter Mittelrippe, $1 \frac{1}{2}$ ' lang, bei 1" breit, ganz unbewehrt, am Grunde tiel rinnig mit aufrechten weichen Ründern, hier wenig umfassend, gleichmässig dunkelgrün. Endknospen, Bracteen bei jeder Bliithe und Schaft lebhaft grasgrïn, filzig bekleidet, erstere am Grunde gelb bemalt.

Stielchen und Fruchtknoten sammt Kelchzipfel, welche letztere 1" lang, schmal spitz, etwas abstehend sind, lebhaft gelb gefärbt.

Kronenbläter rein weiss, flatterig, von einander abstehend, rachenfürmig geüfinet, etwas ïbergebogen, spitz endend, 2 " lang, jedes cinzelne $1 / 2$ "breit. Staubfüden ans der Bliithe heraushängend, rein weiss, kïrzer als die Kronenblätter. Staubbentel 5" lang, rein gollgelb. Ciriffel lebhaft grün. Die Blüthen sind sparrig vertheilt, aber sehr zierlich und schön.

Pite. undulata Hort.

Diese ist die merkwürdigste Form unter allen mir bekanuten Species von Piteairnia. Der Blïthenstand bietet niehts Anssergewöhnliches, allein die Laubblätter sind einzig in ihrer Form, nicht nur in diesem Genus, sondern überhaupt in der ganzen Familie der Bromeliaceen! - Am meisten hat diese Blattorm noch Aehnlichkeit mit jener von Phlom., obwohl so breite Blattspreite auch hier sich nicht findet.

Laubblitter 8'lang, am Grunde glänzend schwarz, glatt, schalenfürmig umfassend; dann beginnt, rein begränzt, ein brauner Filz, welcher sich auf der ganzen Unterthiche der Blätter findet, gegen oben aber ins weissliche übergeht. Nach der schatenförmigen Ausbreitung, welche 1" lang ist, wird das Blatt plötzlich stielrund, über '2"“ dick, mit tiefer, schmaler Mittelrinne, welche sich endlich bei 1' Länge als Blattspreite auszubreiten beginnt; von hier an wird das Blatt schnell breiter, bis es endlich die grösste Breite nämlich $61 / 2$ ", erlangt. Gegen das Ende ninmı das Laubblatt schnell an Breite ab und endet in eine lang gedehnte stumpfe Spitze. Der Rand ist ganz glatt und tief' spitz wellig; der Mittelnerv bildet eine tiefe gleichfürmige Rimne, welche sich gegen das Blattende ganz verliert. Von dieser Rime geht die so schnelle Ausbreitung des Laubblattes aus. Solehe Bliatter, deren stielrunder Theil steif aufrecht steht, besitzt die Pflanze mehrere, welche damn nach allen Seiten iiberhängen. Der Bliithenschaft erheht sich gerarle, steif, und ist sammt 
den sparrig vertheilten Blüthen $2^{1}{ }^{\prime}{ }^{\prime}$ lang. Der Blüthenstand ist 11" lang. Die Bracteen bei jeder Blüthe sind schiffförmig spitz, die längsten $1 \frac{1}{2}{ }^{\prime \prime}$ lang, alle lebhaft griin und etwas roth bemalt. Der $3^{\prime \prime \prime}$ dicke Schaft ist der ganzen Länge nach lebhaft roth. Fruchtlinoten und Kelchzipfel, beide $1 \frac{1}{2}$ "lang, aufrecht, letztere tief geschlitzt und anliegend, lebhaft ziegelroth gefärbt und nur wenig mehlig, wie bestäubt. Blüthenstielchen $3 / 4$ "lang, lebhaft roth. Kronenblätter 2 "lang, kräftig aufrecht, am Rande gegen oben wellig, rund, rachenfürmig. Griffel und Staubbeutel von gleicher Länge mit den Bliithenblättern, -- lebhaft gelb. Narbe tief lilafarbig. Die Blüthen stehen alle aufrecht. - Von dieser ansgezeichneten Pflanze findet sich eine gute Abbildung in der PrivatBibliothek Sr. M. des Kaisers.

\section{Unterabtheilung.}

Gesammtblüthenstand ein in Grunde der Laubblätter sitzender Blithenbüschel.

Pite. Warszewitzian a Klotzsch.

Eine Pitcairnia mit eingeschlossenen Genitalien.

Simplex, erecta, heterophylla; trunco ad basin magis incrasso; foliis inferioribus squamaeformibus brevibus ovatis longissime spinescentibus infra apicem hamato-spinosis, superioribus oblongis setoso-acuminatissimis glabris laeribus, margine integerrimis, evanescente vellere scapo duplo brevioribus; scapo terminali evanescente lanato; bracteis lanceolatis acuminatis adressis; pedicellis brevibus albido-tomentosis; floribus pallide coccineis galeatis; genitalibus inclusis; perigonii foliolis intus ad basin squama incisa, margine libera instructis; filamentis styloque glabris; avario triangulari-pyramidato similibero.

Die ganze Pflanze ist $2^{\imath}$ hoch, an der Basis bis zu einer Höhe ron 2 " eifürmig-knollenartig verdickt und an dieser Stelle mit 3" langen, ciförmigen, lang-gegranten, dicht anliegenden Blättern besetzt, deren lang hervorgezogene Dornenspitzen mit hackenfürmigen, zurückgekrümmteu, schwarzen Stacheln versehen sind. Die darüber stehenden Blätter sind fusslang, kahl, etwas glänzend, 10 bis 12 “' breit und am Rande, wie

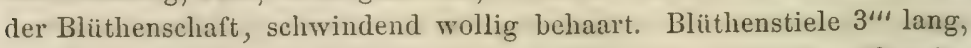
wollig behaart. Aeussere Blïthenhülltheile blassroth, kahl, lanzettförmig, lang zugespitzt, $10^{\prime \prime \prime}$ lang. Innere Blütheuhülltheile hochroth, rachenförmig, $2 \frac{1}{6}$ " lang. Grifiel $2 "$ lang. Staubgefïsse $2 \frac{1}{2}{ }^{\prime \prime \prime}$ lang. Vou dem 
Garten-Inspector Herrn ₹. W a r sze w i c z in Nord-Peru entdeckt und eingetührt; von dem Handelsgürtner Herrn L. M a th i e u in Berlin gezüchtet.
Berlin, 25. August 1855.
Dr. Klotzseh.

\section{Pitc. Morrenii Lemaire.}

Paxton's Flower-Garden, tab. 68. - Jardin fleuriste III, tab. 291.

Pflanze am Grunde wie eine Knolle verdickt, mit bauchig umfassenden Deckblïttern, welche in eine scharf hackige, schmale, bei 3" lange Granne endigen, hier trocken, meist farbig dunkelbraun, holzig. Die kugelige Stammverdickung beträgt 11\%“"Durchmesser. Aus diesem Vorbläterbiischel erheben sich die steif aufrechten, tiefrinnigen, lebhaft grïnen, unbewchrten, $1 / 2$ " langen und nur $2 \frac{1}{2}$ " gleich breiten, stumpf endenden Laubblätter, in deren Mitte der Blïthenbüsehel sitzt. Bliithen in gleicher Höhe stchend. Bracteen bei jeder Blüthe, Fruchtlinoten, Kelchzipfel und Kronenblätter steif aufrecht, gleichmässig feurig ziegelroth, mit blutroth bemalt. Kelchizipfel tief geschlitzt, spitz, etwas abstehend, 1" lang. Kronenblätter an Ende weit abstehend, rachenförmig, $2 \frac{1}{2}$ " lang. Stanbläden und Griffel weiss, viel länger als die Kronenblätter. Staubbentel aufrecht, goldgelb. Narbe diese iiberragend, lebhaft blutroth. Knospe pfriemenförmig spitz.

Pitc. exs capa Hooker.

$$
\text { Botanical Magazine, tab. } 4591 .
$$

Planze am Grunde knollig aufgetrieben durch gewimperte Vorblätter, holzbramn. Die Verdickmng betrïgt 1". Lanbblitter steif aufrecht, lebhaft grüun, bis $3^{4}$ lang und nur $V_{1}$ " breit, mit stark entwickeltem Mittelnerv, am Grunde umfassend.

Blüthenbüschel sehr kurz gestielt, zwisehen den Laubblättern sitzend.

Blüthenstand mit lederbraunen, dann schmutzig grünen, gewimperten, 1 "langen, sehr zahlreichen Vorblättern besetz1. Bläthen alle nach einer Seite (gegen das Licht), selust die Knospen stark nach abwärts gebogen. Fruchtlinoten und tief geschlitzte, abstehende, spitze Kelchzipfel gelblich griin. Kronenblätler am Grunde eine dïnne Rölre bildend, dann gleichmïssig tief gü̈finıet, mit zurïckgeschlagenen Lappen. Staubbentel kürzer als die Kronenbläter, in eine Reihe geordnet, iiberhängend, goldgelb. Griftel zwisehen den Blättern versteckt, selır kurz.

Pite. longifolia Beer.

Puya longifolia, Annales de Gand, II. - Paxton's Flower-Garden III, tab. 86. (Hierzu fehlt die Beschreibung.)

Vorblitterbuischel sehrstark entwickelt, am Grunde stark umfassend, braun, holzig, lanzettförmig, scharf hackig endend, mit einer scharfen 
Granne versehen. Die Pflanze bildet eine mässige Stammverdickung. Die Laubblätter sind schlaff überhängend, bis $2^{\prime}$ lang, $4^{\prime \prime \prime}$ breit, mit stark entwickeltem Mittelnerv, spitz endigend, der ganzen Länge nach rinnenförmig. Die ganze Blüthe lebhaft ziegelroth, steif aufrecht. Bractee 3/." lang, am Grunde umfassend, herzförmig spitz. Fruchtknoten uud Kelchzipfel - letztere tief geschlitzt, schmal spitz endend - 3" lang. Kronenblätter aufrecht, fast regelmässig geöffnet, 2 "lang. Genitalien nahe beisammenstehend, steif aufrecht. Staubbeutel gelb, kürzer als die Kronenblätter. Griffel 4"“ über die Kronenblätter vorragend, lebhaft blutroth.

Pite. heterophylla Beer.

Puya heterophylla. Botanical Register tab. 71 (1840). - Dietrich, botanische Zeitschrift, 118.

Vorblätterbiischel sehr holzig, lederbraun scharf bewehrt und gegrant, am Grunde stark bauchig, nach allen Seiten gerichtet. Laubblattbüschel wenig blättrig. Blätter aufrecht, vom Grunde ans gleich breit, lang, gestreift, mit Mittelrimne, 8 "lang, $1 / 2$ " breit, stumpf spitz endend, lebhaft grasgrün. Der Blüthenstand erscheint bei halber Entwicklung der Laubblitter. Die Blïthen bilden einen Büschel in Mitte der Kurzen, grünen Laubblätter. Sie stchen sehr nale beisanmen, sind aufrecht und lebhatt schaltirt blutroth gefürbt. Blume kurz, kaum 1" lang, flatterig, ein Blatt stark überhängend. Die flatterigen Genitalien sind viel kürzer wie die Blumenblätter und goldgelb. Manche Blithe steht in gleicher Höhe mit den jungen Laubblättern.

\section{Pitc. monstros a Beer.}

Diese merkwürdige Pflanze gleicht der ganzen Form nach Pitcairnia longifolia. Sie treibt einen zwischen den Laubblättern sitzenden Blüthenbüschel. Die Blumen tragen eine schüne lichte Rosafarbe, bestehen aber aus zwei Blumenblattkränzen, wo sich constant, statt eines der ïusseren Blumenblatter, ein Staubfaden mit dem Staubbeutel befindet. Es bildet daher diese ble i b end e monstrose Erscheinmg den so seltenenFall, die Staubäden auch ausser den Kronenblättern erscheinen zu sehen. Ich habe diese seltenen Zustände dureh drei Jahre beobachtet, aber immer alle Blïthen gleich umgestaltet gefunden. Diese Form lebt in Schönbrunn mit Namen "Piteairnia iridiflora Hort."

\section{COCHLIOPETALUM Beer.}

\section{Cochl. albiflos Beer.}

Piteairnia albiflos Herbert, Bot. Mag. tab. 2642.

Pflanze ohne Vorblätterbüschel am Spross oder am Bliithenschafte. Laubbätter glatt, lebhaft grïn; auf der Unterfläche blasser von Farbe, 
glänzend; $3 / 4 "$ breit, 1 ' lang, mit deutlichem Mittelnerv, etwas iiberhängend. Schaft, Bliithensticlchen und Bracteen bei jeder Bliithe, lebhaft hellgriin. Stielchen $3 /, "$ lang. Bractee 4 "“ lang. Fruchtknoten knotig, bauchig, und Kelchzipfel - beide hellgrïn, letztere sehr tief geschlitzt und fein spitz endend, 1/2 "lang. Blumenkronenblätter 4" breit, 2" lang, alle gleichmässig abstehend und die Zipfel stark zuriickgerollt, rein milchweiss; hier hat die Bliithe 1 "Durchmesser. Griffel so lang wie die Kronenblätter. Narbe dreitheilig. Staubfäden sammt Beutel kürzer als die Kronenblïtter, letztere goldgelb, -. aufrecht, in Mitte der Blïthe stehend. Knospestumpf, pfriemenförmig. Blüthen sparrig, an den wagerechten Blüthenstielchen aufrecht stehend. Blüthenstand unverzweigt, g"lang.

\section{Cochl. flavescens Beer.}

Pitcairnia flavescens Hort.

Eine sehr reich blïhende, wohlriechende Species, deren Bliithenstand fast einseitwendig erscheint, wenn derselbe nicht durch Einfluss des Standortes sich so bildet. Pflanze auffallend grösser als Cochl. albiflos, glatt, gleichförmig grasgriin. Laubblätter 18" lang und 10"“ breit. Blithen sammt Stielchen steif abstehend; erstere 2 "lang. Kronenblätter fast gleich breit ( $\left.3^{\prime \prime}\right)$, jedes fiir sich ganz frei abstehend, an den Enden stark einwäits gerollt, strohgelb. Stanbfarden kiirzer als die Kronenblätter. Staubbentel goldgelb, auffallend schmal. Griffel hellgriin, so lang wie die Kronenblitter. Kelchzipfel weit geschlitzt, schwefelgelb mit schwachfarbig griner Spitze. Fruchtknoten rein geförbt, lebhaft grasgrün. Stielchen dümn, steif. Bractee kaurn t/2 "lang, lanzettlich schmal. Blïthen sehr zahlreich, eine sehr lockere unverzweigte Aehre bildend. Bliithenschaft glatt, $2^{\prime}$ sammt dem $8^{\prime \prime}$ langen Bliithenstande, steif, $2^{\prime \prime \prime}$ dick, mit einzelnen Laubblättern besetzt.

Diese sehr schöne, nach Orangenblüthe duftende Planze dürfte nicht sehr bekannt sein.

\section{Cochl. Sehüchii Beer. \\ Tillandsia Schüchii Beer.}

Diese schöne Pflanze unterscheidet sich vollkommen von Cochliop. albiflos. Ich habe dieselbe seiner Zeit mit dem Namen "Tillandsia Schüchii", zu Ehren des brasilianischen, damals in Wien weilenden Professor Sch ii ch genannt und an verschiedene Gïrten vertheilt. Sie kam auch durch mich in den Deckersehen Garten zu Berlin, wurde von Dr. Dietrich gesehen und damals schon in der Allgemeinen Gartenzeitung darauf hingewiesen, dass diese Pflanze die Pitcairn, albiflos sein 
dürfte. Dr. Dietrich wies auf dem gebränchlichen botanischen Wege nach, dass es keine Tillandsia sei, worin er vollkommen recht hat; aber Pitcairnia albiflos ist es auch nicht! Dr. Dietrich hatte auch aus Versehen Beer und Fenzl als Benenner genannt. Ich habe gleich beim Bekanntwerden dieses Irrthums nach Berlin an Herm Director Ot to geschrieben und ihn und Dr. Dietrich mit diesem Irrthume bekannt gemacht, aber auch, wie natiirlich, Dr. Fenzl hiervon benachrichtigt, welcher in bekannt liebenswïrdiger Weise - seinen hochgeehrten Namen nicht einzog. Nun hat Herr Regel in der Züricher Gartenflora erst kürzlich den Namen Tillandsia Schüchii wieder eingezogen, was schon Dr. Die tri ch gethan, und dafiir den Namen Pitcairnia albiflos gegeben. Beide Herren haben recht gethan, indem diese Pflanze wirklich zur Gattung Pitcairnia gehört. Die Pflanze wurde in meinem Garten aus brasilianischem Samell gezoger. (Die Beschreibung folgt im Anhange.)

\section{Cochl. s ta $\mathrm{m}$ in e $\mathrm{um}$ Beer.}

Pitcairnia staminea Lodd. Bot. Mag. tab. 2411. - Loddiges Bot. Cabinet tab. 722. Sertum botanicum van Geel.

Pflanze sehr zierlich. Laubblätter $3 / 4$ " breit, über 2 ' lang, ganz unbewehrt, lebhaft griin, anf rer Unterfliche mit fein kleiigein, weisslichen Anfluge. Schaft sammt Bliithenstand steil' aufrecht, diinn, bei 2 ' hoch, letzterer iiber 1' lang. Schaft, Bliithenstielchen, Fruchtknoten und Bracteen schmutzig griin nit I'urpur bemalt. Kelchzipfel sehr weit geschlitzt, fein spitz endend, 1 " lang. Kronenblitter 1\%" lang, mehr als die Hiilfte zuriickgerollt, lebhat blutroth. Genitalien liinger als die Kronenblïtter, sämmtlich feurig roth. Sie ragen bei der geöfïneten Blüthe um $2^{\prime \prime}$ vor und stehen aus der Blumenröhre gleichmässig steif vor. Knospe sehr spitz, pfriemenförmig, bei dem Erscheinen schon lebhaft roth. Blïthenstand pyramidal. Blïthen sparrig, alle gegen aufwärts stehend.

\section{ORTHOPETALUM Beer.}

Orth. lanuginosum Beer.

Pitcairnia lanuginosa. Ruitz et Pavon. Flora Peruviana et Chilensis tab. 258. - Kerner, Hortus sempervirens, tab. 247. - Salvi, Flora Italica III, tab. 99.

(Beschreibung von Ruitz et Pavon.)

Pflanze: Schaft traubig ährenförmig, einfach. Blätter nahe an einander, schmal schwertförmig, unterhalb filzig, an der Basis sägezähnig. Blumenkrone violett.

Schaft einfach aufrecht, 2 Ellen lang, rund, an der Basis beblättert, hierauf mit abwechseluden, sichtlich entferut stehenden Schuppen bekleidet. 
Laubblätter sich wechselseitig anlicgend, von der Lünge des Schaftes, schwertförmig, schmal, sehr zugespitzt, unterhalb filzig, weisslich grau, gestreift, nervig, an der Basis der Blattränder sägezähnig. Die Beiblätter (tenera) von der Basis bis zur Spitze scharf sägezähnig und roth gefärbt. Die Zähne der dünneren Blätter zurückgebogen, die der älteren einwärts gebogen, sehr scharf, kurz und dunkelpurpur.

Die unteren Schuppen dacliziegelförmig, fast fusslang, sehr schmal, lineal, pfriemenförmig, an der Basis von der Breite von 1 bis $2^{\prime \prime}$; halbstengelumfassend, gestreift, nervig, an der Basis sägezähnig. Die oberen Schuppen merklich kürzer, entfernter stehend, lanzettlich pfriemenförmig, angedriickt. Bliithen in einer fast ährenförmigen, endständigen und einfachen Traube abwechselnd einzeln stehend, mit kurzen Blïthenstielen und Bracteen überall umstellt. Die Bracteen eiförmig zugespitzt, concav, bedeckt mit einem weisslich grauen Filze. Kelch kaum merklich, dreiseitig, auf grïnlichem Grunde weisslich bemalt. Die Blumenblïtter lineal, hell violett, dreimal so lang als der Kelch. Die Staubbentel gelb, fast $3^{\prime \prime}$ lang. Kapsel braun, tief, dreifurchig und iiber 1" breit. Same dunkel fahlgelb, beiderseits mit einer langen Granne versehen.

Pozuzo, auf Felsen. August, September, October.

\section{Orth. pulverulentum Beer.}

Pitcairnia pulverulenta Ruitz et Pavon. Flora Peruv, et Chil. tab. 259.

(Beschreibung von Ruitz et Pavon.)

Pflanze: Schaft rispig zusammengesetzt. Blätter schwertförmig, unterhalb bestäubt. Die unteren Blätter gestielt. Die Blumenkrone hochroth.

Schaft lklafterlang aufrecht, rund, oberhalb bestänbt, unterhalb nur beblïttert. Die Blätter lang, von der Breite über einen Daumen, dachziegelförmig gestellt, zahlıreich, schwertförmig, die Ränder sägezähnig. Die Zähne einwïrts gebogen und schwarz, dicht gestreift, oberhalb ganz kahl, unterhalb bestäubt, weisslich grau, die unteren lang gestielt. Die Blïthenstiele kurz, beiderseits mit zurüickgewendeten Zühnen. Die Rispe endständig, sehr gross, aus sehr vielen abwechselnd stehenden Theilen zusammengesetzt, vielbliithig. Die Scheide lanzett - pfriemlich, halbstengelumfassend, gestreift, concav, je einzeln umstellt. Blïthen abwechselnd stehend, gestielt, mit eiförmiger, zugespitzter, concaver und gestreifter Bractee, bleibend unterstützt, nach allen Seiten gerichtet. Die Blïthenstiele kurz, zierlich, und weisslich grau gefärbt. Kelch dreitheilig; die Zipfel lanzettlich eiförmig, 3““ lang, angedrückt, fast lederartig; halb unterständig bleibend. Blumenblïtter hochroth, länglich lineal, 
dreimal länger als der Kelch, schmal, im Verwelken unter sich zusammengerollt. Staubfäden fast von der Länge der Blumenkrone, pfriemenförmig zusammengedrückt. Staubbentel lineal gelb. Fruchtlknoten halb oberständig dreiseitig. Pistil fadenförmig, von der Länge der Staubäden. Narbe länglich, dreispaltig, die cinzelnen Theile angedriickt. Kapsel rreiseitig, lilein, umwunden ron verwelkten Kelchund Blumenblättern, dreifächerig und dreiklappig. Samen sehr viel, klein, braun.

Standort in Hainen der Anden, an Wegen und auf Triften des Dor. fes Widoc.

Bliithezeit November und December.

Orth. inerme Beer.

Pourretia inermis Pressl. Reliquae Haenkiana, tab. 23.

Laubblätter $1 / 4$ " breit, bei $1 \frac{1}{2}$ " lang. Blithenstand 10 "lang, verzweigt, a lle Blïthen aufrecht stehend und gleichzeitig sich entwickelnd. Bractce bei jeder. Verzweigung des Blïthenstandes, kahnförmig, - abstehend, 1" lang. Fruchtknoten und kaum sichtbare Kelchzipfel verkehrt pyramidal. Kronenl, lïter sehr schmal, 1" lang, steif aufrecht stehend. In verblühten Zustande zu einem braunen Faden zusammengedreht, herabhängend.

\section{HOHENBERGIA Schult. fil.}

Hohenb. strocilacea Schult. fil.

Acantostachys stobilacea Klotzsch. Icones plant. Hort. Berol, tab. 9. - Paxton, Flower Garden III, pag. 46 (256).

Pflanze klein, mit wenigen, etwas iiherhängenden Laubblätern; diese 2 ' lang, $2^{\prime \prime}$ breit, sehr dunkelgriin, rom Grunde an his zu 3"Länge ganz umfassend (scheinloar wie verwachsen), damn tief furchig, rinnig, tleischig, an den Rändern spärlich aber scharf sägezähnig, an Ende stumpf, holzig, spitz. Schaft 1' lang, $2^{\prime \prime \prime}$ breit, vollkommen stielrund, am Ende gekrönt mit drei oder vier verschieden langen $\left(1 \frac{1}{4}\right.$ " bis $13 / 4$ " lang), am Grunde breit scheidig umfassenden Laubblättern, hier purpurfarbig bemalt. Bliithenstand zwischen diesen Lanhblättern fest aufsitzend. Bracteen bei jeder Blüthe, stark umfassend, steif, fast holzig, mit zuriickgrebrgenen Enden und aufrechten Rändern; hier scharf sägezähnig und stachelspitz, lebhaft gelbroth gefärbt. Fruchtknoten. Kelchzipfel und anfrechte Kronenblätter lebhaft schwefelgelb. Selbst die kleinste Knospe ist schon vollkommen gelb gefürbt. Blüthenstand $2^{\prime \prime}$ hoch, 1 $\frac{1}{2}$ "breit, und gleicht der Gesammtform nach einem Tannenzapfen. Fruchtknoten fast ganz sichtbar. 


\section{Hohenb. (?) cyan thiformis Beer.}

Tillandsia cyanthiformis Arrab. Flora Flum. tab. 141.

Aeussere Laubblätter vom Grunde aus übergebogen. Dic folgenden steif aufrecht, gleichmässig sägezähnig, am Grunde hauchig, stark umfassend, hier wahrscheinlich nicht säggezälnig; über 1' lang, 1“ breit. Blïthenschaft rund, anfrecht, sammt dem $3 \frac{1}{2}$ " hohen Blithenstande $1 \frac{3}{4}$ " lang; ersterer trägt ein vollkommen stielumfassendes, am spitzen Ende ïbergebogenes, 6" langes, scliarf sägezähniges Laublılatt. Laubblätterkranz heim Blüthenstande aus zahlreichen 4" langen, 1" breiten, spitz zulaufenden, scharf sägezihnigen, steifen, wagerecht abstehenden Laubblättern gebildet. Blïthen dicht beisammenstehend. Bracteen ungezahnt, spitz aufrecht. Blüthenblätter steif aufrecht. Genitalien etwas kiirzer als die 1" langen Kronenblïter. Fruchtsuoten und schmale, tief eingeschlitzte Kelchzipfel 1 " hoch; letztere stachelspitz.

Es ist keine Beschreibung vorhanden, wesshalb auch iiber die Färbung nichts gesagt werden kann.

\section{Hohenb. (?) terminalis Beer.}

Tillandsia terminalis. Arrab. Flora Flum. Łab, 143.

Laubblätter am Grunde ganz umfassend, hier begränzt bauchig, dann eine tiefe Rinne bildend, allmälig flach wertend, mit spitzem Ende, im Mittel 1" breit, am Grunde 2\%" "breit, über 1' lang. Sägezïhne sehr schief, alle dicht stehend, gegen anfwirts gerichtet. Schaft steif aufrecht, rund, mit ganz umfassenden, steif aufrechten, $2 \%$ “ langen, derb saigezihnigen Laubblittern in halher Höhe geziert, und sammt rem 3 " hohen Bliithenstanke 1//4 hoch, (rsterer fast 1/2" dick. Laubblitter des Blüthenstandes nach allen Richtungen alstehend, zahlreich, bei 3 " lang. Nach der Abbildung ist über die Blïtlenform und, da keine Beschreibung vorhanden, auch über die Färbung nichts zu sagen.

\section{Hohenb. (?) bracteata Beer.}

Tillandsia bracteata Arrab. Flora Flum. tab. 125.

Laubblätter zahlreich, 1 \%' ' lang, am Grunde ganz umfassend, hier his zu "/, der Blattlänge eine tiefe Rinne bildend, dann ganz flach, rinnenförmig, stumpf rund enflend; mit Ausuahme des untersten Theiles der Blätter durchaus sehr gleichmässig, selbst über das Junde Ende sägezähnig, steif aufrecht, dann von der Jitte der Länge an schlaff überhïngend. Schaft rund, aufrecht, bei halber Länge mit einem ganz unfassenden, steif aufrechten, dütenförmigen, spitz zulaufenden, gleichmässig sägezähnigen Laubblatte geziert. Blüthenstand $3^{\prime \prime}$ hoch, dieser 
mit dem Schaft zusammen bei $1 \frac{1}{2}$ ', letzterer $1 / 4$ " dick. Blüthenstand durch umfassende, eine Rinne bildende, spitz zulaufende, gleichförmig sägezähnige, nach allen Richtungen flach abstehende Laubblätter gebildet. Bracteen (?) Blüthen wie bei Hohenb. cyanthiformis.

Von der Färbung ist nichts bekannt.

\section{NIDULARIUM Martius.}

\section{Nid. fulgens.}

Jardin Fleuriste tab. 411, II. (Guzmannia pieta? Hort.)

Diese Pflanze bildet durch ihre ausgebreitet niederliegenden Blätter eine zierliche Blattrosette von 1 $1 / 4{ }^{\prime}$ Durchmesser. Junge Sprossen bilden anfänglich die Blätter wie eine Billbergia, gegen aufwärts gerichtet. Blühbare Pflanzen treiben aus der Endknospe einen Büschel steifer und niederliegender Laubblätter, welche lebhaft weinroth gefürbt und mit schönen grünen Spitzen geziert sind. Zwischen diesen Herzblättern stehen aufrecht die sehr schön blauen, mit weiss verwaschenen, sehr wenig geöffneten Blüthen zu fünf in einer geordneten Reihe zusammen. Die Kelchzipfel sind lebhaft roth gefärlt und zwischen den Herzblättern sichtbar. Laubblätter auf hell lichtem Grunde mit lebhaft dunkelgrïnen Fleckchen, welche so ziemlich gleichmaissig vertheilt sind, - geziert, über 1" breit und bei 8" lang, am Rande sügezühnig, aber nicht stachelspitz. Die Laubblätter der Endknospe 2 $\frac{1}{2}$ "lang, 1 $\frac{1}{2}$ " breit, ebenfalls sägezähnig. Alle Blätter haben einen Mittelnerv und ihr stammumfassender Theil ist bauchig schalenförmig.

\section{Nid. dis c olor Beer.}

Tillandsia (Billb.) discolor Hort.

Der Name "Tillandsia discolor" ist bei dieser Species nicht zu verfolgen, indem derselbe jedenfalls ohne Autorität aus einem Garten verbreitet wurde. Römer und Schultes führen den Namen gar nicht an. (Steudel fragt: T. discolor Hort. Quid?)

Pflanze reichlich beblättert, von trüb schmutzig grünem Ansehen, oft mit violettem Anfluge. Laubblätter 15" lang, 1" breit, von lederartiger Beschaffenheit, am Rande fein sägezähnig, aber nicht stachelspitz. Am Grunde umfassend, 2 " breit und bei 3 "Höhe in die eigentliche Blattbreite schnell ïbergehend, hier am Rande sehr dünn, unbewehrt, weich. Die Laubblätter stehen aufrecht zusammen und sind gegen das Ende etwas übergebogen. Die Endknospe erhebt sich mit einem Schopfe von Laubblättern. Der Schaft ist 4" hoch und steckt zwischen den aufrechten Laubblättern, und wird von diesen auch überragt. Zwischen den Herz- 
blättern, welche ein seltsames fimisch von Purpur-, blauer, griner und rother Farbe tragen, und die in eine iibergebogene lange Spitze enden, stehen die Blüthen in geordneter Reihe zu dreien beisammen. Die lebhaft rosafarbene, kaum geöffnete Bliithe ragt zwischen den Blättern hervor. Fruchtknoten, Kelchziptel und Kronenblätter $2 \%$ " lang, letztere etwas ïber $1^{\prime \prime}$, erstere gelblich weinroth gefärbt.

Die Blüthen sind nur dann sichtbar, wenn man zwischen die Blätter hineinsieht.

Nid. purpureum Beer.

Tillandsia sp. rubra der Gärten.

Pflanze ziemlich klein. Laubblitter sehr glïnzend glatt, innen und aussen lebhaft dunkel purpurroth, über $1^{\prime}$ lang und $1 \frac{1}{2}$ " breit. Zur Bliithezeit werden die Blätter lebhafter roth. Die Lliithenform, Farbe u. s. w. wie bei Nidularium discolor.

\section{CRYPTANTHUS Klotzsch.}

\section{Crypt. a ca u lis Beer.}

Tillandsia acaulis Lindl, Bot. Register, tab. 1157. - Bromelia pumila Schott.

Pflanze klein. Laubblätter am Sande wellig, ïber 1 " breit, 5 "lang, hell griin, mit schwach weiss kleiigem Anfluge, - am Rande scharf bewehrt, mit fleischigem Mittclwulste; die Seitensprosse entwickeln sich am obern Ende der sehr kurzen Stïmmchen. Bläthen in Büscheln zwischen den Laublättern sitzend. Kronenbliitter spitz, fleischig, mit durchsichtig dïnnen Rïndern, llatterig, sehr hinfüllig, im Verblühen hell lederbraun. Genitalien kiirzer als die Blumenblatter. Staubblätter hell gelb. Dies ist ein alter Bewohner der Pflanzensammlungen und hat sich nur durch seine Unverwiistlichkeit erhalten.

\section{Crypt. a caulis var. argenteus Beer.}

Stïmmchen aufrecht, bei 3 " hoch. Laubblätter am Rande scharf bewehrt, stark wellig, mit verlängerten schmalen, weichen Enden, steif, in der Mitte mit breitem, fleischigem, flachem Wulste. Aussentläche glänzend, gleichmässig silberweiss. Innere Blattfläche lebhaft gleichmässig hell grïn, die längsten $4^{\prime \prime}$. Seitensprosse zahlreich am Grunde der Pflanze erscheinend. Blïthen sehr zahlreich in dichten Büscheln zusammenstehend, weiss, flatterig. Knospe stumpf zugespitzt. Kelchzipfel trockenhäutig, hell lederfarbig. Fruchtknoten rein weiss, $3 / 4$ " lang, gleich breit, fast dreieckig. Genitalien rein weiss, so lang als die Kronenzipfel. Die Pflanze bildet durch zahlreiche Nebeusprossen eine liebliche Erscheinung. 
Crypt. a caulis var. ruber. Berl. bot. Garten.

Stämmehen $4 \frac{1}{2}$ "hoch, am Grunde Sprossen treibend, welche bald gleiche Länge mit dem Hauptstamme erreichen. Blätter tief wellig, die breitesten am Grunde 1" breit, 3" lang, dann gegen oben am Stamme dicht vertheilt, - schmäler werdend. Auf der Ober- und Unterfäche fuchsroth, ins Mattgrüne übergehend, wenig weiss, mehlig, wie bestäubt.

Bluithen wie bei Crypt. undulatus.

\section{Crypt. diversifolius Beer.}

Bromelia spec. der Berliner Gärten.

Laubblätter auffallend verschieden an Länge und Breite. - Hauptstämmchen etwas iiberhängend, 9 bis $10^{\prime \prime}$ lang. Am Grunde mit $1 / 2$ " breiten, bis 5" langen Blättern, dann gegen oben, am Stamm, an Länge schnell abnehmend, jedoch an Breite zunehmend, hier 1 $1 / 2$ bis 2 "lang, 1 " breit. Junge Sprossen am Grunde des Hauptstämmchens hervorbrechend, mit fast gleichmässig 5" langen Laubblättern besetzt. Alle Blätter in gleichmïssigen Schlangen-Linien tief wellig, am Grunde schmutzig röthlich, dann gelblich schmutzig grün, endlich an den Spitzen schmutzig saftgriin, an den Rändern sehr fein scharf bewehrt, mit weicher Spitze.

Blüthen wie bei Crypt. undulatus.

\section{Crypt. zonatus var. fus cus Visiani.}

Pholidophyllum, Visiani. - Tillandsia zonata Hort. - Billbergia acaulis fol. brunneis, et fol. viridis Hort. - Tillandsia zebrina Hort. - Till. acaulis zebrina Hort. - Till. acaulis zonata Hort.

Unterscheidet sich nur durch die lebhaft hell lederbraunen, in das Fuchsrothe übergehenden, mit sehr schön gefärbten Querbinden versehenen Laubblätter von Crypt. undulatus. Jene Varietät der Pariser Gärten, mit Namen Pholidophyllum giganteum, ist nur eine in allen Verhältnissen etwas grössere Varietät von Crypt. zonatus var. fuscus.

Blüthen wie bei Chrypt. undulatus.

\section{Crypt. zonatus var. viridis Beer.}

Professor V is i an i hat bei Beschreibung von Phytarrhiza Vis, sein Pholidophyllum selbst wieder eingezogen und beide Species zu Cryptanthus gezogen, - wohin dieselben anch gehören; ich habe sie schon seit längerer Zeit umgetauft. Diese prachtvollen Gewächse wurden im Jardin des plantes in Paris aus Samen gezogen und als Tillandsia zonata verbreitet. 
Stämmchen kaum 1" hoch, am unteren Ende zwischen den Blättern zahlreiche Sprossen treibend. Laubblätter bis 9" lang, 2 " breit, von der Spitze an mit mehreren Längsfalten und einem fleischigen Mittelwulste versehen, am Rande fein scharf bewehrt, gross-wellig mit scharf spitzen Enden. Unterflïche der Laubblätter silberglänzend, am Grunde schmutzig röthlich. Oberfläche sehr schön quer gebändert; diese Streifung ist verschieden breit und unregelmässig, durch eine dicht kleiige Masse von rein weisser und gelblicher Farbe gebildet. Die Blätter sind der ganzen Länge nach mit den zierlichen Querlinden geziert, welche zu der auffallenden Schönheit dieser Pflanze nicht wenig beitragen.

Blüthen wie bei Crypt. undulatus.

\section{CARAGUATA Lindley.}

\section{Carag. lingulat a Lindl.}

Tillandsia lingulata Linné. - Caraguata Plumier.

Jacquin, Select. stirp. Americ. Hist. tab. 62 (164, pag. 92). - Jacquin, Select. Americ. tab. 92. - Annales de Gand., III. - Kerner, Hort. semperv. tab. 274. - Sloane, Nat.

Hist. of Jamaica, tab. 120.

Laubblätter auf der Riickseite vom Grunde aus fein roth linirt. Zur Zeit der Blüthe werden die Herzblatter lebhaft blutroth, rom Rande aus breit verwaschen gefärbt und mit rothen Längsstreifen geziert; endlich verkürzen sich die Blätter der Endknospe, werden am Rande schalenartig gegen einwärts gebogen und schmutzig gelb von Farbe. Blüthen einzeln, zwischen den kürzeren Herzblättern sitzend; diese bilden eine zierliche, runde, gleich hohe Rosette, und die gelblichen, kaum geöfineten Kronenblätter sind kaum sichtbar. Laubuläter am Grunde des Stammes 9" lang, hier den sehr dïnnen Stamm bauchig umfassend, abstehend, dann von der Mitte der Länge an 1 “ breit, allmälig stumpf spitz endend.

Es befindet sich in Schünbrunn eine Varietät dieser Species, welche sich durch die gleichfarbig ungestreiften Laubblatter und etwas mehr rorragende Blüthen unterscheidet. -

Es folgt nun die Beschreibung von J a cqu in :

Blïtter lintal, zungenförmig, ganzrandig, an der Basis bauchig. Blüthendecke einblätrig, mit schwach dreiseitiger Basis. Der Fruchtboden umwachsen, oben dreitheilig und bleibend. Die Zipfel lineal lanzettlich, gerinnt, spitz, aufrecht, gefärbt, zweimal so lang als die Krone. Krone einblättrig, röhrenfürmig; aufrecht, halb dreitheilig. Die Zipfel länglich, stumpf, concav und aufrecht. Staubgefüsse sechs, etwas länger als die Röhre, und dieser der ganzen Lünge nach angewachsen. Staubbeutel lïnglich, spitz, aufliegend. Piștil: Fruchtknoten länglich und 
stumpf. Griffel fadenförmig, von der Länge der Staubgefässe. Narbe dreispaltig, stumpf. Kapsel länglich, spitz, stumpf, dreiseitig, glïnzend, dreifuchrig, dreiklappig. Samen zahlreich, sehr klein, mit haarförmigem, sehr langem Papus.

Stamm beblättert, einfach, aufrecht einzeln, an der Spitze gehäuft stehend.

Wurzelblätter lineal zungenförmig zugespitzt, glänzend, ganzrandig, 1' hoch, zahlreich, durch den hohlen Grund wasserhaltend. Blithen gelb, geruchlos, 3 "' lang. Kapsel braun. - Liebt schattige und feuchte Orte; parasitisch auf abgestorbenen Büumen. Martinique. - Bei den Einwohnern "Ananas de bois" oder „Bromelia sylvatica" genannt.

Carag. splen'dens Bouché.

Flore des Serres, van Houtte, t. 1091. - Nidularium? splendens Hort.

Pflanze im Ganzen kleiner wie C. lingulata Lindl., jedoch im Baue sehr gleichend. Von C. ling. unterscheidet sich indess C. spl. durch die lebhaft hochroth gefärbten Herzblätter, welche in keine andere Fïrbung übergehen. Die imnereten Herzblätter sind sehr verkürzt, am Rande eingebogen, stumpf rundlich endend und sind lebhaft goldgelb gefärbt. Laubblätter am Grunde bauchig, stark umfassend, auf der Unterfläche auf hellgrünem Grunde mit scharf begränzten, fein dunkelbraun rothen Längslinien geziert, - ganzrandig, weich spitz endend, $9 y / 2$ "lang, in Mitte 2 " breit. Die sehr lebhaft leuchtend rothe Farbe der Herzblätter bildet diese Species sehr schön. - Von den Blüthen ist gar nichts zu sehen, da sie einzeln am Grunde der Herzblätter sitzen und von diesen weit überragt werden.

\section{Carag. latifolia Beer.}

Caragnata, latifolia, clavata etc. Plum. nov. gen., p. 10. - Plum. Plant. Americanorum, t. 74.

Diese prachtvolle Pflanze treibt ihre gleich langen Laubblätter nach allen Richtungen; sie sind etwas überhïngend und gleichen der reichen Blätterkrone einer Draceaena.

Laubblätter am Grunde bauchig, dann gleich breit, gauzrandig; schwertförmig, $1^{3} / 1^{\prime \prime}$ breit und bei $3^{\prime}$ lang. Aus dieser herrlichen Blattkrone erhebt sich der reichbeblätterte Schaft und bildet am Ende eine Rosette aus kurzen Blättern, von 6 bis " " Durchmesser. Zwischen diesen Blättern stehen die Blüthen aufrecht, kaum sichtbar; sie sind $3^{\prime \prime}$ lang. Die Kronenblätter stehen röhrenförmig beisammen; die Lappen derselben rund, wenig geöfinet; die Genitalien etwas kïrzer als jene.

Obwohl diese Planze unverkennbar zu Caragnata gehört, ist sie doch sonst nirgend beschrieben oder abgebildet. 


\title{
PITYROPHYLLUM Beer.
}

\author{
Pityr. erubescens. Beer.
}

Tillandsia erubescens Hort. Herrenh. - Tillandsia ionantha Planch. Flore van Houtte 1855. tab. 1006.

Diese schöne kleine Planze bildet durch die mehreren Seitensprossen zierliche Raseı. Vor der Blüthezeit ist die Pflanze ganz gleichmässig dunkel olivengrün, mit weiss kleiigem Anfluge; die Oberhaut der Laubblätter sehr fein warzig, fast raul, besonders an den stumpfen Rändern mehr weisslich erscheinend, mit spitzem Ende. Blattfläche dicklich, am Grunde umfassend, $2 \%{ }^{1}$ "lang, in Mitte $1 / . "$ breit. Zur Blüthezeit fürben sich die sämmtlichen Herzblätter lebhaft roth an den Spitzen, sonst schmutzig lila roth. Blüthen einzeln, röhrenförmig, mit etwas zurück-

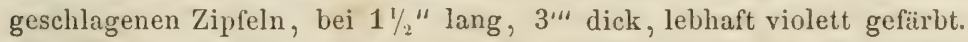
Staubblätter aufrecht, etwas vorragend. Grifiel aufrecht, am Ende dreitheilig, melir vorragend als die Staubblätter.

In der Beschreibung, welche der Abbildung folgt, wird bemerkt, dass die Pflanze nach einer Abbildung nachgebildet sei. Ich glaube, dass die ganze Pflanze grösser gezeichnet wurde, als selbe im natürlichen Zustande gebildet ist, da ich in meiner Sammlung mehrere Species dieser niedlichen Form lebend besitze, - aber einen so auffallenden Unterschied zwischen den Seitensprossen und der blühenden Pfanze, in der Grösse, noch nicht bemerkte. Die Sprossen sind immer sehr ausgebildet, wenn die Pflanze reif zur Blüthe ist, daher auch nicht mehr um vieles verschieden an Grösse.

Diese kleinen Formen leben gesellig auf Bäumen.

\author{
Pityr. gracil e Beer. \\ Pourretia stricta Hort. - Tillandsia Quesneliana Hort.
}

Kleines, zierliches Pflänzchen. Laubblätter 1 1 $/ 2$ "lang, fleischig, tiefrinnig, unbewehrt, fein warzig, dunkel schmutzig grün mit weisslich kleiigem Anfluge, am Grunde stark umfassend. Diese Pfanzen bilden einen kleinen Laubbüschel. Die Blüthen entwickeln sich aus den Laubblattachsen; sie sind einzeln, aufrecht, cylindrisch fast geschlossen, lebhaft licht blau, mit dunkelblan feurig und breit bemalt. Grifiel und Staubfäden dunkel blau, Narbe goldgelb, beide weit vorragend. Die Spitzen der Herzblätter färben sich zur Blüthezeit roth; diese Fürbung schwindet aber nach der Blüthezeit wieder allmälig. 


\title{
PLATYSTACHYS C. Koch.
}

\author{
Plat. set a cea Beer. \\ Till. setacea Sw. Bot. Magazine, tab, 3275.
}

Laubblätter über $1 \frac{1}{2}{ }^{\prime}$ lang, am Grunde wenig umfassend, hier bei $2^{\prime \prime}$ breit, an den Rändern etwas eingerollt, dann flach, schlaff, glanzlos, unbewehrt, allmälig spitz zulaufend, lebhaft hellgrün, mit dicht kleiigem Anfluge; Ränder lederartig weich, dicklich. Die Laubblätter sind strahlenformig abstehend. Der Schaft ist reichlich mit aufrecht stehenden Laubblättern geziert. Der Blüthenstand entwickelt sich aufrecht, ist $8^{\prime \prime}$ hoch, 2 " breit und durch die dicht zweizeiligen Bracteen schwertförmig gebildet.

Bracteen $2 \frac{1}{2}{ }^{\prime \prime}$ lang, $2^{\prime \prime}$ breit, stumpf spitz endend, breitgedruick $\uparrow_{\text {, }}$ hell olivenfarbig, am Rande lebhaft, breit, weinroth bemalt. Die Bracteen stehen so regelmässig, dass sie wie ein geflochtener Zopf aussehen. Die Blüthen erscheinen an dem Rande des Blüthenstandes zwischen den Bracteen; es sieht nur die rein weisse, geöffnete Krone vor. Die Staubbeutel, welche fast rund sind, ragen zwischen den Kronenb]ättern unordentlich und zum Theile selbst iiberhängend ror; die Blithen erscheinen sparsam und verbliihen in einem Tage. Fruchtknoten und Kronenblätter sind 3" lang. Fruchtknoten und Kelchzipfel schmutzig hellgelb.

Plat. an ceps Beer.

Till. anceps Lodd. Loddiges, Bot. Cabinet, tab. 771.

Eine kleine, sehr zierliche Pfanze. Laubblätter am Grunde stark umfassend, hier banchig, auf grünem Grunde lebhaft weinroth gestreift, dann tief rinnig, nach allen Seiten schlaff uiberhängend, auf der Unterfliche weiss kleiig, stumpf spitz, '7"lang, in der Mitte 1/2 "breit. Blüthenstand am kurzen Schafte 3" hoch, $1 \frac{1}{2}$ " breit, wie geflochten, breitgedrückt. Bracteen 1 1/2" lang, $8^{\prime \prime \prime}$ breit, zusamnengedrückt, dicht über einander stehend, hell schmutzig gelb-griin, mit bräunlicher Bemalung.

Kronenblätter flattrig, hell blau, zwischen den Bracteen kaum 1/2" vorstehend, wenig geöffinet. Genitalien nicht sichtbar.

Plat. he ptantha Beer.

Tillandsia heptantha Ruitz et Pavon. Flora Peruviana et Chilensis III, pag, 41.

Ich habe diese sehr gut beschriebene Pflanze ausnahmsiveise aufgenommen, indem dieselbe wahrscheinlich schon lebend in den Pflanzen- 
sammlungen sich findet. - Es folgt hier die Beschreibung von $\mathbb{R}$ uiz et Pavon:

Pflanze: Aehre siebenblüthig, z we i ze ilig. Blumenblätter weiss, an der Spitze violett bemalt. Blätter schwertförmig, pfriemlich, sehr spitz.

Schaft fast 1' lang, aufrecht, einfach, mit länglichen, halb stengelumfassenden und spitzen Schuppen bedeckt. Die Blätter wechselseitig anliegend, fast dachziegelförmig, schwert-pfriemenförmig, sehr spitz, gerinnt, beiderseits weisslich grau, schwach filzig, - ganzrandig. Die Aehre endständig, einfach, meist siebenblüthig. Die Blüthen $\mathrm{zw}$ eizeilig, sitzend; die Bractee lanzett-länglich, concav, - purpur violett. Die Blumenblätter weiss, an der Spitze violett bemalt. Kapsel länglich, unmerklich dreiseitig, mit spitzer Basis und haarförmigen, vielstrahligen und fuchsrothen Papus gekrönt. Same länglich.

Standort: Warme Abhänge in Peru, in den Gefilden der Proviuzen Tarma und Huanuca, auf Felsen und Bäumen. Juni, Juli, August.

\section{Plat. viridiflora Beer.}

Sp. Mexico Heller, aus dem Garten des Herrn Grafen Attems in Graz.

Stattliche Pflanze, mit lederartigen, dünnen, nach allen Seiten abstehenden, allmälig schmäler werdenden, endlich mit stumpper Spitze endigenden, hier zurückgebogenen, welligen, manchmal selbst einfach eingerollten Blättern. Oberfäche trüb grün, mit schwach mehligem An円uge. Unterfläche hellbläulich, bereift wie eine Zwetschge, mit mehligem Anfluge, am Grunde stark umfassend, bauchig, hier $2 \frac{1}{2}$ " breit, dann allmälig schmäler werdend. Breite der Blätter: in der Mitte 1 1/2", Länge von 1' $3^{\prime \prime}$, bis endlich am Blüthenschaft $1^{\prime \prime}$ lang, $3^{\prime \prime \prime}$ breit. Blüthenschaft und Blüthenstand $2^{\prime} 4^{\prime \prime}$ hoch, letzterer $1^{\prime}$ lang. Die Laubblätter werden endlich am runden Schafte sehr kurz und anliegend und bedecken dann den Schaft gänzlich. Der Blüthenstand ist zweizeilig, bei jeder Blüthe etwas knieförmig gebogen, viereckig, $4^{\prime \prime \prime}$ breit. Die Blüthen stehen $1^{\prime \prime}$ entfernt von einander. Die $2^{\prime \prime}$ lange Bractee ist licht grün, matt glänzend, und umgibt, wie eine Düte innig anschliessend, den Fruchtknoten; sie ist am Grunde etwas aufgetrieben, sonst platt gedrückt rund, eiförmig, - spitz endend. Die Blütlıenknospen drängen sich mit der Spitze durch die Bractee und wachsen rasch zu einer Länge von $2^{\prime \prime}$; sie erscheinen gedreht, pfriemenförmig. Mit einemmale öffnen sich die Blumenblätter und stehen wagrecht ab; es ist jedes Blumenblatt gleich breit $\left(4^{\prime \prime \prime}\right)$, mit runden Enden, und $1 / 2$ mal $\mathrm{um}$ sich gedreht, von Farbe hell erbsengrün, glänzend und durchsichtig wie von Glas. Die gelblichen Staubfäden und der grüne Griffel ragen $2^{1 / 2}$ " lang und steif aus der B e ex, Bromeliaceen. 
Blumenröhre hervor. Die selır hinfällige Blüthe dauert nur einen halben Tag und hängt dann sammt den Genitalien schlaff herab; dann umschliesst die Bractee den Fruchtknoten und es hängen nur noch missfarbige, zusammengedrehte Rudimente der Blüthe an der Spitze.

Obwohl nur höchstens zwei Blüthen zu einer Zeit sich öffnen und überhaupt die Fürbung dieser Pflanze durchaus nur aus Grün besteht, so ist dieselbe doch wegen ihres zierlichen Wuchses und der langen Blüthen für jede Sammlung eine Zierde. Diese Pflanze wurde in der Gürtnerei des Grafen A t t e m s zu Graz aus Samen gezogen, welchen Herr Carl Heller aus Mlexico sendete. Sie blühte das erste Mal im November 1854 und ist jetzt in meinem Besitze.

\section{Plat. gla u coph ylla Beer.}

Vriesia (Vriesea!) glaucophylla Hook, Bot. Mag. tab. 4415. - Flore, van Houtte V, t. 432.

Die Laubblätter bilden eine nach allen Richtungen zierlich überhängende Rosette von $1 \frac{1}{2}{ }^{\prime}$ Durchmesser. Sie sind lederartig, weich filzig bekleidet; hierdurch haben sie eine schöne, sehr hell grünliche Fürbung; die Lünge beträgt $2 t$, sie sind an Grunde umfassend, mit steif aufrechten Ründern, der ganzen Länge nach eine tiefe Rinne bildend, all-

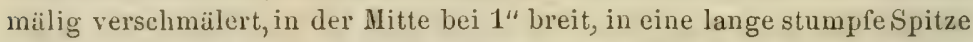
endigend. Schaft steif aufrecht; hier nehmen die Blïtter, je näher sie dem Blüthenstande stehen, eine lebhaft weinrothe Fürbung und endlich eine scheideblattartige Beschaffenheit an, aber auch der Schaft wird hier lebhaft roth gefürbt. Der Blüthenstand ist verzweigt, 9" lang; von den drei oder vier Zweigen, welche in gleicher Höhe aufrecht stehen, ist jeder einzelne Zweig 6 bis " "lang. Die Bracteen stehen hier sich deckend, zweizeilig, schwertförmig, plattgedrückt, aufrecht. Jedes Scheidenblatt liegt mit seinen Rändern auf der nüchsten Scheide. Sie sind im Grunde lebhaft grün, alle an den Spitzen lebhaft weinroth und gelb bemalt. Die einzelne Scheide ist $1 \frac{1}{2}$ " lang und 1 " breit. Blüthe - eine $1 \frac{1}{4}$ " zwischen den Bracteen vorstehende, kaum geöffnete, purpurfarbene Röhre bildend, aus welcher die eben so gefärbten Staubfüden in ungleicher Lünge schlafi heraushängen. Die Staubbeutel sind eiförmig rund und goldgelb. Die Narbe lebhaft gelb.

\section{Plat. in an is Beer.}

Tillandsia inanis. - Paxton Flower Garden I, tab. 210.

Dieses kleine Plänzchen hat Aehnlichkeit mit Till. ery thraea Lindl.; es ist sammut dem Blüthenstand bei $8^{\prime \prime}$ hoch. Stämmehen zwiebelartig rund. 
Die Laubblätter sind am Grunde stark umfassend und stehen dicht beisammen. Das Blatt ist fast pfriemenförmig, dick und unordentlich hin und her gebogen, in Mitte $3^{\prime \prime \prime}$ dick, die längsten $6^{\prime \prime}$ lang. Die ganze Pflanze hell gelblich grün, mit weisslich kleiigem Ueberzuge. Der Blüthenstand ist

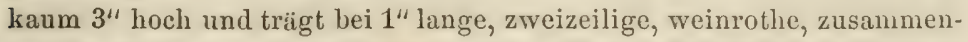
gedrückte Bracteen, welche sich gegenseitig mit den Rändern bedecken. Blüthen hell lila, aufrecht, wenig geöfinet, eine Röhre bildend, 1" lang. Staubfäden schlafi, länger als die Kronenblätter. Staubbeutel lïnglich rund, goldgelb. Das Pflänzchen hat nur drei oder vier Blüthen.

\section{Plat. bulbos a Beer.}

Tillandsia bulbosa Hook. - Exotic Flora, tab. 173.

Blätter am Grunde breit umfassend, hier schalenförmig, $1^{\prime \prime}$ breit, dann bei $3 / 4$ " Länge schon nur noch $3 / 4$ " breit, ganze Länge 6 ", eine tiefe Rinne bildend, welche endlich gegen die Blattspitze ganz verwächst und daher das Blatt an der Spitze pfriemenförmig rund erscheint. Laubblätter und Bracteen am Blüthenstande lebhaft licht grasgrïn, am Grunde etwas mehlig, weisslich bestäubt. Blüthenstand wenig verzweigt, Bracteen zweizeilig, zusammengedrückt, etwas über einander liegend. Blü-

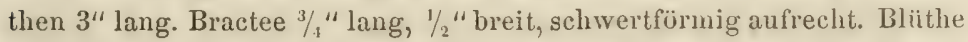
sparsam. Kronenblätter 1/2"vorstehend, eine Röhre bildend. Die Staubbeutel schlaff, vorragend, rund.

Stamm zwiebelartig rund.

Die Laubblëtter des fast runden Stämmchens stehen aufrecht, dann unregeìmässig am Ende übergebogen und überragen um $3^{\prime \prime}$ den Blïthenstand. Die Laubblätter stehen iiberhaupt nach verschiedenen Richtungen gebogen, unordentlich an dem Stamme vertheilt.

\section{Plat. erythraea Beer.}

(Tillandsia erythraea Lindl.)

Tillandsia bulbosa var. picta Hook. Bot. Mag. tab. 4288. - Annales de Gand. III, tab. 255.

Pflanze sammt dem Blüthenstande 8 " hoch. Stamm am Grunde rund gebildet, hier 2 " dick. Laubblätter am Grunde stark umfassend, wie eine Schale gebildet, dann, bei $1 \frac{1}{2}$ " Höhe, ist plötzlich die Blattfläche dergestalt zusammengerollt, dass sie gleichmässig rund und nur $3^{\prime \prime \prime}$ im Durchmesser erreicht, bis sie endlich schmäler werdend stumpf endet. Die Länge eines ganzen Laubblattes beträgt ${ }^{\prime \prime}$. Solche Laubblätter, nur mit schmälerer Basis, stehen bis zum Gipfel des verzweigten Blïthenstandes. Die untersten Laubblätter sind trüb erdfarbig, mit purpur bemalt und mit weisslich kleiigem Anfluge bekleidet. Die ferneren Laubblätter werden grün, mit röthlicher Spitze, endlich aber jene zun:̈chst 
dem Schafte und am Blüthenstande rom Grunde aus lebhaft rein blutroth, mit grasgrünen Blattendeu. Auch hier iiberragen einige aufrechte Laubblätter den Blïthenstand. Die meisten stehen aber steif aufrecht und endlich zierlich übergebogen laerabhängend. Die Bracteen bei den Blüthen stehen zweizeilig dicht an einander; sie sind zusammengedrückt. Der Blüthenstand schwertförmig, die Bracteen variiren sehr in der Länge, sind aber alle lebhaft blutroth. Die Blüthen, lebhaft lilafarbig, stehen 1" lang aus den Bracteen ror, sie sind röhrenförmig, gerade aufrecht, am Ende wenig geöfinet. Die hellgrünen Kelchzipfel manchmal etwas sichtbar. Genitalien aufrecht, 5"' vor'ragenıl. Staubbeutel kugelig gelb. Griffel lebliaft lila.

Diese prachtrolle Pflawze hat $\mathrm{Hooker}$ als Varietät von Tillandsia bulbosa bekannt gemacht, allein ich finde mich reranlasst, den SpeciesNamen von $\mathrm{L}$ indle y beizubehalten, weil diese Pflanze gewiss eine gute Species ist.

Plat. digitata Beer.

Viscum cariophylloides, Katesby, Natural History II, tab. 89. - Tabernaemontani, Kräuter-Buch, 1377.

Diese sehr zierliche Pflanze hat zahlreiche, lebhaft grasgrüne Lanbblätter, die am Grunde wenig umfassend, dann etwas bauchig, mit einwärts gebogenen Rändern, hier 3/4" breit, dann, bei 3 "Länge schon nur noch $3^{\prime \prime}$ breit sind und sich endlich in eine stumpfe Spitze endigen. Sie sind bei 2 ' 4 "lang und bilden die Enden etwas flattrig überhängend. Der $2^{\prime \prime}$ dicke grüne Schaft trügt wenige, $4^{\prime \prime}$ lange, $3^{\prime \prime}$ breite grüne Laubblätter; er ist sammt dem stark verzweigten Blüthenstande uiber $1^{\prime}$ hoch. Die Zweige stehen dicht an einander, sind strahlenfürmig gestellt. Die Bracteen liegen wie geflochten über einander, sie sind weinroth und am Rande licht grün bemalt, ziemlich stark susammengepresst, 1/2" breit, 3/4" lang. Die sehr schönen, lebhaft hellblauen Blüthen stehen stark gedreht, aufrecht, wenig geöffnet, $1^{\prime \prime}$ lang zwischen den Bracteen sparsam vor. Dic hellblauen Staubbeutel und der goldgelbe keulenförmige Grifiel sind aus der Bliithe ganz vorstehend, und letzterer selbst $5 \%$ "länger als die Kronenblätter. Die Zweige am Blüthenstande sind von 2 bis 5 " lang und durchaus gleich breit (1/4). Diese Pllanze wird, wenn sie zur Samenreife gelangt ein selır verändertes Aussehen haben, indem dann die Farbe der Bracteen verschwindet und selbe grün werden, aber auch die grünen schmalen Fruchtknoten gleichmässig 1" lang vorstehen, der plattgedrückte Blüthenstand entwickeli sich hierdurch nur noch auffallender. 
Bei der nun folgenden Tillandsia havanensis des Jacqu in kann man die Fruchtbildung auch von dieser Art studiren.

Es folgt hier die Beschreibung von $\mathbf{K}$ atesky:

Diese Pflanze bildet eine runde, angeschwollene Wurzel, aus welcher eine Menge Faserwurzeln entspringeu, mit denen sich selbe an den Aesten der Büume festhält, wo sie ein wenig in die Rinde cindringen. Aus der runden Wurzel treten mehrere Blätter hervor, welche etwas gefaltet, nach Art der Ananasblätter gestaltet sind. Sie sind ron aussen hervorragend und breit, gegen unten sind sie immer verjüngt und enden am oberen Theile in einer geraden, weichen, gegen aussen gebngenen, herabhängenden Spitze. Aus der Mitte dieser Blätter erhebt sich ein runder gerader Stiel, an welchem sich in der Höhe fünf rothe, spitze und muschelartig geformte, bei 5 bis $6 "$ lange Blätter befmden, an deren Seite sehr anliegend (obliquement) mehrere cylindrisch blane, angeschwollene einblättrige blaue Blüthen mit mehreren Staubfïden und cinem gelben Stiele stehen. Die Bliithe ist durch ein einziges Blatt gebildet und eigenthümlich spiralig gedreht. Diese Pflanzen finden sich von rerschiedener Höhe, nämlich 1 bis $2^{\prime}$ hoch und sind immer ganz anfrecht. Die zusammenstehenden Laubblätter enthalten nanchmal zwei Quart reines Trinkwasser. Viele derselben sind für Durstige ein wahres Labsal, indem, wenn auch die Sonne noch so lieiss scheint, desshalb doch immer das Wasser, welches diese Planzen enthalten, kalt und frisch wie aus einer Quelle ist. Die oben beschricbene Pflanze ist sehr gemein auf Bäumen und bedeckt diese oft dergestalt, dass man sie für Laub und Bliithe der Bäume ansieht, was einen sehr schönen Anblick gewährt.

Findet sich auf mehreren Inseln von Bahama, gewöhnlich auf grossen Bäumen von Mahagony, dem Sapadillo, Mancanel u. s. w.

\section{Plat. havanensis Beer.}

Tillandsia havanensis. Jacquin. Select. stirp. americ. histor. tab. 183, pag. 94. Jacq. Select. americ. tab. 94 (in Notta: Tillandsia polystachia).

Die Allardtia cyanea Dietrich, Platystachys Koch steht dieser Pflanze hinsichtlich der Gestalt des Bliithenstandes am nächsten, aber auch Viscum caryophylloides Catesby steht diesen beiden Species ebenfalls sehr nahe. Die zwei Abbildungen unseres grossen Ja c q u in sind jedoch beide nach abgeblühten, mit den weit vorragenden SamenkapseIn versehenen Exemplaren gezeichnet. Dieselbe Fruchtbildung fand sich nach meiner Untersuchung im Berliner botan. Garten im März 1855 an der Allard. cyanea ebenfalls. Koch hat den Namen .;Allardtia" eingezogen, indem schon ein (nach General Allard) genanutes Genus "Allardia" von Brongniard besteht. 
Dass man wo möglich gleichlautende Namen bei Aufstellung der Genera zu vermindern sucht, hat jedenfalls sehr viel für sich, indem z. B. bei dem kurzen Namen "Schmit" wohl sechs verschiedene Buchstaben sich finden können, aber der Fall sein kann, dass sechs Genera mit den wenigstens gleichlautenden Namen belegt würden. Die Benennung „Platystachys" ist sehr bezeichnend für den Blüthenstand; ich fand mich desshalb auch bewogen, diese Benennung zu benützen. Bei der zweiten Abtheilung, wo die Pflanzen mit ebenfalls zweizeiligem Blüthenstande zusammengebracht sich finden, habe ich den Genus-Namen "Vriesea" (nach Prof. de Vriese), welchen Lindley der Tillandsia splendens Brongniard zuerst beilegte und sie "Vriesia Speciosa" nannte, - beibehalten, da einige schöne Gewächse unter dem Namen „Vriesia" schon sehr verbreitet in den besseren Planzen - Sammlungen sind.

Pflanze klein. Laubblätter alle vom Grunde aus einen gleichförmigen Buischel bildend, aufrecht, tiefrinnig, $4^{\prime \prime \prime}$ breit, bei $1^{\prime}$ lang. Die Laub1)ictter am Schafte gehen schnell in anliegende, stumpf spitze Scheidenblattlildungen iiber. Der Schaft erhebt sich sammt dem platten, verzweigten Blüthenstande aufrecht, ist steif, nur $2^{\prime \prime \prime}$ dick, bis auf den Grund zwischen den umfassenden Laubblättern sichtbar, 1' $3^{\prime \prime}$ hoch. Zweige und Hauptachse am Blïthenstande, von gleicher Länge $\left(3^{1 / 2}{ }^{\prime \prime}\right)$ und Breite $\left(1 \frac{1}{2}\right.$ "). Bracteen sich gegenseitig nicht deckend, gegen das stumpf spitze Ende etwas nach aussen gebogen, sehr platt gedrückt, 5"' breit. Kelchzipfel zwischen den Bracteen vorragend. Blumenkrone über 1" vorstehend. Genitalien nicht sichtbar.

(Blüthe vermuthlich blau.)

Plat. ju ncea Beer.

Bonapartia juncea Iuiz et Pav. - Fiora Peruviana et Chilensis, tab. 262.

Diese zierliche Pflanze bildet einen nach allen Richtungen strahlenförmigen, bei $10^{\prime \prime}$ breiten, $1^{\prime}$ hohen, den verzweigten, steif aufrechten Blüthestand weit überragenden zarten Laubbüschel, welcher in allen seinen Theilen mit weisslich mehligem Anfluge reichlich bekleidet ist. Die Laubblätter sind alle (selbst zwischen den Zweigen am Blüthenstande) am Grunde bauchig umfassend, dann eingerollt, pfriemenförmig, tiefrinnig, hier $1^{\prime \prime \prime}$ breit, am bauchigen Ende aber zwischen $3 / 4$ und $1^{\prime \prime}$ breit. Solche, gegen den Blüthenstand etwas kiirzer werdende Laubblätter bedecken den Schaft gänzlich und sind in grosser Anzahl vorhanden. Endlich erscheinen zwischen den bauchigen Enden der Laubblätter die Zweige und die Hauptachse des Blüthenstandes. Diese sind etwas verlängert eiförmig, plattgedrïckt, durch die sich deckenden aufrechten, stark umfassenden, über $1 / 2^{\prime \prime}$ breiten, $3 / 4$ " langen, plattgedrück- 
ten Bracteen gebildet. Blïthe violett, aufrecht, röhrenförmig, $1^{\prime \prime}$ lang, $2^{\prime \prime \prime}$ dick. Die Genitalien weit vorragend. Staubbeutel rund, gell. Griffel länger als dic Staubfäden. Narbe dreitheilig. Kelchzipfel gelb, kaum zwischen den Bracteen sichtbar.

Es folgt hier die Beschreibung von Ruiz et Pavon:

Pflanze: Blätter mit weisslichem Anfluge, halb pfriemenförmig, gerinnt und länger als der Halm.

Der Halm einzeln, 1 $\frac{1}{2}{ }^{\prime}$ lang, aufrecht, fest, rund, einfach, iiberall beblättert und durch die zusammengerollten Basen der Blätter gänzlich bedeckt. Blätter dachziegelförmig, zahlreich, lïnger als der Halm, ungleich, halb pfriemenförmig, gerinnt, an der Basis sehr breit; die Wurzelblätter abstehend zuriickgebogen, die mittleren Blätter etwas abstehend, die stengelständigen aufrecht. Die Achre endständig, aus $\gamma$ bis 12 in Thyrsusform zusammengehäuften Aehrchen zusammengesetzt. Die Aehrchen länglich, lanzettlich, zusammengedrïckt, vielblïthig, die un* teren kürzer. Die Bliithen dachziegelförmig, z w e i z e i li g, sitzend, ganz von Bracteen umgeben. Die Bracteen länglich, spitz, liahnförmig und lederartig, trockenhäutiger Beschaffenheit. Kelch lederartig trockenhäutig, lebhaft gelb, zweiblätrig, den äusseren Blättchen ist das innere entgegengesetzt, das um die Hälfte enger ist. Die Blumenbliitter violett, von der Basis bis zur Spitze um sich gerollt. Staubbeutel gelb. Kapsel pyramidenförmig, umhüllt durch den Kelch, und braun.

Standort: Haine der Peruv. Anden, gegen das Dorf Muna, aul Bäumen und Felsen, an äusserst warmen Orten. September, October.

Der Saft ist gegen Wundschäden sehr heilsam.

\section{Plat. polystachia Beer.}

Renealmia polystachia Jacquin, Historia select., pag. 93 .

Schaft mit dachziegelförmig gestellten seitlichen Aehren. Kelch: Blüthendecke einblättrig, flach oder convex, bleibend. Die Röhre sehr kurz, den Fruchtuoden umwachsend. Der Saum aufrecht, sehr lang, zusammengeneigt, zweispaltig. Der iussere Zipfel lanzettlich länglich, gerinnt, zugespitzt; der innere länglich zugespitzt, nach hinten an den zusammengeneigten Seiten gerinnt, nach vorne flach, oberhalb zweispaltig. Kronenblätter drei, lineal, cuncav, geriunt, suitz, aufrecht, an den Seiten sich gegenseitig anliegend, beilünfig zweimal länger als der Kelch. Staubfäden sechs, fadenförmig, aufrecht, dem Fruchtboden eingefügt, die Krone iiberragend. Staubbentel länglich, stumpf aufliegend. Fruchtknoten eiförmig, stumpf, dreiseitig, in einen fadenförmigen, den Staubgefässen an Länge und Lage gleichen Grifłel übergehend. Narben drei, rundlich abstehend . 
Stengel beblättert, aufrecht, $3^{\prime}$ lang. Blätter lineal, pfriemlich, zugespitzt, ganzrandig, gerinnt, am Grunde breit und bauchig, zahlreich, die unteren $2^{\prime}$ lang, die Aehren seitenständig, zehn an der Zahl, 1' lang, carminroth, am Halm abwechselnd stehend. Blïthenscheiden carminroth, oberhalb dachziegelförmig, die Aehren ganz bedeckend. Blüthen sitzend, einzeln, geruchlos. Krone blau. Frucht unbekannt.

Standort: Havanna, auf felsigen Hügeln u. s. w., parasitisch auf Bäumen. Blüthezeit: Januar.

J ac quin.

\section{Plat. parviflora Beer.}

Till, parvillora R, et P. - Flora Peruv, et Chil., Ruiz et Pav, t. 260.

Pflanze klein, sammt dem Blüthenstande kaum $1^{\prime}$ hoch und mit weisslichen Schüppchen bekleidet. Rispe drei- bis siebenährig. Blüthen klein, zweizeilig. Laubblätter am Grunde stark umfassend, dann fast pfriemenförmig, allmälig stumpf spitz endend, alle gerade aufgerichtet. Der steife dünne Bliithenstengel erhebt sich iiber die 6" langen Laubblätter. Die Blätter am Stengel sind dütenförmig umfassend, mit eingerollten Rändern und nach aussen gebogenen stumpf spitzen Enden.

Deckblättchen bei jeder Blüthe, $2^{\prime \prime \prime}$ lang; zusammenged rückt - abstehend, grau von Farbe. Blïthenstielchen sehr kurz. Kelchzipfel trockenhäutig, sammt den Fruchtknoten $3^{\prime \prime \prime}$ lang. Kronenzipfel ausgebreitet, rund, weiss.

Es folgt hier die Beschreibung von $\mathrm{Ruiz}$ und $\mathrm{P}$ avon:

Pflanze: Rispe einfach, drei- bis siebenährig. Blüthen klein, zw eizeilig. Blätter fast pfriemenförmig, mit sehr breiter Basis.

Schaft aufrecht, einzeln, einfach, r'und, zierlich, 1 ' hoch, ein wenig gebogen, purpurroth, kahl, mit abwechselnd stehenden, pfriemenförmigen, gerinnten, scheidenförmig stengelumfassenden, nur wenig entfernten und weichlichen Schuppen bedeckt.

Blätter sich wechselseitig anliegend, fast dachziegelförmig, fast pfriemlich, gerinnt, gegen oben abstehend, zurïckgebogen, bei $1^{\prime}$ lang, gestreift, weisslich grau, mit sehr dicht gestellten, kleienartigen Schuppen bedeckt. Die Rispe endständig, aus drei bis sieben abwechselnd stehenden $\mathrm{zw}$ wizeiligen Aehren zusammengesetzt. Die Aehren entfernt stehend, abstehend, vielblüthig, durch eiförmig lanzettliche scharfe, kurze und weisslich graue Bracteen unterstiitzt, mit kurzem Bliithenstiele verflochten; weisslich grave, hin und her gekrümmte Spindel. Die Blüthen abwechselnd stehend, $\mathrm{z}$ w e i z eilig sitzend, mit eiförmigen, kleinen, spitzen Bracteen besetzt, die concav und um die Hälfte kürzer 
als der Kelch sind. Der Kelch trockenhäutig, blass, fast dreiseitig. Die Zipfel unter sich etwas gewunden. Drei Blumenblätter, noch einmal so lang als der Kelch, oben etwas abstehend, weiss, nur einen Tag dauernd. Kapsel lineal, achtmal länger als der Kelch, zugespitzt, dreifächerig, dreiklappig. Die inneren Klappen ausserhalh glatt und blass, innerhalb dunkel purpurfarben, glänzend. Die Samen lineal länglich, röthlich, mit behaartem Papus gekrönt.

Standort: Anden, Peru, Umgegend von Mruna. August, September, October.

\section{Plat. purpurea Beer.}

Till. purpurea R. et P. - Flora Peruviana et Chilensis, Ruiz et Pavon t. 270.

Pflanze klein, sammt dem Blüthenstande bei 10" hoch, mit weisslichem, auch granem, kleiigem Anfluge bekleidet, - von unordentlichem Aussehen. Laubblätter am Grunde stark umfassend, $1^{\text {" breit, }}$ dann allmälig bis zum stumpfen Ende schmäler werdend. Schaft $1^{\prime \prime \prime}$ dick, mit dütenförmigen, spitz endenden, aufrecht stehenden Laul)blättern, welche $1 \frac{1}{2}$ " lang sind, sparsam besetzt. Blüthenstand 3 " hoch, verzweigt. Zweige aufrecht stehend. Deckblättchen rosafarb, bei jeder Blïthe $1 / 2$ "lang, fast anliegend, plattgedriickt, kahnförmig. Fruchtknoten am Grunde stumpf, rund, stiellos. Kelchzipfel rosafarb, tief geschlitzt, spitz. Kronenblattzipfel ausgebreitet von $3^{\prime \prime \prime}$ Durchmesser, tief purpurfarbig, gegen unten in weiss übergehend.

Es folgt hier die Beschreibung von Ruiz et $\mathrm{Pavon}$ :

Pflanze: Rispe vielährig, rosenroth. Blüthen zweizeilig. Die Fläche der Blumenblätter purpurroth. Laubblätter schwert-, pfriemenförmig, zurückgebogen.

Schaft einzeln, 1' hoch, aufrecht, rund, ganz einfach, kahl, mit abwechselnd stehenden, pfriemlichen, langen und gerinnten Schuppen (Blättern?) bedeckt, die unterhalb breit und scheidenförmig stengelumfassend, zusammengeneigt und von Knoten zu Knoten weisslich grau sind. Blätter sich wechselseitig anliegend, fast scheidenförmig, schwert-pfriemenförmig, gerinnt, stark abstrebend, zurïckgebogen, bei $1^{\prime}$ lang, weisslich, mit sehr dicht stehenden kleienartigen Schüppchen bedeckt. Die Rispe endständig, aus 5 bis 9 abwechselnd stehenden Aehren zusammengesetzt. Bracteen eiförmig, spitz, concav, gestreift, weisslich grau. Aehre länglich, lanzettförmig, gestielt, viclblüthig. Blüthen zweizeilig, dachziegelförmig, sitzend, mit länglichen, concaven und rosenfarbigen Deckblättern umstellt. Kelch länglich, rosenfarb. Kelchzipfel etwas gewunden, gestreift. Blumenkrone unterhall zusammengerollt, oberhalb ausgebreitet, hier dunkel purpurfarbig, 
gegen unten weiss von Farbe. Die Kapsel länglich cylindrisch, zugespitzt, blass. Die inneren Klappen ausserhalb glatt, innerhalb purpurschwarz glänzend. Samen zahlreich, fahlgelb, mit rauhem Papus gekrönt.

Standort: Peru, auf felsigen, sandigen Orten sehr häufig in Lima, Canta, und Huarocheri auf Hügeln. Juni, Juli.

In Lima nennt man es Cardo de Lomas.

Plat. K u n thiana Beer.

Tillandsia Kunthiana Gaudichaud. Bonite, Atlas botanique, tab. 53.

Leider ist $\mathrm{zu}$ diesem Prachtwerke bis jetzt noch keine Beschreibung erschienen, wesshalb über die Färbung der Pflanze auch nichts gesagt werden kann.

Pflanze einen zierlichen aufrechten, bei $6^{\prime \prime}$ im Durchmesser haltenden, reich mit kleiigem Anfluge bekleideten Blätterbüschel bildend. Laubblätter am Grunde über 1 " breit, fast reitend, stark umfassend, mit stark entwickeltem Mittelnerv und stumpfen, etwas überhängenden Enden von $8^{\prime \prime}$ Länge. Schaft und Blüthenstand $1^{\prime}$ hoch, letzterer für sich $3 \frac{1}{2}$ " lang, ersterer mit vollkommen umfassenden Blättern, deren spitze Enden von verschiedener Länge ( $3 \frac{1}{2}$ bis $\left.4^{\prime \prime}\right)$ gegen aufwärts stehen. Der Blüthenstand verzweigt. (Vielleicht treibt der Schaft am Grunde schon melırere Seitenzweige. - Nau beliebe, die sehr schöne Abbildung zu besehen.) Zweige und Hauptachse gleich lang, kräftig, $2 "$ lang, 2" breit. Bracteen bei jeder Blüthe, schifförmig, plattgedriickt, abstehend, $1 / 2$ " breit, 3/." lang. Kelchzipfel zwischen den Bracteen etwas vorragend. Kronenblätter rölrenförmig, etwas bauchig, Zipfel lanzettförmig spitz, ausgebreitet. Genitalien kürzer als die Kronenblattzipfel, nicht sichtbar.

Plat. a zurea Beer.

Till. azurea Pressl. - Reliquiae Haenkiana, Pressl. tab. 24.

Pflanze schlank, bei $1 \frac{1}{2}$ ' hoch, durch dicht kleiigen Anflug sehr filzig, silberglänzend bekleidet. Laubblätter am Grunde umfassend die Ränder eingerollt, dann an der Spitze verwachsen, rund endend, am Rande ungleich, dicht filzig. Blüthenstand aufrecht, stark verzweigt, $4 \frac{1}{2}$ " hoch. Zweige gleich lang $\left(2 \frac{1}{2} "\right)$. Bracteen zweizeilig ste. hend, kahnförmig, offen, an der stumpfen Spitze verwachsen, aufrecht, wenig zusammengedrückt, 1" lang, 4"“ breit. Kronenblätter herzfürmig, spitz, glatt, ausgebreitet, kamm $3^{\prime \prime \prime}$ breit und etwas linger', lebhalt lrellblau. Die Pflanze bildet nur wenige Laubblätter, welche vom Grunde aus, entfernt von einander, bis zum Blüthenstande vertheilt stehen. 


\section{Plat. Plumieri i Beer.}

Caragnata clavata et spicata, foliis serratis. Plumier, nov. Gen., p. 10, - Plumierii, Plantarum Americ, tab. 75. - Tillandsia serrata. Lamarque Encyelopedie, tab. 224.

Laubblätter am Grunde selir wenig umfassend, fast gleich breit, allmälig spitz endend, sägezähnig, 6" rom Grunde aus glattrandig, 11/2" lang, in Mitte $1 \frac{1}{2}{ }^{\prime \prime}$ breit. Schaft und Blüthenstand steif aufrecht, letzterer durch dicht stchende, $1 \frac{1}{2}{ }^{\prime \prime}$ lange, herabgebogene, zahlreiche $\mathrm{Z}$ weige lieulenförmig rund. Jeder Zweig ist von einem herabgebogenen, abstehenden, kahnförmigen, $2 \frac{1}{2}$ " langen, spitz sägezähnigen Blatte bekleidet; ähnliche Blätter umgeben aufrecht, sich gegenseitig deckend, den Schaft. Die Bliithen stehen zweizeilig, deren Bracteen $3 / 4$ " lang, plattgedrückt; sie lagern dergestalt über einander, dass sie wie geflochten erscheinen. Die Blüthen stehen zwischen der Bractee, gegen abwärts geneigt, 1 "lang vor und haben runde gerade Lappen.

Diese schöne Pflanze hat einige Aehnlichleit mit der Tillandsia longifolia Meyen, jedoch schon der Umstand, dass sie bewehrte Blätter hat, - unterscheidet sie von der gïnzlich unbewehrten Tillandsia longifolia hinreichend.

\section{VRIESEA Lindley.}

Vries. speciosa Hook.

Bot. Mag. t. 4382. Tillandsia splendens Brong. Flore, van Houtte II, 1846.

Laubblätter glatt, glänzend, lederartig, ganzrandig, kelchbildend, zusammenstehend, prachtvoll auf hellgrünem Grunde, aussen und innen mit lebhaften, breiten rothbraunen Querbinden der ganzen Länge nach geziert; sie sind $1^{\prime} 4^{\prime \prime}$ lang und im Mittel $2^{\prime \prime}$ breit, am Grunde tiefrinnig umfassend, hier 3 " breit, aufrecht, dann zierlich übergebogen, rund und weich spitzig endend. Da diese herrliche Species, durch Samen vermehrt, wurde und sich schon sehr verbreitet hat, so ist es nicht nöthig, noch ferner auf die Schönheit der Laubblätter hinzurveisen. Schaft und Blüthenstand steif aufrecht, zusammen $18^{\prime \prime}$ lang, letzterer $11^{\prime \prime}$ lang und $2^{\prime \prime}$ breit, durch sich gegenseitig deckende, 1 "breite, am Grunde halb umfassende, $3^{\text {" }}$ lange, am spitzen Ende ganz flach zusammengedrückte, dann gegen unten etwas bauchige, prachtrolle blutrothe, zweizeilig stehende Bracteen schwertförmig gebildet; hier ist der Schaft viereckig und bei jeder Scheide schwach kniefürmig hin und her gebogen. Unter dem Bliithenstande erscheint der Schaft ganz rund und ist mit dütenförmigen, ganz einhüllenden, 2 "langen, sehr schönen, auf gelblichem Grunde roth-braun gefleckten, mit brauner, stumpfer Spitze endenden Bracteen ganz be- 
deckt; sie stehen im Kreise von 1 -4, und es zeigt sich bei jeder Scheide am Schafte eine ganz kleine sogenannt schlafende Knospe. Zwischen jeder flachgedrückten rothen Scheide am Blüthenstande stebt dicht am Schaft gelehnt die sehr kurz gestielte Blüthe. Der Fruchtknoten ist sehr klein, der Kelchzipfel 1" lang, bis auf den Grund geschlitzt, aber es ragt nur die 1/1/2 lange, 3 " breite, spitz endende gelbliche, am Ende etwas geöffnete Blumenkrone zwischen den Bracteen herror. Genitalien gleich lang. Staubbeutel länglich, gelb. Griffel eben so gefärbt, beide etras geneigt aus den Kronenblättern rorragend. Erst nachdem die Pflanze geblïht hat, dehnt sich der Schaft noch dermassen, dass die Bracteen sich nicht melr decken und besonders von unten gegen oben jede Bractee freisteht und derSchaft hierdurch theilweise sichtbar wird. Der Blüthen. stand ist anfänglich grün, dann, bei weiterer Entwicklung, lebhaft roth mit grün bemalt, dann, nach der Blïthezeit, verliert sich die Rötlı wieder allmälig, bis derselbe wieder ganz grün gefürbt erscheint.

\section{Vries. in eurvat a Gaud.}

Bonite, Voyage au tour du monde, Gaudichaud, t. 18.

Die Laubblätter sind dünn, glïnzend, ganzrandig, weich, aufrecht, sehr zart, mit Längspunkten und Strienchen dicht gezeichnet, von verschiedener Länge ( $3^{\prime \prime}$ bis $\left.1^{\prime}\right)$, gegen den Grund schmäler werdend, hier den nur 2" dicken Stamm ganz umfassend, dann in der Mitte iiber $1^{\prime \prime}$ breit, stumpf spitz endend. Bliithenstand steif aufrecht, $10^{\prime \prime}$ hoch, $2^{\prime \prime}$ breit, hier die Bracteen zweizeilig, wie geflochten über einander liegend, zusammengedrückt, gegen innen gebogen, an den Rändern sehr lein wellig, mit Längsstreifen versehen. Tou den Blüthen sind nur die Kronenzipfel etwas zwischen den Bracteen vorstehend.

\section{Vries. ensiform is Beer.}

Tillandsia ensiformis Arrab. Flora Fluminensis, t. 129.

Laubblätter alle aufrecht, unbewehrt, glatt, einen schlanken Kelch bildend, am frunde schmäler werdend, hier 3 " breit, gegen oben $2^{\prime \prime}$ und darïber breit, eine tiefe Rinne bildend, gegen das Ende ganz flach ausgebreitet und wahrscheinlich 1 1/2' lang. Blïthenschaft rom Grunde aus rund, mit Bracteen, welche $1-4$ im Kreise stehen, dicht besetzt, bis zum Blïthenstande $1 \frac{1 / 2}{\prime}$ lıoch. Blïthenstand 9 "lang, von unten auf mit zweizeiligen, schifförmigen, wenirg plattgedrïckten, abstehenden Bracteen besetzt, aus deren oberem zusammengeneigten Ende die Blu* menkrone 3/," lang vorsieht. Die Staubueutel haben gleiche Länge mit den Kronenblättern, der Griffel ist aber um $3^{\prime \prime \prime}$ länger. Da diese Blätter etwas zurückgeschlagen sind, so stehen die Genitalien vor. Hier ist von 
einer Scheide zur anderen ein Zwischenraum, der sich aber allmälig verliert, und die obere Hälfte des Blïthenstandes erseheint durch die sich deckenden Bracteen wie geflochten, schwertförmig.

\section{Vries. le e urvata Gaud.}

Gaudichaud, Bonite, Voyage au tour du Monde, tab. 69.

Laubblätter glatt, weich, ganzrandig, sehr diinn, mit Längslinien und Punkten geziert, kelchbildend zusammenstehend, aufrecht, dann schlaff überhängend. Am Grunde schmäler, dann über $2^{\prime \prime}$ breit, endlich schnell schmäler werdend, in Mitte $1^{\prime \prime}$ breit, verschieden lang (1' g" und kürzer). Schaft rund, steif aufrecht, bis zum Bliithenstande 1' lang, mit dicht anliegenden Bracteen im Kreise $1-4$ besetzt. Blüthenstand " hoch. Bracteen zweizeilig, die unteren abstchend, 1" breit, zusammen. gedrückt an den Ründern, in Mitte sehr zierlich gleichmässig, aber nur $1 \frac{1}{2}{ }^{\prime \prime}$ tief, mit runden Fültchen besetzt. Die Blüthe ist von den Bracteen ganz umhïllt und es steht nur ein kleiner Theil der Krone hervor. Am oberen Theile des Blïthenstandes decken sich die Bracteen, welche alle gleichmässig 2" lang und 1" breit sind, gegenseitig; es umhüllt daher die Bractee die Bliithe erst dam, wenn sie dieselbe herabbeugt.

\section{Vries. conferta Gaud.}

Gaudichaud, Bonite, Voyage au tour du Monde, t. 65.

Laubblätter weich, glänzend, ganzrandig, am Grunde den sebr dünnen Stamm ganz umgebend, hier 3:" breit, dann bauchig $2^{\prime \prime}$ breit, endlich in Mitte $1 \frac{1}{4}$ " breit, verschieden lang (über $1 \frac{1}{2} \%$. Blüthenschaft am Grunde rund, sehr stark, $1 / 2$ " dick, bei $1^{\prime}$ Höhe aber nur noch $3^{\prime \prime \prime}$ dick, mit ganz bedeckenden Scheiden im Kreise $1-4$ besetzt. Blüthenstand 9" hoch, zweizeilig. Bracteen alle in gleicher Entfernung von einander abstehend, ganz umfassend, $2 "$ lang, 1 " breit, wenig zusammengedrückt. Dic Entfernung ron einer Bractee zur gegenüuerstehenden beträgt $1 / 2$ “. Die Kronenblätter stehen ganz geöffnet, aufrecht, allein zwischen den Bracteen hervor.

\section{Vries. platynema Gaud.}

Gaudichaud, Bonite, Voyage au tour du Monde, tal. 66.

Laubblätter glatt, weich, ganzrandig, am Grunde sehr dünn, den Stamm ganz umhüllend, dann bauchig breiter werdend, hier $3 / . "$ breit, endlich in Mitte 1" breit, ron ver'schiedener Länge, überall mit feinen Längs- und unterbrochenen Querlinien dicht besetzt, steif aufrecht, dann schlaff überhängend. Blüthenstand steif aufrecht, zweizeilig. Bracteen in gleicher Entfernung von einander stehend. Hier ist die Bractee nur 
halb so lang als der $1 \frac{1 / 2}{2}$ lange Fruchttknoten und die Kelchzipfel; beide zusammen haben eine verlängert eiförmige Gestalt, und wenn sich die $1 \frac{1}{2}$ " langen, runden Kronenblätter vordrängen, so senkt sich der Fruchtknoten sammt der Bractee bedeutend herab, wesshalb auch diese Species, durch die gleichmässig herabgeneigten Blüthen, sehr leicht zu erkennen ist. Die Entfernung von einer Blüthe zur andern beträgt $3 / 4$ ". Die Scheide ist bauchig, gegen die Spitze stark zusammengedrückt und 1" breit.

\section{Vries. imbricata Beer.}

Till, imbricata Arrab. Flora Fluminensis, tab. 131.

Laubblätter weich, glatt, ganzrandig, verschieden lang $\left(1 \frac{1}{2}{ }^{\circ}\right)$, in der Mitte $2^{\prime \prime}$ breit, stumpf spitz endend, steif aufrecht, dann gegen aussen gebogen. Am Grunde sehr schmal, dann bauchig, $2 \frac{1}{2}$ " breit. Schaft aufrecht. Bracteen am zweizeiligen Blüthenstande in gleicher Entfernung, ohne sich zu decken, ron einander stehend, schiffartig gebildet, am spitzen Ende ganz zusammengedrückt, bei $2^{\prime \prime}$ breit, 3 " lang. Von der Blüthe ist gar nichts sichtbar.

\section{Vries. gigantea Gaud.}

Gaudichaud, Bonite, Voyage au tour du monde, tab. 70.

Pflanze vermuthlich sehr gross und umfangreich. Laubblätter glatt, ganzrandig, gleich breit, weich, mit langer Spitze endend, 3' lang und $2 \frac{1}{2}$ "breit. Der Blüthenstand aufrecht, verzweigt, sehr kräftig, die Zweige $15 \frac{1}{2}$ " lang, jeder der Zweige ist wieder verzweigt, aber am oberen Ende und darunter nur mit einzelnen Blüthen besetzt. Bei den Seitenzweigchen, welche in der Abbildung zu sehen sind, ist es merkwürdig, dass die Blüthen, welche einzeln stehen, bedeutend grösser sind, wie jene an den Hauptzweigen; auch scheint es, dass diese Pflanze sehr lange in Blüthe stehen muss, da sich Knospen und am untern Theile aufgesprungene, also vollkommen reife Kapseln gezeichnet finden. Die Blüthen variiren von 1 " bis über $1 \frac{1}{2}$ ". Sie stehen überall zweizeilig. Die Seitenästchen sind von $2 \frac{1 / 2}{\text { bis }} 3^{\prime \prime}$ lang. Die Bracteen sind $3 / 4$ und $1^{\prime \prime}$ breit, zusammengedrückt, am Ende flach spitz abstehend, dann den Fruchtknoten und den Stiel umfassend, eiförmig, etwas gestreift. Fruchtknoten sehr klcin. Kelchzipfel lang, bis auf den Grund geschlitzt, spitz, hier etwas abstehend, beide $1 \frac{1}{4}$ " lang und $1 / 2$ " dick. Kronenblätter steif aufrecht, rund, $1 / 2$ " lang, $2^{\prime \prime \prime}$ breit. Jede Verzweigung trägt eine schiffartige, zusammengedrückte Bractee von 2 " Länge.

Ich kenne fünf lebende Formen dieser Familie, welche alle den Namen „riesig" verdienen. Die unvergleichlich reiche Pflanzensammlung 
zu Schönbrunn bei Wien birgt im Parasiten-Hause, im freien Grunde stehend, drei auffallend herrlich grosse Formen, mit Namen Bromelia sceptrum, Bromelia sp. Brasil. und Bromelia sp. Mexico. Diese drei Gewächse sind wahrscheinlich auch drei gute Arten, obwohl ich zweifle, dass die echte Bromelia sceptrum Fenzl (Agallostachys anthiacantha Beer) darunter sich befinde. Walurscheinlich sind es drei neue Arten zur Gattung Agallostachys. Die steif aufrechten Laubblätter erreichen die auffallende Länge von 20 bis $24^{\prime}$. - Die sehr starken Sprossen erscheinen bei diesen Gewächsen wie dicke beschuppte Schlangen, welche auf der Erde hinkriechen und erst bei 6 bis $8^{\prime}$ Länge die aufrechten Blätter treiben. Die vierte Form lebt in der reichen Pflanzensammlung des Herrn Decker in Berlin, als Bromelia sp. Mexico. Diese gigante Form bildet dicht zusammenstehende, steif aufrechte, am Grunde etwas schmäler

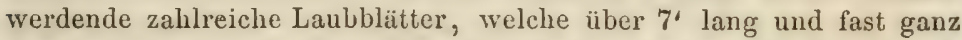
gleichmässig $2 \frac{1}{2}$ " breit sind. Sie bilden der ganzen Länge nach eine tiefe Rinne; die Ränder sind fein braun sägezähnig, die Blattenden scharf stachelspitz. Die Innenfläche der Blätter ist lebhaft grau-grün, die Aussenfläche auf schmutzig hellgrünem Grunde matt silberglänzend und mit einigen bräunliclien Querbinden geziert. - Die fünfte gigante Form ist: Billbergia Skinneri, aus van Houtte's Garten. Diese Form, welche ich in einem vierjährigen Exemplare besitze, verspricht an Grösse und Zierlichkeit der Formen alle anderen zu überbieten. Diese junge Pllanze hat jetzt schon Laubblätter von $5^{\prime}$ Länge und $3^{\prime \prime}$ Breite, welche nach allen Richtungen in zierlichen Bogen überhängen.

\section{Vries. alo ëfolia Beer.}

Till. aloifolia Hook. Exotic Flora, t. 205. - Kerner, Ilort semperv. t. 822. (Till. flexuosa Sw.)

Pflanze aufrecht, durch das Anliegen der Laubblätter unter einander am Grunde eiförmig rund, hier $1 \frac{1}{2}$ " dick. Laubblätter verschieden an Länge, jene am Grunde 2"lang, dann immer länger werdend, bis 1' lang, alle unten bauchig, bei 2 " breit, dann allmälig schmal, und spitz endend, weich, glatt, hell olivengrün, mit dunkelgrünen schmalen Querbinden, und am Ende schmutzig weinroth bemalt, die unbewehrten Blattränder manchmal gegen innen eingerollt, sonst steif aufrecht und etwas abstehend. Schaft, Bracteen und Kelchzipfel hell olivengrün und schwach weinroth bemalt. Ersterer sammt dem einfach verzweigten, zweizeiligen Blüthenstande 1 $12^{\prime}$ hoch, dieser für sich $8^{\prime \prime}$ lang. Bracteen am Schafte verschieden lang, vollkommen umfassend, schmal, ausgebreitet. Bractee jede Blüthe ganz umhüllend, fast anliegend, kürzer als der $1 \frac{1}{2}$ " lange Fruchtknoten und Kelchzipfel, wenig plattgedruckt. Kelchzipfel

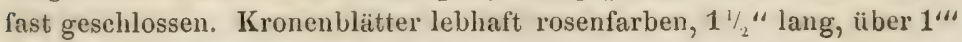


breit, etwas bauchig, spitz endend, hier stark übergebogen, bis auf den Grund frei. Genitalien so lang als die Kronenblätter, von einander entfernt stehend. Staubblätter goldgelb. Griffel rein weiss.

\section{Vries. ten u ifolia Beer.}

Till. tenuifolia Linné. Jacquin select. Americ. Hist. pag, 92, tab: 63. - Kerner, Hortus semperv., tab. 358. - Till. flexuosa Person.

Es folgt hier die Beschreibung von J a c qu in :

Blätter lineal, pfriemlich, ganzrandig, dachziegelförmig gestellt. Achre einfach, schlaff. Kelch: Blïthendecke einblättrig, am Grunde schwach dreiseitig und den Fruchtboden umwachsend, oberhalb dreitheilig bleibend. Zipfel länglich stumpf, concav, zusammengeneigt, die Krone wenig umfassend und zweimal kürzer als diese. Krone dreiblättrig, lineal, concav, aufrecht, stumpf, an den Seiten sich wechselseitig anliegend und so einer langen, cylindrischen, einblättrigen Rühre täuschend ähnlich, aber den Fruchtknoten einwärts, zusammengeschnürt, die Spitzen flach und zurückgebogen. Staubgefässe sechsfadenförmig, von der Länge der Krone. Staubbentel länglich aufliegend. Fruchtknoten eiförmig. Griffel fadenförmig, aufrecht, ein wenig länger als die Staubgefässe. Narbe dreispaltig; die Zipfel länglich, stumpf, abstehend. Kapsel länglich, stumpf, dreiseitig, zugespitzt, sehr glänzend, einfächerig, dreiklappig. Samen zahlreich, sehr klein, mit cinem sehr langen, fadenförmigen Papus.

Stamm einfach, auch üfter's verïstelt. Die Aehre sehr schlaff, endständig, mit einblättrigen, concaven, länglichen, stumpfen, eng umfassenden und röthlichen Blüthenscheiden bekleidet.

Blïthen glänzend, geruchlos, zweizeilig, carminroth, innerhalb der Blïthenscheide durch den kürzeren Kelch eingeschlossen. Kapsel braun.

Standort: Cartagena, auf Bäumen, besonders an Mimosen, die am Gestade wachsen. Blüthezeit: Juni und Juli.

\section{Vries. psitta cin a Lindl.}

Bot. Register 1843, tab. 10. - Tillandsia psittacina Hook, Bot. Magazine, tab. 2841. Sertum botanicum van Geel.

Diese schöne Pflanze gleicht dem Blattwuchse nach der Guzmannia tricolor. Ganze Pflanze lebhaft glänzend. Laubblätter weich, schön grün, am bauchigen, etwas umfassenden Grunde schmutzig röthlich gefürbt, von fast gleicher Länge. Am Grunde $1 \frac{1}{2}$ " breit, dann bei $1 \frac{1}{2}$ " Höhe $3 / 4$ " breit, 8" lang, stumpt spitz, am Rande wellig, unbewehrt, mit dem oberen Theile ïberhängend. Schaft steif aufrecht, mit aufrecht anliegenden grünen, roth bemalten Bracteen im Kreise von $1-4$ besetzt. Bluthenstiel lebhaft blutroth glänzend, etwas hin und 
her gestreift, bei $1 \frac{1}{2}$ 'lang. Blüthenstand für sich $1^{\prime}$ lang, unverzweigt, zweizeilig, sparrig. Blithen $L^{\prime \prime}$ weit von einander entfernt stehend. Knospe aufrecht, sobald sich aber die Blüthe verdrängt, fast wagrecht abstehend. Fruchthnoten und Kelchzipfel ?" lang, gelb mit roth bemalt. Bractec bei jecter Blüthe, iiber 1 $1 \frac{1}{2} "$ lang, dicht anliegend, lebhaft blutroth. Kronenblïtter $4^{\prime \prime \prime}$ lang, grünlich gelb, ausgebreitet. Genitalien länger als jene, flatterig. Staubblätter gelb. Narbe dreilappig, schmutzig grün.

Nach dieser Species hat Prof. Lindley die Gattung Vrisia aufgestellt (nach Prof. W. de Vriese in Amsterdam); der Genus-Name muss aber Vriesea geschrieben werden.

\section{Vries. simplex Beer.}

Tillandsia simplex Arrab. - Flora Fluminensis, tab. 130.

Wahrscheinlich der Vriesea psittacina nahe stehend. Laubblätter alle bis auf den Grund sichtbar, aufrecht, verschieden lang ( 8 bis $12^{\prime \prime}$ ), $1 \frac{1}{2} "$, breit unbewehrt. Schaft stark, aufrecht. Blüthen eine von der andern $2^{\prime \prime}$ entfernt, zweizeilig stehend. Fruchtknoten und Kelchzipfel $1 \frac{1}{2}$ " lang, eiförmig spitz. Bractee umhüllend, spitz, 1" lang.

Nach der Abbildung wären die Kronenblätter um vieles kürzer als die Kelchzipfel.

Eine Beschreibung fehlt.

\section{Vries. gracilis Gaud.}

Gaudichaud, Bonite, Voynge au tour du monde, tab.67.

Eine sehr zierliche Pflanze, mit reichlich verzweigtem Blüthenstande. Laubblätter glatt, ganzrandig, von einander abstehend, mit punktirten Längsstreifen geziert, '7" lang, zungenfürnig, mit schwacher Spitze, am Grunde stark umfassend, wie eine Tulpe zusammenstehend. Schaft aufrecht, kräftig, mit umfassenden, dütenförmigen, etwas nach aufwärts gebogenen Bracteen besetzt. Die oberen Zweige entwickeln sich hier früher wie die unteren. Der Blüthenstand ist für sich $1 \frac{1}{2}{ }^{\prime}$ lang, die längsten Zweige 8". Die Blüthen stehen zweizeilig, sparrig, und 1 "von einander entfernt. Die $1 \% "$ langen und 'y". breiten Bracteen bei jeder Bliithe umhüllen den Fruchtiknoten dergestalt, dass nur die Kelchzipfel vor'stehen. Die Bliithe ist aufrecht, $1 / 2$ " lang. Die Genitalien nicht sichtbar.

\section{Vries. regin a Beer.}

Tillandsia regina Arrab. - Flora Fluminensis, tab. 142.

Diese Pflanze ist nur ihrem Blüthenstande nach hier anzuführen. Da aber die Zeichnung vollständig unverständlich, auch keine Beschrei- 
bung vorhanden ist, begnïge ich mich damit, selbe nur namentlich anzuführen.

Vries. ma culatá Beel.

Tillandsia maculata, Ruiz et Pav. Flora Peruv, et Chilensis, tab. 26\%. - Kerner, Hort. semperv, tab. 515.

Es folgt hier die Beschreibung von $\mathrm{Ruiz}$ et $\mathrm{Pavon:}$

Pflanze: Pispe zusammengesetzt, röthlich, mit fast getheilten Aehren und lanzett schwertfïrmigen, gefleckten Blättern. Pflanze kahl, oft ganz röthlich.

Schalt einfach, fast $3^{\prime}$ lang; aulrecht, röthlich gegliedert, oberhalb rispig, mit eiförmigen, knieförmig grebogenen, spitzen, gestreiften und stengelumfassenden Schuppen besetzt, von denen die unteren nahestehend und zusammengedreht, dic oberen etwas entfernter stehend und anch kïrzer sind. Die Blätter; wurzelständig, sich gegenseitig anliegend, lauzettlich, schwertïrmig, mit stumpfer Spitze, zurückgerollt, gestreift, beiderseits glänzenr, gerinnt, mit rusafarbigen und röthlich purpurfarbenen Flecken reichlich verziert, die äusseren allmälig grösser werdend und etwas mehr abstehend. Die Rispe $1 \frac{1}{2}$ ' lang, röthlich, aus abwechselnd stehenden, fast getheilten, mit Bracteen umstellten Aehren zusammengesetzt. Die Aehrchen etwas abstehend, 1" lang, vielblüthig, mit länglich lanzettförmigen, spitzen, halbstengelumfassenden, concaven, angedrückten und gestreiften Bracteen umstellt. Die Blüthen abrechselnd, zw eiz eilig, dachziegelförmig, sitzend, durch concare, längliche unrl spitzige Bracteen abgesondert. Die Bracteen und Kelche röthlich. Die Blumenblätter violett, unterhalb zusammengedreht, oberhalb etwas abstehend, einen 'Tag dauerud, klein, verwelkend, bleibend. Die Kapsel länglich, blass, die inneren Fächer ausserhalb rauh. Die Samen zahlreich, lineal, gell, mit papusartiger, behaarter Krone.

Standort: Haine in Peru, besonders bei Muna u. s. w., auf Bäumen und Felsen.

Blüthe: Juli, August, September.

Diese Pflanze wird zum Schmucke in den Vorhallen der Tempel gepflanzt und enthält zwischen den Blättern Wasser.

Vries. ru bra Beer.

Tillandsia rubra Ruiz et Pavon. - Flora Peruviana et Chilensis, R. et Pav., tab. 266.

Folgt die Beschreibung von $\mathrm{Ruiz}$ et $\mathrm{Pavon}$ :

Pflanze: Die Rispe einfach, roth, mit unverzweigten Aehren, schwertförmigen und fast zugespitzten Blättern. Planze kahl. 
Schaft aufrecht, einfach, rund, 3 bis $4^{\prime}$ hoch, unterhalb mit abwechselnd stehenden Blüthen, scheiłenförmigen - und scheidenförmig zusammengewundenen, zugespitzten, gestreiften, stengelumfassenden und auch 1, "laugen Schuppen bedeckt, oberhalb rispig. Blätter wurzelständig, sich gegenseitig anliegend, die änsseren allmälig länger, abstehend, zurückgebogen und fast 2 ' lang, die inneren aufrecht; alle schwertförmig, fast zugespitzt, unterhalb weiss silbergläuzend, oberhalb sehwach grünlich und gestreift. Die grösseren Blätter unterhalb, gegen die Basis zu, mit kleinen, kaum sichtbaren Punkten gezeichnet.

Die Rispe $1 \frac{1}{2}$ ' lang, aufrecht, röthlich, aus vielen Aehren zusammengesetzt, mit abwechselnd stehenden einfachen, länglich lanzettförmigen, abstehenden Bracteen, die zugespitzt, kahnförmig, röthlich und 1" breit sind, umstellt. Die Aehren fast 1'lang, sitzend, verflacht, vielblüthig.

Die Bliithen abwechselnd, z weizeilig, dachziegelförmig sitzend, iilserall mit Bracteen umgeben. Bracteen länglich, gerinnt, dunkelroth, an der Spitze gelblich. Kelch röthlich gelb, von der Länge der Bracteen. Blumenblätter drei, klein, röthlich, violett, von der Mitte bis zur Spitze abstehend, zurückgebogen, einen Tag nur blühend, verwelkend. Die Kapsel länglich, blass, die inneren Klappen ausserhalb raul, gerändert, innerhalb schwarz, glïnzend. Samen zahlreich, lineal, fahlgelb, papusartig gekrönt.

Standort: Peru, an warmen Abhängen; Tarma.

Blüthe: März, April.

\section{TUSSACIA Willdenow.}

Tuss. vitellina Klotzseh.

Tillandsia vitellina Kilotzsch. - Jcones plantarum, Hort. Berolinensis tab. 40.

Dieses sehr zierliche lebhaft grasgrüne, glänzınd glatte, gänzlich unberwehrte, im Ganzen nur $t^{\prime \prime}$ hohe Pfänzchen, hat einen einfach rerzweigten, über 6" langen, nur mit einigen fahlgelben, umfassenden anliegenden, schmalen, mit der Spitze abstehenden Bracteen besetzten Schaft. Die Blüthen stehen einzeln, speerig, Fruchtknoten und die sehr kurzen Kelchlappen haben zusammen eine etwas verlängerte, spitze, eiförmige Gestalt, von " 7 "' Länge und 3 "' Breite, ersterer mit einer anliegenden spitzen glatten, etwas kurzen Bractee besetzt. Kironenblätter ganz flach, spitz, ausgebreitet, von hochgelber Farbe, $3^{\prime \prime \prime}$ breit und $3^{\prime \prime \prime}$ lang. Die Laubblïtter sind tief rinnenförmig, an Rande wellig und enden allmülig mit weicher Spitze, sie sind am Grunde stark umfassend, die untersten kaum $1 / 2$ "lang; die längsten 5 "lang, alle aufrecht, dann gegen die 
Mitte zierlich nach aussen iibergebogen. Die Genitalien gar nicht sichtbar.

\section{Tuss, fulgens Klotzsch.}

Tillandsia fulgens Klotzsch im Berliner Museum, Noo. 1230, Merida, 1814 und Abbildung von Moritz.

Diese sehr schöne Pflanze hat Moritz ans Merida in getrockneten Exemplaren und eine Abbildung derselben dem Berliner Museum gesendet, diese Mittheilung, søwie viele andere werthvolle Aufschlüsse, verdanke ich dem würdigen Herrn Director Dr. Klotzsch in Berlin. Die Pflanze hat lederartige glatte Blätter, welche am Grunde stark umfassend und sehr bauchig. endlich schmäler werden, in lange schmale etwas zurïckgebogene unbewehrte Zipfel endigen. IIierdurch bekommt die Pflanze am Grunde eine runde Gestalt von uber 4" Durchmesser. Die Blätter stehen aus der. Mitte gerade in die Höhe, und erreichen fast 1' Länge bei wenigstens 4" Breite an Grunde. Die Farbe der Laubblätter ist ein lebhartes Colorit (wenigstens zur Blüthezeit) ron dunkel olivengrün, mit mattrothen zerstreuten Punkten, bis endlich bei einigen B]ättern die reinste Blutfarbe vorherrscht. Der Schaft ist mit dem Blüthenstande uiberhängend, $1^{\prime} / 2^{\prime}$ lang, iiber $2^{\prime \prime \prime}$ dick, lebhaft rosenfarb. Die lebhaft blutrothen Bracteen sind umiassend, anliegend, schmal, flatterig, abstehend, spitz endend. Der Blïthenstand stark verzweigt, von einem Zweige zum andern kniefürmig gebogen, diese aufrecht stehend, mit einer ebenfalls anfwärts stehenden, nicht umfassenden länglich herzförmigen, in eine flattrige lebhaft blutrothe Spitze endigend. Die Zweige in gleicher Entfernung sparrig am Blüthenstande, fast gleichlang $\left(2 \frac{1}{2}\right.$ bis $\left.2^{\prime \prime}\right)$. An diesen aufrechten Zweigen, am stark hängenden Blüthenstande stehen die kleinen Blüthen fast wagrecht ab. Fruchtknoten und Kelchzipfel fast rund, letztere etwas abstehend, von lebhafter Orangefarbe mit einer nach unten stehenden umfassenden spitzen Bractee von licht lederbrauner Farbe besetzt. Blumenkrone goldgelb, die Zipfel ausgebreitet, etwas zurückgebogen. Die Genitalien gar nicht sichtbar. Fruchtknoten und Kelchzipfel kaum 1/2" lang, ersterer 4" breit. Kronenblätter $5^{\prime \prime \prime}$ lang.

\section{Tuss. nitida Beer.}

Tillandsia nitida Hooker. Exotic Flora, tab. 218.

Die Pllanze bildet 4 Blätter von verschiedener Länge ( 3 bis $10^{\prime \prime}$ ), welche ganz unbewehrt, kelchbildend zusammenstehen. Die ganze Pflanze ist bis auf die Kronenblätter dunkel olivengrün, glatt und glänzend. Der sehr düne Schaft erhebt sich aufrecht (nach der Zeichnung) über $1 \frac{1}{2}{ }^{\prime}$, ist 
stark verzweigt und mit schmalen, umfassenden, anliegenden, spitzen Bracteen spärlich besetzt. Die Bliithen stehen unordentlich und sparrig alle gegen aufwärts gerichtet. Fruchtknoten und Kelchzipfel, welche kaum zu bemerken sind, laben eine eirunde Form, sind 4"' lang und von einer kirzeren, von unten auf fest anliegenden Bractee begleitet. Die Kronenblätter sind ausgebreitet, rund, schmutzig gelb, $1^{\prime \prime \prime}$ breit und etwas länger. Die Genitalien sind gar nicht sichtbar.

\section{'Tuss. sessiliflor a Beer.}

(Tuss. cornucopia Dr. Bertero. Berl. Museum, 1821, Jamaica.)

Tillandsia sessilifora Ruiz et Pav. Flora Peruv, et Chil., tab. 271.

Folgt die Beschreibung von $\mathrm{Ruiz}$ et $\mathrm{P}$ avon:

Pflanze. Schaft einfach, ährig, Blüthen einzeln stehend, sitzend. Die Blätter zungenförmig, tiefrinnig (retusus).

Planze zweijäh ri g, kahl.

Schaft 1' lang a u frecht, zierlich, rund, doppelt so lang als die Blätter, gegliedert, mit scheidenförmigen zusammengerollten, entfernt stehenden, länglichen stumpfen und gestreiften Schuppen besetzt. Laubblätter wurzelständig, sich wechselseitig anliegend, zierlich, flach, fast zungenförmig, tiefrinnig, gestreift, bei 1`lang, $1^{\prime \prime}$ breit, die äusseren allmälig kürzer werdend. Die Aehre endständig; einfach, über $1 / 2{ }^{`}$ lang, aufrecht. Blïthen abwechselnd stehend, einzel n sitzend, mit eiförmigen spitzen concaven Bracteen umstellt. Kelchzipfel oval, stumpi gestreift. Kapsel eiförmig, spitz, dreililappig, die äussern Klappen spreublättrig, die inneren $\mathrm{zu}$ innerst violett schwarz. Die Samen fahl gelb, lineallänglich, mit Papus gekrönt und speisgelben Zotten (villis).

Standort: an warmen Orten in Peru in der Provinz Huanuco.

Im November und December fanden die Verfasser diese Species mit Frucht beladen.

\section{GUZMANIA Ruiz et Pavon.}

\section{Guzm. erythrolepis Ad. Brongn. Flore de Serres, van Houtte, tab. 1089.}

Laubblätter aufrechtstehend, mit einigen Längsfalten versehen, lang gedehnt, stumpf spitz endend, glattrandig, hellgrün, glänzend, an den Rändernn bei einigen Blättern hell lederbraun, verwaschen gefärbt, ïher $1^{\prime}$ lang, $2^{\prime \prime}$ breit, die Herzblätter etwas kürzer. Stamm sehr dünn, von den Blättern ganz bedeckt. Schaft mit licht lederfarbigen Hochblättern (Bracteen) dicht besetzt. 
Blüthenstand walzig keulenförmig, durch dicht anliegende, lebhaft blutrothe, eiförmige, in eine grïne Spitze endigende Bracteen gebildet, $4 \frac{1}{2}$ " hoch, über $1 \frac{1}{2}$ " breit. Bliithen zwischen den Bracteen einzeln erscheinend, schnell verwelkend, aufrecht, kaum $1 / 2$ " vorragend, rein weiss. Kronenzipfel anfrecht, stumpf spitz endend, an der Bractee anliegend. Knospe ebenso gefürbt, stumpf spitz eudend. Der Schaft wird vou den Laubblättern weit iiberragt, und ist übcrhaupt wenig sichtbar. Der Blüthenstand hingegen ist vollkommen sichtbar. Von den Genitalien ist nichts zu sehen, indem selbe viel kürzer als die aufrechten, eine Röhre bildenden Kronenblätter sind. Diese noch wenig verbreitete Art stammt aus dem Jardin des Plantes zu Paris und wurde von Linden auf der Insel Cuba gefunden und auch lebend eingeführt.

Guzm. tricolor Ruiz et Pav.

Ruiz et Pavon, Flora Peruviana et Chil., tab. 261.

Loddiges, Bot. Cabinet, tab. 462.

Exotic, Flora, tab. 63.

Lindley, Collectanea botanica, tab. 8.

Annales de Gand. III.

Flore de Serres, $\operatorname{van}$ Houtte, IX, tab. 918.

Wir haben sechs Abbildungen dieser schönen Pflanze. Jedenfalls ist Guzm. tric. in Exotic Flora eine Pflanze, welche nicht hierher gehört. Nicht minder zu beriicksichtigen ist jene Abbildung in Lorld. Bot. Cabinet, indem auch hier Abweichungen in Form und Farbe sich zeigen; allein diese sind doch nicht so auffallend, dass sic Aulass gäbeu, hier eine andere gute Species vor sich zu haben, indem nur in den matter gestreiften Bracteen und in der fehlenden Purpurfarbe, welche den Uebergang der griinen, violett gestreiften zı den hochrothen Bracteen bildeı, Veränderungen sich zeigen. Diese Unterschiede können durch Standort und Cultur herbeigeführt sein, oder der Zeichner hat nicht genau nachgebildet. Es bleibt daher nur Guzm. tricolor der Exotic Flora hier auszuschliessen und für sich als gute Species zu behandeln. -

Pflanze kaum 1' hoch, mit zahlreichen Blättern, welche alle steif aufrecht stehen; sie sind ganz unbervehrt, glatt, glänzend, lellgrün, mit den spitzen Enden manchmal überhängend, in Mitte 1“ breit, am Grunde bauchig. Der Blïthenschaft erhebt sich steif aufrecht und ragt mit dem $5^{\prime \prime}$ hohen Blüthenstande über die Blätter weit vor. Die Bracteen sind am Schaft und Blithenstande, steif aufrecht, etwas bauchig, anliegend, $1 \frac{1}{2}$ " lang und $3 / 4$ " breit. Erst in der Hitte bekommt der Bliithenstand eine schwach keulenförmige Gestalt. Hier ist derselbe 1 $1 \frac{1}{\text { " dick }}$ und endet in eine stumpf runcle Spitze. Die Färbung der Bracteen ist auffallend, sehr verschieden. 
IVir wollen von der Spitze des Bliithenstandes beginnen. - Hirr sind die Bracteen dachziegelförmig iiber einander liegend und $1 \frac{1}{2}$ " der Länge des Bliithenstandes lebhaft samtig hochroth, damn folgen zwei Reihen lebhaft hellvioletter Bracteen, und endich finden sich bis anf den Grund lebhaft hellgrïne, mit breiten, entschieden rein begränzten Längslinien gezierte, am Rande violett verwaschene Bracteen. I)iese Streifung mit den hochrothen Giptel zeichnet die Gummania vor allen Bromeliaceen rortheilhaft ans. Die fliithen erscheinen zwisehen den Bracteen; sic sind aufrecht, rein weiss, etwas bauchig, wenig ausgcbreitet. Zipfel 3/, lang, üher 2" breit. Manchmal sind die Kelchzipfel sichtbar. Genitalien kürzer als die Kronenblätter, daher nicht sichtbar.

Standort nach Ruiz et Pavon: Peruv. Gebirge bei Pillao und Chicahoassi auf Baumstämmen.

Blïtlie: October, November.

\section{Guzm. sympaganthera Beer.}

Pourretia sympaganthera Ruiz et Pavon.

Guzmania tricolor. Exotic Flora, tab. 163.

Laubblätter 1" breit, nur gegen unten allmälig an Breite zunehmend, und zwar bis zu $1 \frac{1}{\text { " }}$; hier etwas an den Rändern eingerollt, bei 2' lang, allmälig spitz endend, lebhaft hell bläulich grün, ganz unbewehrt, glatt, glänzend. Schaft mit fahl gelblich grimen aufrechten, in eine lange schmale Lappe endigenden umfassenden Bracteen besetzt, sammt tem 6" hohen Blïthenstande iiber 1' hoch. Bracteen am Bliithenstande dachziegelförmig stehend, gegen rlas Ende eine schwache Keule bildend. Jene am Gipfel hell gleichmaissig leuerroth, die iibrigen hellgriin. mit einigen dunklen Lïngsstreilen und am Rande, besonders die Spitze, weinroth bemalt. Die zwischen den Bracteen kaum vorsehenden rein weissen Blïthen sind keulenförnig. Genitalien nicht sichtbar.

\section{LAMPROCOCCUS Beer.}

\section{Lampr. fulgens Beer.}

Aechmea fulgens Brong. Paxton, Hag. of Botany $\mathrm{X}$, pag. 176. - Annales de Flore et de Pomone. - Flore van Houtte IV, 1816.

Die Abbildung in den Annales scheint nicht nach Acchm. fulgens, sondern nach Aechm. miniata Hort. gemacht zu sein. -

Laubblätter becherförmig zusammenstehend, am Ende ausgebreitet, abstehend, glänzend, fein sägezähnig, gleichmïssig lebhaft grün, am 
Grunde bauchig, hier 3 " breit und glattrandig, in Mitte $2^{\prime \prime}$ breit, $1^{\prime} 4^{\prime \prime}$ lang, am Rande wellig, mit sehr kurzer Spitze am stumpf runden Blattende versehen. Der 5" dicke Schaft und der 8" hohe verzweigte Bliithen. stand erheben sich aufrecht, mit Ausuahme der hellblauen Kelchzipfel und der $3^{\prime \prime \prime}$ langen, etwas flattrigen, hell lilafarbigen Kronenblätter, an allen Theilen glänzend, lebhaft blutroth gefiirbt. Die Genitalien sind gar nicht sichtbar. Bracteen am Schafte, flatterig, missfarbig, hängend. Zweige nur 1" dick, knieförnig hin und her gebogen. Beere eirund, sammt dem fleischigen, hellblauen, steifen, zusammengeneigten Kelchzipfel 1/2" lang, 4" breit, sehr kurz gestielt. Die Beeren entwickeln sich alle zugleich, sind anfänglich hell grün roth, färben sich aber sehr schnell lebhaft blutroth. Die Verbindungs - Organe des jungen Sprosses sind bei 6" lang, fingerdick, holzig und mit hellbraunen Scheiden umgeben.

\section{Lampr. fulgens var. discolor Brong.}

Aechmea discolor Hort. Aechmea fulgens discolor Brong. Bot. Mag., tab. 4293. - Annales de Gand. II, tab. 65 .

Der Blüthenstand ist jenem bei Aechm. fulgens gleich, nur die Laubblätter variiren, indem bei Aechm. discolor die Unterflächen der Blätter lebhaft röthlich lila gefärbt sind. Die Kelchzipfel haben an mancher Pflanze eine dunklere Färbung, allein auch hieranf ist kein Werth zu legen, da ich von Aechm. miniata discolor Sämlinge gezogen habe, welche aus einer Beere Aechm. miniata und Aechm. miniata discolor erzeugten.

\section{Lampr. miniatus Beer und}

$\because \quad, \quad 9$

var. discolor Beer.

Aechmea miniata und Aechmea miniata discolor Hort. - Aechmea fulgens, Annales de Flore et de Pomone:

Laubblätter 2 " breit, 2 ' lang, lederartig; glatt, glänzend, am Grunde

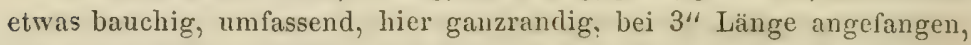
das ganze Blatt sehr fein, gleichmässig sägezähnig, mit ganz kurzer, stumpfer, brauner Spitze endigend. (Bei Lampr. glomeratus ist die Unterfläche der Laubblätter kriiftig, hellgrïn und mit weisslichen Anfluge wie bestäubt erscheinend; die Varictät, ,discolon" dagegen hat die Unterblattflächen glänzend, dunkel rubinroth, am Grunde mit griin verwaschen.) Dic Laubbblätter bis zur Hälfte der Länge steif aufrecht, abstehend, dann in zierlichen Bogen nach allen Richtungen überhängend. Die Blatttächen haben wenig sichtbare; unregelmässige Längs- 
falten. Der ïberaus zicrliche Bliithenstand und 4". dicke Schaft iiher 2' hoch, steif aufrecht. Ersterer gleichmässig stark verzweigt und hierdureh rund und stumpf pramidenförmig erscheinend. Zweige alle wagrecht abstchenr, bei jeder Blütlu, entschieden kniefömig gebogen, sehn diimn, lehhaft fleischroth gefürl,t. Knospe anfänglich lıell erbsengrïn, dam, bei halber Entwicklung, mit fleischroth reichlich bemalt, endlich hell lebhaft fleischroth, eine ciliomige glänzende Beere bildend. Die Kronenblätter schon bei dem ersten Vordringen, lieblich himmclblau gefärbt. Diese Färbung zeigt anch die vollendete Blüthe, welche, $3^{\prime \prime \prime}$ lang, ihre stumpf runden Kironcnblattzipfel gar nicht öfnet. Endlich, beim Abblïhen, drehen sich die Kronenblitter, otwas linger werdend, schwach um sich selust und zeigen eine reine helle Rosenturbe. Die Blüthe erreicht die Länge von " "." Der am Grunde lebhaft braune Schaft wird zwischen den Blïthen sehr schön lackroth gefürut und bleibt in krältiger Gestalt bis zum Gipfe]. Von unten aul ist der Schaft mit umfassenden, fahl hellgelb grïnlichen, flattricren, sehr dünnen und durchsichtigen, weichen, lanzettrörmigen Bracteen hesetzt, welche sich, obwohl hier nur selsr kurz, selbst zwischen der untersten Bliithenstand-Verzweigung finden. An den eirunden, fleischigen, glanzenden Beeren siml die ganz kleinen anliegenden, wie die Beeren gefärbten weichen Bracteen kann sichtbar. Ific Beere sitzt stiellos fest auf. Lampr. miniatus und Lampr. min. discolor sind wahrscheinlich die zierlichsten Formen dieser Gattung. - Bei allgemeiner Betrachtung erscheint der Blüthenstand von den liellgriinen, sehr zahlreichen Knospen begrainzt, dann folgt dic lehlafte Fleischfarbe der Beeren, gehoben durch die liell himmelblanen Blüthen, in deren Mitte der kräftige lackrothe Hauptstiel theilweise sichtbar ist.

\section{Lampr. glo meratus Beer. und ", var. discolor Beer. Aechmea glomerata und A. glom, discolor Hort.}

Bliithenstand verzweigt, eine sehr dichte, stumpf pyramidale, $3^{\prime \prime}$ bohe, $2 \frac{1}{2}$ "breite Aehre bildend. Schaft, Stielchen und Beeren sammt Kelchzipfel feurig zinnoheroth. Stielchen bei jeder Beere sehr stark kuieförmig gehogen, die Beere 5"“ lang und ïber 2"“ breit. Bliithenkrone nicht geöfinet, bei $4^{\prime \prime \prime}$ lang, schïn dunkel lila, mit purpur an Ende bemalt. Kronenblattzipfel mit rein weissem Rande. Im Verblühen verandert sich die Blumenfarbe in hell weinroth und endlich in schmutzig strohgell,. Der Schaft ist hei $5^{\prime \prime}$ dick, vom Grunde aus griin, daun roth gefärbt, mit kurzen, sehr hinfäligen, anfänglich rothen, dann missfarbigen Bracteen sparsam besetzt. 


\section{Lampr. ram os us Beer.}

Brom. ramosa et racemoso ete. Mlumieri Plant. Americ, tab. 64.

Pflanze einen dichten Büschel zungenförmiger, autrechter, ganz gleich hoher, iiber 24 langer, in IItte $1^{3 /,}$ " breiter, selbst über das runde Ende fein sägezihhniger Laubl,litter bildend, welehe am Grunde wenig umfassend, damn beiderseits stark eingebogen sind, desshalb bis zur halben Länge schmäler erscheinen. Der Blätterbuischel ist oben trishterförmig erweitert und umschliesst den aufrechten; vom Grunde aus ïber 4' langen Schaft sammt Blüthenstand. Der Schaft ist $5^{\prime \prime \prime}$ dick, mit einigen flattrigen, weichen, 2 bis 3 "langen, sehmalen Bracteen, selbst bei jedem Zweige am Blithenstande besetzt. Der Bliithenstand triigt mehrere abstehende; etwas anfgerichtete Aeste, welehe dicht mit runden, stumpf spitzen, erbsengrossen Beeren besetzt sind. Die Kelchzipfel sind fleisehig, stumpl, etwas iiber 1“" lang. die Blüthenkrone katum vorstehend. Den Gipfel des iiber 1' langen Bliithenstandes bilden ebenfalls dicht stehende Beeren. Yon Bracteen an den Bliithen ist nichts hemerkbar.

Diese stattliche schöne Pflanze isi ihrem Blattwuchse nach einzig in ihrer Art. Van Hout te's Aechmea surinamensis dürfte wahrscheinlich diese hier beschriebene Prachtpflanze sein.

Lampr. corallinus Beer.

Aechmea corallina Brong.?

Die Pllanze stummt ans der Sammlung des Herrn II orel in Paris; sie ist hellgrün, glänzend. Lanbblätter über 1' lang, etwas uiber 1" breit. Die Blätter bilden eine zierliche schmale Becherform. Blüthenstand verzweigt, von den Laubblättern weit äherragt. Hochblätter missfarbig, hinfällig. Schaft und Stielchen schmutzig ochergelb. Beeren tief gefurcht, lebhaft zinnoberroth. Kelchzipfel etwas dunkler gefärbt, zusammen $1 / 2$ " lang. Kronenblitter kaum geöfinet, aufrecht, rein weiss.

\section{BILLBERGIA Holm et Thunberg.}

Billb. py ramidalis Lindl.

Botanical Magazine tab. 1732.

Professor Jindley zieht anch Billb. nudicaulis Willd. hierlier, wir werden aber diese Species sehr versehieden finden ron Billb. pyramidalis. Die echte B. pyram. ist in den Sammlungen selten zu treffen, indem die noch schünere B. fastnosa, in ilen meisten Gärten sich als B. pyram. findet. Lindley war der erste, welcher eine Species Billbergia, die in 
den Gärten blühte, abbildete, wesshalb ich mich auch bewogen fand, mit dieser Species zu beginnen. Wenn nan die Abbildungen der Billbergien, welche hicrher gehören, mit einander vergleicht, so findet man, dass die meisten derselben als Varietäten von Billb. pyramidalis zu betrachten sind, allein eine wohlklingend benannte Pflanze ist auch angenehm.

Pflanze mit wenigen auf der Rückseite weisslich gebänderten aufrechten Bläittern, diese steif, am Giunde ïber 1 1/2" breit umfassend, "rrtallinig, s" lang, allmälig in eine Spitze cndigend. An Rande gleichförmig, mit kleinen scharfen Sägezähnen besetzt, am Grunde weinroth, dann lebhaft grasgriin, mit mehreren mehr oder minder tielen Längsstreifen versehen. Bliithenschaft, Fruchtknoten und Kelehzipfel selı dicht, weiss wollig bekleidet. Bracteen am Schafte lebhal't weinroth, aufrecht, seidenartig, dünn, unbewehrt, nit etwas welligen Rande und stumpf spitzem Ende. Schaft und Blüthenstand steif anfrecht, durch viele aufrechte Bliithen, stumpf pyramidal gebildet. Blïthe sammt Fruchtknoten ? ${ }^{1}: "$ laug, erstere für sich iiber $1^{\prime \prime}$ lang. Kronenblaitter. eine Röhre bildend, deren Zipfel ansgebreitet, wenig ïbergebogen, gleichmïssig leuchtend, glïnzend ziegelroth, mit lebhaft blauer breiter Bemalung am Rande eines jexlen Kroneublattzipfels. Griffel so lange als die Kronenblätter. Staubbeutel gelb, Fäden weiss, beide kürzer als die Kronenblïtter, aber zwirchen denselben sichthar, Blïthen ohme Bracteen.

Hauptmerkmal dieser Species: Blühenschaft, Fruchtknoten und Kelchzipfel rein weiss, stark wollig bekleidet. Bracteen ganz gleichfärbig, lebhaft weinroth.

Billb. py ramidalis. var. bicolor Lindl. Botanical Register, tab. 1181.

Eine schöne Pflanze mit aufrechten, am Grunde verbreiteten hier stark umfassenden, $21 / 2$ " langen, $1_{/ 4}^{3 /}$ " breiten Laubblättern geziert, welche weich spitz enden, und deren Ränder mit feinen, scharf spitzen braunen Sägezähnen bewaffnet sind, die Aussen- und Innenfläche derselben ist licht saftgriin, auf der Aussenseite sieht man schmale, regelmässige, blass weisse Querbinden.

Bliithenstand steil aufrecht, von den Laubblättern weit iiberragt, thyrsusförmig. Schalt, Fruchtknoten und Kelchzipfel auf hell fleischfurbem Grunde, weiss wollig bekleidet. Hochblätter hell rosalarbig, in Mitte nit dunkler rerwaschener, rein weisser Spitze. Kronenblitter bhutroth, gegen unten fast weiss, rihrenfïmig zusammenstehend, unten etwas bauchig. Kronenzipfel aussen lebhaf; dunkelblau, innen hell lila, ungleichförmig, etwas zurïckgeschlagen. Kelchzipfel mit weisser Spitze. 
Staubbeutel goldgelb, aufrecht vieles kïrzer als die Kronenblätter. Pistil mit schraubig gedrehtem Ende, hier lilafarbig. Staubfäden weiss. Diese Pflanze ist sehr verschieden von B. pyram., durch kräftigen Bau und Blüthenfarbe. Prof. I.indley gibt ihr eine grosse Verbreitung in Südamerika.

Billb. pyramidalis var. minor. Antoine et Beer. Pitcairnia decora? Linden? - Billbergia decora Hort.

Diese Species ist wohl die kleinste an Gestalt und in den Gärten sehr hëufig als B. uudicaulis und B. decora Linden benaunt zu finden. Blïthenstand aufrecht, Bliitlien wenige, lebhaft blutroth mit blan berandeten Zipfelı, diese fast regelmässier; aber wenig zurïckgeschlagen. Schaft und Fruchtknoten weiss gelblich, sehr wenig filzig. Kelchzipfel stumpf spitz, hier hell lederlnaun, dam licht tleischfarb gefärbt, weiss filzig lekleidet. Hochblitter (Bracteen) am Schafte hell schmutzig rosa, zunächst den Blïthen mit griinerSpitze, weiter unten aber mit laubblattähnlicher, kaum . $1 / 4$ " langer Spitze endigend.

Schaft und B] iithenstand 10 " lang, Bliithenstand $2 \frac{1}{2}$ " hoch, $1 \frac{1}{2}$ " breit, Schalt ïberall zwischen den Hochblättern sichtbar. Laubblätter, am Frunde etwas bauchig umfassend hier 3 " breit und verwaschen schmutzig weinroth. Blattfäche eine tiefe Rimme bildend, in Mitte $1 \frac{3}{4}$ " breit, an den Pändem ungleichnässigr, fein sägezähnig, mit feiner weicher Spitze endigend. Die längsten Blätter sind 10" lang, sie stehen alle steil aufrecht und sind ziemlich zahlreich. Da diese Species im Januar hlïht, so erscheint sie doch, trotz der minderen Pracht, wiinschenswerth für jene Sammlung.

Billb. nudicaulis Beer.

Bromelia nudicaulis Linné, Bot. Register, t. 203. - Sertum botanicum, van Geel, t. 150.

Laubblätter 2" breit, am Grunde wenig umfassend, steif aufrecht, dann etwas übergebogen, bei $10^{\prime \prime}$ lang, lebhaft grün, mit kräftigen Längsstreifen versehen, am spitzen Ende etwas iibergebogen, gleichmässig, mit scharfen schmutzig braunen Sägezähnen besetzt.

Blithenschaft steif aufrecht, zwischen den Laubb]ätern bei 6 " vorragend, hellgriiı. Bracteen fahl lederlarb. Blüthen an 1/2" langen Stielchen sitzend, diese und der Fruchtknoten weiss, etwas filzig bekleidet. Kelchzipfel aufrecht, tief geschlitzt, filzig; hell weinroth hemalt, von der Blüthenkrone etwas abstehend. Kronenblätter schr weit geöffnet, un-

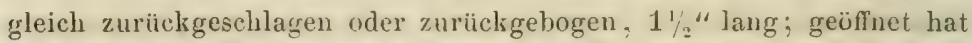
die Blïthe $1^{3} / 1$ "Durchmesser, sie ist von Farbe lebhaft glänzend, blutroth, am Rande schmutzig, bläulich bemalt. Knospe etwas nach aussen gebogen, stumpf endend, lebhaft blutroth mit blau reichlich bemalt. 
Die Blïthen stehen alle weit vor. die Bracteen umgeben die Blïthen aufrecht, ohne die Stielehen zu lusheken, an den Bliithen keine Bractee. Hauptmerkmal dieser Species: Die schmutzig lederfarbigen Bracteen am Schafte.

Billb. bi color Loddiges.

Bot. Cabinet, tab. 19. - Billtergia Loddigesii Steudel.

Lanbblätler den Blüthenstand weit überragend, nach rerschiedenen Richtungen unordentlich alsstehend. daher div Aus-enblitter bis auf dem Grunde sichtbar.

Die Blitter am Rande wellig; sthr fein sägrezähnig; mit langgedehnten, iibergebogenenspitzen Enrlen, glänzend hellgrün, mit schönen dunkelgrünen Querbinden greziert, 1' lang; ' "breit. Schaft steif aufrecht, $t^{\prime \prime \prime}$ dick, hellgrïn, weissfilzig bekleiklet. Bracteen wenig umfassend, autrecht, anliegend, schmutzig gelblich, sehr licht weinroth. Fruchtknoten und Kelchzipfel etwas buchig, fast cimnd, letztere tief geschlitzt, beide $7{ }^{\prime \prime}$ lang, $4^{\prime \prime \prime}$ breit, Stielchen $3^{\prime \prime \prime}$ lang; filzig weisslich, mit matt weinrothen Fleckchen geziert.

Blithenstand $2 y_{2}^{\prime}$ "hoch, "2" breit. Die 1latterigen, 1" breiten, offenen Blüthen überragen die Kuospen. Kronenblätter bläulich blutroth, mit dunkelblan bemalt, weit geöfnet, zungenförmig, etwas zurückgeschlagen. Knospe stumpi; kugelfürmig, von Farbe ler offenen Blüthe, nur $1 / 2$ "lang. Staubfiden aufrecht, zusammenstehend, hellroth. Staubbeutel länglich goldgelb, um "if "kürzer als die 1 1/2" langen Kronenblätter. Griffel weiss, Narbe gedreht, lebhaft blau.

Hauptmerkmal dieser Species: Die anf lichtem Grunde dunkelgrün beränderten Laubblätter.

Billb. thyrsoidea Martins.

Botanical Magazine, tab. 4756.

Laubblätter alle am Grunde etwas abstehend, daun steif aufrecht eine tiefe Rimne bildend, am Grunde stark umfassend, hier glattrandig, dann bei $3^{\prime \prime}$ Länge angefangen gleichmässig, klein sägezähnig. Die schwache Stachelspitze etwas zurückgebogen, $1 \frac{1}{2}$ ' lang, in Mitte 2 " breit, am Grunde fast 3" breit. Schaft und Blithenstand steif aufrecht, Bracteen am ersteren, Kronenblätter und Knospe ganz gleichfärbig; hell weinroth. Schaft hellgriun, ins röthlich hellgelbe übergehend. Stielchen, Fruchtknoten und tief geschlitzte, anliegende Kelchzipfel weisslich, reichlich gelblich roth bemalt, filzig. Knospe kenlenfürmig, gebogen, $1 \frac{1}{4}$ "lang, 3 " breit. Kronenblätter $1 \frac{3 / 4}{4}$ lang, vom cirunde auf eine $3 / 4$ " lange Rühre bildend, dann flach ausgebreitet, zungenförmig, glänzend, 
einfach zuriickgerollt. Der Bliithenstand 5" hoch, 31/2" breit, sehr reichb]ithig. Die rothen Bracteen an Sthatte cnden mit erbsengrüner Spitze.

Hauptmerkmal dieser Species: Der ganz gleichfärbig hell weiurothe Blüthenstand, ohne blanen Anflug oder Bemalung.

\section{Billb. Croyiana Lemaire.}

Jardin fleuriste, $I Y$, tab. 413.

Laubblatter am Grunde eine Röhre bildend, bauchig tiefrinnig, auf der Unterfäehe lebhaft aber sehr schmal, weisslich, der ganzen Länge nach gebändert, am Rande tief' sägerahnig, das stump spitze wehrlose Ende 1" lang übergebogen. Schaft und Blïtlenstand steif aufrecht, sehr liräftig. Ersterer hellgrün, ctwas weiss melılig bestäult. Bracteen hier sehr zahlreich, anfrecht abstehend, gegen den Bliithenstand einen ab. stehenden, gleich hohen Kranz bildend. Blïthenstand bei $4^{\prime \prime}$ hoch und eben so breit, durch die gleichförınig nach aussen gebogenen, strahlenförmig dicht stelıenden, sehr zahlireichen Bliithen und Knospen - halbkugelförmigg gebildet. Bractecn und Blüthen leblatt blutroth, an den spitzen hier iiberall blan bemalt. Fruchtknoten gelblich. Kelchzipfel rein weiss, blutroth punktirt, beide filzig bekleidet. Stielchen eben so gefärbt und 1“" lang. Knospe gegen aussen gebogen, stumpf pfriemenförmig, $1 \frac{1}{2}$ " lang, $3^{\prime \prime \prime}$ breit. Kronenblitter $1 \frac{3 / 4}{4}$ lang, bauchig zusammenstehend, dann flach" ausgebreitet, am Ende wenig zurückgebogen, glänzend.

Ha utmerkmal dieser Species: Die gleichfarbigen Bracteen und Blüthen, welche beide blau bemalt sind.

Unter obigem Namen befindet sich in den Sammlungen eine der Billb. nudicaulis sehr nahe stehende Form; sie ist jedoch nur als Varietät von Billb. nudicaulis zu betrachten und ist von Billb. Croyiana ganz verschieden.

Billb. fastuosa Beer.

Pitcairnia fastuosa. Morren, Annales de Gand. III, tab 412. - Bromelia pyramidalis, Reichenbach. Hortus botanicus pag. 22, tab. 156.

Laubb]itter bei versehiedener Cultur auch versehieden lang und breit. Bei guter Zucht sind die Laubblätter 2 " breit, 1' $10^{\prime \prime}$ lang, sehr schwach und klein, sägezähnig, ohne Stachelspitze, auf der Oberfläche lebhaft grasgrïn, am Grunde dunkelbraun bemalt. Untere Blattfäche dicht weiss lileig iiberzogen, mit schmalen griinen Querbinden geziert, am Grunde tiefrinnig, ganzrandig, wenig umfassend, am Rande der ganzen Lünge nach wellig. Die ersten Blätter der $2{ }^{\prime}$ hohen Ptlanze sind von verschiedener Breite und Länge ( $G^{\prime \prime}$ u. s. w. ; sie sind an den Rän- 
dern etwas eingerollt und, so wir alle Blätter dieser schönen l'flanze, nach allen Richtungen abstehend.

Schaft und Bliithenstand steil, grerade, oft eine sanlt gehogene Linie nach aufwärts beschreibend, sehr liriltig, rom Grunde aus 1' 10" Jang, ersterer 1/2" dick, lebhaft licht griu, mit wenigem weiss wolligem Anfluge. Bracteen lebhatt hellroth, weich, anliegend, nicht umfassend, mit latublattählicher, hell weisslich griiner; ftin sägezähniger; welliger, stumpf zugespitzter; bei $1^{\prime \prime}$ langer Spitze. I) Be Bracteen verlaufen am Schafte sichthar in ciner langen grerulen Narbe; gegen den Blithenstand zu nehmen dieselben an Länge zu und verlieren die Ianbblattartige Spitze gänzlich. Sie sind hier $t^{\prime \prime}$ lang, etwas schmutzig hellroth, mit sehr geringem Anfluge von weisser Wolle. Blüthenstand 6" hoch, 4" breit; lei den unteren Blïthe'n findet sich ein Bracteen-Rudiment am Stielchen. Knospen und geöfnete Bliiflen leurig; fleischroth, blau bemalt. Fruchtknoten " "lang: last stiellus, hellgrün mit stark mehligem Celserzuge. Kelchzipfel stumpt spitz; tief geschlitzt, " " "lang, lebhaft hellroth; nit weiss mehligem Anfluge. Lronenbläter gränzencl, 4".' breit, rom Grunde aus "ine etwas hathehige Röhre bildend. 1 " " lang, die Zipfel wenig zurückgebogen. Blüthe weit geöfnet.

Staubfüden dicht beisammenstehend, weiss, Staubbentel goldgelb. Griffel lebhaft blan, dic Stanbïiden iiberragend, - beide aber kürzer als die Kronenblätter. Die nach allen Richtungen strahlenförmig gestellten Bliithen bilden eine halb runde Bliithenmasse von prachtvollem Ansehen.

Ha utmerkmal dieser Species: Die anf der Kehrseite weissen, mit grïnen schmalen Querbinden gezierten Laubblätter; die lebhaft rothen Kelchzipfel; der grïne Schaft.

Billb. splendida Lemaire.

Jardin fleuriste II, tab. 180, 181.

Diese herrliche Species unterscheidet sich durch die Laubbläter schon vollkommen von den übrigen Species dieser Gattung.

Die Laubblätter steheu, rom Grunde aus anfstrebend, alle strahlenförmig ab und nehmen an Länge allmälig zu, so zwar, dass die untersten eine stark umfassende bauchige Schale mit kurzem, sclımalem Ende, die oberen hingegen, obwohl im Grunde gleich gefürbt, eine bei $2^{\prime}$ lange, $13 / 1$ " breite, tiefrinnige, scharf sägezähnige, stumpf endende Blattfläche bilden, welche, ron lebhaft griuer Farbe und mit einigen dunkleren Querbinden versehen, der Pflanze auch olne Bliithe zur Zierde gereichen.

Schaft und Blüthenstand sind vom Grunde aus steif aufrecht, und letzterer allein 6 " hoch und 5 " breit. Der hellgrüne, etwas weiss bereifte 
Schaft ist sehr weich und dicht mit njeht unfassenden, steif anfechten, weichen, gleichfarbig lebhaft rothc", tn ter Spitze bräunlich endenden, 4" langen, $1 / 2$ "breiten Bracteen besetzt, welche endlich den Bliithenstand, gleich hoch, im dichten, lebhal't rothen Kranze umgeben. Blïthenstand durch eine grosse Anzahl sehr dicht beisammenstehender Blïthen mu Knospen geziert, welche strahlenfïmig abstehend eine prachtyolle, last kugelrunde Gestalt bilden. Blïthe und Knospe lebhaft scharlachroth. Die Krouenblattziplel sind um seh wenig blau bemalt und etwas zurückgerollt.

Die Kuospen sind alle nach aussen gebogen, stumpf pfriemenförmig, an Ende blau bemalt. Fruchtknoten wenig sichtbar, hell gelbgrün. Kelchziptel stumpf, anliegend, auf weissem Grunde licht weinroth gepunktet, beide weiss filzig bekleidet. Diese Species jst unstreitig die schönste von allen bis jetzt bekannten Billbergien.

Hauptmerkmal dieser Species: Der scharlachrothe Blïthenstand mit den blauen Enden.

Die nur $1 / 2$ " breiten, steif aufrechten, gleich langen Hochblätler (Bracteen).

Die oben genannte Abbildung erreicht bei weitem die Schönheit dieser Pflanze nicht.

\section{Billb. punicea Beer.}

Rillb. fasciata splendens Hort.

Pflanze schlank aufrecht, jedes Laubblatt bis auf den Grund frei, die unteren kiirzer, die oberen bedentend lïnger, alle steif aufrecht, nur einge etwas überluängend. Blïthenstand von den Laubblättern weit überragt. Laubblätter am Grunde den dünnen Stanm ganz umfassend, bauchig, mit schmalem, braunem, unbewehrtem Rande, dann der ganzen Länge mit sehr feinen Sägezähnen bewaffnet, die Blattenden steif, braun, holzig, spitz. Aussenseite bis ïber die halbe Blattlänge mit gleichmässig 1\%" breiten weissen Querbinden geziert. Alle Laubblätter in Mitte gleich breit $\left(2^{\prime \prime}\right)$, die unteren $1^{\prime} 3^{\prime \prime}$, die oberen Laubblätter aber $2 \frac{1}{2}$ 'lang. Schaft steif' aufrecht, auf hell verwaschen weinrothem Grunde stark mehlig bestäubt, von den anliegenden Hochblättern fast ganz bedeckt, 6" dick. Hochblïiter lebhaft gleichmässig scharlachroth, mit dunkelblau rother langgedehnter Spitze, am Grunde verwaschen gelbroth. Frnchtknoten fast stiellos, gefurcht, dunkel rosa, stark, weiss mehlig bestäubt, $3^{\prime \prime}$ dick und 6" lang. Kelchzipfel am Grunde bauchig, tief geschlitzt, etwas eingebogen, stumpf, - verlängert spitz endend, 9"' lang, am Grunde zusammen verwachsen und lier gleichmässig 4"' dick, auf' hell scharlachrothem Grunde fein weiss dicht 
bestäubt. Kronenzipfel der ganzen Länge nach gleichmässig feurig scharlachroth, nur an den Zipfelrïndern - schwach lila verwaschen gefärbt, eine Röhre bildend, dann mit den Enden zurïckgebogen, vom Grunde aus 2 "lang und $4^{\prime \prime \prime}$ breit. Staubfäden rein weiss, $1 \frac{1}{2}$ " lang. Staubbentel aufrecht, fast $3^{\prime \prime \prime}$ lang, - hoch goldgelb. Griffel aufrecht, vom Grunde aus rein weiss, gegen die Narbe lebhaft lila bemalt. Narbe gedreht, tannenförmig, lebhaft dunkel lila gefürbt. Griffel und Narbe zusammen $13 / 4$ "lang. Knospe pfriemenförmig, etwas gegen aussen gebogen, an der stumpfen Spitze dunkel lila hemalt. Schaft sammt Blüthenstand 18 "lang, letzterer für sich $5 \frac{1}{2}$ " lang und nur 1" dick. Stamm dieser auffallenden Art 8" lang und 1" dick. Diese Gattung besitzt 23 Laubblätter.

Nachdem schon eine Billb. splendida rorhanden, have ich nöthig gefunden, den Garten-Namen „Billb. fasc. splendeus" einzuziehen.

Merkmal dieser Art: Der ganz gleichfarbig lebhaft scharlachrothe Blüthenstand und die ganz gleichfarbigen Hochblätter.

\section{Billb. Paxtonii Beer.}

Billuergia thyrsoidea, Martius. Paxton's Flower Garden III, t. 74. - Jardin fleuriste, t. 267.

Nachdem ich nicht herausfinden konnte, welche der zwei Abbildungen mit Namen Billbergia thyrsoidea jene ist, die Herr v. Martius in Brasilien fand und die sich in Römer und Schultes Seite 1260 unter "Billbergia thyrsoidea von Schultes fil." beschrieben findet, habe ich mich bewogen gefunden, jene Form, welche $\mathrm{Pax}$ ton abbilden liess, von Billb. thyrsoidea zu trennen, und nun zu benennen, indem diese Form nur allein in $\mathrm{Paxton} F$. G. zu finden ist.

Lanbblätter steif aufrecht, glatt, gleichfarbig, lebhaft grasgrün, nur auf der Aussenseite mit einigen wie angehauchten weisslichen schmalsu Querbinden geziert, am Rande ganz fein sägezähnig, an der Spitze in... 1" lang, entschieden übergebogen, 1' lang, 2\%" breit, am Rande ina wellig. Die Laubblätter stehen am sehr dümen Stamme sich ver chin. lernd beisammen und bilden daher eine Becherform.

Bliithenstand eine Kenle bildend, von prachtvoll leuchtender l:us:farbe. Der Schatt ist von den rollkommen regelmässig; dachziegelf insig aufrecht stehenden Bracteen ganz bedeckt, und diese bilden bei den Blüthen eine zackige Krone von ganz gleicher Höhe. Die Blüthen stehen alle aufrecht, gegen inmen gebogen, und bilden daher eine rein begränzte Keulengestalt. Kelchzipfel auf rosa Grunde, lebhaft hochroth bemalt und rein weiss eingefasst. Kronenblätter alle steif aufrecht, kaum geöfnet, lebhaft fleischfarbig; 1" lang; 3" dick. Die aufrechten 
gelben Staubbeutel stehen zwischen den fast geschlossenen Kronenblätteru vor. Knospe unterscheidet sich sehr wenig von der geöffneten Bliithe. Der Blüthenstand erseheint rund und dicht geschlossen, und hat bei 3" Höhe $21 / 2$ "Durchmesser.

Merkmal dieser Species: Der gleichfarbige, dicht keulenförmige Blïthenstand.

\section{Unterabtheilung: Cremobotrys.}

Billb. z e.brin a Lindl.

Loddiges Botanical Cabinet, tah. 1912. - Botanical Magazine, tab. 2686. - Sertum hotanicum van Geel.

Die Billbergia larinosa der Gärten unterscheidet sich von Billb. Zeuriua nur dadurch, lass bei ersterer die Laubblätter nichl mit weissen Querbinden geziert sind, allein auch dieses Merkmal ist nicht constant, indem hier sehr viel auf den Standort der Pflanzen ankommt. Ich habe bei jenen Pflanzen von B. Zebrina, welche in sehr schattigen feuchten Stellen des Hauses cultivirt wurden, die wichtige Bemerkung gemacht, dass die Lanbblätter hier an Länge (bis $4 \% 2^{\prime}$ lang) bedentend zunehmen, aber dass sich dam die (Lnerbinden ganz verlieren, daher die Blätter schön gleiclimässig dunlelgrïn wurden, wo jeh anderseits an B. farinosa die Bemerkung mathte, dass diese Ptlanze an hellen heissen standorten kïrzere, aber gebäuderte Blätter bildete. Diese Erseheimng ist dann sehr auffallend, indem die ersen Sprosseu solcher Pflanzen in der ganzen Erscheinung viel robuster, aber auch der Mutterphlanze durch die schün gebänderten Blätter ganz unähnlich werden. Das hier Bemerkte werle ich an seinem Orte zu erklären suchen.

Wir haben hier eine der ältesten Species vor uns, welche unseren Sammlungen zur grossen Zierle gereichen. Im Jahre 1816 erschien schon die erste Abbildung von Billb. Zebrina. Es wird wenige Pflanzenfreunde gęben, welche sie nicht schon in Blithe gesehen, und loch ist dieses herrliche Gewächs noch immer ein Liickenbüsser in den Pflanzensammlungen. Dass sich unter den vielen Formen dieser Species, wche wahrscheinlich schon ïfter frisch eingeführt wurden, mehrere Varietäten befinden, ist gewiss, allein die Unterschiede sind nicht erheblich. So zeigt die Abbildung in I.odd. Bot. C. mit jener im Bot. Mag. und ebenso die im Sertum Botanicum, jede eine nerklich verschiedene Pllanze, welche nicht durch eine urichtige Zeichnung entstanden sein dürften.

Die Laubblatter finden sich je nach dem standorte, ganz steif autrecht, oder sie hängen bei bedeutenderer Länge schlat ïber, aber immer 
bilden sie eine rein runde, vom Grunde aus gleich dicke Röhre von 2" Durchmesser, die Breite betrïgt '2 $1 / 2$ " und zwar der ganzen Länge nach gleichmässig. Die Ränder sind schwach sägezähnig, das Blattende zungenförmig ohne Stachelspitze. Das ganze Blatt bildet eine gleichmässige tiefe Rinne. Las röhrenförmige Zusammenstehen der Laubblätter variirt von 1 bis 2 Höhe. Die Farbe ist lebhaft dunkelgrün, mit meh* oder minder starker, gut begränzter weisser Querbänderung, diese besteht aus einer kleiigen Masse, welche sich von der Blüthe wegreiben lässt. Gewöhnlich finden sich diese Bänder nur am untern Theile der Pflanze und zwar meistens auf der Unterfläche der Laubblätter. Aus den röhrenförmig zusammenstehenden, sich gegenseitig anschliessenden Laubblättern, deren gewöhnlich nur 4 sich finden, erhebt sich der stark überhängende Blüthenschaft und wächst sehr schnell bis zu der Länge von $4 \frac{1}{2}$ ', er ist der ganzen Länge nach mit etwas flatterigen seidenartig weich und glänzenden prachtvoll hochroth gefürbten, bis $1 / 2$ ' langen und über 1" breiten Bracteen vom Grunde aus besetzt, und diese finden sich auch selbst an dem unverzweigten 1'langen Blüthenstande zwischen den Bliithen. Schaft, Fruchtknoten und Kelchzipfel rein weiss, sehr stark wollig bekleidet. Schaft 3“", ganz gleichmässig dick. Fruchtknoten etwas knotig, so lang als dick. Kelchzipfel anliegend, tief geschlitzt, 4*” lang. Blumenkronenblätter $2^{\prime \prime}$ lang, bis zu dem Kelchziptel schneckenlienig zurïckeingerollt. Staubfïlen weiss. Staubbeutel blau, Griffel kaum länger als die Stanlfäden, beide nahe beisammenstehend. Knospe hellgrün, glänzend pfriemenfürmig, 2" lang. Die stark ïberlıängende Traube trägt einzelne und etwas abstehende, zahlreiche, ganz freie Blüthen. Die Kronenblitter sind anfangs hellgriin, dann nach dem Zurückrollen, welches sehr schnell geschieht, lebhaft. gelbgrün.

\section{Billb. P o rte a n Brong:?}

Diese Pflanze führte Morel in Paris aus Brasilien ein. Obwohl sie gewiss nur eine Varietät der Billb. Zebrina ist, so mag ihr doch der Name bleiben, da sie in den Sammlungen schon stark verbreitet ist.

Sieben Laubblätter, alle sehr steif aufrecht, $3 \frac{1}{2}$ 'lang, bei 3 " breit, am Grunde nicht sägezähnig, dann aber scharf sägezähnig, mit weichè Spitze, ganz gleich breit, vom Grunde aus eine $2^{\prime \prime}$ dicke Röhre bildeul, dunkel schmutzig griin, mit schwacher weisslichter Bänderung aber nur auf der Aussenseite der Blïtter geziert. Der Schaft ist verhältnissmässig dünn $3^{\prime \prime \prime}$, vom Grunde aus $4 \frac{1}{2}$ ' lang, stark überhängend, mit lebhat fleischrothen, auf der inneren Seite lichteren, stark abstehenden, über 1/2' langen, an den Rändern eingerollten, weichen, wie Seide glänzenden, mit hell grüner Spitze versehenen Bracteen besetzt. 
Blüthenstand sehr loker. Schaft, Fruchtknoten und Kelchzipfel stark weiss wollig bekleidet, lełztere mit einigen schmutzig blauen Längsstreifen geziert. Kronenblätter hell gelb grün, iiber $2 \frac{1}{2}$ " Jang, dïtenförmig, sehneckenlinig bis zu den anliegenden Kelchzipfeln sehr stark zuriickgerollt. Staubfäden, $2 "$ lang, Pistil $23 \%$ " lang, erstere auf graulichtem Grunde blau bemalt, letzterer ganz blau, beide nahe zusammenstehend. Griffel von gleicher Länge mit den Blumenblättern.

Form des Blüthenstandes ganz wie bei Billl. Zebrina.

\section{Billb. violacea Beer.}

Brom. sp. Brasil., durch Appun gesammelt.

Ganze Pflauze sehr leicht grüngelb, sparsam mit weissen Querbinden geziert, durch die inneren steif aufrechten Laubblätter eine schlanke nur $1 \frac{1}{2}$ " weite, aber über 2 ' lange Röhre bildend, nur die Enden dieser Blätter hängen herab. Aeussere, also untere Laubblätter weit alstehend, schlaff überhängend. Alle gleich breit $\left(21^{\prime \prime}\right)$ und bei $4^{\prime}$ lang, mit zienlich entfernten scharfen Sägezïhnen besetzt. Laubenden stumpf spitz. Blüthenschaft entschieden überhängend, am Grunde glatt, dann reichlich sammt den Fruchtknoten und Kelchzipfel weiss mehlig bestäubt. Blïthenschaft sammt Blüthenstand 4' lang, erstere von Grund aus, mit eingerollten umhüllenden, dunkel violetten, etwas steilen, gänzlich unbewehrten, Hochblättern (Bracteenj) lresetzl. Diese ündern, je nüher sie den Blüthen stehen, ihre Farbe, werden endlich rein weiss und lebhaft dunkel weinroth geftirbt. Frnchtlsnoten eirund, gross, untörmlich hökerig, auf fast sehwarzgrünem Grunde, weiss melılig, der dunkle Grund liegt theilweise bloss. Knospe pfriemlich rund bei $2 \frac{1}{2} "$ lang sehr hellgelb. Geö̈lnete Blüthe, Kronenblätter schneckenlinig der ganzen Länge nach zurückgerollt, hochgelb. Genitalien weit vorgestreckt, an einander anliegend, Griffel vorragemd, sämmtlich an Grunde hell, schmntzig grün, am Ende bläulich.

Billb. in carnata Beer.

Brom, incarnata Ruiz et Payon. Flora Peruv. et Chil, tab, 255.

Es folgt hier die Beschreibung von $R$ uiz et $P$ avon:

Pflanze: Laubblätter sägezïhnig und stachelspitz, mit einfacher ii berhäng ender. Tranbe, die sehr grossen unteren Bracteen lanzettlich. Pllanze peremnirend und äusserst schön.

Stengel einzeln aufrecht, 2 ' lang, rund knotig, ganz einfach, unterhalb mit Blättern, oberhalb mit Bracteen besetzt. Laubblätter unten umfassend, ron der Mitte an sägezähnig, kleiig, die unteren Blätter läng. lich, stumpf spitz. 2' lang, die oberen Blätter länglich, schwertförmig, 
die Dornen (Zihue) schwarz-roth. Bracteen abwechselnd, gestreift, hocliroth. Bliithenstand endständig, 1'hoch, iiberhängend (flexuosus), weiss, wellig, vielbliithig. Blüthe spärlich (zerstreut) sitzend, überall mit lanzettförmigen ho chrothen Bracteen besetzt. Kelch oberständig, ble i bend. Kelchzipfel weisslich mit purpur bemalt, dreitheilig, lappig, lanzettförmig, spitz zulaufend, aufrecht, viermal kürzer als die Blumenblätter. Blumenblitter drei, lanzettförmig, spitz zulaufend, aufgerichtet, röthlich violett, im Verblïhen stark schneckenlinig zurïckgerollt. Stanh)fäden purpurfarbig. Staubbeutel gelb. Griffel purpurfarbig, länger als die Krone. Samen sehr viele, klein und braun.

Standort: An den Abhängen der Anden, unter Bäumen bei Pozuzn.

Bliathezeit: September, October. Ruiz et Pavon.

Es ist beachtenswerth, die $\Lambda$ bbildung dieser Pflanze mit der trefflichen Beschreihung zusammenzuhalten, nm sich zu ïberzeugen. wie eelbst in Werken mit sehr guten Zeichnungen gänzlich verhildete Dar. stellungen sich finden.

\section{Billb. vittata Morel?}

Paxton, Flower Garden IIL, tab. 77. - Jardin fleuriste 111, tab. 271.

Die steif aufrecht stehenden Laubblätter eine $2 \frac{1}{2}$ " dicke Röhre bildend, in der Höhe von $1 \% 2$, damn ein inneres Laubblatt alle Blätter iiber'ragend, $3^{\prime}$ lang. Alle Lanbblitter zungenförmig, zuriickgeschlagen endigend, von Grund anf fest anliegend, dann mit einemmale wagrecht. abstehend: Sägezähne schwarz, sehr schart, glatt, wie aus Blech ge schnitten. Laubblätter last glejchnässig, 3" breit, mit verschieden breiten, ganz scharf begränzten weissen Querbinden, inuen und aussen reichlich geziert. Der junge Spross dieser Pflanze hat hingegen eine bedeutend andere Gestalt. - Laubblïtter fast schlaff ïberhängend, 3' lang, 11/4" breit, eine gleichförmige Rinne bildend. - bis auf den Grund rrei, endlich ist das jüngste Blatt steif aufrecht, im jungen Zustande schon äber "2" breit. (Erst nachdem die Pflanze die blühbare Stärke erreicht hat, bilden sich die Laubblätter nach obiger Beschreibung.) Blüthenstand prächtig, sammt dem Schafte stark ïberhüngend. Bracteen flattrig hängend, weich und glänzend wie Seide, lebhaft licht tleischroth, $1 / 2$ 'lang. Schaft und Stielchen licht schmutzig gelb-griin. Fruchtknoten und Kelchziptel, welche etwas ahstehend und sehr tief geschlitzt sind, eigenthümlich röthlich nanquintarbig. Kronenblätter $1 \frac{1}{2}$ "lang, ein fich, gegen inuen eingerollt, an Grunde röhrenförmig, hier licht strohgelb, dann in blutroth und endlich an den Zipfeln in dunkelblau tibergehend.

Staubfäden an Grunde hell rosa, dann hellgelb. Staubbeutel tief 
orangefarben: Griffel diese uberragend, Narbe liellblau, beide so lang als die Kronenblätter. Genitalien sehr nahe beisammenstehend.

Die Uebergänge der hier so sehr verschiedenen Farben sind nicht zu heschreiben; es bleibt daher nur iibrig, die Farben zu nennen.

Der Blithenstand ist sehr kräftig, bei 1'lang. Die Blïthen slehen in fast stiellosen Büscheln zu zweien oder dreien beisammen und bilden eine reiche Traube von prachtrollem Ansehen.

Billb. a mabilis Beer.

Billbcrgia Moreliana, Hort. Jardin fleuriste II, tab. 148, - Gardener's Magazine of Botany III, tab. 33 .

Aus einer Species „Morel Brasil." ist "Billh. Moreliana" entstauden. Im Ganzen ist diese Species der Billb. vitata sehr ähnlich, allein in allen Theilen kleiner u. s. w.

Laubblätter 20"lang, 2 " breit, mit schwarzen platten Sägezähnen besetzt, - ganz steif anfrecht, wie von Blech. Die Sägezähne beginnen erst bei der oberen Hälfte der Blattlänge; sie enden breit zungenförmig, mit zurickgebogener weicher Spitze. Durch das nahe Zusammenstehen der Blätter bildet sich eine vollkommen rumde Röhre. Die Blätter sind imnen und anssen schmutzig dunkelgriin, mit röthlichem Anfluge, und sind mit starken, weissen, verschieden breiten Querbinden geziert. Bliitheuschaft stark ïberhängend, sammt Stielchen, Bracteen und Kelchzipfel lebhaft fleischroth. Fruchtknoten röthlich aschfarbig. Die Kelchhiitter $3 /, "$ lang, die $\mathrm{Zipfel}$ wenig gegen aussen gebogen, hier lebhatt dunkelblau. Kronenblätter 1" lang, stumpf spitz endend, zwetschkenblau, eingerollt, am Grunde eine Röhre bildend, rou hell gelh in dunkel blutroth iibergehend, dam blau. Die orangegelben, nahe beisammenstehenden Staubbeutel und das blaue, letztere etwas ïberragende Pistil ragen beide weit aus der Blïthenröhre vor.

Diese zierliche Planze ist blühend sehr leicht von Billb. vittata zu unterscheiden, indem nicht allein die Farben, welche den Bliithenstand zieren, sehr verschieden sind, sondern hier auch der junge Spross genau so aussieht, wie die ausgevildete Pflanze. Auch hier, wie bei B. vittata, stehen wohl die Bliithen in Büscheln zu zwei bis dreien beisammen, aher die Kelchzipfel, welche bis zum Fruchtknoten geschlitzt sind, wie nicht minder die gekrausten Enden derselben, bilden aufallende Unterscheidungs - Merkmale von B. vittata.

\section{Billb. Wetherelli i Hook.}

Botanical Magazine, tab.4835. - Billb. dubia, van Houtte.

Laubblätter saftig grün, mit theilweise hellgelben Rändern, wenig bewehrt, innen und aussen lebhaft grasgrün, glänzend. Blattenden un- 
bewehrt. Durch das dichte Anlipgen der Laubblatter unter sich rom Frunde aus eine geven die Mitte etwas hauchige Röhre bildend, welche an 6" laug und am oberen Ende $1 \frac{1}{2}$ " breit, hier eine rein runde Oeffnung zeigt, ats welcher der $3^{\prime \prime}$ dicke, thischige. weiss filzige Bluthenschaft überhängend sich entwickelt. Hochblïter (Bracteen glatt, schlaff herabhängend, mit etwas anfwärts gebogener Splitze, zart rosa ron innen, von aussen feuriger roth. Kelchziplel weiss filzig der Jäng̨ nach rosa hemalt. Kronenblatter an fimude golblich, die Ziffel leblaft blau. Befruchtungs-Organe kiirzer als die Kronenblatter, Joch gell von Farbe. Die Bracteen sind auch zwischen den Blithen vertheilt.

Die Abbildung, welche sich von dieser sehr zierlichen Pflanze in oben genanntem Bot. Mag. findet, ist um mehrere Tage zu frib gemacht worden, indem, nach Exemplaren zu urtheilen. welche bei mir bluhten, der Blithenstand bei gänlicher Entwicklung eine verkehet pyramidale Form hat, die Blithen aber alle wagercht abstehen. Natürlich ist dann der ganze Bliithenstand $n$ mindestens 3 " länger und bei weitem schöner.

Jede Blüthe, die Stielchen und der merkiviirdig verkümmernde Ansatz zu Seiten - Zweigen als kleine, 1“" lange Zäpfchen - vollkommen sichtbas.

\section{Billb. Glymiana Hort. Berol.}

Diese zierliche Pflanze hat hinsichtlich der Blitter Aehnlylukeit mit Billbergia thyrsoidea Mart. - Laubbläter lebhaft grüu, glänzend, aufrecht, zmngenförnig, entfernt sägezähnig, mit weicher Stachelspitze, am Grunde umfassend, 10 bis 18 " lang, bei "- breit, auf der Unterfläche mit parallelen weisslichen Linien gezicrt. Blïthenschaft lein weiss bestäubt, zierlich ibbrhängend, lebhaft hell rusenfarbig: auf weissem Grunde reichlich bemalt. Hochblätter in eine lange weiche Spitze endigend, am Grunde wenig 1 mfassend, bei 3 " lang, 1" breit, hell rosenfarbig mit griin an den Rindern bemalt. Bliithen nicht sehr zahlreich. Fruchtknoten kaum gestielt, etwas knutig; - hellgelh. Kelchzipfel hei 1" lang, gelblich weinroth. Kronenblätter am Grunde hochgelb, Zipfel derselben dunkelblau. Genitalien kürzer als dit $1^{1}$, " langen Kronenblätter.

Diese sehr zarte. liebliche Pflanze hat hinsichtlich des Bliithenstandes einige Aehnlichkeit mit Billbergia Wetherelii Hook., ist jedoch in allen Theilen feiner geformt.

Merkmal der Species: Die grünlich berandeten, rosafarbenen Hochblätter: 


\section{Billb. Moreliana Hort. (Paris).}

Ich habe diese herrliche Pflanze von $H$. Mnrel in Paris selhst gekanft und bin daher gewiss, die echte Species vor mir zu haben.

Blüthenstand sammt Schaft stark überhängend; ersterer verkehrt pyramidal, über 1' lang, prachtvoll! Deckblätter lebhaft rosenfarhig, gegen anfwärts abstehend, flattrig, oft einfach eingerollt. Fruchtknoten kaum $1 / 4$ " lang, rein weiss. Kelchzipfel 1/4" lang, am Grunde lebhaft fleischrotlı, die Enden der stumpfen Zipfel rein weiss. Bliithenblätter $2^{\prime \prime}$ vorstehend, abwärts gebogen, röhrig zusammenstehend, an Grunde hell goldgelb, mit violettem Saume; so weit die Zipfel sich öffnen, hell blau lila; der untere Zipfel lippenartig herabgeneigt, die zwei oberen helmartig aufgerichtet. Grifel schmutzig blau, Staubblätter goldgelb, beide kürzer als die Kronenblätter. Knospe pfriemenförmig, etwas übergebngen, stumpf spitz, dunkel purpurblau. Schaft rein weiss. Dieser, wie auch die Fruchtknoten und Kelchzipfel dicht mit rein weissem Flaume bedeckt. Von den sehr zahlreichen Blüthen trägt jede ein langes Deckblatt, erstere gegen aufwärts gerichtet. Pflanze den Blättern nach wie B. Wetherelii, jedoch diese um $4^{\prime \prime}$ länger.

Billb. iridifolia Nees et Martius.

Bot. Register, tab. 1069. - Sertum botanicum, van Geel.

Ptlanze dunkelgrün. Laubblätter weich, mit tiefer Mittelrinne, am Rande stark wellig und mit weit von einander stehenden Sägezähnen besetzt, auf der Unterfläche mit weiss kleigem Ueherzuge, am Ende spitz zulaufend, ganz unhewehrt, iiber $1 \frac{1}{2}{ }^{\prime}$ lang, in Mitte 1 “ breit, an Grunde stark umfassend, sechs an der Zahl. Schaft iiberhängend, mit Bracteen besetzt. Bliithenstand $1 / 2$ ' lang. Bliithen einzeln, wagerecht abstehend, jede Bluithe mit einer Bractee geziert. Alle Bracteen lebhaft blutroth, weich seidenartig glänzend, abstehend. Blïthen sparrig. Fruchtknoten und Kelchzipfel orangegelb, letztere lebhaft dunkelblau bemalt. Kronenblätter etwas zurïckgeschlagen, hier lebhaft dunkelblan, gegen unten in goldgelb übergehend. Staubfäden und Griffel hellgriin. Staubueutel goldgelb, beide so lang als die Kronenblätter.

Diese schönn Pflanze ist schon langre in den Sammlungen hekannt, und man findet selbe mit dem Species- Namen Billh. iriditlora und iridifolia, welche beide gleich wenig bezeiclınend für diese Pflanze sind.

\section{Billb. viridiflora $\mathrm{H}$. Wendland.}

Flore ran Houtte, tab. 1019, 1020.

Wir haben hier ene eigenthïmliche Form ror uns, welche der Kronenblattform nach an Pitcairnia erinnert. Aber nicht diese allein sind 
es, welche Unterschiede bieten, die bei anderen Arten von Billbergia, die mir bekannt sind, nicht vorkommer. Bei oljger Form sind die Kelchzipfel sehr lang geschlitzt, lebhaft hellgriun, spitz, - die Fruchtknoten aber schmutzig braun und glatt. Die Kronenblätter 21/2" lang, lanzettlich spitz endend, rachenförmig, lebhaft grün. Griffel so lang wie die Kronenblätter, hellgriin. Staubbentel sammt Fäden um vieles kürzer als der Griffel, erstere goldgelb. Hochblätter am stark hängenden Schafte, fein sägezähnig, aufrecht, bei :?" lang, blutroth. Schaft sammt Bliithenstand 3 ' lang, ersterer schmutzig purpurfarbig, diinn. Dic Blüthen haben $2 \frac{1}{2} "$ lange Stielchen.

Diese Pflanze dïrfte jedoch im lebenden Zustande mit der Zeichnnng der Flore nicht ganz ïbereinstimmen, indem selbst hier sich mehrere verschieden gestaltete Fruchtknoten gezeichnet finden, von welchen sich nicht klar herausstellt, welehe die eigentlich richtige Form ist.

Billb. pallida Beer.

Bromelia pallida. Reichenbach, Magazin der Aest. Botanik, tab. 94.

Lanbhitter am Grunde einen bauchigen Bogen bildend, welcher niber $1 \%$ " breit, bei 2 " Höhe sich schnell bis anf $1 / 2$ " breit verschmälert, danu gegen die Mitte der Länge des Laubblattes wieder 1" breit wird und endlich hei seiner ganz'n Länge von 1'stumpl'spitz endet; an den Seitenrändern befinden sich sparsame Sägezähne. Alle Lanblbläter stehen rom Grunde aus al. Der Schaft erscheint aufrecht; schwach herabgebogen; ist, so wie die /weige an Bliithenstande, schön purpurfarlig. Alle Bracteen lebhaft blutroth, fist wagerecht abstehend. Der hellgriine Fruchtknoten hat mehrere tiefe Längsfurchen. Die Kelchzipfel sind etwas hauchig, tiel geschlitzt, 1 "lang, fast durchsichtig, hellgelb, mit lebhalt hlaner Bemalung an den Zipfeln. Ire Kronenblätter ganz ähnlich gefärbt, beide gleich lang. Bei jocler einzelnen Blïthe befindet sich eine ganz kleine herzförmige, leblatt hochrothe Bractee; diese allein unterscheidet schon Billb. pallida von Billb. amoena. Reichen bach hat diese wichtigen kleinen Bracten auch am oberen Theile des Blithenstandes gezeichnet, $\$$ o Jingegen hei den anderen Bliithen an den Zweigen nichts zu sehen ist; aber an lebenden Pflanzen wird man sie stetş beobachten können.

Billb. dis color beer.

Pitcairnia discolor? Herbier General des Amateurs, V, tab, 345.

Laubbliitter unregelmässig zusammenstehend, lebhaft grïn, auf der Kehrseite streifig. Blüthenstand iiberhingend, 11/2"lang. Schaft und Stielchen selbst zwischen deu unteren Bracteen stark sichtbar. Bracteen 
am Schafte und hei jeder Verzweigung am Bliithenstande, - lebhaft roth, seidenartig weich. Jede einzelne Bliithe trägt eine grime kleine Bractee. Fruchtknoten und Kelchzipfel hellgriun mit purpurnem Anfluge, letztere, wie anch die gelben Kronenblatter lehatt dunkelblan, breit bemalt. Kronenbläter ausgebreitet, sehr wenig zurïckgebogen. Genitalien weit vorragend. Staubblätter goldgell. Grifłel griin.

Diese Speeies gleicht woll der Billb. amoena, allein sie ist durch Grösse und die grüien Bracteen lei den Bliithen, wie auch in der Färbung sehr gut unterschieden.

\section{Billb. a mo en a Lindl.}

Jacquin, Privat-Bibliothek Sr. MI. des Kaisers, - Tillandsia amoena Loddiges, Bot. Cabinet tab. 76. - Pourretia magnis patha Acad. Re di Torini, tom 3!, tab. 19.

Pflanze: mit glatten, glänzenden Blättern.

Laubblätter verschieden lang, kelchbildend zusammenstehemi, die unteren etwas iibergebogen, kurz; die oberen anfrecht, 10" lang; mittlere Breite 1/2". Am Grunde bauchig; stirle umfasseud, hier nicht sägezähnig, daun gleichförmig sägezühnig, stumpf spitz e'ndend. Schaft aufrecht, auch ïberhängend, grïn, mit rothen, aufrechten, anliegenden, umfassenlen, schön rothen Scheiden sparsam hekleiclet. Blüthenstaur wenig blumig. Blïthen einzeln stehend, aufrecht. Fruchtknoten schmutzig, sehr hellgriiu, tief" grerieft, $1 / 2 "$ lang und $2^{\prime \prime}$ dick. Kelchipfiel bauchig, tief geschlitzt, 3“" dick, $1^{\prime \prime}$ lang. Kronenblätter am Grunde eine tiefe Röhre billend, dann zurïckgeschlagen, nicht eingerollt, stumpt spitz, beide hell gellogriin und an den Enden lebhaft dunkelblan liemalt. Genitalien etwas länger als die Kronenblätter; gerade, dicht beisunmenstehend. Staubfälen licht grïn. Staublentel länglich, lebhaft orangenfarbig; Griffel etwas länger. Narbe dreitheilig, hellgriin.

\section{Billb. variegata Beer.}

Tillandsia variegata. Arrab, Flora Fluminensis tab. 132.

Schon mehrere Male darauf hingewiesen, dass das oben genannte, so kostbare Werk ohne Beschreibung und nicht ganz zuverlässiger Zeichnungen sei, crlaube ich mir nur zu bemerken, dass diese Species gewiss einen überhängenden Bliithenstand haben diirfte, inclem schon der diunne Schaft darauf hinweist. Weiter ist ïber diese schione P'llanze nichts bekannt.

Billb. marmorata Lemaire.

L'lllustration Horticule, tab. 48.

Diese kräftige schöne Species hat einige Aehulichkeit mit der eben erwähnten Till. variegata Arrab. 
Lanhblatter verschieden lang, alle aufrecht. abstehend. eine gleichmassig tiefe Rinne hildend, am Ende fast zweilappig, mit stumpf spitzem Ende, vollkommen grleichmässig sägezähnig und besouders die inneren, längsten Laubblitter sehr zierlich auf grïnem Grumde braun gefleckt. Diese Fleckehen reihen sich gleich Querbinden an einander, stehen sehr dicht beisammen, und gereichen diese Syecies zur besonderen Zierde. Die Oberfläche der Blätter ist lebhaft grasgrün, ihre Länge variirt von 2 bis $2 \frac{1}{2}$. Bliithenschaft, Bracteen, sowie die Zweige am Bliithenstande sind lebhaft hellroth, mit tief blutroth, reichlich bemalt. Der stark verzweigte Blithenstand ist iiber 1' hoch und '“ breit ron pramidaler Gestalt, jeden Zweig begleitet eine abstehende. hauchige, stumpf spitz endende, umfassende Bractee. Nur die Endblüthen der Zweige, sowie atch jene der Hauptache tragen eine kurze rothe Bractee, welche wahrscheinlich aut eine Verkïmmerung der Endknospen schliessen lässt. Die Fruchtknoten sind eiförmig. glïnzent. grün. Dic Kelchlappen anliegend, fleischig, hell violett, ersterer ' " lang. f"u dick, letzterer 4"“ lang. Kronenbliitter steif anfrecht, rund endend, sehr wenig geöfinet, fast 1" lang, 3“" Durchmesser, am Grunde hell b]äulich, dann in lebhalt dunkelblau übergehend, Knospe hell violett.

Billb. Libonian a de Jonghe?

Jardin Fleuriste II, tab. 2, - Flore, van Houttc. tab. 1018.

Diese Pflanze hat sehr eigenthïmliche Merkmale, welche sich unter den vielen Billhergien un bei dieser finden. Hierher gehören vor Allem, die sehr kleinen farblosen bractecn. Doch in der Gesammtform ist sellue als eine gute Species von Billbergia, unverkennuar.

Pflanze klein, der Form nach, der Billb. iridifolia selı älınlich. Blïthenschaft etwas überhängend, dünn, glatt, stielrund, grïn. Bracteen schmal schmutzig lederbraun. Bliithen sparrig, abstehend. Fruchtknoten und Kelchzipfel 1": "lang, ' " "breit, lebhaft zimoberroth. Kronenblatter röhrentörmig, am Grunde weisslicht, gegen die Zipfelenden lebhaft dunkel, Zwetschkenblau, die Kronenzipfel etwas zurickgeschlagen. Befruchtungsorgane kürzer als dic Blumenblätter. Laubblätter röhrenförmig, am Grunde zusammenstehend, dann abstehend, aufrecht, mil schlaffen Enden, lebhaft grasgrüı, Aussentläche etwas lichter blïulich grün. An den Rändern wenig; aber scharf bewehrt. Sprosse sehr zahlreich, anfünglich wagrecht, lann kniefömig steif aufgerichtet.

Billb. py ramidata Beer.

Bromelia pyramidata etc. Plumierii Plant. Americae, tab. 62.

Wenn man die vielen Abbildungen dieses älteren Werkes genau studirt, so findet man, dass die Pflanzen mit einer grossen Gewandtheit 
und Naturtreue wiedergegelıen sind. I)iess veranlasste mich, anf die mell. reren Bromeliaceen, welche das Werk cnthält, besonders achtsam zu sein, da hier einige Formen vorkommen, welche sich sonst nirgends, weder beschrieben, noch abgebildet wieder finden, wie z. B. tab. LXIII und LXIV. Vergleicht man dagegen die Flora Flumiensis unserer Zeit, mit den manierirten, zum Theile fömlich unkenntichen Abbildungen, so muss man die höchste Achtung vor jener Epoche bekommen, in welche die Herausgabe des Werkes von Plumier fällt.

Pflanze sehr kräftig; mit steifen, am Grunde stark umfassenden hier eine Rinne bildenden, dann allmälich flach werdenden, mit einer schmalen Lappe spitz endenden, tief sägezähnigen, 1\%' langen, $1 \frac{1}{2}$ “ breiten Laubblättern, wie bei Ananassa sativa. Schaft und Blüthenstand steif aufrecht? 1\%' hoch, ersterer mit weichen, etwas flatterigen, aulrechten, wenig umfassenden, $1 \frac{1}{2}$ " langen, sparsan besetzten, letzterer fïr sich 4" hoch, mit unregelmässigr zusammenstehenden, sparrigen, aufrechten, sitzenden Blüthen besetzt. Fruchtknoten und spitze, schmale Kelchzipfel über $1^{\prime \prime}$ lang, ersterer $5^{\prime \prime \prime}$ dick, eiförnig. Kromenblätter aufrecht, 1" lang, zungenförnig. Genitaljen in gleicher Höhe mit den Kronenblättern.

\section{Billb. decor a Poeppig el Endl.}

Ioeppig et Endlicher. Nova genera plautarum, tab. 157

Obwohl der Blithenstand dieser sehr schönen Pflanze steif, aufrecht gezeichnet ist, anch in der Beschreibung durch Poeppig und Endlicher im Eingange aut einen einfachen, aufrechten Blüthenstand hingewiesen, darn aber ferner gesagt wird, ,schatt aus dem Grunde der Blätter anfstrebend, einfach, einzeln, am Grunde wenig gebogen - sch wach, sehlaff u. s. w." - bin ich doch iiberzeugt, dass dem ganzen Baue des Blïthenstaudes und der Kronenziyfel nach, der Blithenstand dieser Pflanze entschieden überhängend ist.

Laubblätter sägezähnig und stachelspitz, spitz zulaufend, gleichfärbig, an Grunde scheidig umfassend, bei 3' lang und 3" breit. Schaft überhängend kahl, griin, mit Purpurpüulstclien besetzt. Unterhalb von abwechselnd stehenden Bracteen (Hochblättern) eingeschlossen, welche gegen die Blithen wenig von einander absteheur, blassroth, kah], etwas bestäubt, 4-5" lang, $12-15$ " breit, flatterig, weich gauzrandig sind. Blüthen locker stehend, 3"lang, durch kurze anliegende Bracteen gestützt. Kronenzipfel nach dem Eröffnen schueckenlinig zuriickgerollt, hell gelb, ins grime spielend. Fruchtknoten furchig, Kelchzipfel fast fleischig, beide weiss mehlig bestäubt. Genitalien aus der Blüthe weit vorragend, nach dem Aufblïben spiralig gedreht. 
Diese sehr schöne Pflanze diirfte wahrscheinlich eine Varietät der Billbergia rosea sein.

Es folgt hier die Beschreibung von Poeppig et Endlicher:

Blätter sägezïhnig und stachelspitz, spitz, flach, gleichfarbig, die Bracteen der einfachen und aufrechten Traube sehr gross, lanzettlich; die Zipfel der äusseren Blüthenhülle gleich und spitz, die der inneren an der Basis mit doppeltem Kamme versehen.

Wächst als Parasit auf Büumen in den Provinzen Yuyurimagna und Mayıia. Blüthezeit im Mai.

Die Pflanze schön, doch selten zu finden. Stamm sehr kurz, kriechend, hie und da Blätterbüschel und blühende Schafte tragend. Die Blätter wechselseitig, an Grunde scheidig, aufrecht, an der Spitze schlaff, flach, zungenfürmig, in der Mitte ein wenig verbreitert, spitz, sägezähnig, die Zähne vorwärts schanend, gebogen, lederartig, flach, stechend, etwas verdickt, l'“ lang, nervig gestreift, unterhalb schilderig und nicht verschiedenfarbig, 3' lang und 3" breit. Schaft aus dem Winkel der Blätter aufstrebend, einfach, einzeln, am Grunde wenig gebogen, rund, kah], grün, mit purpurnen Pünktehen besetzt, schwach, schlaff, unterhalb von alwwechselnd stehenden Bracteen eingeschlossen, die angedrückt, zusammengerolli, scheidig, in der Mitte bauchig, zugespitzt, nervig gestreift, blassroth oder weisslich und 3 bis $4^{\prime \prime}$ lang sind. Die oberen Bracteen, welche die Traube stiitzen - acht bis zehn an der Zahl stehen von einander wenig ab, sind list stengelumfisseml, alsstehend oder wagerecht an der sipitze selılati, lanzettlich, zugespiszt, nervig gestreift, kahl, die jüngeren unterhalb bestänbt, alle rosenfarbig purpur, sehr schön, 4 bis 5 "lang, 12 bis $15^{\prime \prime}$ breit, zart häntig und schlafi. Die Traube, oder vielmehr die Aehre endständig, einfach, fünfzehn- bis zwanzigblüthig, beilüufig $1 / 2$ ' lang, so wie die äusseren Blüthenhülleu mit einem weissen, kleiigen Staube dicht bestreut. Die Blüthen abwechselnd oder anch zerstreut, fast 3 " lang, abstehend, jede einzelue durch anliegende Bracteen gestiitzt, lünglich, sehr stumpf, kahnfürmig, um die Hälfte kürzer als der Eierstock. Bluithenhülle oberständig, die äussere cylindrisch aufrecht, dreitheilig, mit gleichen Zipfeln, die länglich lanzettlich, spitz, $6^{\prime \prime}$ lang, $2 \frac{1}{2} "$ " breit sind. Die Zipfel der inneren Bliithenhülle viermal liinger als die äusseren, mit diesen abwechselnd stehend, lanzettlich lineal, etwas zugespitzt, ober der breiten Basis verschmälert, schlafi abstehend und weitschweifig, bald nach dem Aufblühen spiralig znsammengerollt, dann gelb ins Grïne spielend, an der Basis mit zwei Schuppen versehen, die einen gewimperten Kamm tragen, lineal und sehr kleiu sind. Staubgefässe sechs, länger als die innere 
Bliithenhülle. Staubfäden fadenförmig, ganz an der Basis spiralig zusammengerollt, sonst frei, dem Grunde der inneren Zipfel angewachsen. Die Staubbentel in der Mitte angewachsen, aufrecht, lineal, beiderseits stumpf, zweifücherig, aufwärts aufspringend, nach dem Aufblïlien oft. spiralig gedreht. Eierstock glockenförmig, ausserhalb von zahlreichen Furchen regelmässig durchzogen, an der Spitze flach, dicht bestäubt, innerhalb dreifächerig und viellinig; die Eichen kugelförmig, von zarten, zweitheiligen Samenträgern, an einem Faden bängend. Der Grifiel einfach, anfrecht, fadenförmig, dreifurchig, länger als die Bhäthenhiille. Narben drei, spiralig eingedreht, lineal, begränzt durch zweizeilige Reihen von fleischigen Wimpern. Die Frucht ist nicht bekannt,

\section{Billb. purpurea Beer.}

Bromelia pyramidata purpurea etc. Plumierii, Plant. Americanorum, tab. 63.

Diese ausgezeichnete Form ist mir auch nicht annäherungsweise, weder in Herbarien noch in der Literatur vorgekommen. Jedenfalls wird dieselbe, wemn einmal lebend in den Sammlungen, ein wahrscheinlich fest begränztes Genus bilden. Einstweilen mag sie bei Billbergia, in deren Nähe sie jerlenfalls gehört, ihren Platz finden.

Pflanze ohne Blüthenstand 8" hoch, durch zahlreiche, verschieden lange $\left(1 \frac{1}{2}\right.$ bis $\left.9^{\prime \prime}\right)$, anfrechte, anliegenle Lanbbläter tulpenförmig gebildet. Die untersten Blätter sind kurz, wenig umfussend, allmälig spitzendend, gleichmässig scharf sägezïhnig, in Mitte 1/2", am Grunde 1 1/2 "breit. Die inneren Lanbblätter stehen in fast gleicher Höhe steif aufrecht und enden in einer $3 / 4$ " langen, ungezahnten, schmalen Spitze; diese Blätter sind in Mitte über $1^{\prime \prime}$ breit, am Grunde aber wahrscheinlich $1 \frac{1}{2}$ bis $2^{\prime \prime}$ breit. Aus diesen kelchartig dicht zusammenstehenden Blättern erhebt sich der 7"“ dicke (sammt dem über $1^{\prime}$ hohen Blüthenstande), $2 \%^{\prime}$ hohe Schaft. Dieser trägt drei bis vier Bracteen, welche $1^{\prime}$ r" lang und nur 1" breit, sich am Schafte 4" hoch anschliessen, dann aber gleich einem allmälig stumpf spitz endenden, wenig welligen, ganzrandigen, weichen Bande herabhängen. Der Blüthenstand ist der ganzen Länge nach mit bei 2 "langen, 4 " breiten, aufrechten, sich deckenden, ganzrandigen, weichen, stumpf spitzen Bracteen dicht umstellt. Dieses macht, dass derselbe ziemlich gleichmässig 1\%" dick (mit Anschluss der Blüthen) erscheint und dem Bliithenstande von Pitcairnia bracteata einigermassen änlich ist. Die Kronenblätter sind ïber $1^{\prime \prime}$ lang, $4^{\prime \prime \prime}$ breit, steif aufrecht, die Genitalien stehen weit vor.

Wahrscheinlich hat der Autor diese herrliche Pflane nach der Färbung der Bracteen "purpurea" benannt. 
Billb. te trantha Beer.

Tillandsia tetrantha. Ruiz et Pavon. Flora Peruv, et Chil, tab, 265.

Es folgt hier die Beschreibung von $R u i z$ et Paron:

Pflanze aufrecht; Blüthenstiele vierblüthig, zurückgebogen.

Schaft einfach, wenig länger als die Blatter, mit vielen Scheiden belileidet, rund und hin und her gebogen. Die Wurzelblätter unterhalb (tlexuosus), unter sich wechselseitig in einer Schlanchform zusammenstehend, von der Mitte bis zur Spitze auseinandergehend, abstehend, lanzett schwertförmig, breit, mit zurückgebogenen Spitzen und mit purpurrothen Punkten bezeichnet. Die Blithenseheiden wechselständig, fast dachziegelförmig gestellt, lanzett eiförmig, spitz, rosenroth mit hochroth bemalt die unteren aufrecht, concav, mit zurückgerollter Spitze. Die Blumenblüthenscheiden abwärts gebogen, fast kahnförmig, ein einziger Blüthenstiel, aus der Achse einer einzelnen Scheide hervorgehend, vierblüthig. Die Blüthen fast sitzend, in Reihenfolge aufblühend. Kelch gelb, trockenhäutig, dreitheilig; die Zipfel länglich, unter sich un sich gedreht, unterständig, bleibend. Blumenblätter drei, violett, unterhalb zusammengedreht, oberhalb abstehend, länglich keulenformig, spitz, verwelkend, nur einen Tag blïhend. Sechs Staubfäden, dem Fruchtboden eingefïgt, kïrzer als die Blumenblitter und ziemlich flach. Stanbbentel anfliegend, gelb. Pistil kurz, dreifurchig. Narben drei. Kapsel dreiseitig dreifurchig, pyramidenförınig, dreifücherig.

Standort: Anden, auf Bäumen und Felsen bei Muna.

Bliithezeit: Juli, August.

Wenn es regnet, wird die Kelchform, welche die Blatter bilden, mit Wasser erfüllt, welches durch mehrere Tage bleibt und dann verdunstet.

Billb. saxatilis Beer.

Tillandsia saxatilis Arrab. Flora Fluminensis, tab. 139.

Von dieser schönen Pflanze weiss man nur dureh die Special-Benennung, dass sie auf Steinen wäehst. Wahrseheinlich sind die Laubblitter tigerfellartig, roth gefleckt, was dieser Pllanze zur grössten Zierde gereichen muss. Dem Wuchse nach gleicht sie Lamprococcus fulgens. Der dünne Schaft erhebt sich, reichlich mit aufrechten, lanzettfürnigen Bracteen ivesetzt. Der Blüthenstand ist kaum $2^{\prime \prime}$ hoch, die Bliithen sehr klein, aufrecht. Kelchzipfel und Fruchtknoten fast rund, diese zwei Theile zusammen etwa nur über. $1 / 2$ "lang.

Leider ist gar nichts Bestimmtes ïber diese herrliche Pflanze zu sagen, deren Einführung ein wahrer Schatz für unsere Pflanzensamm. lungen wäre. 
Billb.? Beer.

Caragnata variae species etc. (Caragnata, Yunca) Marggrawti, Plantae Brasilianae III, t. 37

Diese Abbildung habe ich hier zugezogen, um wo möglich alle Abbildungen, welche sich in den botanischen Werken finden, in Betrachtung zu ziehen und einzureihen. Ich glaube nicht zu irren, wem jch annehme, dass die hier gezeichnete Pđanze einen überhängenden Blitheustand hat. Bei Puiz und Paron, bei Endlicher und Poe $\mu^{-}$ pig kommen aufiallende Beispiele dieser Art vor; welche am gelıürigen Platze sich besprochen finden. Diese Pflanze wird daher der Billbergia farinosa sehr ähnlich sein. Ich enthalte mich jedoch, diese unbestimmte Form zu benennen.

\section{Billb. rose a Hort. (Linden?)}

Aeussere Laubblätter ' $2 \%$ " lang, abstehend, innere 3 ' 2 " lang, aufrecht, eine lange Rölıre bildend. Auf der Aussenflïche auf trüb grüıeın Grunde unten röthlich, der ganzen Länge nach reichlich weiss gebändert und zierlich gefleckt. Die Oberfläche schwach weisslich gebändert. Die ausseren Blätter gut I" breit, gleich breit, bandartig überhängend, bei $21 / 2$ " breit, die Spitze zurückgebogen. Blattränder vom Grunde aus unbewehrt, daun mit unregelmässig entfernt stehenden steifen, geraden Sägezähmen bewaffnet. Blattspitze unbewehrt. Blütheuschaft entschieden überhängend, sammt dem 9" langen Blüthenstande vom Grunde an 4" lang, bei 4" dick, stielruml, der ganzen Länge uach nit auliegenden autrechten, weichen, ganzrandigen, nichst dem Blïthenstande aber abstehenden, schön rosalarbeneı, nur schwach mehlig bestäubten Hochblättern besetzt. Zwischen den Lanbblättern vertrocknen die Bracteen sehr schnell und werden dann missfarbig. Schaft, Fruchtknoten und Kelchzipfel auf sehr hellgriinem Grunde dicht wie mit weissem Mehl bestäubt. Knospe pfriemenfürmigg, $2 \frac{1}{2} "$ lang; glänzend hellgrïn. Die Kronenbliatter rollen sich beim Oeffnen schnell und vollständig und schneckenlinig sehr zierlich zurïck, aber beim Verblühen rollen sich die Blätter wieder auseinander und hängen endlich einzcln fadenförmig und missfarbig herab. Genitalien so lang als die Kronenblätter, gerade ausgestreckt. Griffel etwas länger als die Staubulätter, dick, bläulich, drei . lappig endend. Staubfäden und die sehr dïnnen Staubblätter an Griffel dicht anliegend, erstere dick, mit blïulicher, stumpler Spitze. Fruchtknoten banchig gefurcht, sammt dem Kelchzipfel 1" lang, stiellos. Jeder Fruchtknoten trägt eine anliegende, herzfümige, 3"“ lange Bracteole, welche bei jenenFruchtknoten, die zunächst den Bracteen stehen, schwach rosa gefärbt erscheinen. Beim Vordrängen des Bliithenstandes sind die geschlossenen Bracteen fast lederfarbig; erst bei der Ausbreitung desselben 
gewinnen sie die zarte Rosentarbe. - Diese sehr schöne Pflanze habe ich als letzte Species gewählt, da selbe den Uebergang zu Hoplophytum bildet, indem hier die Kelchzipfel eine schwache Neigung zu stachelspitzen Enden zeigen.

\section{HOPLOPHYTUM Beer.}

\section{Hopl. fasciat um Beer.}

Billbergia fasciata, Lindl, Bot. Register tab. 1130, Billbergia rhodo-cyanea Lemaire. Flora van Houtfe III, tab. 207. - Bot. Mag. tab. 4883.

Wenn man lebende Pflanzen von Billb. fasciata und Billb. rhodueyanea vor sich hat, so findet sich nur, dass die erstere Pflanze kleiner und schmichtiger als die zweite. Wenn man aber die Blüthenstände. und die beiden oben genamnten Abbildungen zu Rathe zieht, dam sieht man, dass gar kein Grund vorliegt, welcher die nene Benennung rechtfertigt, wesshalb ich die Benennung "rhodo-cyana" einziehe mul den alten Special-Namen, fasciatum" beibehalte.

Ich fing mit dieser Species die Sippe an, weil selbe schon sehr rerbreitet ist und anch sehr willig blïht, was bei mehreren der hier zugezogenen Species eben nicht der Fall ist. Auch mag hier bemerkt sein, dass bei geeigneter Cultur der Bliithenstand bedentend kräftiger wirl, ohne aber an Höhe zuzunehmen. -

Pflanze kräftig, schön, auf dunkel blau-grïnem Grunde lebhaft, aber schmal gebändert und gefleckt. Laubblätter steif anfrecht, am Ende etwas iibergebogen, vom Grunde aus alle frei, hier wenig umfassend, glatt, weichrandig, dann mit unregelmässigen scharfen Sägezähnen bewaffnet, mit schwach spitzem Stachel endigend, in Mitte iiber $2 \frac{1}{2}$ " breit, 20 "lang. Die inneren Blitter sind breiter als die änsseren, und stehen in gleicher Hühe ausgebreitet. Schaft holzig, sehr steif, lüugs gefurcht, matt rüthlich grïn und mit stark weiss wolligem Anfluge. Bracteen sowohl am Schaft als auch am verzweigten pyramidalen, 5" hohen, 4 " breiten Blïthenstande lebhaft, rosenfarben. Bracteen alle steil, eigenthïmlich trocken, mit scharfen Sägezähnen besetzt, stachelspitz endend: sie bilden den Blüthenstand, indem sie überall weit die Blüthen überragen und mit ihren nach aufwärts gebogenen spitzen Enden eine herrliche rosenfarbene Pyramide bilden. Am Schafte sind sie sparsam vertheilt, derselbe desshalb sichtbar. Sie sind nur halb schaftumfassend, 3 "lang, 1/2" breit, anliegent, mit gegen anfwärts gebogener Spitze. Die Blïthen, welche in Ḱnospe hell himmelblan, endlich sehr wenig geöfinet sind, verïndern die Farbe in ein schönes Purpur. Dis Kronenblatter 
stehen aufrecht und sind 1 $\frac{1}{2} "$ lang. Fruchtknoten und Kelchzipfel, die mit einer Stachelspitze versehen sind, haben eine dichte, weiss wollige Bekleidung; aber nur die Kelchzipfel sind manchmal zwischen den Bracteen sichtbar. Schaft und Blüthenstand erreichen eine Höhe von 17“", sind aber nur wenig iber die Laubblätter erhoben.

\section{Hopl. paniculatum Beer.}

Bromelia exudans, Loddiges, Bot. Cabinet tał. 801.

Bromelia bracteata Sw., Kerner, Hortus semperv. tab. 401.

Bromelia paniculigera Sw., Reichenbach, Hortus tab. 139, 140.

Jacquin, Privat-Bibliothek Sr. M. des Kaisers (ohne Benennung).

Diese Pfanze hat einige Mühe verursacht, indem fünf Abbildungen copirt werden mussten. Lind ley weist daranf hin, dass diese Pflanze zwischen den Laubblättern, welche kelchbildend und dicht zusammenstehend, eine bedeutende Masse trinkbares Wasser besitze, das dem durstigen Reisenden eine grosse Wohlthat bereite; - aber dieser Umstand allein weist schon darauf hin, dass wir es mit keiner Bromelia zu thun haben, indem hier gar keine Species vorkommen kann, welche Wasser in bedentender Menge durch die Stellung der Laubblätter aufzuhalten vermag, hingegen die meisten Pflanzen dieser ganzen II. Unterabtheilung wirllich an ihren natïrlichen Standorten - Wasser zurückzuhalten vermögen, welches sich bei ihnen gewöhnlich auch findet. Der Standort der Pflanzen wird wohl hier Alles dazu beitragen, ob das zwischen den Laubblättern enthaltene Wasser zum Genusse tauglich sei oder nicht.

Reichenbach spricht die Mreinung ans, dass diese Species besser „B. capituligera" benannt sei. Um aber passende Special-Benennungen in der Pflanzen-Beschreibung einzufïhren, müsste ein guter Theil dieser Benennungen umgearbeitet werden, da die Ptlanzen nur zu oft SpeciesNamen tragen, welche geradezu der Erkenntniss melır schaden als nützen.

Unter den fünf hier genannten Abbildungen fand ich jene in Reichenbach's Hortus am ausfïlrlichsten, indem hier in zwei Abbildungen, einmal die ganze Pflanze und dann der Bliithenstand gut gezeichnet ist. Ich besitze in meiner Sammlung eine Menge Species, welche ähnliche Wuchsverhältnisse haben, allein in Blüthe sah ich sie weder bei mir noch in anderen Gärten. -

Laubblätter alle steif anfrecht, eine tiefe Rinne bildend, welche erst an den spitzen Enden verflacht; 2" breit, bei $3^{\prime \prime}$ lang, am Ende gegen aussen strahlenfürmig abgebogen, gleichmüssig scharf sägezähnig. Schaft steif anfrecht, holzig, auf schmutzig grünem Grunde, stark weiss wollig bekleidet, $4^{\prime \prime \prime}$ dick, sammt dem lkegelförmig runden, $6^{\prime \prime}$ hohen, 4 " brei- 
ten, melırmals kurz verzweigten Bliithenstande $21 / 2$ ' hoch. Der Blüthenstand trägt die Bliithen in Büschcln zusammenstehend, welche von anliegenden, herzö̈rmigen, steif spitzen, hell gelb-grïnen, etwas gestreiften Bracteen dergestalt umgeben sind, dass jeder Büschel wie eine kurze Kenle gebildet erscheint. Zwischen diesen Bracteen stehen die Blïthen. Die Kronenblatter hellgell, etwas röthlich bemalt, kaum geüfinet, gerade abstelend, mit stmupfer spitze endigend. Fruchtsnoten und Kelchzipfel, wclehe stachelspitz sind, haben ebenfalls eine gelbe Färbung und sind etwas weiss wollig bekleirlet. Jeder Zweig rom Bliithenstande ist von einer abwïrts hiingenden, sehr lebhaft blutrothen, ganzrandigen, steifen Bractee von 4" Lünge und 1/2" Breite umgeben. Diese hängenden rothen Bracteen und die gelb-griin gefürbten Bracteen bei den Blïthen gereichen der Pflanze zur grossen Zierde.

\section{Hopl. m u ero n ifl or a Beer.}

Aechmea mucroniflora Hook. Bot. Mag. tal. 1832.

Hooker weist auf Acchmea R. et Pav, hin, in Uebereinstimmung der stachelspitzen Kelchzipfel. Der Antor weist ferner darauf hin, dass bei dieser Pflanze die Blitter, die Bractecn, die Kelchzipfel und die Kronenblattzipfel stachelspitz seien. Ferner findet er sie verschieden von Aechmea Mertensis, welche ebenfalls in Denerara heimisch ist.

Laubblätter ïber 1' lang und $1 \frac{1}{2}$ " breit, unten knglig, rund, umfassend, ganz glatt, steif anfrecht, an dher Spitze übergebogen, tief scharf sïgezähnig und wenig stachelspitz, bïnlich hellgrïin, glatt, glänzend, eine tiefe Rinne bildenrl. Blithenstand hei 3 "lang, 1 $\frac{1}{2}$ "breit, um vieles von den Laubliaittern iiberragt, steif aufrecht. Bliithenstiel hellgelb, in saftgriin übergehem\}. Bracteen steif abstehend, sïgezihnig, lebhaft hellroth, mit lichterem gelben, weisshichem Rande, kahnförmig. Blüthen dicht gedrängt stehend, nicht geölfnet, goldgelb, mit branner Stachelspitze an jedem Blumenblatte. Keleh weisslich grün, ebenfalls mit brauner Stachelspitze an jedem Kelchzipfel. Bracteen bei den Blïthen, lebhat griin, umfassend, mit einer braunen Stachelspitze endigend. Befruchtungsorgane kürzer als die Kronenblätter. Die Blïthen, welche $3^{\prime \prime \prime}$ lang sind, entwickeln sich alle zngleich. Die Kromenblattzipfel sind stark gedreht.

\section{Hopl. e y an eum Beer.}

Nidularia cyanea, Berliner bot. Garten.

Dieses seltene Pflinzehen erhielt ich mit obigem Namen aus dem königlichen botànischen Garten bei Berlin (1854).

Pflanze 9" hoch. Laubblatter alle steif aufrecht. wrechieden lang 
(5 bis 9 "), "'"' breit, auf der Innenfläche matt grün glänzend, aussen mit fein weisslichen Längslinien geziert; am Blattende vereinigen sich diese Linien zu einer weissen scharfen Spitze. Das Laubblatt ist am Grunde bauchig, mit weichen lederbraunen Rändern, etwas zusammengedrückt, am Grunde stark umfassend, sonst mit einigen sehr entfernt stehenden kleinen scharfen Sägezähnen bewaftnet. Der Blüthenstand ist aufrecht, nur $2 "$ hoch, also von den Laubblättern weit überragt, mit aufrechten, weichen, vollkommen umfassenden, bauchig herzförmigen, spitz endenden Bracteen, selbst zwischen den Blüthen besetzt, hier aber eine tiefe Rinne bildend, mit einwärts gebogener langer Spitze; die Blüthe hellblau, ausgebreitet, zwischen den stachelspitzen Kelchzipfeln vorstehend. Fruchtknoten etwas bauchig, tieffurchig, 3"“ lang, über 1“. breit. Kelchzipfel 4"“ lang. Die Knospen stehen alle in gleicher Hölıe beisammen und bilden eine runde Masse ron 3/4" Durchmesser.

\section{Hopl. angustifolium Beer.}

Aechmea angustifolia Poeppig et Endlicher. - Nova genera plantarum, Poeppig et Endlicher, tab. 159.

Laubblätter durch mehrere verwelkte braune Schuppen umstellt, aufstrebend, an der Spitze schlafi, an der schlanchförmigen Basis verbreitert, sich wechselseitig deckend, lineal zugespitzt, scharf sägezähnig, Oberfläche grün, Unterfläche durch kleiigen Anflug weisslich, 2‘ lang, 7“" breit. Schaft dünn, steif, mit einigen anliegenden Hochblättern besetzt; unter dem Blüthenstande stehen mehrere 21/2" lange, $3 / 4$ " breite, ziemlich steife, schwach bewehrte Bracteen dicht beisammen und stïtzen im Kreise stehend den Blüthenstand; sie sind lebhaft scharlachroth. Blüthenstand bei 9" lang, sehr verzweigt. Zweige über 1" lang, abstehend oder herabliängend. Blüthen selnr zahlreich, $4^{\prime \prime \prime}$ lang. Kelchzipfel mit abstehender, scharfer Spitze. Deckblatt bei jeder Blïthe, diese umhüllend, mit kurzer stechender Granne bewehrt, innerhall glatt, von aussen mehlig weiss bestïubt. Blumenblattzipfel bewehrt, matt gelb.

Genitalien nicht sichtbar. Poeppig und Endlicher bemerken in ihrer Beschreibung: „Die Blüthen abwechselnd, beinahe zweizeilig, ährig u.s.w.", dann: „die obersten leer oder in eine Bractee verwandelt." - Dieses ist aber nicht der Fall; die Pflanze, welche beschrieben und alogebildet wurde, befindet sich im k. k. Museum. Hier hatte ich Gelegenheit, mich zu überzeugen, dass Verkümmerungen der Blüthen gar nicht vorkommen, ein Umstand, welcher Aechmea Ruiz et Pavon so sehr auszeichnet, indem hier die verkümmernden Blüthen an den Zweigenden ein sehr gutes Erkennungszeichen bilden. 
Es folgt hier die Beschreibung von Poeppig und Endlicher:

Schaft einfach, Rispe ährig, an der Basis durch gezähnte Bracteen umstellt, Zweigchen abstehend, abgebogen, vier bis zehnbliithig; die Bracteen der Bl ü then kahnförmig, dreizähnig, wobei der mittlere Zahn eine Granne trägt, ausserhalb filzig, die inneren Zipfel unbeschuppt und stachelspitz; die Blätter lineal, von der Basis aus erweitert, schmal und länglich zugespitzt. P'arasitisch auf Bäumen jn den Wäldern der Provinz Mayna. Blüthezeit im ganzen Jahre.

Beschreibung: Rhizom kurz, verkehrt kegelig, Wurzel kahl, b ra un. Die Laubblätter (beiläufig sechs) durch verwelk te bra une Schuppen umstellt, a ufstrebend, an der Spitze schlaff, an der schlauchförmigen Basis verbreitert und sich wechselseitig deckend, lineal zugespitzt, flach, mit kurzen, geraden, flachen, sehr spitzen, starren und 1 “ langen Dornen gezähnt, oberhalb kahl, nerviggestreift, grün, unterhalb durch kreisrunde Schüppchen schilferig, weisslich, $1 \frac{1}{2}$ bis $2^{\prime} \operatorname{lang}, 6$ bis $8^{\prime \prime}$ breit. Schaft gefurcht, mit abwechselnd stehenden, angedrïckten Scheiden, die schlaff, zugespitzt, weiss, filzig und flockig sind. Die endständigen Bracteen die Rispe stiitzend, abwechselnd einander genähert, etwas abstehend, sitzend, flach, lineal, lanzettlich, zugespitzt, mit häutigen, dornenartigen, zurïckgebogenen Zähnen bewafinet, kahl, scharlachroth, 11/2 "lang. Die Rispe beilüufig dem dritten Theil des Schaftes an Länge gleich, ist aufrecht, ährig, cylindrisch, flockig, filzig, die oberen Aestchen horizontal, dic unteren abgebogen, gleich, bei 3 bis 6 " von einander abstehend, ein wenig hin uñd her gebogen, eckig, vierbis zehnblïthig, selten länger als $1 / 2 "$. Die obersten Bliithen leer oder in eine Bractee verwandelt, jede einzeln, durch eine breit eiförmige oder fast kreisförmige Bractee gestiitzt, die in einen zuriickgebogenen kurzen, stechenden Dorn auslauft, kahnförmig und oft becherförmig zusammengerollt, innerhalb geglättet, ausserhalb mehlig, starr und hart. Dic äusseren Zipfel der Bliithenhülle, drei an Zahl, sind bleibend, spiralig zusammengerollt, concav, gleich, fast eiförmig stumpf, der abwechselnde Rand in einen grossen eiförmigen Lappen verbreitert, einnervig, in eine zurückgebogene und starre Stachelspitze endend. Die inneren Zipfel an der Basis zusammengerollt, innerhalb nackt, länger als die äusseren Zipfel, länglich, schief, spitz, mehr häıtig, gelb, sehr vergänglich. Staubgefässe sechs, deren drei den inneren Zipfeln ganz am Grunde angewachsen sind; die anderen drei vor den äusseren Zipfeln sind angefuigt. Staubfïden schmal; die Antherne lineal länglich, stumpf, am Rücken angeheftet, nach aussen aufspringend. 
Hopl. spicatum Beer.

Aechmea spicata Martius. - Nova genera plantarum Poeppig et Endlicher pag. 43.

Es folgt hier die Beschreibung von Poeppig und Endlicher:

Schaft einlach. Rispe ährig, an der Basis durch gezähnte Bracteen eingehiillt. Zweigchen sehr richt gestellt, anlrecht, zwei- bis vierblüthig.

Die Bracteen der Blïthen sind fast hechertörnnig, ganzrandig, die finsseren Zip, fel der Blïthenhille kahl und dornig l,egrant, die inneren zugespitzt, an der gefransten Basis schuppig; die Blaitter aus schlauchförmiger Basis, zungenförmig, mit stumpfer Spitze. (Schultes fil. I., L. l. c.,

Standort: Baumstämme bei Ega, Provinz Rio Negro.

Blüthezeit: Januar.

Endlicher hält diese Species gleich mit Aechmea angustifulia, und bemerkt, das, mur ein Unterschied darin hestehe, dass Aechmea spicata einen krältigeren Ban unl einen nufrechten Schaft besitze.

\section{Hopl. Mertensis Beer.}

Aechmea Mertensis Hook. Bot. Mag. tab. 3180 .

Diese schöne Sprecies ist rler Aechmea angustifolia (Hoplophytum) sehr ähnlich. Laubblätter ziemlich weich, am Rande stark wellig; sehr ticf, scharf, schwarz sägezilhnig, mit weiss kleiigem Aufluge auf beiden Flächen belsleidet, $2 "$ hreit, $1 \frac{1}{2}$ ling. Die Laubhlatter stehen vom Grunde aus weit ab, sie sind hier tief rinnig: diese festalt verliert sich aber bald und die Fläche zeigt dann eine nur schwache Rinne.

Der Blüthenstand ist gu lang, gleichmässig 1 1 $\frac{2}{2}$ " diek, im Ganzen hetrachtet hellgrün mit stark röthlichem Aufluge. Die Blïthen stehen in dichten $1^{\prime \prime}$ breiten und $1^{\prime \prime}$ lingen Büschehn dergestalt nahe beisammen, dass das Ganze eine dichte Masse bildet. Die unteren Blithenbiischel und der kraiftige, anfrechte, hellgriune, holzjge, 4" dicke Schaft sind mit steif ahstehenden. dann herah,gebogenen, scharf sägezähnigen, spitzen, 3" langen und 3":" breiten, lebhat weinrothen, am Grunde in hellgriin iibergehenden Bracteen besetzt. Jeder Bliithenbiischel hat eine robuste $4^{\prime \prime}$ dicke Basis. Jede Blüthc trägt einc steif aufrechte, stachelspitze, vollkommen umhiullende IBractee. Fruchtboden und die scharf stachelspitzen Kelchziptel sind schmutzig weisslich und bilden znsammen eine verlängerte Eilorm. Die Kronenllatter sind ïber 2 “. lang, flatterig, offen, hell fenerroth.

Das nahe Zusammenstehen einer so grossen Menge, wenn auch sehr kleiner, aber lebhalt gefürbter Blüthen rerleiht dieser Pflanze ein sehr zierliches Aussehen. 
Hopl. su aveol ens Beer.

Aechmea suaveoleus Ku. et Westk. Floral-Cabinet III, tah. 134.

Die Pflanze bildet vom Grunde aus, durch das innige Zusammenstehen der wenigen schr steifen, aufrechten, dunkel schwarz-grïnen, glänzenden, bei $1 \frac{1}{2}$ ' langen, rinnenförmigen, über $1^{\prime \prime}$ breiten, sehr scharf sägezïhnigen und derb stachelspitzen Lanbblätter, eine lange, glatte Röhre. Der Schaft entwickelt sich holzig, steif aufrecht, nur $2^{\prime \prime \prime}$ dick, dicht mit weiss wolligem Antluge anf rein hellem Weinroth, und besetzt mit sehr wenigen dicht anliegenden, etwas abstehenden, ehen so gefärbten Scheiden. Die Lünge sammt. dem 5 $1 / 2$ " hohen Blütlenstande beträgt vom Grunde aus ïber $1 \frac{1}{4} 4^{\prime}$. Der Blïthenstand ist stark verzweigt, die Zweige bei jeder Bliithe etwas knieförmig gehogen. Bliithen wagerecht abstehend, sparrig, einzeln stehend.

Fruchthnoten, Kelchzipfel und Bracteen bei jeder Blïthe, lel,haft rosenroth und filzig bekleidet, die zwei ersteren fast rund; Zipfel scharf stachelspitz, 4"' lang. Bliithe 2“" lang, kaum geöffnet, sehr hinfällig, lebliaft blau.

Die Pflanze bildet eine leichte, zierliche, aufrechte Tranbe.

\section{Hopl. purpureo roseum Beer.}

Billbergia purpurea rosea Lindl. Bot. Mag. tab. 3304 .

Es ist in hohem Grade interessant, zu sehen, wie zwei der ersten Botaniker der Jetztzeit, nämlich Hooker und Lind ley, die Merkmale dieser schönen Familie beniitzten. Hooker hat sich an die von $\mathrm{Ruiz}$ und Pavou für Aechmea antgestellten Merkmale gehalten, aber doch dic Autoren der Flora Peruviana et Chilensis nicht ganz gewiirdigt. Lindley dagegen sieht in eben dieser Form eine gute Billbergia, und ist daher meiner Meinung nach bei seiner Bestimmung den richtigeren Weg gegangen.

Bei dem schönen Genus Aechmea werde ich ausführlich auf die Meinungsverschiedenheiten und deren Ursprung zurïckkommen.

Die Pflanze hat zwei vollkommen verschiedene Wachsthumsverhältnisse, dabei blüht sie nur äusserst selten. Jener Trieb, welcher zur Blüthe gelangt, ist aufrecht, steif und hart wie Eisenblech, von dunkel-, fast schwarz-griiner Farbe. Die wenigen Laubblatter bilden cine vollkommen runde, steif anfrechte Rïhre; sie sind über $1^{\prime}$ lang, $2^{\prime \prime}$ breit, mit sehr spitzem Ende, an den Rändern sehr scharf sügezühnig, am Grunde wenig umfassend. Der juingere spross hingegen hat $1 \frac{1}{2} \cdot$ lange, tiefrinnige, am Grunde glattrandige, hier stark umfassende, $1 / 2$ " breite, scharf sägezähnige, stark überhängende Laubblätter, 
Bluthenschaft stcif aufrecht, fein weiss wollig bekleidet sammt dem viel verzweigten Blithenstande, welcher 9 " hoch ist, $2^{\prime}$ lang.

Schaft, Stielchen, Bracteen, Fruchtknoten und Kelchzipfel lebhatt rosalarben, nur die Bracteen etwas lederbraun bemalt.

Kronenblätter steif aufrecht, röthlich blau, wenig geöffnet.

Kelchripfel und Bracteen scharf stachelspitz. Die Stanbfiden mit goldgelben aufrechten Staubl)]ïttern sind in Mitte der Laubblätter, welche sie überragen, sichtbar.

Im Ganzen betrachtet gleicht diese sjecies sehr der Aechmea suaveolens, indem selbe nur durch garinge Nerkmale miterschieden sein dürfte.

Hopl. distichanthum Beer.

Aechmea distichantha, Lemaire. Jardin fleuriste III, tab. $26 \%$ - Billb.? pulystachia. Paxton's Flower Garden III, tab. 80.

Die Abbildungen in Paxton und jene im Jardin fleuriste sind ganz gleich, daher eine derselben - eine Copie.

Die Pflanze ist auffallend kräftig und durch die am unteren Ende sehr bauchig erweiterten, wenig mmfassenden Laubblätter hier ganz rund, am Grunde sind die Blatter über 3 " breit, aber bei 2 "Höhe verschmälert sich das Blatt mit einemmale und bildet eine abstehende, dann gegen aufwirts gebogene Rinne von ' $2^{\prime \prime}$ Breite und $2^{\prime}$ Länge. Die ganze Pflanze ist wie mit Hehl bestüubt, der Blïthenstand aber sehr wollig bekleidet. Die in Mitte stehenden Laubulitter sind aufrecht, nur der 6" hohe Bliithenstand ragt iiber die Blattspitzen hinaus. Die Blätter haben sehr kleine Sägezähne. Der Schaft erhebt sich steif aufrecht, ebenso der durch sehr nahe zusammenstehende Zweige dicht mit Bliithen, besetzte pyramidale Bliithenstand. Blüthenkrome eine fast gleich weite, $4^{\prime \prime \prime}$ lange, hellblaue Röhre bildend, in deren Mitte die gelben Staubblätter sichtbar sind. Fruchtknoten und stachelspitze Kelchzipfel 1\%" " lang, mit einer ganz umhiillenden 5 " hohen stachelspitzen Bractec innig umschlossen.

Mit Ausnahme der blauen Kronenblitter ist der ganze Blïthenstand dergestalt dicht mit blutrothen Fleckchen bedeckt, dass er, im Ganzen betrachtet, sehr zart rosenfarben erscheint.

\section{Hopl. a ugustum Beel:}

Tillandsia augusta Arrab. Flora Fluminensis tab. 135. - Pironneava glomerata, Gaudichaud. Bonite, Atlas botanique tab. 63.

Bei beiden oben genamnten so kostbaren Werken fehlt die Beschreibung gänzlich. Ich besitze eine Pflanze aus Belgien, mit dem Namen „Billbergia Skimnerii“ bezeichuet, welche vielleicht auch hieher gehört; 
bis aber diese schone Ptlanze, welehe fur diese Familic ricsige Verhaltnisse entwickelt; zur Blïthe gelangen diurfe. wird es wohl moch cinige Jahre erfordern.

Die Abbildung in Flora Flunin, zeigt einen kräftigen Stamm, welcher bis zu den ersten Blättern $4^{\prime \prime}$ dick und über $3^{\prime \prime}$ hoch erscheint. Die Lanbblätter sind 5\%" breit, ïlser 2" lang; fein sägezähnig und an dem Grunde wenig umassend, hier eine tiefe Rinne bildend, dann flach ansgebreitet, abstehend. Schaft und sehr verzweigter Blüthenstand sind his auf die kurzen Kronenblïtter und die Bracteen am Schafte mit dichtem Filze bekleidet. Der $3 / 4$ "dicke Schaft und 1/4' lange Bliithenstand sind zusammen über ' 2 ' laug. Die Blïthen stehen an kurzen kräftigen Stielen in runden Bïscheln beisammen. Fruchtknoten und die sehr kurzen. scharf' stachelspitzen Kelehzipfel bilden eine wollig runde Beere von 4 ".. Länge und $3^{\prime \prime}$ Breite. Der obere Theil derselben, sowie dic etwas gestreifte halbumfassende Bractee sind stark wollig bekleidet.

Jeder Blithenbüschel deren die Pflanze wohl 70 bis 80 besitzt hat 1 "Durchmesser und 3/4" Höhe. - Leider ist von der Färbung dieser grossen Pflanze gar nichts bekannt, obwohl ich vermuthe, dass die langen Bracteen, welche die Zweige und den Schaft bekleiden, lebhat roth gefärbt sein dürften.

Hopl. poly stach i um Beer.

Tillandsia polystachia Arrab. Flora Fluminensis. tab 138.

Die Pflanze hat fast gleich lange zungenförmige, bis auf den Grund freistehende, gleichmässig flieht sägezähnige, 1' lange, 1" breite Lauhblätter, aus deren Mitte sich der 1/2" dieke Schaft sammt dem einseitig verzweigten, platten, 6 " hohen, 3 " breiten Bluithenstande - steil aulrecht erhebt.

Aus der Zeichunng ist es unmöglich, eine nur halbwegs geniigende Beschreibung zusammenzustellen, indem der ganze Bliithenstand wie ein Cactusblatt breitgedrïckt erscheint, an den Rändern aber die Bliithen einzeln an langen dïnnen Stielchen aufrecht stehen. Die Frncht scheint eine Beere zu sein. Kelchzipfel stachelspitz. Die Kronenblitter steif aufrecht und etwas geöfnet. Da keine Beschreibung zu diesem nun schon öfter genannten Werke gemacht wurde, so weiss man auch iiber die Färbung u. s. w. nichts Gewisses.

Hopl. tetrastach y um Beer.

Tillandsia tetrastachya Arrab. Flora Fluminensis tab. 137.

Eine vierührige Pflanze; dies hat A r a b veranlasst, diese Specics so zu benennen. Vermuthlich hat derselbe eine abgebluihte, fruchttragende 
Pflanze abgebildet, indem der aufrechte Schaft eine dicht mit Beeren (welche Stachelspitzen tragen) besetzte Aehre besitzt. Die Pflanze trägt alle Blitter steif anfrecht, von gleicher Höhe (1'lang), an fler Spitze spitz, eingerollt, schmal verlängert, siigezihnig.

\section{Hopl. un ispicatum Beer.}

Tillandsia uni-spicata Arrab. Flora Fluminensis tab. 124. - Lromelia nudicaulis Ker.? Exotic Flora tab, 143.

Laubblätter von verschiedener Länge, unten eine Röhre bildend, hier tief rinnig, wenig unfassend, gleichmässig $2^{\prime \prime}$ breit und iiber $2^{\prime}$ lang, schwach sägezähnig, auf beiden Fliichen lebhaft hellgrïn und glänzend. Bliithenstand weit vorragend, etwas übergebogen, die ersten Bracteen alle steif aufrecht, hell lederfarben, dam gegen den Blüthenstand immer heller, schïn rosenfarbig werdend. Stiel leicht filzig bekleidet und der ganzen Länge nach gleichfarbig hell lederbraun und fleischig.

Der Bliithenstand ist unverzweigt, die Blüthen sitzen stiellos am fleischigen Schafte. Fruehtknoten und Kelchzipfel sind zu einer Beere verwachsen, letztere mit gegen einwärts gebogener Stachelspitze bewehrt, beide von hellgrïner Farbe. Jede Bliithe trägt eine sehr kleine rosalarbene Bractee, welche kaun die Hälfte des dunkelgrïnen, etwas filzigen Fruchtknotens (Beere?) erreicht. Bhiithenkronenblätter aufrecht, sehr kurz zusammengeneigt, 1/4" lang, hoch goldgelb. BefruchtungsOrgane viel küirzer als die Kronenllätter, desshalb gar nieht zu sehen.

\section{Hopl. I an uginosum Beer.}

Billbergia lanuginosa Hort. Bot. Garten in Hamburg.

Laubblätter zahlreich, alle gerade aufstrebend; die längsten $2^{\prime} 10^{\prime \prime}$ lang, in Mitte 3" breit, in eine hellbraune, zuriickgebogene, etwa 1" lange Spitze endigend. Der obere Theil der Laubblatter merklich zungenförmig verbreitert, alle sehr hellgrün, mit ganz feinen entfernt stehenden braunen Sägezähnchen bewafinet, vom Grunde aus stark umfassend und hier eine etwas bauchige Röhre bildend. Sprossen zahlreich, niederliegend, 3/4" dick, bis 3" lang, mit braunen, steifen, scharf bewehrten, sich deckenden, mit der Spitze abstehenden Niederbliittern besetzt. Die Laubblätter entwickeln sich ganz aufrecht. Bliithenschaft sammt dem 8" langen Bliithenstande vom Grunde aus 1' 10" lang, etwas übergeneigt, jedoch nicht iiberhïngend, sehr' wenig weiss filzig bekleidet. Am Grunde rein weiss, dann, subald der Schaft zım Lichte gelangt, allmälig rosa werdend, endlich zwischen den einzelneu sparrigen abstehenden Bliithen lebhaft scharlachroth. Hochblätter kahnförmig, steif; anfrecht, glänzend, ganzrandig, etwas gestreift, prächtig scharlachroth, mit fast scharfer 
Spitze endigend. Blithen zahlreich. Fruchtknoten hellgelb grün, etwas gefurcht, auf einem röthlichen Ringe am Schatte fest aufsitzend. Kelchzipfel rundlich, etwas gedreht, lebhaft hellgelb, mit auswirts gebogener gelber, sehr dïnter Stachelspitze. Kronenblitter etwas hanchig. steif anfrecht, hochgelb, die Ziplel etwas abstehend. Genitalien um vieles kürzer als die Kronenblätter, hellgelb.

Länge der ganzen Bliithe sammt Fruchtknoten bei $1^{\prime \prime}$.

Obwohl der Special-Nane „lanuginosa" hier sehr wenige Herkmale bietet, habe ich doch vorgezogen, diese Benennung heizubehalten. Zunächst gränzt diese Form an Bromelia mudicanlis (Exotic Flora t. 143) und an Tillandsia unispicata (Flora Fluminensis t. 124).

\section{Hopl. plat y n e ma. Beer.}

Pironneava platynema Gaud. Bonite, Voyage au tour du monde. Gaud, tab. 64.

Diese Pflanze muss, der Zeichnung eines Laubblattes und eines Theiles des Bliithenstandes nach zu urtheilen, sehr gross und ausgebreitet sein, indem das Laubblatt über $3 \frac{1}{2}$ " lang und $1 \frac{1}{2}$ " breit, sehwach siigezähnig und ganz platt gezeichnet ist. Der Zweig des Blïthenstandes ist aufrecht, etwas übergebogen, ibber 1' lang; von unten anf trïgt derselbe mehrere kurze, dütenfürmig umfassende, gestreifte, spitz endende Bracteen. Bei $5 \frac{1}{2}$ "Länge fangen die Bliithen an, welche zu 2 bis 3 zusammenstehend, kurze Verzweigungen bilden. Jede Bliithe hat eine etwas ahstehende, scharf stachelspitze, schalenförmige, $4^{\prime \prime \prime}$ lange, mit Längsstreifen gezierte Bractee. Der Fruchtknoten endet mit den stachelspitzen, etwas nach aussen gebogenen Kelchzipfeln und hat eine verlängert eiformige Gestalt von 1/2" Länge. Die Kronenblätter sind so lang wie der Fruchtknoten, am Grunde eine dünne Röhre bildend, dann steif aufrecht, bis zum Grunde geöffnet, von einander alsstehend. Jede dieser kleinen Verzweigungen umgibt eine 1/1," lange, sehr spitz zulaufende, etwas abstehende spitze Bractee, welche zwischen den Blïthen iiberall vorragt.

Von der Färbung ist nichts bekannt.

\section{Hopl. l ingul a tu m Beer.}

Bromelia lingulata L. Privat-Bibliothek Sr, N. des Kaisers (Jacquin).

Die zierlich aufrechten, am Grunde last reitend zusammenstehenden Laubblätter sind am Grunde $41 / 2$ " breit, dann in Mitte $2^{\prime \prime}$ und uiber $1^{\text {" }}$ lang, steif lederartig, hell lichtgrin, mit braunen, sehr feinen, gleichmässigen Sägezähnen überall besetzt. Die Pflanze hat im Ganzen 11/2' Höhe. Der Schaft ist sehr dünı (3“"'), steif aufrecht, hellgrïn, mit kurzen lederbraunen Bracteen sparrig besetzt. Der ganze $9 "$ hohe, nur wenig verzweigte Blüthenstand iiberragt die Laubblätter. Die Bliithen sitzen 
stiellos, mit einer 3 " langen hellbraunen Braetee besetzt. Fruchtknoten cirund, braune Stachelspitze, Kelchzipfel 5"' lang; 3"' breit, matt griin wie der Sehitt gefairht. Kronenblïtler weiss, 3 "' lang; zuriickgesehlagen. ausgebreitet.

Hier ist wahrlich die PAlanze mit ihren Laubblüttcrn schöner als der Blüithenstand.

\section{Hopl. spicatum Beer.}

Pothuava spicata Gaud. Bonite, Voyage au tour du monde tab.117.

Laubblätter am Grunde kelchbildend zusammenstehend; bis zur Hälfte der Länge glattrandig, dann gegen oben scharf sägezälnnig und lappig, faltig, mit einer Stachelspitze endigend, iiber $1 \frac{1}{2}{ }^{\prime}$ lang, $2 \frac{1}{2}$ bis 3 " breit. Blüthenschaft überhängend, mit weichen, an der Spitze übergebogenen glattrandigen 5 " laugen, 3/4" breiten Bracteen der ganzen Länge nach bis zum Blüthenstande gleichmässig besetzt. Blïthenstand durch das ganz nahe Zusammenstehen der einzelnen hängenden Bliithen eine dichte, einfache, 5" lange, über 1" breite Aehre bildend. Fruchtknoten und gegen aussen gebogene stachelspitze Kelchzipfel eiförmig verlïngert, 3/4" lang, 3" dick, stark wollig bekleidet. Kronenblatter kaum vorstehend.

Ueber Farbe etc. ist nichts bekannt.

\section{Hopl. com a tum Beer.}

Pothuava comata Gaudichaud. Bonite, Voyage au tour du monde, Gaud. tab. 116.

Laubulätter am Grunde wenig umfassend, hier glattrandig, dann sägezïhnig, stumpf spitz, nebst dem Mittelnerv noch mit zwei gleichlaufenden Lüugslinien geziert, alle kelchbildend zusammenstehend, $2^{\prime}$ lang, $1 \frac{1}{2}$ " breit. Bliithenstand steif aufrecht, filzig bekleidet, mit schmitlen, aufrechten, nicht gauz umfassenden, sehr spitz endenden Bracteen ziemlich dicht besetzt, sammt dem Blüthenstande 1' 8" lang.

Blïthenstand durch regelmässig sehr dicht stehende Blïthen rein eirund. Bliithen aufrecht. Fruchtknoten und stachelspitze Kelchzipfel ciförmig, 1/2 "lang, $1 / 4$ " breit. Kronenblätter gar nicht sichtbar. Bracteen bei jeder Blüthe, flatterig, gestreift, spitz endend, 1" lang, fast 1/2" breit, am Grunde umfassend. Die regelmässige Stellung der aufrechten Beeren (?) und der viel längeren Bracteen an denselben macht den Blüthenstand sehr zierlich.

Diese Planze hat ihrem Blüthenstande nach einige Aehnlichkeit mit Echinostachys; aber nur die regelmässig gedrängt stehenden Beeren und die flatterigen Bracteen stellen dieselbe der obigen Gattung nahe. 


\section{STREP'TOCALYX Beer.}

\section{Strept. Poeppigii Beer.}

Sp. Amazonas. Ega. Poeppig. (Kaiserl. Museum in Wien.)

Laubblätter steif anfrecht, eine Röhre bildend, $1 \frac{1}{2}$ " breit, 11/2" lang, dunkel stahlgrün, gleichmässig scharf sägezähnig und stachelspitz. Schaft stark überhängend. Blüthenstand bis ans Ende verzweigt. Zweige hüngend; jeder Zweig trïgt eine horizontal abstehende, kalnfürmige, sügezïhnige, 2" lange und 1" breite, mit Längslinien versehene Bractee. Auch der Schaft ist mit ganz gleichen Bracteen besetzt, nur mit dem Unterschiede, dass hier die Bracteen steif aufrecht stehen und anliegen. Jede Blüthe trägt eine kleine herzförmige, nach seitwärts abstehende gestreifte Bractee. Schaft und Blüthenstand, mit Ausnahne der Kronenblätter und siimmtlicher Bracteen, mit dichtem, hellbraunem Filze bekleidet. Fruchtknoten gegen oben erweitert. Kelchzipfel weit geschlitzt, unter sich verwachsen, zusammengefaltet, weich, $2 \frac{1}{2}$ mal mo sich gewunden, mit dem Dorn 3/," lang, in Nitte $3^{\prime \prime}$ breit. Kronenblätter $1 / 2$ " lang, flatterig.

\section{PUYA Molina.}

Puya coarctata Beer.

Pourretia coarctata. Ruiz et Pavon. Flora Peruv, et Chil, tom III, 34, auch Prodromus ron R. et Pav. - Pourr. coarctata R. et Pav. Gaudichaud, Bonite, Atlas botanique tab. 41. Pourr, coarctata R. et Par. Poeppig et Endl. Nova genera plantarum pag. 41.

Stamm im Alter 4 bis 6’ lang, dam sparsam rerzweigt. Zweige fast eben so dick wie der Hauptstamm, mit den Ueberbleibseln der Laub. blätter besetzt, und wenn auch diese endlich abfallen, zeigt sich der Stamm regelmässig netzartig gefurcht, wie ungeführ alte Stämme mancher Palme.

Die Laubblätter bilden eine Krone wie bei Ýucea, aber die Blätter selbst haben ganz die Gestalt eines Bromelien-Blattes, nur mit dem Unterschiede, dass hier die Laubblätter anf der Unterfläche fast rein weiss erscheinen und das ganze Blatt etwas tleischig ist. Laubulitter ïber 4' lang, am Grunde 1\%" breit, allmälig gegen die Spritze schmäler werdend, endlich spitz endigend. Zähne an den Blättern hackig und sehr scharf.

Bliithenstand stark verzweigt. Bracteen eilanzettfürmig, aufrecht, an den Zweigenden eine lange Walze bildend. Bliithen sehr wenige, gleichzeitig geötlinet, und zwar nur an dem unteren Theile der Zweige, 
indem alle Enden am Blüthenstande uur sterile Bracteen billen. Bliithen über 2 "lang, glatt, weit geöffnet, schmutzig gelb.

Genitalien kaum vorragend. Staubbeutel tief orangefurbig. Der Sehaft ist bei $2^{\prime \prime}$ dick und iiber $6^{\prime}$ hoch. Die Hochblätter hängen an denselben schlaff herab; auch bei jeder Verzweigung am Blüthenstande steht ein schwach sägezähniges, 2" breites Deckblatt von verschiedener Länge. Der Schaft, Blïthenstand (Bracteen etc.) sind lebhaft grün gefürbt.

Die Kronenblätter ïber 2 "lang, Zip, fel abstehend, etwas zuriickgebogen, gelblich griin, an der Basis mit einem purpurfarbigen Flecken gezeichnet, beim Verwelken spiralig eingedreht. Fruchtknoten eifürmig, kaum merklich dreiseitig. Die ganze Blïthenähre pyramidenförmig, uber 1' lang und prachtvoll. Genitalien gelb.

Obwohl in guten Planzen-Sammlungen diese Species nicht selten lebend zu treffen ist, scheint es doch zu einer grossen Seltenheit zu gehüren, dieselbe in Blüthe zu sehen. Jedenfalls müssen die Exemplare sehr alt sein, bis man auf den Blüthentrieb rechnen kann.

Folgt die Beschreibung von $\mathrm{Ru}$ iz et Pavon :

Pflanze. Die Aehre zusammengesetzt, gerlungell. Blätter schwertförmig, stachelspitz. Kronenblütter gell, an der Basis mit einem purpurnen Flecken.

Stamm zwei Klafter lang, aufrecht, einfach, unterhalb beblättert, durch sich dachziegelförmig deckende Blattspuren stark verlickt, oberhalb rund, mit Schuppen oder kurzen Blättchen versehen, welche abwechselnd und entfernt stehen und beinahe lanzettförmig scharf sind. Laubblätler zahlreich, an der Basis des Stanmes dachziegelförmig stehend, 4' lang, 2" breit, gerinnt, beiderseits kahl, oberhalb glänzend, am Rande sïgezähnig, hellgrün. Sägezähne von einander entfernt, starr, dic unteren zurickgedreht und mit einem weissen Filze bedeckt. Die oberen einwärts gedreht und kahl.

Die Aehre endständig, fast lyramidentörmig, sehr gross, ans sehr vielen gestielten Aehrehen zusammengesetzt, lie gedrungen, wollig und beinahe 1' lang sinr, mit gestielten Deckblättern besetzt unrl vielblïthig.

Die Blïthen dicht ährig, sitzend, mit dentlich entfernten Bracteen. Die Bracteen der Aehrehen lanzettlich, halbstengelumfassend, verwelkend. Bracteen der Bliithen lïnglich, zugespitzt, rinnig. Kelch unterstïndig, dreitheilig, fllzig; die Zipfel eiförmig lanzettlich, zugespitzt, angerlriickt, bleibend. Blnmenblätter drei, lanzettlich, iiber $2 "$ breit, an der Spitze abstehend, zurückgetreht, gelblich griu, an der Basis mit einem purpurnen Flecken bezeichnet, beim Verwelken spiralig eingerlreht. Stanbfiiden 
pfriemlich, länger als der Kelch. Staubbeutel lineal, an der Basis leicht zweifedrig und gelblich. Fruchtlnoten eiförmig, kaum merklich dreiseitig. Pistil fadenförmig, dreifurchig, von der Länge der Staubfäden. Narben drei, fast spiralig. Kapsel eifürmig, schwach dreiseitig, dreifurchig, dreifüchrig, dreiklappig, braun. Samen klein, zahlreich, braun.

Standort: Chili, an sandigen Hügeln; durch die Provinz Conception sehr verbreitet.

Blïthezeit: September, October.

Die Einwohner von Chili benüitzen den Stamm, dessen Substanz korkartig und sehr leicht ist, zu verschiedenen Geräthschaften.

Puya alpestris Beer.

Pourretia alpestris Poeppig et Endlicher. Nova genera plantarum tab. 156.

Es folgt hier die Beschreibung von Poeppig et Endlicher:

Stamm kurz und anfrecht. Blätter sehr schmal, schwertförmig, wenig stachelig; auf der Unterseite weiss. Die Aelre zusammengesetzt, cylindrisch.

Sie wachsen auf Vorbergen bei Antuco im östlichen Chili.

Blüthezeit: Februar.

Die Pflanze, obwohl sie gegen dic anderen species unscheinbar zu mennen, ist doch schön. Bei dieser Species werden einige Sprossen kriechend gefunden. Die Wurzelblätter zahlreich, die äusseren länger, die inneren merklich kürzer, an der Spitze absteheud, zurückgebogen, sehr schmal schwertförmig, zugespitzt, in einen lurzen Dorn auslaufend, flach, am Rande spärlich stachelig, gestreift, oberhalb grïn, glänzend, glatt, unterhalb weiss filzig, am Grunde verbreitert, 1' lang und 1/2" breit, die Stacheln zurïckgebogen, gegen die Spitze des Blattes gew endet, scharf, purpur-kastanienfarbig. Der Stamm ist mit wenigen Blättern besetzt, die kïrzer und schmäler als die Wurzelblätter sind, zugleich unbewaffnet, hinfällig und dann wellenförmige Narben am Stamme zurücklassend. Schaft kaum 3' hoch, steif aufrecht, runl, mit einer rothen Oberhant bedeckt, flaumhaarig.

Der Blüthenstand rispig, die Zweigchen zerstrent abwechselnd, eine straussartige cylindrische Aehre bildend, anfrecht abstehend, gefurcht, durch weissen Filz ausgezeichnet; 3" lange Bracteen am Grunde eines jeden Zweigchens sitzend, halbstengelumfassend, zugespitzt, am Rande bisweilen mit kratartigen, in eine Granne auslaufenden Zähnen besetzt, nervig, häutig, weiss, mit kleienartigem, abfälligem Filze bekleidet, $1 \frac{1}{2}$ bis $2 "$ breit. Blïthen auf ein eckiges Blüthenstielchen gestützt, mit lineal lanzettlicher, hätiger Bractee, anfrecht, ron 
mittelmässiger Grösse, schön, ohne Geruch, 1 1⁄2" lang; die inneren läng. lich, fast eiförmig, an der Spitze sehr kurz zugespitzt, über der Basis ein wenig verschmälert, unterhalb zusammengerollt, oberhalb abstehend, zurückgebogen, nervig, auf der Aussenseite aus dunkelblau in grïn übergehend, kahl, nach dem Oeffnen der Blüthe damu spiralig zusammengedreht, purpurn.

\section{Puya chilensis Molina.}

Puya chilensis Mol. Bot, Mag. tab. 4715.

" Flore van IIoutte tab. 869,870 .

$"$ "Compositiones histor, Chilensis et Hispanicae pag. 170. Abbé Molina.

Renealmia ramosa lutea u. s, w. Pater Feuillé, amerik. Pflanzen tab. 39.

Es folgt hier die Beschreibung von Molina.

DerStamm von der Puyagen. nova wird im ganzen Königreich Chili statt des Korks gebraucht. Diese Pflanze, welche der Bromelia ananass sehr ähnlich ist, schiesst aus der Wurzel drei bis vier ungeheure Stämme von der Dicke eines Menschen herror, die nicht länger als ungefähr 20", und überall mit schwammigen, in einander gefiigten Schuppen bekleidet sind. Mitten aus diesen Stämmen schiessen die Blätter hervor, welche 4' lang, am Rande mit gekrümmten Stacheln besetzt, die denen der Ananas völlig ähnlich sind. Zwischen diesen erhebt sich ein Stamm auf eine Höhe von 9', und 3" im Durchmesser, nit einer dunkelgrünen, harten Rinde bedeckt, welche mit einer weisslichen Materie, von der Consistenz unseres gemeinen Korks angefüllt ist. Der Gipfel dieses Stammes theilt sich in mehrere kleinere Zweige, welche mit Blättern, noch viel kleiner als die Wurzelblätter, und mit gelben Blumen bekleidet werden, die 4" lang sind, aus 6 irregulären Blumenblättern bestehen und sich in eine grosse Pyramide vereinigen. Die Frucht dieses sonderbaren Gewächses ist eine dreifüchrige Kapsel, mit unendlich vielen kleinen schwärzlichen Samen angefïllt. Die Honigbehälter sind voll Honig, der von den Kindern begierig gesucht wird.

Die Araucanischen Provinzen bringen noch drei oder vier andere Arten dieser Gattung hervor, welche den Honig in sehr grosser Menge geben, der von den Eingebornen gegessen wird.

\section{Puya coerulea Lindl.}

Bot. Register tab. 11, 1840.

Diese in den "Reisen in Chili" von Mier's benannte Pourretia coerulea ist in B. Reg. nicht ausführlich beschrieben. Es wirl dort mur auf die Verschiedenheit von Pnya coaretata und obiger Species hingewiesen. Dem Laubblatte nach zu urtheilen, welches aber auch nur theilweise abgebildet erscheint, diurte diese Pflanze, deren Laubblätter auf der 
Unterfäche schmntzig gelblich erscheinen, - den Wuchs von Puya coaretata besitzen. Der Blüthenstand ist aufrecht, verzweigt, die Hochblätter am Schafte fahl lederfarbig und fein sägezähnig. Fruchtknoten eiförmig, sammt den zur Zeit der Blüthenentwicklung tief geschlitzten Kelchzipfeln hellgrün gefärbt. Kronenblätter aufrecht, wenig geöffuet, sehr hinfällig, bei $1 \frac{1}{2}$ "lang, schön dunkelblan, arm blïhend, zusammengedreht, röthlich lila werdend.

Die verkümmernden Enden des Blüthenstandes sind hier nicht zu bemerken, obwohl dieselben gewiss vorhanden waren. Wahrscheinlich waren die Blüthenzweig - Enden ganz vertrockuet mul wurden desshalb bei der Abbildung entweder gar nicht berïcksichtigt oder absichtlich weggelassen.

Puya? Gaudini Beer. (Fossile Pflanze.)

Bromelia Gaudini Herr. Flora tertiaria Helveliae, 3. Lieferung.

(Man sehe die Vorrede.)

\section{MACROCHORDIUM de Vriese.}

\section{Macr. tinctorium de Vriese.}

Niederländische Gartenbau - Schriften.

Billbergia tinctoria Martius, Annales de Gand. III. tab. 56.

Laubblitter alle vom Grunde ans steif abstehend, am Rande wellig, in der Mitte $1 \frac{1}{2}$ " "breit, verschieden lang (bis $2 \frac{1}{2}{ }^{\prime}$ ), an dem weichen, spitzen Ende stark zurückgebogen, wie eingerollt, der ganzen Länge nach mit sparrigen, kleinen Sügezühnen besetzt. Oberfliche lebhaft dunkelgrün, Unterfläche weiss, fein gestreift, matt silberglänzend. Schaft sammt dem 3" hohen Blüthenstande 1 $\frac{1}{2}$ ' lang, mit dichten, fahl-rothen, anliegenden, trockenen Bracteen besetz.t. Schaft und Grund des Blüthenstandes dicht weiss wollig bekleidet. Bläthenstand verlängert eiförmig, walzenförmig, 3 " hoch und gleichmässig über 1 " breit. Bliithen in spiralig geordneten Reihen stehend, zwisehen der weissen Wolle gebettet. Es stehen nur die fleischigen, hellgrïnen, zusammengeneigten Kelchzipfel wie eine kleine Kugel von $2^{\prime \prime \prime}$ Durchmesser vor. Der weiss wollige runde Fruchtknoten sitzt zwischen der Wolle fest aut. Blithen gerade abstehend, in der Knospe hellgriu, danu beim Aufbliihen schwärzlich griin, endlich nach dem Verbliihen ganz schwarz und hinfällig. Nach dem $A$ b. blühen wächst der Fruchthnoten rasch vor und bekommt eine eiförmig stumpf aufsitzende Gestalt; hier stehen dann die ganz entfirbten Bracteen am Schafte.

B e er, Bromeliaceen. 


\section{Nacr. melan anth u m Beer.}

Bromelia melanantha. Bot. Register tab. 766.

Es ist zum öfteren darauf hingewiesen, dass diese und Billbergia tinctoria e in e Species seien. Allein sie sind sehr leicht erkenntlich verschieden von einander.

Planze gainz steif aufrecht. Lanbblïtter am Grunde kelchbildend zusammenstehend; nur einige der Blätter sind an der Spitze eingerollt. Sägezähne an den hellgrünen, glänzenden Blättern sehr scharf, dicht stehend, schwarz, ebenso die lange Stachelspitze der Laubblätter. Der Blüthenstand überragt, steif anfrecht, nur wenig die aufrechten Laubblätter. Schaft und Blüthenstand mit bliunlich sehmutzig weisser Wolle dicht bekleidet. Bracteen an ersteren lederbram, trocken, spitz, sich gegenseitig deckend. Bliithenstand gleichförmig, 1" dick und 1 1/2" lang. Fruchtknoten und dicht anliegende Kelchzipfel kugelförmig, $3^{\prime \prime}$ Durchmesser, hell gelb-grün, sitzend. Die Blüthen abstehend, $2^{\prime \prime \prime}$ lang, brannschwarz.

\section{Macr. bromeliaefolium Beer.}

Tillandsia bromeliaefolia. Rudge, Plantarum Guianae tab. 50.

Diese Pflanze bildet nur 3 bis 4 Blitter, welche vom Grunde ans einen schmalen zierlichen Kelch formiren, der am Grunde einen kugligen Knoten bildend, hier kaum 1/2" dick, dann allmälig erweitert unl bei 4" Höhe 1 1/2" Durchmesser hat.

Die Laubblätter sind am Grunde ganz umhüllend, hier ganzrandig, weich, dann der ganzen Länge nach scharf sägerähnig, in Mitte 11/2" 1,reit, allmälig spitz endend, $2^{\prime} 3^{\prime \prime}$ lang, mit mehreren Längslinien geziert; sie sind bis über dic Hälfte der Länge steif anfrecht, dann mit einemmale schlaff überhängend. Der Schaft erhebt sich gerade aufrecht, holzig, steif, sammt dem Blïthenstande, welcher nur 2" hoch ist, 1' 10" hoch, beide weiss filzig bekleidet. Bliithenschaft $2^{\prime \prime \prime}$ dick, mit diitenrörmigen, ganz umhüllenden, etwas abstehenden spitzen, schmutzig purpurfarbigen, trockenen, etwas gestreiften Bracteen von verschiedener Länge besetzt. Die Bracteen nüchst dem Blüthenstande stehen tichte:P beissmmen und gewimnen bedentend an Lünge; sie sind hier andrecht atstehend und die längsten 3" lang. Der Blïthenstand ist ei-walrenförmig, 2" hnch, 1" dick. Die Blithen in geordneter Spirale. Die Kr ronenblätter, welche anfainglich grïn erscheinen, werden beim Verblühen lebhaft schwarz; sie sind flattrig, sehr geöfnet. Die Genitalien lürzer als die Kronenblaitter und sichtbar.

Rudge bemerkt, dass yliese und die vorhergehende Speeies (Bro- 
melia longifolia desselben Werkes) noch an lebenden Pflanzen weiter zu erforschen wären."

\section{Macr. pulehrum Beer.}

Bromelia tinctoria der Pariser Gärten.

Eine stattliche Pflanze mit aufrechten breiten Blittern, und jedenfalls die schönste Species unter den Macrochordien.

Laubblätter steif aufrecht, gleichmässig hellgriin, am Rande stark wellig, schwach stachelspitz, der ganzen Länge nach mit einer gleich breiten (1/2"), flachen Rinne versehen, am flachen Ende übergebogen, hier auch wellig eckig, schwach stachelspitz endend, hier etwas zurückgerollt, an den Rändern schwach sägezähnig, 1'9" lang, 21/4" breit, vom Grunde aus bis 8" Länge, 5" breit, hier weich, ganzrandig, braun besäumt. Die Laubblätter bilden durch das dichte Zusammenstehen am Grunde eine schöne Kclchform. Bei alten Pflanzen wird der Stamm durch das Abfallen der Laubblatter endlich sichtbar; er wird 3 bis $4^{\prime \prime}$ hroch, $1 \frac{1}{2}$ " breit, und treibt mehrere wagrecht abstehende Sprossen. Der Schaft erhebt sich in Form einer Keule, durch schöne blutrothe Bracteen gauz bedeckt, welehe dann der bei $3^{\prime \prime}$ hohe, $1 \frac{1}{2}$ " breite, runde Blïthenstand durchbricht. Dieser Grad der Entwicklung ist fiir die Pflanze der giinstigste, indem die anliegenden rothen Bracteen mit dem hellgelben Blüthenstande einen sehr schönen Effect machen. Der Schaft und Bliithenstand erhebt sich endlich iiber 9 hoch. Die Blïthen stehen in geordneter Spirale; sie sind lebhaft schwarz-braun und an den Rändern weiss filzig, etwas gegen oben zusammengedreht, spitz endend. Die Ge-

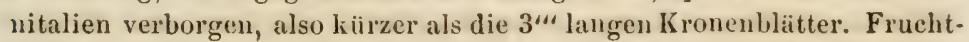
knoten und anliegende fleischige Kelchziplel eifömig, lebhaft hellgrïn, j"' lang, 1\%"“ dick. Jede Blïthe trügt eine ganz umhïllende, weiche, ganzrandige, mit herabgebogenen weichen Spitzen versehene, unterhalb tieffurchige, mit weisser Wolle bekleidete, etwas schmutzig lederfarben bemalte, sichtbare Bractee. Zunächst dem Blïthenstande stehen melrere zungenfümige, lolzige, weiss wollig bekleidete, steif aufrechte, 1"lange, \% breite Bracteen. Die Bracteen am Schafte sind kahnförnig spitz. irei absteliend, am Grunde halb stielumfassend, 2\%" "lang, 1 "breit, steif, trocken, lebhaft blutroth, am Grunde in violett ïbergehend. Der Schaft ist sehmutzig röthlich und dicht mit weisser Wolle bekleidet.

Macr. strictum Beer.

Beer's Garten, aus Samen. Brasilien.

Pflanze steif gerade aufgerichtet. Laubbläter am Grunde 3" breit. bauchig, ganzrandig, bei 5 " Hïle mit einemmale $1 \frac{1 / 3}{/ 2}$ breit. 2" 2" lang, 
ganz gleich breit, scharf sägezähnig, an der scharfen Spitze $1 / 2$ " eingerollt, hellgrïn, mit gleichmässig silberglänzendem, wolligem Anfluge. Lanbblitter sechs bis sieben, alle gleich hoch. Schaft mit dem $3^{\prime \prime}$ hohen, 1" dicken, walzenförmig runden Blütlıenstande $3^{\prime}$ lang, sehr dicht mit weisser Wolle bekleidet. Brarteen am Schafte, bis zum Blüthenstande schmutzig weinroth, glatt, fein sägezähnig, gestreift, trocken, steif, mit sehr spitzem Ende, hier derb hellgrün, holzig, mit rothem Anfluge. Sie nmhüllen den Schaft der ganzen Länge nach, gegen den Blüthenstand kürzer werdend, hier 1" lang, am Grunde aber 5" lang. Der Blüthenstand trägt unterhalb eine umhïllende, $3^{\prime \prime}$ lange, in Mitte etwas eingeschnïrte, mit langer, dichter, rein weisser Wolle bekleidete Bractee. Die Blüthen stehen in einer Spirale. Fruchtknoten und Kelchzipfel eiför-

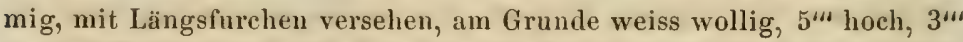
breit, hellgrün, mit Purpurfarbe bemalt. Kronenblätter fleischig, schwarz, aufrecht, flattrig, offen. Genitalien kïrzer als die Kronenblätter, goldgelb, sichtbar. Bractee bei jeder Blüthe, ganz umfassend, mit grünem Rande, glatt, weich, dann mit langer weisser Wolle dicht bekleidet.

\section{ECHINOSTACHYS Brongniard.}

\section{Echin. Pinellian a Brongn.?}

Laubblätter alle steif aufrecht, am Grunde bauchig, eine tiefe Rinne bildend, $2 \frac{1}{2}$ " breit, in Mitte $1 \frac{1}{2}$ " $-22^{\prime \prime}$ "lang, scharf stachelspitz, gleichmässig fein sägezähnig, flach endend, lebhaft grasgrün, auf der Unterfläche durch kleiigen Anflug schwach weisslich gebändert, nur die zwei untersten Laubblätter etwas übergeneigt. Blüthenschaft bis zum Bliithenstande 1' 4" lang, mit weichen, trockenen, mit Längsstreifen versehenen, etwas bauchigen, sehr spitz endenden, lebhaft prächtig blutrothen, an der Spitze grasgrün bemalten, verschieden langen, am Grunde stark umfassenden Bracteen besetzt. Der Schaft hell roth, nur nahe am Blüthenstande sichtbar.

Blïthenstand walzenförmig, unten mit herzförmigen, stark weiss wolligen, steifen, gewimperten, braun gegranten Bracteen umstellt. Die Blüthen stehen sehr dicht in Spirallinien beisammen; jede Bliithe trägt eine lang und scharf gegrante, haarige, am Grunde mit weisser Wolle umgebene braune Bractee. Die Granen bilden am Ende des Blüthenstandes einen aufrechten braunen Schopf. Frnehtknoten und stachelspitze Kelchzipfel eirund. hellgrün, wenig braun behaart. Kronenbläter in der Knospe goldgelb, die geöffnete Krone wagrecht abstehend, sehr dunkel schwarzbrann, innen hellgelb, filzig. Der Blüthenstand ist $23 / 4$ hoch 
und 1" breit (ohne geöffnete Bliithei, von stumpf kegelförmiger Gestalt; an Grunde durch die Wolle rein weiss, dann durch die gleichzeitig sich entwickelnden Knospen hellgrün, und endlich durch die dicht strahlenförmig abstehenden Granen der Bracteen lebhaft lcderbraun. Der Granenbiischel steht wie eine kleine anfrechte Garle am Ende des Blïthenstandes und trïgt viel zu dessen zierlich schöner Gestalt bei.

\section{Echin. ros ea Beer.}

Fchinostachys Pincliana, ans dem Garten des van Houtte.

Laubblätter zahlreich, abstehend, dann ïbergebogren, am Grunde kelchbildend zusammenstehend, hier glattrandig, $3 \frac{1}{2}$ " breit, dann allmälig versehmälert, - in Mitte 2" breit; 1' 5 "lang, mit sehr sehwacher Stachelspitze, die Ränder aber mit regelmässig dicht stehenden, ${ }^{\prime \prime}$ langen, gerade abstehenden schwarzen, scharfen Sïgeziihnen besetzt; auf der Ausscufläche auf lebhaft grasgrïnem Grunde mit zart weissem $\Lambda$ nlluge geziert. Unterflïche sehr schön, wie silberglïnzend, mit einigen dunklen Querbinden. Schaft weiss wollig bekleidet, 1'lang, diinn, von stark umfassenden, dann bauchigen, steif aufrecht und spitz endenden Bracteen ganz eingehüllt, diese zart und schön hell rosenfarben, mit bräunlicher Spitze, die Rïnder derselben fast weiss. Die rothe Bractee zunächst dem Blüthenstande ist schon hellbraun gegrant.

Blüthenstand $13 / 4$ " hoch und über $3 / 4$ " breit, von steif aufrechten, stark weiss wollig bekleideten, stumpf spitzen, $4^{\prime \prime \prime}$ langen und eben so breiten Bracteen umstellt. Bracteen bei jeder Blüthe, sehr stark weiss wollig bekleidet, dann mit einer braunen, scharf spitzen, behaarten Krone von 4"' Länge versehen. Fruchtknoten und stachclspitze Kelchzipfel lebhaft grün, am Grunde stark weiss wollig bekleidet. Kuospen hellgrïn, dann tief orangefarben, endlich geöffnete Krone, braun-schwarz, abstehend, 2 " lang, im innern grïnlich filzig. Der Grancubuischel am Ende des Blüthenstandes bilçet eine kleine ausgebreitete Garbe; dieser Pflanze gereichen die braunen abstehenden Granen zur besouderen Zierde.

Echin. ey lindrica Ad. Brongn. (Fossil.)

Jonographie des plantes fossiles p. W. P. Schimper et Mouquet tab. 23.

Schimper sagt über diese Formen: „Wir wollen bei diesen wenigen Ueberresten, bei denen sich kein befriedigendes Urtheil fällen lässt, nicht versuchen, an welche Pflanzenform der Jetztzeit selbe sich anschliessen dürften."

Die Form des abgebildeten Blïthenstandes erlaubt dennoch, wenn anch nicht mit voller Bestimmtheit, eine Anreihung an levende Formen. 
Eine Aehnlichkeit findet sich mit den lebenden Echinostachys, wesshalb ich mich bewogen fand, sie hier anzureihen. Der Umstand, dass sich bei der fossilen Pflanze keine Spur von Granen findet, welche die lebenden Echinostachys so sehr auszeichnen, ist wohl nicht gering, allein diese Fortsätze der Deekblätter konnten auch zu Grunde gegangen sein.

Echin. ob long a Brongn.

Ionographie des plantes fossiles p. Schimper et Mouquet tab. 23.

(Siehe Echinostachys cylindrica.)

\section{CHEV ALIERA Gandichand.}

Chev. ornat a Gaud.

Bonite, Voyage autour du monde. Gaud, tab. 62.

Pflanze mit wenigen tief rinnenförmigen, am Grunde wenig um. fassenden, bei $2^{\prime}$ langen, bis 5" Höhe ganzrandigen, dann gleichmässig sägezähnigen, schwach spitz endenden, in Mitte $1 \frac{1}{2}$ " breiten, am oberen Theile flachen Laubblättern.

Schaft gan z nackt, steif aufrecht, rund, 5 " hoch, 4"“ dick. Blïthenstand 6 " hoch, $2^{\prime \prime}$ breit, walzenförmig (einer etwas verlängerten Ananassa ohne Blüthenschopf gleichend). Fruchtknoten am Grunde frei, diese und die stachelspitzen Kelchzipfel anf breiter Basis anfsitzend, bauchig flaschenförmig, von 1/2" Durchmesser, von einer lang stachelspitzen, etwas faltigen Bractee umgeben. Blüthenkrone ganz versteckt, die Blüthen in spiraliger Reihe dicht aneinander. Der Blüthenstand endet mit den aufrechten zahlreichen Spitzen der Bracteen.

Farbe u. s. w. nicht bekannt.

\section{Chev. spha er oceph a la Gaud.}

Bonite, Voyage autour du monde. Gaud. tab. 61.

Wir sind bei einer Pflanzenform angelangt, welche eine auffallende Aehnlichkeit mit Ananassa sativa hat; leider fehlt die Beschreibung hierzu, was um so mehr zu beklagen ist, da hinsichtlich der Blattformen u. s. w. es von Wichtigkeit wäre, zur Beurtheilung auch die Beschreibung zuziehen zu können.

Laubblätter allmälig spitz endend, wahrscheinlich ïber $1 \frac{1}{2}$ ' lang, in Mitte $1 \frac{1}{2}$ " breit. Schaft mit ganzrandigen, nur an den Spitzen etwas sägezähnigen Bracteen besetzt, welche auf der Abbildung als gegenständig gezeichnet erscheinen. 
Blüthenstand fast kugelrund, 6" hoch, 5" breit. Fruchtknoten und stachelspitze Kelchzipfel kugelig, 1/2“ im Durchmesser, umgeben von umfassemlen ganzrandigen, mit scharfer Stachelspitze aufwärts stehenden Bracteen. Bracteen und Fruchthnoten am Grunde frei. Die Kronenblitter stehen nur selı wenig zwischen den Kelehzipfelı vor.

ANANASSA Lindley.

(Siehe die Abhandlung iber Ananassa.)

\section{TILLANDSIA Linné.}

Till. us n e oides Linné.

Die Pflanze bildet lang herabhängende, sehr schwer zu entwirrende Massen matt gelber, wolliger, fadenartiger, dünner Aeste, welche die Zweige der Bäume u. s. w, nach Art unseres Bartmooses in ungeheuren Massen bedecken.

Es dürfte bis jetzt noch nieht gelungen sein, diese Pflanze lebend nach Europa zu bringen, da sie unterwegs sehr leicht vertrocknet. Die ganze Pflanze ist gewölnlich fahl hellgrün.

Leider fehlt es noch an Pflanzen, an denen man die Blïthe gehörig studiren könnte. So findet sich jene Form, welche in Brasilien so häufig an den Baumisten gleich einem Barte herabhängt, und die nach Director Schott in Schönbrunn ganz kleine, den weiblichen Blithen bei Vallisneria spiralis einigermassen gleichenden, also grünlichen Blüthchen bilden sollen, - nicht in den Herbarien, welehe ich untersuchte; wohingegen jene Formen der Till. usneoides, welche sich in anderen Theilen von Amerika finden, in sehr instructiven Exemplaren aulbewahrt sind. Es ist mit Gewissheit anzunehmen, dass unter jenen Formen, welche sich mit der Benennung „Till. nsneoides" in den Herbarien finden, mehrere gute Species vorhanden sind.

Möge es einmal Jemanden gefallen, diesen seltsamen Gebiliten an den natürlichen Standorten im lebenden Zustande eine besondere Aufmerksamkeit zu widmen.

Es folgt hier die Beschreibung von $\mathrm{Ru}$ iz et $\mathrm{P}$ a von und Anderen:

Blüthenstiel einblüthig, kurz. Stengel ästig, fadenförmig, heralıgebogen, hangend. Blätter pfriemlich, fadenförmig.

Tillandsia (usneoides) fadenförmig, verzweigt herablängend, scharf. Li in né, Sp. Plant. II, pag. 9. 
Viscum caryophylloides: Aeusserst zart, von den Aesten der Bäume nach Art des Mooses, herabhängend. Die Blätter wie bereift. Die Blumenkrone dreiblätrig. Samen fadenförmig. Sloa ne, Jamaica 77, Hist. I, pag. 191, Fig. 23. -

Die Pflanze perennirend, weisslich, iilıerall mit kleienartigen, dicht gestellten und trockenhäutigen Schuppen bedeckt, mit zahlreichen und gehäuften Sprossen, die verzweigt, sehr lang und herabhängend sind. Die Wurzel haarförmig und dünn. Der Stengel rund, gebogen, schlaff hängend, 2 bis 4' lang, fadenförmig, durch Abgliederungen verdünnt, zusammengedriickt. Die A ste ganz gleich. Die Blätter abwechselnd, am Stengel entfernt und an den Zweigen nahe stehend, cylindrisch pfriementürmig, fast haarfein, gebngen und scheidig. Pie Blïthenstiele platt gegenständig, einfach, ans den Scheiden der Bliitter entspringend, einblïthig, an der Spitze zweiblittrig, das höher stehende Blatt selir kurz. Der Kelch trockenhäutig, die Blättchen derselben unter sich zusammengedreht. Blumenblätter drei, purpurfarbig. Die Kapsel länglich lineal, schwach dreiseitig, dreiklappig. Die Klappen gedoppelt; die äusseren weisslich, die inneren purpur-fahlgelb. Die Samen länglich lineal, fahl gelblich mit Papus.

Standort: Warme Abhänge in Peru, Tarma, Huanuco u. s. w., auf Bäumen, Sträuchern, Cactus und Felsen besonders vorkommend, auf den Gattungen Achras, Lucuma, auf Pirus malus und Laurus persea; in Tarma, Salvage genannt, wie auch Chaopera u. s. w.

Blithe: Oetober, November, December.

R. et $\mathrm{P}$ av.

\section{Till. erin it a. (Autor?) [Herbar Willdenow.]}

Diese PQanze bildet höchst merkwürdige, lange, weitschweifige, glänzend schwarze, kaum rosshaardicke fadige Aeste, welche sich oft gemeinschaftlich mit Till. usneoides finden.

Die Sternschuppen scheinen bei dieser Species nur ganz klein und hinfällig zu sein, indem man bei bedeutender Vergrösserung nur die Ueberreste von Schuppen findet. Dic Laubblätter kaum 1/4" lang, umhiillend, glatt, zungenförmig endend. Blüthen einzeln, mit drei Stuitzblättchen umstellt. Die Kronenblätter innen und aussen stark behaart. Neben der Blüthe erscheinen keine Verzweigungen; dies ist auch die Ursache, dass diese Form sich sehr wenig verzweigt und desshalb auch nur ein ganz loses Gewirre bildet.

Leider ist es noch nicht vergönnt, in Europa diese seltsamen, abweichenden Formen in lebendem Zustande zu studiren, wesshalb auch über die Färbung der Bliithen wenig verlässliches zu sagen ist. Wahı- 
scheinlich gibt es hierron noch mehrere gut unterscheidbare Formen: allein selbst hierzu ist das Material der IIerbarien noch nicht ansreichend versorgt.

Till. trich oides Humb. Bonpl. Kth.

I'luckenectii Opera omnia I. tab. 26, fig. 6. (?)

Zweige fadenförmig, hellbraun, von der Dicke eines starken Rosshaares. Blätter alle umhüllend, nur am Ende etwas geöffuet, $1 / 2$ "lang. Blüthen einzeln aus einem umhüllenden Blatte hervortretend, aus welchem sich auch Scitenverzweignngen bilden. Von e in em Blat te $\mathrm{zum}$ andern beschreiben die $Z$ weige entgegengesetzte halbe Bogen. Die ganze Pflanze dicht mit sternförmigen Schuppen besetzt, welche jedoch bei todten Pilanzen leicht abfallen, wo dann der schwärzliche Zweig zu sehen. Kronenblätter stumpf spitz, innen stark behaart. Die Staubbentel lurz gestielt, mit den Kronenblittern verwachsen. Kelchzipfel fast $1 /$, lang; diese und die $1 / 4$ "weit vorragenden Kronenblätter zusammen bei $1 / 2$ " lang, diese hell gelblich gefïrbt.

Diese Form bildet keine so lang herabhüngenden Zweige; es ist mehr einem Gewirre von Rosshaaren vergleichbar. Wahrscheinlich treibt der Sämling erst einen ganz kleinen aufrechten, linienförmigen Blattbiischel, aus dessen Blattachseln sich dann erst die langen Seitenzweige zu entwickeln beginnen. Unter den Restiaceen finden sich Formen, welche, wenn man einzelne Verzweigungen des Blüthenstandes betrachtet, eine auffallende Aehnlichkeit mit den Formen von Tillandsia haben.

\section{DIAPHORANTHEMA Beer.}

\section{Diaph. eapillaris Beer.}

Till. capillaris R, et P. Flora Peruv, et Chil. R. et Pav, tab. 271 .

Es folgt hier die Beschreibung von $R$ uiz et $\mathrm{P}$ avon:

Pflanze. Blüthenstiel meist einblumig, haarduinn, kahl, dreimal länger als die Blätter. Die Blätter lineal pfriemlich, der Stengel gabeltheilig.

Die Pflanze durch zahlreiche Sprossen rasenbildend, weisslich grau, mit sehr kleinen kleienartigen Schuppen dicht bekleidet. Der Stengel gabeltheilig, beblättert, $1 / 2^{\prime}$ hoch. Blätter dachziegelförmig, zweizeilig, dicht stehend, lineal pfriemlich, aufrecht abstehend, dann zuriickgebogen, gerinnt, mit gestreifter Basis, halbstengelumfassend. Die Blüthenstiele achselständig (axillaris), aufrecht, dreimal länger als die Blätter, leicht gestreift, haarfein, kahl, einblüthig, seltener zweiblüthig, 
gegen die Basis einblättrig, oberhalb nackt. Bracteen einzeln stehend, länglich, kahl, zusammengerollt, nervig. Kelch dreitheilig; die Zipfel zusammengerollt, letlerartig, truckenhäntig, schwäzlich violett. Blumenblätter kaum länger als der Kelch und weiss. Staubbentel gelb. Kapsel lineal, zweimal länger als der Kelch, dreiklappig. Die äusseren Klappen blass, die inneren schwillig, glïnzend, schwïrlich violett. Die Samen länglich lineal, mit weissem, behaartem Stiele.

Standort: Warme Orte in Peru; sehr häufig anf Mauern, Bäumen und Felsen.

Bliithezeit: November und December.

Sie unterscheidet sich von der ilur verwandten Tillandsia recurvata durch die zahlreichen mit mehr kleienartigen leprosus) Schuppen bedeckten Sprossen, durch gabeltheilige Stengel und gedrängtere, breitere und kürzere Blätter, die aufrecht abstehend eine schmale Basis haben; ferner durch die haarfeinen Schäfte, die dreimal länger als die Blätter und glänzend kahl sind; durch die einzeln stehende, einblüthige, nackte, stumpfe und zusammengerollte Bractee, und endlich durch die griinliche Kapsel.

\section{Diaph. virescens Beer.}

Till. virescens R. P. Flora Peruv. et Chil., R. et Pav. tab. 270.

Es folgt hier die Beschreibung von Ruiz et Pavon:

Blüthenstiel einblüthig, von der Länge der Blätter. Die Bractee ein• zeln stehend, zusammengerollt. Blätter lineal pfriemlich. Kapsel grüulich.

Pflanze rasenbildend, niedrig, weisslich, mit kleiigem Anfluge und 1" langen zahlreichen Sprossen. Blätter dachziegelförmig; zweireihig, lineal p frienulich, unterhalb dem Stengel angedrückt, oberhalb absteheud, lier zurückgebogen, an der Basis gestreift. Blïthenstiel achselständig, einzeln stehend, von der Länge der Blätter, einblïhig. Die Bracteen einzeln, etwas abstehend, einbliithig, länglich, zusammentrerollt, grestreift. Der Kelch spelzartig, kurz. Blumenbläter liaum den Keleh iiberragend, an der Spitze etwas abstehend. Kapsel doppelt so lang als der Kelch, griunlich, dreiklappig, die inneren Klappen purpur-schwarz. Die Samen klein, fahlgelb mit Papus.

Standort: Warme Abhänge in Peru, Huanuco.

Blüthezeit: December und Januar.

\section{Diaph. un iflora Beer.}

Till. uniflora Knuth. - Sloane, Jamaica, Vol. I, tab. 121, Kig. 1.

Pllanze lilein, ganz mit lichtbraunem Filze dicht bekleidet. Laulsblätter am Grunde umfassend, dann verwachsen, pfriemlich, aufrecht, 
und anch in einem Bogen gegen abwïrts geneigt, bis 2" lang, 1" dick. Bliithenstiel sehr diinn, anfrecht, filzig, seitenstindig, am oberen Theile der Pflanze $2 \frac{1}{2} "$ lang.

Blüthenstand aus melureren ïbereinander liegenden Bracteen zu einem kleinen Aehrehen gestaltet. Bliithe purpurfarbig.

Die Pflanze verzweigt sich stark und bildet ein Stïmmchen von 11/3" Höhe.

Diaph. versicolor Beer.

Sloane, Jamaica, Vol. I, tab. 122, Fig. 1. - Till, tenuifolia? Römer et Schultes pag. 1215.

Die Pflanze bildet am Grunde einige unregelmässige, stumpf zungentörmige, breite, bauchige, bei 1" lange glatte Blätter, aus deren Mitte sich ein dicht stehender Büschel aufrechter, 4 bis $9^{\prime \prime}$ langer, stumpf endender runder, am Grunde wenig umfassender Laubblätter erhebt. Der seitenständige Blüthenstand trïgt anliegende Laubblätter; welche die Blüthen weit überragen; diese sind purpurfarbig und von einer umfassenden spitzen Bractee von 1" Länge umgeben.

Die Lanbblättel sind vom Grunle aus griin und enden mit einer rothen Spitze.

\section{Diaph. subulata Beer.}

Till, subulata Arrab. Flora Flumin, III, tab. 127.

Eine kleine Pfanze mit aufsteigendem Wuchse; sic bildet Biischcl von strahlenförmig abstehenden, pfriemlichen Spitzen, am Grunde mit amfassenden, bei 3 "langen, in Mitte $2^{\prime \prime}$ breiten Laubb]ättern. Der reich beblätterte Blïthenstand ist achselständig, hier die Blätter 3/4 Iang. Blïthen aus aufrechten, anliegendenScheiden hervortretend, wahrscheinlich purpurfarbig. Die Kronenblätter ansgebreitet, 3“" lang.

\section{Diaph. triflora Beer.}

Till. triflora Arrab. Flora Flumin. tab, 134.

Eine bei $1 \frac{1}{2}$ ' hohe, vom Grunde aus stark verzweigte, aufrechte Pllanze, welche bei den oberen $\mathrm{Zweigen} \mathrm{Biischel} \mathrm{von} \mathrm{Wurzeln} \mathrm{treilst} \mathrm{-}$ (sich wohl hiermit an den Bäumen u. s. w. aufrecht erhält). Die Laubblätter sind reitend, wechselständig, ziemlich gleichmässig $1^{\text {" lang }}$ und $1^{\prime \prime}$ breit, wahrscheinlich rund und am umfassenden Grunde plattgedrückt. Die Zweige sind bei 3" lang. Am Ende der Zweige erscheinen die Blïthen in hängenden Büscheln, und zwar aus der Achsel des rorletzten Blattes. Die Kronenblätter glatt, am Ende rund und $4^{\prime \prime \prime}$ litn!r, vermuthlich violett oder purpurn von Farbe. 
Diaph. recurvata Beer.

Till. recurvata Linné. Flora Peruv, et Cbil, R. et Pav. tab. 271.

Es folgt hier die Beschreibung von $\mathrm{Ruiz}$ et Pavon:

Blüthenstiel zw e iblü th i g, mit kleiigem Ueberzuge, wenig länger als die Blätter, die fast pfriemlich, geneigt und aufrecht sind.

Tillandsia (recurvata) mit fast pfriemlichen, gebogenen und scharfen Blättern, einbliithigen Halmen und zweibliithigem Balge. Li n né, Sp. plant. tom II, pag. 9.

Pflanze rasenbildend, mit zahlreichen gehäuften Sprossen, die 4 bis $5^{\prime}$ hoch, aufrecht, zweitheilig oder einfach, zugleich mit weisslicher Kleie überall bedeckt sind. Die Blätter abwechselnd, zweireihig, dachziegelförmig, pfriemlich, oberhalb gerinnt, unten mit breiterer Basis; die unteren zurückgebogen, die mittleren fast horizontal abstehend, die oberen aufrecht und länger. Die Blüthensticle einzeln stehend, fadenförmig, wenig länger als die Blätter, unmerklich gestreift, gegen die Basis einblättrig, zweiblüthig. Bracteen drei, die Blüthen umfassend, lanzettlich, spitz, aufrecht, - angedrüelst; die äussere Bractee grösser und spitzer. Der Kelch zur Blüthezeit purpurfarbig, die Blumenblätter violett, die Staubbeutel fleischroth. Die Kapsel lineal cylindrisch, fast dreimal länger als der Kelch; die Klappen gedoppelt, die äusseren weisslich, spelzig, die inneren purpur-fahlgelb, mit papusartigem, haarigem Stiele.

Standort: Wärmere Orte in Peru, häufig in den Provinzen Huanuco und Tarma, auf Bäumen, Felsen und Mauern.

Blüthezeit: December und Januar.

Die Abbildung der Till. recurvata aus Slaone, Jamaica, Hist. I, pag. 190, tab. 121, ist der obigen vollkommen gleich.

\section{Diaph. b iflor a Beer.}

Till. biflora R. et Pav. Flora P'eruv, et Chil. R. et Pav., tab. 268.

Diese Pflanze hat die Laubblätter kelehbildend zusammenstehen und gleicht in der Tracht derselben der Guzmania tricolor; nur sind hier die Laubblätter viel kürzer und auch schmäler.

Es folgt hier die Beschreibung von $\mathrm{Ru}$ iz et $\mathrm{Pavon}$ :

Pf'lanze. Schaft traubig, Blüthen gepaart, Blätter schwertförmig, spitz. Pflanze perennirend kahl, oft Sprossen treibend.

Schaft einzeln, einfach, $1 \frac{1}{2}{ }^{\prime}$ lang, aufrecht, rund, mit abwechselnd stehenden lanzettförmigen, spitzen, gestreiften und stengelumfassenden Schuppen besetzt, oberhalb traubig. Die Blätter schwertförmig, spitz, sich gegenseitig anliegend, fast gleich lang, aufrecht abstehend, gestreift, die äusseren ein wenig zurückgebogen. Die Traube einfach, $1 / 2$ ' lang. 
Die Blüthen abwechselnd stehend, gepaart, mit kurzen Bliithenstielen versehen und mit langen, lanzettlich spitzen, concaven, gestreiften, an der Spitze grünlich blassen, zurücligebogenen Blïthenscheiden umstellt. Die Kapsel länglich, 1" lang, gerade, von okergelber Farbe. Die Samen zahlreich, lineal, papusartig rauh gelsrönt.

Standort: Peru, Anden bei Muna. Früchte: August, September. Die Blüthezeit ist nicht angegeben.

\section{DYCKIA Schultes fil.}

\section{Dyckia rariflora Sehult. \\ Bot. Register tab. 1782. \\ Bot. Magazin tab. $3 \$ 49$.}

Dieses kleine Pllänzehen ist sehr verbreitet in den Sammlungen und erträgt eine sehr niedere Temperatur, - wie keine andere dieser Familie. Die Laubblätter stehen alle strahlenförmig, gleichmissig steif ab und bilden einen sehr zierlichen Blattbiischel. Der Schaft ist sehr steif, bei $1 \frac{1}{2}$ "lang, anfrecht, mit kleinen trockenen Scheiden besetzt. Die Aehre einfach. Blüthen schön zinnoberroth; eben so auch die Blüthenstielchen und die Kelchzipfel gefürbt. Die Kronenzipfel abstehend, ganz geüfnet; die Genitalien kürzer als diese. Staubbentel goldgelb.

Laubblätter tiefrinnig, fast fleischig, allmälig schmäler werdend, mit stumpf spitzen Enden, am Grunde stark umfassend, an den anfgebogenen Blatträndern mit sehr entfernt stehenden, fast gerade anfgerichteten Sägezähnen bewatinet. Auf der Aussentläche hell lebhaft grün, Unter@äche dieht und fein weiss linirt, bei 5 "lang, kaum in Mitte $1 / 3^{\prime \prime}$ breit.

Dyckia princeps Lemaire.

Jardin fleuriste tab. 224, 225.

Diese słattliche sehr schöne Pflanze bildet einen Buischel fiei abstehender, am Grunde wenig unfassender, fleischiger, entlernt sägezähniger, gegen das Ende schlaffer, stumpf spitz endender, 1" breiter, 1. $8^{\prime \prime}$ langer, etwas gestreifter Lanbuliatter. Der Blïthenstand erhebt sich aufrecht, stark verzweigt. Blüthen wie bei Dyckia rariftora.

\section{Dyckia tuberosa Beer.}

Till. tuberosa Arrab. Flora Fluminensis tah. 136.

Die Pflanze bildet einen runden, bei $2 \frac{1}{2}$ "Durchmesser haltenden Stamm, mit einen Biischel abstehender, ïbergebogener, fleischiger, 1/2" breiter und bei 1' langer, gleichmässig entfernt abstehender sägezähniger 
Laubbätter besetzt. Das Ende der Blätter ist stumpf und wehrlos. Der unverzweigte Blïthenstand erhebt sich seitlich zwischen den unteren Laub. blättern nnd trägt bei einer Iöhe ron $11^{\prime}$ nur wenige, etwas geneigte Blüthen. Fruchtknoten und Kelchzipfel fast kugelig, 1/2" lang. Kronen. blätter dreieckig zusammenstehend, auch ${ }^{2} / 2$ "lang.

Färbung unbekannt.

\section{AECHMEA Ruiz et Pavon.}

Aechm. panieulata R. P.

Flora Peruv, et Chilensis. Ruiz et Pavon tab. 264.

Es folgt hier die Beschreibung von Ruiz et Pavon:

Prodrom us Flora Peruv, et Chil. Ruiz et Pavon, pag. 37, tab. 8.

A echmea R. et Pav.

Kelch: Blüthendecke doppelt; die äussere unterständig, glockenförmig, trockenhïutig, dreispaltig, die Zipfel last rundlich, stumpf, der dritte Zipfel stachelspitz (Liactee). Der inmere (eigentliche) Kelch oberständig, dreitheilig. Zipiel eifürnig, zusammengerollt.

K rone dreiblättrig, die einzehnen Blittter lanzettlich, an der Spitze zuriickgebogen und dann verschmälert.

Nectorium: zweiförmige Schuppen an der Basis eines einzelnen Blumenblattes.

S t a u b e fässe sechs, fadenförmig, von der Länge der Krone. Die Staubbentel lineal.

Pistil: Fruchtknoten eiförmig. Stiel ladenförmig, von der Länge der Staubgefässe. Narbe dreitheilig, die einzelnen Theile spitz.

Kapsel eifürmig, dreilächrig, dreiklappig.

st a men viele, fast eiförmig.

Unterseheidungs - Charakier:

Krone dreiblittrig. Keleh doppelt, der innere oberständig; der dritle Zipfel des äusseren Kelches stachelspitz.

bie Kronenblitter drehen sich zur Zeit der Reife mit den Stanbgefässen nud dem Stengel spiralig zusammen. Species nur eine, krautartig.

Das Genus "Aechmeac luaben wir nach dem dritten Zipfel des äusern Kelches, der in einem Stachel endet, benannt. 
Aechmea paniculata.

Pflanze: Schaft traubig, rispig. Blätter schwertförmig, gerinnt, sägezähnig, ganz kahl.

Schaft seitenståndig (lateralis), aufrecht sich entwickelnd, 2 ' hoch, rund, mit einer grossen Rispe, aus sehr vielen langen und vielblithigen Trauben zusanmengesetzt. Blätter zahlreich, dachziegelförmig, schwertfürmig, gerinnt, an den Rändern sägezähnig, unterseits weisslich. Die ïnsseren Blaitter nach und nach kürzer werdend. Die Zähne eingebogen und fahlgelb. Rispe gross, endständig, in sehr viele Tranben verzweigt.

Blïthenstiele: die gremeinen 1' langr und noch darüber, traubig verzweigt, mit lanzett-daumenbreiter, scharfer, gestreifter und abhängender Bractee umstellt, vielblithig. Blithensticlchen zerstreut, zwei- bis dreiblüthig, an der Basis und in der Mitte mit stachelspitzen Rudimenten von zwei bis drei verbildeten Blitthen, durch eine lange, halbpfriemenhörmige, stachelspitze und herabgebogene Bractee unterstützt.

Blïthen: die innersten sitzend, die endständigen mit Blüthenstielchen.

Der untere Keleh (Bractee), oder viehmehr dic Schuppe, den Frththlunteu umfassend, einblätterig, becherförmig, schwach dreifielrig oder dreikertig, lalb zusammengerollt, von oben bis zur Basis gespalten, gestreift, trockenhüutig, die mitllere Nervatur in eine scharfe, priemenfömige stachelspitze endigend und bleibend. Der obere Keleh die Kelchzipfel, dreitheilig, Jederartig, trockenhüutig bleibend, die Zipfe] am Rande um sich gerollt. Die Krone gelh-griü, viermal länger alsder Kelch. Die Staubbutel aufliegend, gelb. Samen länglich, etwas zusammengedriickt, schwarz, ju einem weichen Fruchtbrei eingebellet. Die Blumenblitter rollen sich beim Verblühen zusarnmen.

(Siehe Flore Peruv, et Chil. pag. 47, tab. 264.)

Standort: Haine der Anden. Peru anf Bämmen. Poznzo an inszerst warmen Orten. Blïthezeit September; October.

\section{Acchm. setigera Martius. \\ Herbar des Wiener Musenms.}

Blïthenstand steif anfrecht, stark verzweigt, an then unieren, 1 " bis $1 \%$ "langen Zweigen sind die Bhiithen ganz verlïmmet. Es fimlen sich

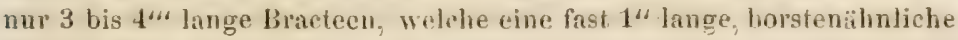
Stachelspitze tragen.

Die Bracteen bei den blithen sind sehr eigenthimlich gestaltet: ein. Drittheil der Hreite ist ter Länge nach tiet' geriflt, banchig; nnd tragt eine lange borotenähuliche stachelspize; die zir ei anderen Dritt 
theile sind glatt und enden ebenfalls banchig. Diese Bractee umschliesst die Blüthe dergestalt, dass die Borste in die Mitte zu stehen kommt und verursacht, dass wenn man nicht genau sieht, man zwei sich kreuzende Bracteen zu selsen glaubt, wovon die eine glatt und glänzend, die andere aber gestreift und matt erscheint. Dieselbe Bildung findet sich bei A. paniculata.

Obwohl hinsichtlich der Entwicklung des Blüthenstandes weder in Römer und Schultes, noch bei Endlicher etwas erwälnnt wurde, glaube ich doch voraussetzen zn dïrfen, dass auch diese Pflanze einen seitenständigen Blüthenstand habe.

Es folgt hier die Beschreibung von Poeppig et Endlicher:

Schaft beblätert, die Rispe traubig, cylindrisch, mit am Grunde nackten und entfernt stehenden zwei- bis dreibluithigen Zweigen. Die Bracteen der Blüthen ungleichseitig, in einen Becher zusammengerollt und lang dornig begrant. Die ïusseren Zipfel der Blüthenhülle stachelspitz, die inneren spitz, an der Basis gefranzt. Die Blätter aus banchig verbreiteter Basis zungenförmig und wie abgebrochen spitz.

An Bäumen bei Ega. November.

Endlicher sagt: Die von Schultes als gute Species in Zweifel gezogene Planze hat ihren Charakter darin, dass dieselbe, obwohl sie einen beblätterten Schaft treibt, dennoch einen mit Bracteen besetzten Blïthenstand treibt. Diese Species ist am furchtbarsten in allen ihren Theilen bewehrt.

\section{DISTEGAN'THUS Ch. Lemaire.}

\section{Disteg. basilate $\mathrm{r}$ a lis Lemaire. Flore de Serres, van Houtte.}

Planzenform sehr zierlich, lange Sprosse treibend, welche entweder kriechend oder herablängend (je nach dem Standort auf den Bäumen) sich finden. Stamm verkürzt. Laubblïtter dentlich gestielt, in Länge von $1 / 2$ bis $1 \frac{1}{2}$, ani der Untertitiche weiss filzig, am Gunde tiefrinnig, stark umfissend, damn gestielt, hier $1 / 2$ "breit, mit gerade abstehenden Stachelzähnen besetzt. Mit einemmale breitet sich die Blattfäche $3 \frac{1}{2}$ " ans, bekommt eine herzförmige Gestalt mit weichen wolligen Rändern und mit kleinen scharfen Sägezähnen bewaflıet. Die Laubfäche endet in eine sehr verlängerte Spitze, welche weich spitz endend, hier stark zuriickgebogen ist. Blïthenstände kugelig, stiellos, 4" lang, 2" breit. Deckblätter lachziegelfürmig, eifürmig, am Gruntle verlängert, an den Rändern fein scharf sägezälnig und stachelspitz, lebhaft weinroth. Blüthen 
einzeln, zwischen den Bracteen, lebhaft hellgelb. Kronenblätter gleichförmig ausgebreitet, bei $3 / 4$ " lang. Kelchzipfel schwach stachelspitz. Genitalien zwischen den Kronenblättern kaum sichtbar. Staubblätter tief orangefarben. Beeren dicht zusammenstehend, 1" lang; 1/2 "breit, schmutzig braun-gelb, eiförmig verlängert.

\section{A n h a n g.}

\section{Cochliopethalum Sehüehi i Beer.}

(Beschreibung zu Seite 70.)

Pflanze von sehr zartem Bau. Laubblätter zierlich in einem Bogen alstehend, am Grunde breit nmfassend, hier hell lederbrann, mit durchsiehtig dïnnem, weissem Rande, tann gelblich weiss, cndlich del ganzen Lïnge nach gleichmässig hellgelb-grïn, 1/2'lang, mit kurzen, braunem, fast stehendem. spitzem Ende, - 1/2" breit, der ganzen Länge nach eine tiefe Rinne bildend, oft die Blattränder eingerollt.

Schaft sammt dem Blüthenstande $1 \frac{1}{2} \mathbf{x}^{\prime}$ lang. Blüthen zalılreich, fast gerade abstehend, rein weiss, köstlich nach Jasmin luftend. Kelchzipfel lanzettlich spitz, in Mitte ', breit, stark zmrïckgerollt, wie bei Cochliopethalum stamineum. Fruchtkusten und Kelchzipfel hell gelbgrün, der Schaft am oberen Ende elen so gefïrbt. Grifiel und Staubfiden hell grünlich gell, Staublentel schr schmal, spitz endent, tief orangefarbig.

Genitalien so lang wie die 1\%"langen Kronenzipfel; sie ragen daher aus iler geöfneten Bliithe, und zwar sthr nahe aurecht zusammenstehend, aus der Blütlie weit vor.

Diese Art ist in allen Theilen viel zarter gebaut als Cochl. albiflos; sie unterseheidet sich dureh die Laublüatter, Farbe und Gestalt der Blüthe ganz leicht erkenntlich von dieser.

\section{Pitcairnia Karwinskyana Schult.}

Man beliebe in der Abhandlung „Bemerkungen iiber die Blattorgane bei den Bromeliaceen" über obige Art nachzulesen. - 
Stamm kugelig verdickt. Laubblätter tiefrimnig, ganzrandig, nur am Grunde mit einigen braunen Sïgezähnen bewaffnet, - lebhaft grün, auf beiden Flächen glänzend glatt, allmälig weich spitz endend, in Mitte der Länge $3 / 4$ " breit und - 21" lang, schlaff überhängend.

Schaft steif aufrecht, stielrund, weisslockig bekleidet, hell gelbgrün. Blätter am Schafte nur 6" lang, mit braunen Sägezähnen bewaffnet, dann in der Nähe des Blüthenstandes bis $1 \frac{1}{2}$ " rerkürzt, anliegend; an den Rändern auf hellgrünem Grunde weiss flockig.

Blüthenstand 9" hoch, prachtroll scharlachroth, pyramidal. Bracteen etwas länger als die $1 / 2$ " langen Stielchen. Ersterer auf hellgrünem Grunde schmutzig bemalt, letzlere nur hellgrün, beide weiss flockig bekleidet. Fruchtknoten und Kelchzipfel 1" lang, lebhaft scharlachroth gefärbt. Kronenblätter vom Grunde aus fast 3 "lang, in Mitte 1/2 " breit, hell scharlachroth, durchsichtig, an einem Rande etwas flatterig, wellig, hier und am Grunde mit weissen Streifchen und mit kleinen Flecken geziert. Griffel so lang wie die Kronenblätter, weiss mit roth sehr fein punktirt. Narbe lebhaft blutroth. Staubfäden kürzer als der Griffel, eben so gefärbt. Staubbeutel schmal, aufrecht, goldgelb.

Diese sehr schöne Art ist Seite 66 der Pitcairnia undulata Hort. anzureihen. 


\section{B e m e r kungen}

über die

\section{Gattungen bei den Bromeliaceen.}

\section{Die Gattung ENCHOLIRIUM Martius.}

Von dieser schönen Gattung sind bis jetzt nur einige Arten bekannt, und ron diesen wahrscheinlich nicht eine - lebend in Europa. Sie wiirden durch Gestalt und Blïthenpracht eine grosse Zierde der Pflanzensammlungen sein!

Jene Pflanzenformen, welche bei Linden in Brüssel, bei de Jonghe u. a. m. unter dem Namen Encholirium sp. verkauft werden, sind jedenfalls sehr wünschenswerthe Gewïchse, für deren Einführmg diesen Herren Dank gebührt, - aber hieruuter dürfte sich kein Encholirium, wohl aher schöne Arten, zu Platystachys und Vriesea gehörend, befinden.

Die echten Arten von Encholirium bilden steif aufrechte, kleine Stämmchen, deren scharf hewehrte Laubblatter in gleichen Abständen am Stamme vertheilt sind.

\section{Die Gattungen BRomeLIA Plumier mal AGALLOS- TACHYS Beer.}

Die Wahl eines Repräsentanten für die Gattung Bromelia fiel auf Bromelia longifolia Rudge. Ich habe die Abbildung von B. longifolia Rudge in Paxton's Flower Garden zur Beurtheilung der Form gewählt, indem dieses Werk leichter zuguinglich ist, als 
das Werk Plantae Guianae von Rudge, wo die echte Bromelia longifolia Rudge abgebildet ist. Die Unterschiede der Formen dieser hier genannten zwei Abbildungen betreffen jedoch nur Artencharaktere. Der Gesammtform nach sind beide gleich gute Repräsentanten. Das hierauf bezügliche findet sich bei der Beschreibung der Arten.

Professor Lindley bemerkte schon bei Beschreibung der B. long. R. in Flower Garden, dass ihm die Blattaustände und hauptsächlich die Blattlängen auflallende V'erschiedenheiten zeigen mit der Beschreibung in Pl. Guianae von Rudge.

Es sei mir hier erlaubt, beispielsweise einer Pflanze zu gedenken, welche ich für eine gute Bromelia erkemne, die aber von Sir Hooker zu Billbergia gebracht wurde, obwohl Graham schon viel früher dieselbe Pflanze als Bromelia heschrieb. Es ist diess Billbergia cruenta Hook. B. Mag. t. 189\%. - Wenn man diese Pflanze in der Ablildung betrachtet, so bemerkt man, dass unter dem kopftörmigen und bewehrten Blüthenstande der Schaft mit umhïllenden steif aufrechten Laubbättern besetzt ist, deren Ende rein begränzt lebhaft hochroth gefärbt erscheint. Es ist mir aber keine Art ron Billbergia der Autoren bekannt, bei welcher die Blüthen, selbst zum öfteren sammt den Bliithensticlehen, nicht vollkommen frei und bis auf den Gịud sichtbar wären, es gibt auch keine Billbergia, welehe nicht am Schafte weiche flatterige, meistens schön roth gefürbte Hochblätter trüge. Man konnte sich nämlich, wenu man die schon so lange in Europa lebend sich findende Billbergia pyramidalis nur einmal blühen sah, -- nicht mehr im Hauptcharakter der Gattung Billbergia irren, und so trugen sich die augenfälligen Merkmale von Billbergia (mit geringer Ausnahme - wie bei Billhergia fasciata Lindl. u. s. w.) auf alle später benannten Arten von Billb. über, ohne dass die Blattzustände einer nähern Beriicksichtigung unterzogen wurden. Bei weitem auffallender ist dies jedoch bei der Gattung Pitcuirnia, indem man hier, die Blätterformen berücksichtigend, - sich gar uicht irren komnte, - und auch nie irrte, - indem ich in Her- 
barien, Beschreibungen und Abhildungen diese Pflanzenform stets gut erkannt fand.

Ich fand mich reranlasst, die Hauptformen von Bromelia in zwei Gattungen zu scheiden. Die Formenverschiedenheit von Broinelia longifolia als Repräsentant der Gattung Bromelia und von Bromelia antiacantha Bertoloni als Repräsentant der von mir aufgestellten Gattung Agallostachys, - werden diese Trennung gewiss rechtfertigen. Dic Uebergangsform ron Bromelia zu Agallostachys bildet Bromelia ignea Beer (Trew et Ehret Plantae selectae 1. LI.), indem der Schaft sich mit den Laubblättern schon bedeutend erhebt, die Bliithen aber hier noch, ohwohl schon verlängert, kopfförmig dicht beisammen stehen.

Dat in dieser Bearbeitung der Familie der Bromeliaceen ein hesonderer Werth auf die Entwicklungsweise des Bliithenschaftes gelegt ist, und die Eintheilung auch hiernach durchgefiihrt ist, so werden hierüber einige Worte hier einen passenden Platz einnehmen.

Bei der I. Hauptabtheilung, welche in zwei Unterabtheilungen zerfällt, heisst es:

I. Unterabtheilung: Schaft, seiner ganzen Länge nach mit Laubblättern beseizt. - Phyllantheae.

II. Unterabtheilung: Schaft, seiner ganzen Länge nach mit deckblattartigen Hochblättern besetzt. Lepidantheae.

Um sich von der I. Unterabtheilung einen klaren Begriff $z u$ verschaffen, wird wohl die Figur I. Agallostachys antiacantha Beer geniigen. Aber auch auf treffliche andere Abbildungen vermag ich hinzuweisen. - Man beliehe den Durehschnitt von Bromelia Karatas in Jacquins Plant. hort. bot. V. 1. 31, dann den Durchschnitt von Bromelia humilis in Jacquin's Jcones Plant. t. 60. zu besehen. Hier hat Jacquin zwei Pflanzen, damals sehr seltene Gewächse, geopfert, um sie im Durchschnitte abbilden zu lassen. Er hat es offenbar gethan, um den Aufbau des Gewächses bis 
zum Blüthenstande klar und deutlich zu zeigen. - Er hat demnach selbst auf die Entwicklungsweise der Pflanze ein grosses Gewicht gelegt, und so ist es mir nur gegönnt das auszusprechen und nutzbringend zu machen, was der grosse Gelehrte wahrscheinlich damals schon als eine gut bezeichnende Eigenschaft erkannte.

Für meine Anschauungsweise sind solche Vorboten von grosser Wichtigkeit.

Die II. Unterabtheilung: Lepidantheae ist an jeder Art von Billbergia, wie auch an allen hierher gehörigen Gattungen leicht zu erkennen. Um aher vollkommene Ueberzeugung sich zu schaffen, beliebe man eine blüheude hierher gehörige Pflanze der ganzen Länge nach zu durchschneiden, um zu sehen, wie das letzte Laubblatt ganz kurz aber vollkommen laubblattartig gebildet ist, und wie der Schaft am Grunde schon mitweichen mehr oder minder gefärbten Hochblättern, - der ganzen Länge nach bis zu den Blüthen ganz gleichförmig besetzt ist. Also mit der Entwicklung des Blithenschaftes, endet bei dieser II. Unterabtheilung die Laubblattbildung gänzlich; hierdurch ist der verkürte Stamm, die kelchartig oder röhrenförmig zusammenstehenden Laubblätter bedingt, und desshalb sind diese Gebilde auch selbst schon vor der Blïthezeit leicht erkenntlich.

Hier andert sich nie zur Bliithezeit die Farbe der Laubblïtter; die Zeit des Blüthentriebes hingegen bezeichnet sich bei Bromelia und bei Agallostachys immer durch die meistens rothe Färbung der frïher grünen Herzblätter. Nach dem Abblühen verliert sich jedoch diese oft prachtvolle Erscheinung wieder allmälig, und dasselbe Laubblatt, welches vor kurzem noch im herrlichen Roth strahlte, hekömmt endlich seine mrsprünglich grüne Färbung. wieder.

Solche Merkmale der Entwicklung sind wohl nur an lebenden Gewächsen zu beobachten, - aber wemn solche Beobachtungen einmal festgestellt sind, dam wird man sie auch an jeder getrockneten Pflanze leicht erkennen. Es ist mir nur eine Pflanze bekannt, welche ich nach deren Blüthenstande und der Blüthen- 
form nicht einzureihen vermag. Diese Form ist Tillandsia xiphioides Ker. B. Reg. t. 105. - Hier mag aber Zeichnung und Beschreibung fehlerhaft sein, denn diese Pflanze gehört wahrscheinlich nicht zu den Bromeliaceen, aber auch nicht zu den Irideen! Bei Bestimmung lebender oder getrockneter Formen der Familie der Bromeliaceen, hat sich sonst meine hier durchgefïhrte Eintheilungsweise noch immer giltig bewiesen, indem ich stets selbst bei mangelhaften Exemplaren in Herbarien u. s. w. - mit Bestimmtheit Abtheilung und Sippe zu nenuen vermochte.

\section{Die Gattung: ANOPLOPHYTUM Beer.}

Die meistens kleinen Formen, welche diese Gattung bilden, sind eine auffallende Erscheinumg hei den Bromeliaceen, deren Charakter gewöhnlich im kräftigen Bane und den bewehrten Blättern besteht. Bei Anopl. haben wir hingegen sehr zahme Pflänzchen vor uns, welche an keinem Theile der Pflanze eine Bewehrung, ja selbst nie steife Blätter tragen, da hier die Laubblätter immer von lederartig weicher Beschaffenheit sind. Manche Arten gleichen einen Sprosse unserer Gartennelke; dies veranlasste wahrscheinlich auch Rossi, scine Tillandsia dianthoidea aufzustellen. Uebrigens ist Anoplophytum jene Form in Brasilien, Mejiko u.s.w., welche in den Auden von Peru, Chile u. s. w. sich in der Gattung Diaphoranthema wieder finden, aber die tropische Gluth der Farben, welche die ersteren so sehr zieren, finden sich bei letzteren, welche nur auf hedeutenden Höhen, ja selbst am ewigen Schnee vegetiren, nur sehr sparsam, indem sich hier selbst die Farbe der Blïthen nicht über die Purpurfarbe erhebt.

\section{Die G attung: PHLOMOSTACHYS Beer.}

Die Gattung Puya, wie sie jetzt besteht, bietet so auffallende Verschiedenheiten in der Tracht der Pflanzen, dass ich hierauf gerne hinweise. Um sich die Ueberzeugung dieser Formenverschiedenheiten zu verschaffen, beliebe man 
Puya maidifolia, Annales de Gand. tab. 289,

"Chilensis, Bot. Mag. tab. 4715, und

"heterophylla, Bot. Reg. 1840, tab. 71

zu besehen. Wie weit stehen diese drei Pflanzen der Gesammtform nach, von einander entfernt! Hingegen ist Neunannia als Genus aufgestellt, wo die Neumannia gigantea u. N. imbricata sich weder in der Gesammttracht, noch am Blïthenstande, und selbst der Blithenform nach von P'uya (wie P. maidifolia) nicht unterscheiden lassen. Welchen Werth man in neuester Zeit auf die Blattform zu legen beginnt, haben erst kïrzlich Dr. Koch und Sello bei Aufstellung ihrer Pitcairnia maizaifolia gezeigt, aber diese Pitcairnia mazaif. ist auch nur eine gute Species zu Phlomostachys. Als Specialname ist jedoch maidifolia oder maizaifolia nicht gut gewählt, - da alle Arten von Phlom. maisblattartige Belaubung als einen Hauptcharakter der Gattung haben sollen. Obwohl ich gerne zugebe, dass Phlomostachys uahe an Pitcairnia steht, habe ich mich dennoch bewogen gefundeu, diese Form nicht zu Pitcairnia zu ziehen. J)er Unterschied in der Gesammtgestalt ist zu auffallend, da sich hier zwei gatnz verschiedene Blattformen, nümlich Laubblätter und bewehrte Niederblaitter finden, welche bei Phlomostachys nie vorkommen.

Der kleinste Blattrieb unterscheidet schon beide Genera von einander, indem bei Phlomostachys der Trieb nur einzelne Blitter bildet, welche den später erscheinenrlen ganz gleich sind. Bei Piteairnia hingegen bilden sich sehr verschiedene Blattorgane in dicht znsammenstehenden Büscheln, welche bei der ersten Entwicklung sich schon deutlich erkennbar zeigen und jene Ierkmalc bieten, die bei keiner anderen Gattung der Familie der Bromeliacern sich wiederfinden, - abgesehen ron allen den sonstigen Unterscheirlungsmerkmalen, welche bei meiner Eintheilung aufgezeichnet sind.

An Phlomostachys reiht sich das Genus (2uesnelia ganz natiillich an, und diese beiden Genera erhalten durch gegenseitige Betrachtung des Plüthenstandes gewiss eine gute Erklärung. 


\section{Die Gattung QUESNELIA Gaudichaud.}

Hiervon ist nur Quesnelia rufa aus dem Atlas botanique von Ga udicha ud bekannt. Diese Art findet sich auch sehon sehr verbreitet in den Sammlungen lebender Gewärchse. In den Gärten ist diese Form als ,Billbergia Quesneliana" bekannt und auch in der Flore de Serres von van Houtte als Tillb. Quesneliana abgebildet.

In besonders kräftiger Ausbildung lebt diesc schöne Pflanze im Schönbrunner Pflanzengarten, wo ich sic durch mehrere Jahre beobachtete.

Dieselbe erreicht eine Höhe von mehreren Klaftern. Eigentliche Seitenzweige bildet sie wenige. Die Vorlingerung dieses Gewächses geschicht, indem sich an dem abgeblühten Stamm ein Seitenspross entwickelt, weleher den abgebliihten Theil der Pflanze um ein bedentendes überwächst, um endlich zu blühen und sich wiefler von einem eigenen Sciten-Sprosse nach cincm Jahre ïberwachsen zu sehen. Auf diese Weise erhebt sich immer nur der wherste Zweig kraftiger als die oft in Mehrzahl arscheinenden Sprossen, und verlängert hierdureh diese Pflanze.

Wahrecheinlich wïchst Quesnelia, an den baumstïmmen angelehnt, in den Wählern zu einer bedeutenden Höhe hinan, inden diege Pflanze der ganzen Lïnge nach eine Henge Wurzeh treibt um sich hiermit gut zu befestigen vermag:

Die Unrichtigkeiten in der Zeichnumg zu dent Atlas botanique finden sich an dem geeigneten Platze besprochen.

\section{Die Gattungen PITCAIRNIA lHeretiere, COCHLIOPE-} THALUM Beer und ORTHOPETALUM Beer.

Iiese so überaus reiche Gattung, welche an wärmeren (Orten in Amerilia eine grosse Ausbreitung hat, ist durch die trefflich ausgesprochenen Formen der Kronenblatter und deren Stellung unter sich, wie nicht minder durch die Blattformen dieser Gattung ebenfalls so eigenthümlich gestaltet, dass sich dieselbe sehr leicht und gut begränzen lässt. 
Die Piteairnien mit rachenförmig geschindelter Blïthenkrone zerfallen in drei Unterabtheilungen.

Als Repräsentanten dienen für diese Abtheilungen:

Pitcairnia bracteata, Bot. Mag. tab. 2813.

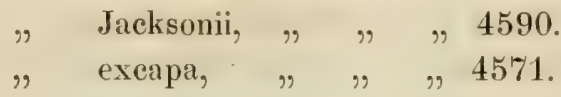

Jene Piteaimien, welehe nebst anderen Unterscheidungsmerkmalen gleichmässig schncekenlinig zurückgerollte Kronenblätter bilden, habe ich mit ,Cochliopetalum" benannt, und hiermit eine Gattung gebildet.

Endlich waren noch die Formen von Pitcairnia auszuscheiden, welche gleichmässig starr aufrecht stehende Kronenbütter bilden. Ich habe diese Formen ,Orthopctalum" benannt und mit diesen die Gattung gleichen Namens gebildet.

Als Repräsentanten dieser zwei Gatturgen belicbe man, für Cochliopetalum - Pitcairnia albillos, Bot. Mag. tab. 2411, und für die Gattung Orthopetalum - Pitcairnia lanuginosa, Flora Peruv. et Chil. tab. 258, Ruiz et Pavon, zu beschen.

Nur durch diese 'Trennumgen aus der Gattung Piteairnia der Antoren, war ich im Stande, die so schr verschiedenen Formen, welche sich hier finden, gut auseinander zu halten.

Schliesslich mag hier noch bemerkt werden, dass unter anderen Pflanzenfamilien L a mo u rouxia der Blumenkronenform nach einige Achnlichkeit mit meinen Piteairnien hat.

\section{Die Gattung HOHENBERGIA hïmer ef Schultes.}

Link, Klotzseh und Otto haben aus Hohenbergia, der bekannten Form der Sammlungen, welche den Namen Hohenbergia strobilacea triggt, ,Acantostachys" gebildet und ihre Acantostachys strobilacea, ohne Berïcksichtigung der Hohenbergia strolilacea der Gärten, anfgestellt. Diese zwei Formen sind, obwohl sie unzweifelhaft beide zu Hohenbergia gehören, zwei gute Arten; da aber wahrscheinlich nur die Hohenbergia 
strobilacea lebend in Europa ist, so mag ihr auch der Name, strobilacea" bleiben.

In der Flora Fluminensis von A r r a b. siud drei Pflanzen abgebildet, deren Zeichnung Zweifel erregt. Ich halse sie zu Hohenbergia gezogen, $u m$ sie einstweilen unterzubringen, bis lebende Exemplare einen richtigen Aufschluss geben werden.

\section{Die Gattung CARAGUATA $R$. et Pavon.}

M a rgravius (Piso) hat in seinem Werke, ,Plantae Brasilianae" Seite 37, 39, 113 drei Pflanzenformen abgebildet, nïmlich Seite 37 Caraguata seu erva babosa, seite 39 Caraguata acanga und Seite 11:3 de Varias Caraguata (Carag. guaca), welche Gewächse vorstellen, die wahrscheinlich zu Aloe gehören.

Director S ch ot t. zu Sehönbrumn machte mir die Mittheilung, dass in Brasilien alle Bromeliaceen, "Caraguata" (Caruata) genanut werden, welche zwischen den Laubblittern oft bedeutende Mengen von Wasser zuriickzuhalten vermögen (Billhergia, Vriesea 11. m. a.). Caraguata lingulata Lindley und melirere andere Gattungen aus der Familie der Bromeliaceen haben jedoch nicht das Vermögen, viel Wasser zwischen den Laubhlittern zuriickzuhalten, - jedentalls nicht genügent, um eines Nenschen Durst zu löschen.

In den Sammlungen lebender Gewaichse ist Cirraguata lingulata Lindl. schon sehr verbreitet, aber jene Camguata, welche in dem unvergleichlich nuitzlichen Werke vou Plumier (Plant. Americanorum tab. 33) sich abgebildet findet (von Römer et Schultes VII, 2, Seite 1230 jedoch zu Caraguata lingulata gezogen wurde), ist gewiss eine sehr gute Art und deren Einführung in die Sammlungen höchst wünschenswerth.

\section{Die Gattung PITYROPHYLLUM Beer.}

Diese Gattung hat nur ganz kleine Iflänzchen, welche an Baumstämmen oder zwischen Felsen wachsen und sich den peruanischen und ehilesischen kleinen Formen von I)iaphoranthema 
anreihen. Die Laubblätter hei Pilyrophyllum sind eigenthümlich, fast scharf runzlig an den Rändern, fleischig spitz endend, besonders vom Grunde aus mit glänzendem, silberweissem, kleiigem Ueberzuge greziert; wie lilden, indem sie sich stark rerzweigen, zierliche kleine Rasen.

Auch hei dieser Gattung fürlen sich zur Blithezeit die oberen Blattspitzen schön roth, und erhalten durch die lang vorstehenden, immer blauen Blïtlien ein sehr zierliches Aussehen.

Die Gattung NIDULARIUM Martius.

Diese Formen haben wie so viele zu den Bromeliaceen gehörige Gewächse die eigenthümlichen Reize, dass (wie bei manchen Euphorbiaceen) - wenn die Pflanze sich ihrer Bluithezeit nähert - die Laubblätter, welche das Herz bilden, eine brillante, meistens rothe Färbung erhalten.

Bei Nidularium ist diese Esscheinumg besonders auffallend, da die gewöhnlich aufrecht stehenden Laubblätter zur Blüthezeit sich flach legen und hierdurch einen zierlichen Stern bilden, verschönert durch die lebhat blanen oder purpurfarbigen Blüthen.

\section{Die Gattung CRYP'TANTHUS Dietrich.}

Durch genaue Untersuchungen und Vergleiche, welche ich zwischen den Pflanzenformen von Cryptanthus und Pholidophyllum machte, finde ich mich veranlasst, Pholidophyllum ganz einzuziehen und mit Cryptanthus zu vereinen. Ein bemerkenswerther Unterschied wäre nur die Querbänderung der Laubblätter, welche Pholidophyllum auszeichnet; allein auch Cryptanthus acaulis (Bromelia acaulis, auch Brom. pumila der Gärten) hat weisslich gebänderte Blätter, welche, besonders wenn die Blätter der Pflanze ganz abtrocknen, sehr gut sichthar werden und dann auch dieser Pflanze zur Zierde gereichen.

Es mag hier erwähnt werden, dass diese Pflanzenform im Alter sehr zierliche, am oberen Theile der Pflanze ziemlich stark verzweigte Stïmmehen bildet und durch ihre oft lebhafte Bronzefarbe eine eigenthümlich liebliche Gestalt hat. - (Es ist mir eben 
bekannt geworden, dass V is i a n i sein Pholidophyllum sellsst einzog und als zu Cryptanthus gehörend erkannte.)

Wremn es bei der Gattung Bromelia ein Hauptmerkmal ist, dass der Blithenstand ron den Laubblättern dicht umgeben, in Mitte derselben sich sitzend findet, so ist bei Nidulariae das Hauptmerkmal, dass die Blüthen zwischen den Herzblä tternvertheilt sitzend sich finden.

Es kann nach dieser Erklärung beim Bestimmen kein Inthum obwalten, indem diese Zustände auf den ersten Blick sich vollkommen klar darstellen, und keinem Zweifel Raum geben, ob eine Pflanze dieser oder jener Gruppe angehört. So wird man bei Cryptanthus wohl einen Büschel Blïthen in Mitte der Laubblätter sehen, allein bei genaner Betrachtung sitzen die Blüthen auch hier in unregelmässigen Büscheln zwischen den Herzblättern vertheilt, und nur durch das nahe Zusammenstehen der Herzblätler erscheinen die Blüthenbüschel als ein vereinter Blüthenstand.

\section{Die Gattung PLATYSTACHYS C. Fock.}

Professor lioeh in Berlin hat fiir Allardtia Dietrich den Gattungsnamen, „Platystachys" gewählt. Diese Benennung ist so treffend für die Ciestalt des Blüthenstandes der hierher gehörigen Formen, dass ich mich bewogen fand, diese Benemnung zu benitzen und den Formen wie Tillandsia setacea u. s. w., also jenen Gewächsen dieser Familie, welche der I. Unterabtheilung angehören und sich durch einen rein zweizeiligen Blüthenstand auszeichnen, den Namen ,Platystachys" zu geben.

Aber ich habe diese Benenmung gewählt, ohne anf die umfassende Beschreibung, wie sic Prof. Ko ch bekannt machte, einzugehen. Bei meinem ersten Versuche, diese Pflanzenfamilie nach deren Blüthenstande zu bearbeiten - welchen ich im Jahre 1854 verötlentlichte - fand ich schon nöthig, darauf linzuweisen, dass die Formen mit zweizeiligem Blüthenstande in dic I. und II. Unterabtheilung unterzubringen seien. Dieses hat 
sich im ferneren Verlaufe dieser Arbeit auch als nöthig herausgestellt. Merkwürdig sind aber die Blattzustände bei Platystachys und bei Vriesea, indem diese zwei so nahe verwandten Gattungen demnoch durch die Blätter vollkommen verschieden sind.

\section{Die Gattung VRIESEA Lindley.}

Professor Lindley in London hat dieses herrliche Genus auf 'Tillandsia psittacina gegründet (man beliebe Botanical Register 1843 bei tab. 10 die Anmerkung zur Beschreibung dieser Pflanze zu lesen), und es nach Dr. W. de V riese, Professor zu Amsterdam, benannt. Es muss aber hier ein Schreibfehler zu Grunde liegen, weleher sich num schon allgemein verbreitet hat, indem Prof. Lind l e y „Vriesia“" schrieb, statt V rie sea. Ich erlaube mir diesen Namen verbessert zu gebrauchen.

Professor Lindley hat durch Vriesea eine natürlich begränzte Gattung gebildet, welche mit einigen Worten geniggend zu beschreiben ist. Es ist nümlich der zweizeilige Blüthenstand, welcher oft aufiallend an den Blithenstand bei Gladiolus erinnert.

Ich gehe hier, wie bei Platystachys, nicht förmlich auf die Beschreibung ein, wie sie Lindley vorschreibt, indem ich mich bei meinen Bestrebmgen nur an die augenfälligen Merkmale halte, ohne andere subtile Zustände der Blüthe u. s. w., welche weiter führen als zur Erkenntniss dieser Pflanzenform nöthig ist, $\mathrm{zu}$ betrachten.

Es ist wirklich auffallend, wie die Pflanzengattungen so bestimmt begränzte Merkmale tragen. So uahe Platystachys an Vriesea anch stehen mag, finden sich dennoch an Gestalt und Decke der Laubblitter mehrere Merkmale, welche, abgesehen von den Zuständen des Blüthensehaftes, beide Gattungen selır gut aus einander halten. Man beliebe diesfalls die Eintheilung nachzusehen.

Die Gattung TUSSACIA Klotssch.

Diese zierliche kleine Form bildet nur lederartige, gleichmässig dicke manchmal herrlich gefirbte, gewöhnlich aber dunkel 
olivengrün gefübte Laubblätter, welche immer am Grunde den sehr dünnen Stamm bauchig dicht umgeben. Der Bliuthenschaft ist stets sehr dünn, selten aufrecht, oft entschieden iiberhängend, und ist mit trockenhäutigen kleinen Scheidenblättern besetzt. Diese Formen wachsen oft an kaum 1 Finger dicken Baumästen, wie auch an Schlingpflanzen, frei in der Luft schwebend, hier trift es sich manchmal, dass die Pflanze durch die eigene Schwere herabhängend, jedoch freudig wachsend, getroffen wird. Der Gesammtform nach steht Tussacia nahe an Vriesea, allein die Stellung der Blüthen ist dort nie rein zweizeilig.

\section{Die Gattung GUZMANIA R. et Paron.}

Von diesem Genus sind nur einige Species bekannt, woron die ältere, nämlich Gummania tricolor R. et C., sehr verbreitet in den Sammlungen ist. Diese sehönc Pflanze findet sich mehrmals abgebildet. Aber bei den Abbildungen dieser Art glaubt man auch mindestens zwei rerschiedene Formen vor sich zu haben, obwohl nicht immer mit Sicherheit auf getreue Abbildung zu rechnen ist. So ist Guzmania tricolor in Loddiges Bot. Cabinet t. 46\%, dann dieselbe Art in Exotic Flora t. 163. u. die Guzmania tricolor des R. et Pav, welche auch in Annales de Gand III. gut abgebildet ist, - sehr verschieden von einander. Besonders jene Form in Exotic flora dürfte eine gute, noch nicht beschriebene Art sein.

Es ist seit kurzem eine Guzmania erytrolepis eingeführt worden, und ich glaube, nach der Länge der Laubblïtter zu urtheilen, dass diese Pflanze mit jener in Exotic flora gleich ist. Wenn Jemand in die Lage käme, ein Stïck ron einem Blüthenstande von Phlom. und ein Stiick eines Blüthenstandes ron Guzmania bestimmen zu sollen, so diurfte man nur auf die Blumenkrone Rücksicht nehmen, indem bei sonst ziemlich gleicher Gestalt des Blüthenstandes, bei ersterer die Blumenkronenblätter unregelmässig (rachenfürmig), bei Guzmania hingegen sich regelmässig aufrecht stehend zeigen. So klein diese Unterschiede auch sein mögen, - 
sind selbe doch geniigend, um in zweifelhaften Fällen Auskunft zu bieten.

\section{Die Gattungen BLLLBERGIA Holm et Thumb. und HOPLOPHYTUM Beer.}

Wem man die Gattung Billbergia, wie sie besteht, untersucht, so findet man zwei ganz verschiedene Formen vereint, wovon jene Form, welche ich von Billbergia trenne, deren gute Merkmale sich jedoch bei dieser Familie sehr häufig finden und in verschiedenen Gattungen der Autoren vertheilt sind, - selbst eine eigene Sippe bildete. Repräsentanten der echten Billbergien sind Billbergia pyramidalis und Billbergia farinosa. Die ausgeschiedenen Formen von Billbergia u. s. w. bilden eine eigene Gattung mit Namen Hoplophytum. Als Repräsentanten dieser Form diene Billbergia fasciata (B. rhorlo-eyanea) und Aechmea mucroniflora.

Bei meinen Billbergien fand ich fïr gut noch ein Unterscheidungs-Merkmal, eine Unterabtheilung, nïmlich ,Cremobotrys" (wie Billbergia farinosa) aufzustellen.

Wir wollen nun die Unterschiede dieser Abtheilungen betrachten, und zwar erstlich die zu Billb. pyram. gehörigen Formen. - Der ganze Bliithenstand unverzweigt, die Hochblitter weich, aufrecht, der Schaft steif, aufrecht. Die Kronenblätter nur cinfach zurüekgebogen, - nie sclmeckenlinig eingerollt. Genitalien kaum ans der geöffneten Blumenkrone vorstehend. Die Stielchen kaum sichthar, schr kurz. Der aufrechte Schaft von den Hochblättern fast ganz bedeckt. Laubblitter immer zahlreich, am Grunde den verkiurzten Stamm dicht umschliessent, kelehbildend zusammenstehend.

Die Unterabtheilung von Billbergia, wie Billbergia farinosa, - Cremobotrys.

Blüthenstand dünn, weich, überhängend, gewöhnlich verzweigt. Bracteen (Hochblätter) immer weich, seidenartig, flatterig, nach allen Richtungen abstehend, - viberhängend. Oft sellıst 
zwischen den Blüthen vertheilt, Kronenblatizipfel sehr lang, meistens stark nach einwürts schneckenlinig zurückgerollt, - Genitalien weit vorragend, dicht an cinander stehend. Der sehr rerkiuryte Stamm bildet nur wenige $(4-6)$ steif aufrechte, of wie ans Blech geformte, eine schlanke lange Röhre bildende Laubhlätter, von denen gewöhnlich eines oder zwei rimnenförmig mit dem Ende ïberlüngen. Schaft, Stielchen und Fruchtknoten sind weiss, wollig bekleidet, und letztere unregelmässigg knotig.

Ich erlaube mir numbehr auf jene Abbildungen hinzuweisen, welehe die Tracht dieser Pflanzen nicht gehörigg darstellen, und auch der Beschreibungen der Autoren, welche hierzu gehören, zu gedenken. Wemn man die Abloildung von Bromelia incarnata R. Par. Flor. Peruv, et Chil. t. CCLV betrachtet, so sicht man einen steif aufrechten Blithenstand, desisen Schaft mohrere nicht leicht zu crklirende Knoten hesitzt ; niemand denkt hier cincn zierlichen überhängenden Bbiuthenschaft vor sich zu hahen, der mit weichen lehhaft rothen Bracteen geziert ist. WVem man aber die Beschreilung dieser Pflanze liest, dann sieht man all das olsen gesagte bestütigt. Die Autoren sind roll des Lobes iiber die zarte Fïrbung und Gestalt des überhängenden Blüthenstandes.

Die so stark zurïckgerollten Kronenblitter, die weit vorragenden Genitalien, der gefurchte Fruchtknoten, die glattrandig gezeichneten Bracteen, sind Merkmale, welche dem Kemer dieser Familie alsogleich zeigen, dass er eine Pflanze wie Billbergia Zebrina vor sich hat. Ganz derselbe Fall ist es bei der Abbildung ron Billbergia decora, Poepp. et Endl. Nov. Genera Plant. t. 15\%. - Tillandsia variegata Flor. Fluminensis t. 132. Bromelia foliis radicalibus dentato-spinosis. Plumier t. LXII. u. t. LXIII. Wahrscheinlich gehört auch die Abhildung Marggrav's 1. 37. hierher. Alle Abbildungen, welche ron Billhergia amoena und Billbergia pallida sich finden, sind durchgehends mit steif aufrechtem Blithenstande gezeichnet, und doch ist bei heiden Arten bei hallwegs kriftiger Pflanze der Blüh henschaft ïberhïngend.

\footnotetext{
Beer, Bromeliaceen.
} 
Wenn man die hier oben gemachten Bemerkungen iber den fehlerhaft gezeichneten Blüthenstand, und aher anch die ron mir bemerkten: Interschiede dessellyen zwischen Billbergia und Unteralthicilung (Cremolotrys) zusammenhält, so dürfte es sich zeigen, daws es leinahe gleichgiiltig erscheint, ob ein Blüthenstand seiner Stellung nach gut oder schlecht gezeichnet ist, indem die olsen anfegestellten Irerkmale alsogleich solche Fehler erkennen lassen.

Die Gittung Hoplophytum hale ich, wie schon erwähnt, aus verechiedenen Gattungen der Autoren ausgeschieden und hier vereingt. Lie Merkmale sind hier: ein meistens in allen seinen Theilen scharf hewehrter, pyramidaler, oder sehr lockerer - rerzweigter Ijithenstand. Die Blumenkrone a ufrecht, röhrenförmig. Dic Genitalien in den seltensten Fällen sichthar, immer kürzer als die Blumenkronenbliitter. Jede Blüthe trägt eine Bractee.

\section{Die Gattung STREPTOCALYX Beer.}

Die Pilanzenform, welche mich zur Aufstellung ron dieser Gialtung reranlisste, ist: Sp. Poeplyig Amazonas. Ega, aus dem kaiserlichen Museum in Wien. Fs finden sich hier mehrere Exemplare dieser Form. Dere Keleh ist mehrfich schraubenartig zusamniengerollt, die schlaften Bbumenkromenblitter ohne Neigung sich sellst in Vorbliahen zu drehen. Der Schaft ist holzig, üherhängend und, mit Ausnahme der Kronenblitter, an allen Theilen seharf bewehrt.

\section{Die Gattung: PUYA Molina.}

Molina hat im Jahre 17s2 seine Puya chilensis aufgestellt und sehr gut beschrieben, desshall, muss nun Pourretia Ruiz. und Paron, welche in Flora Peruviana et Chilensis im Jahre 1794 aufgentellt erscheint, und ohige Formen mit benenut, eingezogen werden. Wenn man Pouretia lanuginosa und P. pyramidata bee Ruiz et I'ar. hetrachet, so tindet man, dass diese Herren Formen 
zu ihrer Pourretia brachten, welche nicht dahin gehören, indem dieselben guto Bromelien sind. Es war ein Fehlorifl zu nennen, dass spätere Autoren den Formen, wie Puya coarctata, Puya chilensis, Puya coerulea u. s. w., welche bei Ruiz et Paron zwar mit dem Namen "Pourretia" beschrieben, aber nicht alogebildet erschienen, - diese Namen liessen, dit doch $\mathrm{Ruiz}$ et Paron andere Formen als zu Pouretia gehörig, anfistellten. Hooker hat bei der Abbildung in B. Nag. t. 4715 den Namen Puya Chilensis trotz der mehreren in den (xïrten mit P'urat Altenstemin u. a. m. benannten Formen aufrecht erhalten. Willd enow hat eine Bombatee Pourretia (Carranillesia) gernimnt. der Name ist daher bleibend gechrt. Leider trillt diesen Nimenwechsel zaroi Pflanzenformen, welehe bei den Bromeliatecen dureh viele tehende: Species gut vertreten sind! So wurden an Puya Altensteinii (Icones plant. Berolin. t. 1.), wie nicht minder an Pourretia coaretata (Bonite, Gaudichaud u. a. m.) dic cutsprechenden Formen angereiht, und sind nun in allen guten Planzensammlungen zu tinden. Um hier Ordumg zu schatfen, musste ich die P'uya der Gäiten neu henennen und hate hierfiur dru Namen Phlomostachys gewählt; man beliebe diese Gattung nachzuschlagen.

Die Formen von Puya (Pourretia) bilden einen kurzen oft 1' dicken Irauptstamm, weleher wenige aber fast eben so starke Nebenäste treibt.

Es sind daher bammartige Gewiichse; welche einige Aehnlichkeit mit Yucea haben. Sie werden sehr alt und blïhen selten, aber abgesehen von der seltsimen Pracht, welche der aufrechte pyramidale Blithenstand bietet, ist die ganze Esscheinung der Pflanze, durch liriftige Gestalt, sowie durch schöne, scho zahlrevelue, in eine lange Spitze endigende, schmale, schard berrehte, auf der Unterflïche gewöhnlich sillherweisse, zicrlich in einen Bogen herabhängende Laubblaitter, eine grosse Zicrole jeder Pllanzensammlung; in Peru und Chili bedient man sich des Markes dieser Gewächse, wie bei uns des Korkes. 


\section{D i e Gat tung LAMPROCOCCUS Beer.}

Nit dem Namen Aechmea sind mehrere ganz rerschiedene Pflanzenformen benannt worden, und es ist unangenehm, dass gerade eine For'n von Aechmea, wie Aechmea fulgens Brong., welche am entferntesten ron der Aechmea des Ruiz et Pavon steht, num schon sehr verbreitet in den Gärten, Herbarien u. s. w. ist. Es blicb aber desshalb nur das einzige Mittel, die Pflanzenformen wie Aechmea fulgens neu zu benennen.

Es ist unerklärlich, wie man hier die Abbildungen und so vortrefilichen Beschreibungen der Flora Peruviana et Chilensis, wie auch deren Prodromus, ganz unberïcksiehtigt lassen konnte, indem doch schon die Benennung Aechmea hindeutet, dass man es mil einer bewchrten Pflanzenform zu thun habe, - aber gerade die obigen Formen von Acchmea Irongniard tragen nicht eine Spur von Bewelnung an Blühenstande, - so wie auch, dass andere so auffallende gute Merkmale, wie seitenstaindiger Blüthenstand der echten Aechmea u. s. w. - unberiucksichtigt geblieben sind. Die Formen, welche Hooker, Poeppig und Endlicher als Aechmea beschricben, fanden ihre geeigneten Plätze bei meiner Gattung Hoplophytum.

Für die Formen von Acchnea Brongniard ist eine einfache Beachtung der Blithe und Frucht wohl gुenügend, un diese vor Einmischung von Alten, welche in andere Gattungen gehören, vollkommen zu sichern. Die Mrerkmale sind: Beere ciförmig, fleischig, glïnzend. Tronenblätter sehr kurz, kaum geölfinet, hinfällig. Die Kronenblitter verlieren ihre matte Farbe sehr schnell, und dem Beschaner fallen eigentlich nur die schön roth gefärbten Beeren auf, welche den Hauptschmuck der ganzen Pflanze bilken.

Die Unterfliche der Laubblatter ist bei mehreren Species Acehmea Brongniard sehr verschicden von der gewöhnlich grünen Oberflache, indem dieselbe cine lebhafte Purpurfarbung von verschiedener Stärke zeigt.

So finden sich in den Sammlungen lebęnd Aechnea glomerata und Aechmea glomerata discolor., Aechmea fulgens und Aech- 
mea fulgens discolor. Acchmea miniata und Aechmea miniata discolor. u. a. m. Die Bezeichnung discolor bezieht sich aber nur auf die verschiedene Furbe der Unterfläche der Laubhlitter. Diese Färbung ist jedoch nur ein Spiel der Art, indem es sich bei der Kultur aus Samen gewonnener Pflanzen zeigt, dass z. 1). von Acehmea fulgens die Sämlinge aus einer Beere, Pllanzen mit ganz griinen Blättern, aber auch solehe mit violetten Blattunterflichen lieferten.

Die wirkliche Aechmea, wie hiniz und Paron sie beschrieh, und gut abbildete, ist wahrscheinlich noch gar nicht lelend in Europa. Ich weiss aus eigener Erfahrung, wieschwer es hilt, einen ringeführten Namen, wclchen auffallend schöne Gewächse tragen, auszumerzen und einer, wemn aluch vollkommen gegriudeten neuen Benennung Eingang zu verschaflen. Allein hier bleibt mur der WVeg ciner Namensänderung, wenn man den Autoren Ruiz und I'avon jene Priorität sichern will, welche diese ansgezchehneten fielehrten im höchsten Grade verdienen! Leider weiss ich mehrere Beispiele, dass solche neue Benemungen oft gar nicht leericksichtigt wurden, hieran aber trägt manches ummöthige Verändern der Gattungsnamen wohl die grösste Schuld.

\section{Die Gattung MACROCHORDIUM de Triese.}

Diese gut begränzte Galtung bildete Professor de V riese aus Pflanzenformen, wie Billhergia linetoria (anch Billhergia clavata, Billbergia melanantha der Gürten). Macrochortium tinetorium ist in den Sammlungen schon schr lange bekannt und verbreitet. Diese Pflanze wurde nie viel beachtet, da ihr Blïthenstand, wenig gefurbt ist, und nur ihr unverwiistliches Naturell ist schuld, dass sie nichtschon lange wiederaus den Sammlungen verschwand! Aber dieses Genus hat in letzterer Zeit einigen Zuwachs erhalten, u. a. Macrochordium pulchrum Beer (Bromelia tinctoria der Pariser Gärten) u. m. a., welche wahrhalt prachlvoll zu nemen sind.

De Vriese hat sein Macrochordium in den ,Holländischen Jahresschriften" durch Holzschnitte sehr gut erklärlich dargestellt. 
Ich kann, meinen Weg verfolgend, mich auch hier auf die Beschreibung, wie der hochgeehrte Herr P. de Vriese sie mittheilt, nicht einlassen, indem dieselbe weiter führt, als ich für nöthig erachte.

Wie man diese Pflanzenform zu Billbergia stellen kounte, wird wohl Jedem auffallend crscheinen, welcher beide Formen gut kennt. Nicht e in Organ am ganzen Blüthenstande erinnert auch nur entfernt an die Formen von Billbergia.

Merkwürdig ist der Umstand, dass Macrochordium, Echinostachys und Clievaliera, drei Formen, welche zur Sippe Hacrochordiae gehören, alle fast schwarze Blïthen bilden. Die Blithe ist immer sehr klein, hinfüllig und ron hellgelb in braunschwarz ïbergehend.

\section{Die Gattung ECHINOSTACHYS Brongniard.}

Dieses scharf begränzte Genus von Brongniard zählt nur einige Arten, lebend in Europa. Ol,wohl nicht in Abrede gestellt werden kamn, dass hier die ganze P'lanze nicht im Verhältniss zu dem Blithenstande steht, indem die Laubblitter bei $3^{\prime}$ in Durchmesser zusammenstehen, hingegen der Schaft kaum 1/1" dick und der Blithenstand bei Echinostachys P'ineliana und rosea höchstens 2" Länge, bei $11 / 3$ " Dicke erlangen, so ist doch die Gesamnterscheinung der Pflanze sammt dem zicrlichen, schön gefürbten Blüthensehaft und Blïthenstande sehr reizend zu nennen. Dass wir aber Arten, welelse hierher gehören, noeh mit Recht erwarten kïnnen, welche dureh grosse prächtige Blüthenstïnde eine Zierde der Sammlungen zu werden versprechen, zeigt uns eine getrockncte Pflanze, welehe im Wiener Museum, Herbar Nr. 5230 liegt, mit, ,Brasilien“" als Fundort bezeichnet. Diese Pflanze trïgt alle Nerkmale von Echinostachys, aber der Bliithenstand hat hier allein schon eine Lüinge von 8 " und ist mit einer unzähligen Mrenge gleichzeitig geölfneter Bliithen geziert. Leirler liext nur der Blithenschaft im Herbar, - jedenfalls wird aber die ganze Gestalt der Pflanze schön zu nemnen sein. 


\section{Die Gattung CHEVALIERA Gaudichand.}

Leider besitzen wir von dieser interessanten Pflanzenform nur die Abbildungen in Gaudichaud's Bonite. Cheraliera sphacrocephala bildet einen so auffallend schönen Uchergang zu Ananassa sativa, dass ich höchlich erfreut war, eine Formenreihe, wie Macrochordium Echinostachys und Chevaliera zu finden, um auf ganz natürlichem Wege zur ungeschopften Fruchtform, welche sich nicht selten vorübergehend bei Ananassa sativa findet, zu gelangen.

Die Pflanzenform bei Cheraliera bildet wenige aufrechte zierlich ïberhängende Laubblïtter. Diese stehen am Grunde dicht umsehliessend zusammen. Bei Chevaliera ornata ist die ganze Pflanze gezeichnet zu sehen. Der Stamm erscheint erst etwas liriechend, dann mit dem Beginn der Laubblitter sich aufrecht erhelecurl.

Der kriechende Theil des Stammes trägt nur dicht üleremander liegende Schuppen. Wahrscheinlich wachsen diese Formen auf den Bäumen. Auf das gute Merkmal an den Laubblättern, dass nämlich die untere Hälfte nicht sägezühnig ist - sondern nur die obere - ist bei ,Blattformen" hingewiesen.

\section{Die Gattung TILLANDSIA Linné.}

Venn man Tillandsia usneoides und Agallost. antiacantha betrachtet, so setzt die grosse Formenversehiedenheit gewiss in gerechtes Erstaunen. Es diuffe aber wahrlich wenige I'flanzenfamilien geben, deren Gattungen in Grösse und Tracht so weit von einander (ntfernt stehen. Ich glaube, dass nach den trockenen Pflanzen zu urtheilen, Tillandsia usneoides eine allgemeine Benennungist, welche viele gute Arten cuthält, aber gewöhnlich sind die vorhandenen Exemplare nicht von der Art, dass man hei so kileinen Gebilden alle Theile der Blüthe vollstiindig finded Die Tillandsia usneoides, welehe in Brasilien so häulfig vorkïmmt und dort "Greisenbart" genamnt wird, hat ein hell grünes Ansehen, auch die Blüthen sind ganz lilein und hell weisslicht grün. Til- 
landsia usneoides ans IIexiko hingegen hat ein hell gelblichtes Ansehen, die Blüthen sind aber bedeutend grösser und röthlich gefärbt, gelblich gefäbt u. s. w. Tillandsia trichoides Villd. und Tillandsia crinita Willd. sind die fast schwarzen, sehr diunfidigen, ein dichtes Gewirre bildenden aber guten Arten von Tillandsia. Diese sind es wahrscheinlich, welche jetzt schon ziemlich häutig in Europa statt Rosshaar gebraucht werden.

Aber zum Genus Tillandsia gehören nach der jetzigen Bestimmungsweise drei ganz verschiedcnePflanzenformen, wclche ich mich auch veranlasst fand, ron Tillandsia zu trennen, wesshalb nur die Formen von 'Tillandsia usneoides allein mehr die Gattung Tillandsia bilden. Wir wollen num diese so verschiedenen Formen betrachten. Zu leichterer Verständigung bitte ich:

1. Tillandsia usneoides

2. $"$ recurvata

3. $"$ stricta

zu betrachten, der anderen Formen nicht zu gedenken, welche auch Tillandsia benannt wurden. Tillandsia usneoides und die Formen wie Tillandsia recurvata haben a chselst ä n dige B 1 iu thenstände; Till. stricta und ähnliche Formen aber endständige $\mathrm{Bl}$ üth enst ii nd e. Diess trennt die Formen von Tillandsia g a n z natürlich, und ich habe sie an gecigneten Platze eingereiht. Andere Formen, welche bei Tillandsia untergebracht waren, sind gar zu verschieden von diesen Formen, um hier weiter besprochen zu werden.

Wenn man die Abbildungen dieser Familie, welche sieh in der gesammten botanischen Literatur finden, ihrer ganzen Anzahl nach benützt, wie ich es gethan, - dann sieht man erst bei grïndlichen Studien dieser Pflanzenformen, wie sehr fehlerhaft manche dieser Abbildungen angefertigt wurden. Ich erlaube mir hice hei den sonst so wahren Abbildungen in der Flora Peruviana et Chilensis von $R$ uiz und Pavon aufmerlsam zu machen, dass auch hicr, trotzdem die Autoren die Gestalt der Pflanze genau kannten, und unubertroflene Beschreibungen der. 
selben lieferten, demnoch sich bedeutende Zeichnunghfehler finden. Man sieht auf Tafel 271 der Flora Per. et Chil. Tillandsia recurvata abgebildet, fann Till. capillaris und virescens auf Tafel 270. Wenn man diese drei Abbildungen noch so aufmerksam betrachtet, so findet man dennoch keine Spur von einem achselstandigen Blithenstande, wohingegen alle Species, welehe hierher gehören, also auch die drei obengenannten Tillandsiat recurvata, capillaris und virescens auf den ersten Anblick sich im getrockneten Zustande als achsclständig blühend zeigen. Aber R u iz et I'a vo 0 n sagen u. a. bei der Beschreibung von Tillandsia capillaris und Tillandsia rirescens ausdrïclilich: „Blüthenstand atcheclstandig u. s. w." Diesen grossen Gelehrten und Kennern der Pflanzen ist demula bei so kleinen Formen dieses bedeutende Merkmal nicht entgangen.

Tillandsia usneoides bildet nun den Repraiscutanten ron dem Genus 'Tillandsia; alle anderen von den Autoren zu Tilland ia gezogenen Formen sind anderwärts giltig untergebracht.

Es ist zu bedauern, dass es bis jetzt nicht gelingen wollte, lebende Pflanzen der Form Tillandsia usneoides in Europa ciuzuführen, da alle Versuche misslangen. Vielleicht trifft es sich, dass zufüllig bei irgend einer Orchidee, welche sammt dem IIolzstiiclic, worauf sie regetirt, eingeführt wird, sich Sümlinge ron Tillaudsia an der Holzrinde zeigen.

In letzter Zeit hat James Booth in Hamburg in seinem reichhaltigen Pflanzencataloge auch Tillandsia usnevides angefüht, dies ware jedenfalls eine merkwiudige Erscheinung. Eine Pflanze, welche ich von dem Herrn Giereaud aus Berlin mit Namen Tillandsia usncoides erhielt, ist mir ein sehr erwünschtes Pflinzchen, da es wahrscheinlich Diaphoranthema virescens sein durfte, - ebenfalls eine Form, dic liaum noch cinmal lebend in Europa sein mag.

Ich halie über die Formen von Tillandsia usnevides Studien gemacht, welche sich bei den Beschreibungen der Arten dieser Gattung finden. 


\section{Die Gattung DIAPHORANTHEMA Beer.}

Wenn ich auch schon bei Tillandsia dieser Formen gedachte, so finde ich doch nöthig, eine engere Begrïnzung der Gattung Diaphoranthema auch nach den Laubzustïnden u. S. w. zu versuchen. Ich habe mehrere Pflanzen von Diaph. recurvata, Diaph. capillaris und Diaph. virescens genau untersucht, aber nie die Anzahl der Blüthen constant gefunden; immer wechselten dic Blïthen von $1-5$, oft an einer Pflanze. Dies bewog mich auch, den Gattungsnamen zu wählen.

Alle hierher gehörigen Arten sind sehr kleine Pflänzehen, welche Rasen bilden und häufig an und auf altem Gemäuer, auch zwischen Felsen, seltener auf Bäumen gefunden werden. Je nachdem sie einen Standort besitzen, bilden sie runde Rasen oder bekommen an steileren Orten selbst einęn kriechenden Wuchs. Aher es ist auch wahrscheinlich, dass einige Arten immer nur kriechend wachsend gefunden werden. Die Stämmehen sind immer aufrecht und reich beblättert; diese sind fast fadenförmig an den Enden, am Grunde aber breit umfassend, mit brïunlich filzigem Ueberzuge. Die Laubblätter stehen ziemlich zweizeilig am Stamme. Die Höhe der ganzen Pflanze variirt von 2 his $6 "$.

\section{Die Gattung DYCKIA Römer et Schultes.}

Diese Gattung umfasst nun schon mehrere Arten, welche sich auch, bis anf eine, im lebenden Zustande in den Pflanzensammlungen finden.

Die Begränzung dieser Gattung ist durch den achsekstänligen Blïthenstand und die ein Dreieck bildende Blüthenkrone leicht erkenntlich geschlossen.

Es erscheint beachtenswerth, dass nur eine Art in den ailtern botanischen Werken sich findet, nämlich Tillandsia tuberosa. (A ra b. Flora Flum. t. 136.) 
Die Gattung AECHMEA R. et Pavon.

Die geachteten Autoren der Flora Peruviana et Chilensis Prodromus und Flora Peruviana et Chilensis haben Aechmea nach einer merkwïrdig schönen Pflanzenform aufgestellt. Die in Flora Peruv, et Chil, abgebildete Art ist Aechmea paniculata R. et P. - Wir wollen nun die Beschreibung dieses Genus, wie sie sich in den heiden oben genanten Werken findet, belenchten.

In Prodromus sprechen die Autoren als Merkmal dieser Gattung von drei Unterkelehzipfeln und von drei Oberkelehzipfeln. Die unteren seien stachelspitz und hierauf der Name "Aechmea" gegründet. Es sind also hicr drei Bracteolen bei einer Blüthe gemeint.

In der Flora Per. et C'hil. derselben Autoren wurle aber die obige Pflanzenform schon besser besehen und beachtet, denn man fand, dass es nur eine, aber den ganzen Fruchtknoten umhïllende Bractee sei, welche eine Stachelspitze besitzt. Dic Kelchzipfel sind hingegen unbewehrt angegeben und auch wirklich in der Zeichnung unbewehrt zu sehen.

Sir Hooker hat eine Form Aechmea Mertensii (Bot. Mag. t. 3186) und auch Poeppig et Endlicher in Nova Gen. Plantarum t. 159 Aechmea angustifolia benannt. Diese beiden Formen (welehe vielleicht nur eine und dieselbe Pflanze sind) haben die Bracteole und die Kelchzipfel stachelspitz und endlich hat Hooker im Bot. Mag. t. 4\$32 Aechmea mucronitlora abgebildet, bei welcher Bracteole, Kelchzipfel und Kronenblattzipfel stachelspitz sind. Aber die hicr genannten drei Arten ron Aechmea haben weder den seitenstinndigen Blithenstand, noch die so sehr bezeichnenden lang gegranten verkümmerten Blïthen, die allein schon genügen wiirden, um dic Gattung Acehmea gut hezeichnet aufzustellen, da ich mehrere dieser Formen zu studiren Gelegenheit hatte, aber die so selt:ame Verkümmerung der Blüthen sich immer gleich bleibt.

So ist unter anderen Acchmea setigera Mart., ron Poeppig 
(Amazonas VII, 1275) gesammelt, im kuiserlichen Museum in Wien in sehr guten Exwmplaren rorhamben. Arehmm soligera i-t eine ganz gute Art, und ich war erfreut, dureh die Güte meines repehrten Freundes, des IIerrn Dr. Fenzl, diese Pflanze genau unter. suchen zu können. Aber auch hier ist nur die involuerirende bractee scharf und ling gegrant, dic Kelchzipfel jedoch ganz ohne Spur einer Bewchrung.

Das Exemplar des kaiserlichen Huseums von Acchmea angustifolia, wonach Poeppig und End li e her ihre Beschreibung und Abbildungen in "Nova genera plantarum" machten, war fü mich von hohem Interesse.

Wenn man die Abbildung und die Pflanze genau betrachtet, so findet sich hier der gewiss seltene Fall, dass nämlich die $\Lambda$ bbildung getreuer als die Beschreibung ist.

Ich crlaube mir, aus der Beschreibung zwei Säte wörtlich zu geben. Es wird dort gesagt: ,Sehaft einzeln aus den Winkeln (Achseln?) der Blätter aufstrebent", - ferner weiter unten: ,die Bliuthen abwechselnd, beinahe zweizeilig, ährig, gedrängt stehend, vier Linien lang, nicht sichtbar; die obersten leer oder in eine Bractee verwandelt u. s. w."

Diese beiden Sätze lassen sich jedoch an der getrockneten Pflanze des Herbars, welche vollkommen gut erhalten und ganz rollstindig ist, nicht herausfinden, indern einmal der Bliuthenstand nicht aus den Winkeln der Laubblatter hervortritt, sondern endständig ist, - und damn, dass sich gar keine Verkïmmerungen an den Enden der Blüthenstandszweige finden, welche auch nur die entfernteste Aehnlichkeit mit jener merkwiurdigen Verkümmerung hahen, die Acchnea R. et Pav. so sehr auszeichnet und diese fattung hierdurch allein schon vollkommen von allen andern Formen der Bromeliaceen giltig unterscheidet. Wahrscheinlich wollte man durch olige Sätze Aechmea angustifolia I'. et Endl. den Formen von Aechmea R. et Pav. näher bringen, um auf diese Weise die Gattungs-Benennung zu rechtfertigen.

Man beliebe die Abbildung von Aechmea angustifolia Poepp. 
et Endl. in deren "Nova genera plantarum" und jene ron Aechmea paniculata R. et Par. in deren "Flora Peruv. et Chilensis" zu vergleichen, um sich von den hicr angeführten Thatsachen Ueberzeugung zu verschaffen.

\section{Die Gattung DISTEGANTHUS Ch. Lemaire.}

Der Autor hat diese fest begrinzte Gattung, welehe nur dureh einen Reprïsentanten vertreten ist, aufgestellt.

Diese Form ist durch die kurzen, runden, achselständigen Blüthenstände, dann durch die gestielten Lanbblatter, welche nur bei dieser Gattung in solcher Form vorkommen, sehr leticht arkenntlich und hinlinglich verwehieden von allen andern Gattungen dieser Familie.

Vielleichit sind die grossen gelben Becrenfiüchte im volliommen reifen Zustande auch geniessbar. 


\section{B e merkungen}

\section{über die \\ Blatt-Organe bei den Bromeliaceen mnd bei anderen Pflanzen-Familien.}

Bevor ich die Blattformen der Bromeliaceen in Betrachtung ziehe, dürfte es nicht uninteressant sein, auch andere Pflanzenfamilien oder ihre Gattungen zu besprechen, welche den Blattformen nach den Bromeliaceen nahe stehen.

Wie wichtig das Studium der Blattformen im allgemeinen, besonders aber bei guten 'und wahrhaft natürlich begrünzten Pflanzenfamilien ist, diirfte sich bei ferneren Fortschritten auf diesem Folde der Anschaumng erst wirklich nützlich erweisen, indem in nicht seltenen Fällen die Blattformen allein, ganze Familien gut erkenntlich machen werden. Wenn man den Blattorganen in Bezug auf die Bestimmung der Pflanzen einen erhöhten Antheil gegö̈nt hätte, dann würde man z. B. Weldenia nicht zu den Bromeliaceen gebracht haben, da die Blatt\%ustände, wie sie Weldenia zeigt, gar nie - auch nicht ammähermgeweise -- bei der Familie der Bromeliaceen vorkommen.

Wir wollen nun bei Pandaneae R. Br. beginnen.

Viele der hierher gehörigen Gewächse haben beim ersten Anblick wirklich manche Achnlichkeit mit Formen, welche sich bei den Bromeliaceen finden. I iess hat auch Reich en bach bestimmt, die Pandaneen zu der Familie der Bromeliaceen zu ziehen. 
Es ist nicht zu läugnen, dass die Gestalt der Früchte bei Pandanus mit dem Fruchtstande bei Chevaliera Gand, also auch - obwohl noch entfernter - mit den Früchten der Ananassa sativa Lind. einige Aehnlichkeit haben. Die Früchte bei Pandanus sind jedoch immer, oft selbst an langen Stielen - hängend. Die Frucht bei Chevaliera hingegen ist steif aufrecht, der Ananassa mit der Blätterkrone nicht zu gedenken. Pandanus ist immer getrennten Geschlechtes.

Die Laubblatt - Formen leei Pandaneae und bei Bromeliaceae sind trotz ihrer scheinbaren Aehnlichkeit doch leicht ron einander zu unterscheiden, und es genügt hierzu ein, wenn anch nur einen Zoll langes Stïck Blattbreite. Die Laubblatter bei den meisten Formen der Pandaneaen unterscheiden sich nämlich vollkommen von den Laubblittern der Bromeliaceen durch die auf der Blattunterfläche scharf vorragende Mittelrippe, welche, wenu die Laubblätter scharfe Zähne tragen, elenfalls mit scharfen Zähnen besetzt ist.

Jene P'llanzen, welche bei den Pandaneen glattrandige Laubblitter bilden, tragen dieselbe vorragende Mittelrippe auf der Blattunterfläche, allein auch diese ist dann unbewehrt.

Der Durehschnit eines Blattes bei Pandaneae zeigt immer die Form cines Dreieclies. Alle diese Blattzustände kommen aber nie bei den Bromeliaceen vor.

Die herrliche Familie Vellozieac D. Don. bietet ebenfalls mehrere Formen, welche den Bromeliaceen nahe stehcn. Auch die Familie der Velloziaceen fand sich Jussieux veranlasst, zu den Bromeliaceen zu ziehen.

Der oft verzweigte Stamm bei Vellozia mit den Blattbüscheln am Ende der Zweige hat manche Achnlichkeit mit Puya Molina. Nicht minder gleicht Vellozia minima, Vellozia pussila, Vellozia graminea u. s. w. einigen Species, die zu Diaphoranthema (Beer) gehören, wie Diaphoranthema vireseens (Tillandsia), Diaphoranthema recurvata (Tillandsia) $u . m . a$.

Ich crlaube mir hier einige IVorte iiber Vellozia einzusehalten. 
Vellozia bildet gar keine wahren Laubblätter, sondern nur batttragende Scheiden. Man beliebe Vellozia gracilis Mart., Vellozia glochidea Pohl., Vellozia c'yptantha Seub., Vellozia pussila Pohl, Yellozia phalocarpa Pohl, Tellozia tomentosa Pohl, Vellozia Janata Pohl, Vellozia flavicaus Mart. u. m. a. zu hesehen, um zur Ceberzeugung zu gelangen, dass hier die blattragende Schreide durch ihre Stellung an Stumme, wie anch durch die übereinanderliegenden, am Grunde eine Linie und weniger von einander entfernt stehenden faserigen Seheilen u. s. w. Iferkmale bieten, viclehe - auch olne besondere IBerielssichtigung der Blüthen allein genügen diurten, um die Familie Vellozieae leicht erkenntlich zu beschreiben und auch zu begränzen, da diese Zustände der blattragenden Scheirlen hei keiner anderen Pflanzenfumilie sich wiederfinden.

Die Epacrideaen besitzen ebenfalls Formen, welche an Bromeliaceen erimern. In Neu-Seceland findet sich Dracophyllum, Richea, wo die Laubhiatter äber einen Schuh Länge haben und durch ihr dichtes Zusammentehen an manche Species von Anoplophytum, C'ryptanthus crinnern. Aler hei I)racophyllum arboreum, Inügelii us. s. wind die Linublütter durch, auf heiden Seiten sichtbare, sclhst durchsichtige schmale Lüngslinien, wie nicht minder durch die scharfen Ränrler ron den Bbattern der Bromeliaceen gut unterschieden.

Bei Eryngium sehen wir elenfalls Laubblatuformen, welche an jene bei den Bromeliacen armern. Mehrerespecies des Genus

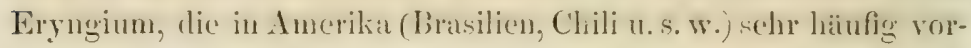
kommen, - wie Eryngium paniculatum Car. (Laroche? Chili), Erynginm marginatum Pohl, Eryngimm rulureaule Pohl (dieses letztere trïgt aber die Wimpern schom gemoinschaftich zu zwei bis drei) - gleichen mit ihren gुewimperten Lanblubtern den Blätern der Pitcairnia angustifolia Ait. u. s. w.

Aber die Laubbläter obiger Eryngien besitzen an den Rïndern lange, gerade, stachelspitz endende IVimpern von weicher Beschaffenheit. Die Blaltunterflichen sind mit ganz feinen, 
dicht stehenden weissen Längslinien geziert. Diese Linien nehmen regelmüssig am Blatte $a b$, indem mit einer jeden Wimper eine Linie sich abscheidet. Das Blatt ist der ganzen Länge nach flach und dünn.

Formen von Eryngium mit unbewehrten, selbst ganz glatten Laubblättern, wie Eryng. longifolium, E. elongatum Pohl und E. enophora Sellow; E. pascuum Pohl und E. lineare Pohl, gleichen erstere ebenfalls mehreren Species von Pitcairnia, die letzteren aber selbst Formen von Anoplophytum.

Die Laubblätter der Bromeliaceen, welche diesen Blattformen dem Anscheine nach gleichen, sind hingegen steif, die Zähne an den Blatträndern scharf spitz, holzig. Die kaum sichtbaren Linien auf der Unterfläche der Blätter verlaufen ununterbrochen bis zum Blattende; der Mittelnerv des Blattes bildet eine mehr oder minder tiefe Rinne.

Astelia Banksii hat auch Laubblätter, welche in Beziehung zu Bromeliaceen berücksichtigt werden müssen, seitdem Warscewitz in Peru eine Bromeliacee fand, deren Blätter durch reiche lange und weisse Behaarung wie beschneit erscheinen. Aber Sprengel fand sich auch bewogen, Coronariae = ? Bromeliae bei Astelia zu berichtigen.

Der Umstand, dass die Laubblätter bei Astelia Banksii am Rande behaart, hier oft eingerollt sind und in eine sehr lang gedehnte Spitze endigen, wie auch, dass selbe eine scharf dreieckige Rinne bilden, unterscheidet diese Bliatter ebenfalls von denen der Bromeliaceen.

Bei dem Genus A lo ë gibt es ebenfalls einige Species, wie: Aloë arborescens, Aloë soccotrina (perfoliata), Aloë microcantha u. m. a., welche Aehnlichkeit mit Blattformen haben, die bei den Bromeliaceen vorkommen; allein die Unterschiede sind hier auch bedeutend. Die oben genannten Formen von Aloë haben beide Blattflächen gleichmässig fleischig. Das Blatt ist sehr leicht zerbrechlich; wo sich Sägezïhne finden, sind diese fleischig und, wemn auch oft stark ausgebildet, demnoch wenig scharf. 
Die bekanntere Blattform bei vielen Species von Aloë ist im Querschnitte dreieckig, gleichmässig fleischig und ganz klar durchsichtig. Blattränder und Mittelrippe, welche letztere gut ausgebildet erscheint und vorsteht, sind entweder rein begränzt, lebhaft gefärbt, oder aber mit groben Zähnen versehen. Es sind demuach die bekannteren Formen von Aloë noch entfernter von den Blattformen der Bromeliaceen stehend als die oben angeführten Species, wie Aloë arborescens u. s. w. -

Das Genus Dasylirium unterseheidet sich durch die verholzenden Blattspitzen, welche auch einen aufrechten vertrockneten Büschel von holzigen Fasern bilden. Es ist getreunten Geschlechtes.

(Juncaceae? bei Xerotes? nach Fenzl.)

Das Genus A gave trägt starke Laubblätter, welche mit einer sehr kräftig entwickelten und entschieden holzbraun begränzten Stachelspitze endigen. Zwisehen den hakenförmigen, stachelspitzen Zähnen (wenn sich an den Blatträndern solche finden) ist die Blattsubstanz immer fleischig und die Riinder selbst zwischen den Zähnen rundlich.

(Agaveae Endl.)

Das Genus Hechtia hat stumpf fleischige, fast runde, allmälig spitz zulauf(nde Blattenden, welche in eine kurze Granne endigen. Die schwache Granne steht bei keiner Species dieses Genus im Verhültnisse zu den derben, stark hakenförmig gebogenen, sehr spitzen Dornenzühnen an den Blatträndern. Hechtia ist getrennten Geschlechtes.

Das Genus Y u e a zeichnet sich durch glattrandige, mit einer vertrockneten Zellschicht bekleidete Blattründer leicht erkenntlich ans. Diese Ränder lösen sich bei mehreren Species stïckweise ab und bilden damn gehogen abstehende, anch zierlich eingerollte Fäden ron hellbrauner oder weisser Fürbung.

(Yucca, Liliaceae Juss.) 
Fernere Versuche werden wahrscheinlich zeigen, dass die monocotylen Gewaichse durch ihre Blattzustände reichlichen Stoft zun Studium, und bei manchen die Laubformen allein ausreichende Mittel zur Bestimmung bieten dürften.

\section{BROMELIA. AGALLOSTACHYS. PUYA. ANANASSA. ENCHOLIRIUMI.}

Laubblätter sehr steif, fast holzig. Oberfläche weich, saftig; glatt, farblos, durchscheinend ganz ohne Blattgrün (Chlorophyl). Die Mittelfläche der Blätter bildet ein Lager grünen Zellengewebes: dam darunter eine Schichte ron geraden starken Bastfasern, welche dicht unter der Oberhaut der Blattunterfliiche sich finden: hierdurch erscheint diese Blattfläche wie fein gestreift. Aus den Blattründern drängen sich die Dornenzïlnne hervor; diese sind anfünglich der ganzen Blattsubstanz gleich, erst später verholzen dieselben gänzlich ınd nehmen eine mehr oder minder dunkle Färbung an.

Die Blätter finden sich immer sehr zahlreich ; sie stehen vom Stamme strahlenförmig ab, - jedes derselhen ist der ganzen Länge nach bis auf den Grund sichtbar.

\section{PHLOMOSTACHYS.}

Laubblïter maisblattartig, seidenartig, düm, weich. Die Blattstellung ist entweder im Quirl (Phlom. Warszevitzii u. a. m.), oder zweizeilig (Phlom. Altensteinii), Alle diese Laubblätter haben einen entschieden starken, auf rer Aussenflicche halb runden, auf der Imnenfliche aber tiefrimnigen Mittelnerr. Die Laubspreite ist der ganzen Länge nach schwach gefaltet. Das Blatt ist bis 3" breit 4' lang, wehrlos, entschieden wellig am Rande und lang spitz, weich endend, durchsichtig; an Grunde fiast stielrund, hier unfassend und oft stark geflügelt. 
Wo die Laubblätter im Quirl stehen, ist der Stamm am Grunde zwiebelartig aufgetrieben, und von da, ab stehen die Laubblätter sparrig nach allen Richtungen. Bei zweireihigem Blattstande stehen selbe fächerförmig, gleichnässig vertheilt. Die Laubblätter haben bei einigen Species einen rostbraunen Anflug von filziger Beschaffenheit, welcher sich hauptsächlich an der Unterfliiche derselben findet.

Blattformen des Genus Quesnelia beliebe mau bei der Beschreibung der Genera nachzulesen.

\section{PITCAIRNIA.}

Diese so bestimmt begränzte und desshalb sehr leicht zu erkennende Gattung ist auch die einzige, welche in Herbarien und Abbildungen sich richtig bezeichnet findet. Jene Formen, welche ich von Piteairnia trennte und zu eigenen Genera erhob, bieten auffallende Unterschiede an der Blüthenform. Hauptsüchlich dienen mir diese neu aufgestellten Genera, um die verschiedenen Formen gut aus einander zu halten.

Die Blattformen von Piteairnia sind gegen die anderen, bei den Bromeliaceen vorkommenden Blätterformen leicht erkenntlich, obwohl es auch hier nicht an Uebergangsformen fehlt. Ich erinnere an Piteairnia undulata, wo die bei 5 " breite Laubblattfläche an langen dünnen runden Stielen sitzt. Die Blattfläche ist stark wellig, seidenartig - der Lünge nach etwas gefaltet - und erinnert an die maisblattartige Belaubung der Gattung Phlom. Aber bei umfassenden Studien der Blattformen dieser Familie zeigt es sich, dass Pitcairnia undulala eine Blattform bildet, welche einzig in ihrer Art ist.

Pitcairnia angustifolia hat wohl der ganzen Länge nach wahrhaft sägezähnige Blattränder, allein deren durchsichtige Beschaffenheit und fleischige Weiche lässt sie doch als Blïtter zu Pitcairnia gehörend erkennen. Die Bezeichnung, ,angustifolia“ passt eigentlich auf alle Blätter bei Pitcairnia und ist desshalb nicht gut gewählt. 
Die Blatt-Erscheinungen sind bei Piteairnia sehr merkwürdig, indem sich

1. Vorblätter (Niederblätter, Schuppenblätter - DeckSchuppe),

2. Laubblätter

bilden.

Die Vorblätter sind eine Blattform, welche sich nur allein bei Pitcairnia findet.

1. Vorblätter.

Diese umgeben entweder den jungen Spross, oder aber die Endknospe, woraus sich der Blüthenschaft mit seinen Laubblättern erhebt. Sie tragen jedoch selten - laubblattähnliche Gebilde oder gehen in solche allmälig über. Sie umfassen, wenn sie den Spross belkleiden, denselben am Grunde breit scheidenartig und bilden hier durch dichtes Zusammenstehen zwiebelähnliche Verdickungen des sehr kurzen Stammes. Wenn die Vorblätter aber die Endknospe umgeben, erscheinen selbe am Grunde zwischen den Laubblïttern. Die Vorblätter sind von sehr derber, selbst holziger Beselaffenheit, gewöhnlich dunkel schmutzig holzbraun, und wenn vertrocknet - glänzend schwarz. Sie sind am oberen Theile, wo sich die scheidenartige Ausbreitung verliert, $1^{\text {"I }}$ breit und bis $21 /$ " lang, und tragen an den Rändern sehr scharfe dornige Widerhaken. Die 3/4 "lange dornenlose Spitze der Vorblätter ist sehr derb und in eine lange scharfe spitze Granne endigend. Im Durchschnitt zeigt sich hier die Blattsubstanz hell lichtgelb. Die Aussensehichte verhältnissmässig breit und dunkel braun-roth. Ein Durchschnitt des umfassenden Theiles der Vorblätter ist weich fleischig, weisslich grün, sehr dünnhäutig, roth gestreift, mit lebhaft rothem Rande begränzt.

\section{Laubblätter.}

Die Laubblätter sind bei Piteairnia immer am Grunde mehr oder minder stark umfassend. Vom Grunde bis zur halben Laubblattlänge eine Rinne bildend, steif, dann gegen oben ganz flach 
endigend. Die Blatter sind vom Grunde aus immer auf der Oberfläche fleischig und hier farblos. Diese fleischige Oberfläche verliert sich aber bei $1 / 4$ der ganzen Blattlänge allmälig, und es bildet sich von da an die ganzrandige, etwas gestreifte oder gradlinige durchsichtige, weiche, am Ende sehr spitz zulaufende Blattfläche.

An fleischigen unteren Theile des Laubblattes finden sich manchmal Sägezähne, - gewöhnlich sind die Laubblätter wenig bewehrt. Oft ist die ganze Unterfläche derselben und, obwohl sehr selten, auch deren Oberfläche rein weiss, bis holzbraun gefärbt. Diese Färbung bildet ein leicht zu entfernender kleiiger Anflug, welcher selbst filzig erscheint. Bei mehreren Species liegt dieser Anflug gewissermassen nur auf den Blättern und ist selbst leicht wegzublasen.

Die Breite variirt bei den verschiedenen Species von 1/2" bis $2^{\prime \prime}$ Breite und $3 \frac{1}{2}$ bis $4 \frac{1}{2}$ ' Länge. Die Laubblätter finden sich immer sehr zahlreich und bilden einen zierlichen Büschel; im Alter aber bilden dieselben Rasen von mehreren Schuhen im Durchmesser.

Jene Pitcairnien, welche einen zwiebelartig verdickten Stamm hilden (wie Pitc. graminea, Karwinskiana u. m. a.) treiben den jungen Spross schon vollkommen verdickt, und von aussen mit stark umfassenden, schwarzbraunen, trockenen, scharf spitzen Scheiden umgeben. Am Ende des verdickten, oben halbrunden Sprosses stehen zwei Kränze von Blattformen.

Den ersten Kranz bilden die Laubblätter, welche hellgrün, etwas gestreift, dicklich, stark umfassend, am Girunde fleischig, hier rein weiss, dann bräunlich; sehr schnell schmal werdend, hier schwach widerhakig, dann aber (der sichtbare Theil) hellgrïn, ganzrandig, allmälig breiter werdend, dann von der Mitte der Laubblattlïnge allmälig weich spitz endigend.

Den zweiten Kranz bilden die Vorblätter.

In Mitte dieser zwei Blattkreise sitzt die Endknospe, welche Laubblätter, Blüthenschaft und Blüthenstand gleichzeitig ent- 
wickelt. Der zwiebelartige Stamm hat nach der Blüthezeit einen Durchmesser von $1 \frac{1}{2}$ bis $2^{\prime \prime}$ und ist mit den vertrockneten braunschwarzen Schuppen ganz bedeckt; er ist mit den vertrockneten Vorblättern gekrönt, aus deren Mitte sich der abgeblühte holzbraune Schaft erhebt.

Hierher gehört auch jene Form, wo die Blïthen einen in Mitte der Laubblätter sitzenden Büschel bilden, wie Pitcairnia excapa u. m. a.

\section{COCHLIOPETALUM.}

Laubblätter am Grunde stark umfassend, hier weisslich durchsichtig und fein gestreift, dann schnell schmal werdend, rinnenförmig, von Nitte der Blattlänge bis ans Ende flach ausgebreitet, ohne Mittelnerv; sie stehen nach allen Richtungen aufrecht, am Ende zierlich übergebogen. Blattfläche glatt glänzend, auf beiden Blattflïchen gleichfarbig hellgruin, von dicklicher Beschaffenheit, manchmal in der Jugend leicht gewimpert, - immer weich spitz endend. Dem Blüthenstande geht kein bewehrter SchuppenblattBüschel voran.

\section{HOHENBERGIA.}

Hohenbergia bildet lange schmale, am Grunde vollkommen umfassende hängende Laubblätter, welche auch noch theilweise wie eine Röhre verwachsen sind. Sie sind sehr fleischig und fast weich anzufühlen, aber an den stumpfen Rändern dennoch scharf sägezähnig. Die Laubblätter am unteren Theile des Blüthenstandes sind bei den meisten Species fast stielrund.

Wenn Tillandsia eyanthyiformis, Till. bracteata und Till. terminalis der Flora Fluminensis von A r ra b. wirklich zu Hohenbergia gehören, dann passt die obige Blattbeschreibung des Genus Hohenbergia nicht vollkommen gut. Leider sind die Abbildungen der Flora Fluminensis oft dergestalt unkenntlich, dass, nur um die Abbildungen nicht zu uibergehen, ich diese Formen hier einstweilen unterbringe. 
Vielleicht belehrt uns eine lebende Pflanze dieser Form einst besser, wohin selbe eingereiht werden soll.

Blattformen der Genera Caraguata, Pityrophyllum und Nidularium beliebe man bei der Beschreibung der Genera nachzulesen.

\section{CRYPTANTHUS.}

Laubblätter vom Grunde aus gleich breit, dann in eine feine, weiche lange Spitze endigend. Der mittlere Theil der Blätter entschieden fleischig, undurchsichtig; zu beiden Seiten aber ist die Laubfläche sehr dünn und durchsichtig, am Rande stark wellig und sehr fein scharf sägezähnig. Auf der Unterfläche ist das Laubblatt stets weiss oder bräunlich filzig bekleidet. Oberfläche entweder glänzend glatt, oder weiss, auch bräunlich schïrfig bekleidet; diese bilden bei einigen Species schöne Querbinden. Der Schurf, welcher die schönen Zeichnungen auf den Blättern bei Cryptanthus bildet, ist sehr leicht wegzuwischen.

Diese Pflanzen bilden oft aufrechte Stämmchen von 3 bis 6 " Höhe und tragen am oberen Ende mehrere Zweige. Die Stämmchen sind mit gerade abstehenden Laubblïttern dicht besetzt. Farbe der ganzen Pflanze entweder hellgrün oder dunkel braunroth.

Zur Blüthezeit ändern die Herzblätter ihre Farbe nicht.

\section{PLATYSTACHYS.}

Laubblätter dicklich, lederartig, trübfarbig, ganzrandig, meist mit weisslichem schurfigen Anfluge bekleidet, in eine langgedehnte Spitze endigend, hier oft eingerollt. Am Grunde tiefrinnig, - auch an den Blatträndern oft eingerollt. Alle Laubblätter abstehend; bei den verschiedenen Species variiren dieselben von $1^{\prime}$ bis zu 3' Länge.

\section{VRIESEA. GUZMANIA.}

Laubbliitter kelchbildend zusammenstehend, bandartig, ganzrandig, auf beiden Blattfächen glänzend, durchsichtig, gleich breit, 
stumpf endigend, lebhaft hellgrun, oft mit feurig roth-braunen Querbinden und Flecken, oder auch mit unregelmässigen grossen rothen reinbegränzten Mackeln geziert. Sie variiren von $1^{\prime}$ bis $2^{\prime}$ an Länge bei den verschiedenen Species. Die Flecken und Querbinden der Laubblätter sind durch die Blattsubstanz gebildet, desshalb auch vollkommen ausdauernd.

\section{LAMPROCOCCUS.}

Dieses Genus enthält die Formen, welche Brogniard zu Aechmea gezogen. Ich habe am geeigneten Platze auf die Unhaltharkeit dieser Species bei Acchmea hingewiesen. Die Blattformen der hierher gehörigen Species sind sich alle ziemlich gleich, - die Blätter sind glänzend, ganzrandig, stehen eine Röhre bildend zusammen, aber die Blattenden stehen steif gerade ab, so zwar, dass die Laubblätter - welche nie sehr zahlreich sind - eine schöne aber unregelmässige Rosette bilden. Am Grunde haben die Laubblätter der Länge nach einige Einbuchtungen.

Der Wuchs muss entschieden kriechend genannt werden; alte Pflanzen bilden viele Seitenzweige, welche ganz lose, nur mit einem Kranze kurzer Wurzehn versehen, sich befestigen und ihre Nahrung hauptsächlich aus der feuchten Luft entnehmen. Sic wachsen alle an und auf Bäumen, wo sie Rasen von mehreren Schuhen im Durchmesser bilden.

\section{BILLBERGIA, HOPLOPHYTUM, MACROCHORDIUM ECHINOSTACHYS, CHEVALIERA.}

Laubblätter rinnenförmig, gleichmässig trüb grün, lederartig, steif, selbst holzig, auf der Oberfläche etwas rauh, auf der Unterfläche glatt, seidenartig anzufühlen, oft durch kleiigen Anflug weisslich erscheinend, oder auf beiden Seiten stark sichtbar, rein weiss gefleckt oder mit verschieden breiten Querbinden geziert. Der Standort der Pflanze hat entschieden Einfluss bei dieser bandstreifenartigen Zierde, indem bei dunklem, sehr feuchtem Stand- 
orte die kleiige Masse, welche dic Blitter theilweise bedeckt, nicht gehörig abtrocknen kann und desshalb die Flecken und Querbinden an den Blättern fast gar nicht zu bemerken sind, wo hingegen ein Spross derselben Pflanze, welcher an einen hellen und trockenen Standort gestellt wird, auch alsbald die schöne Zeichnung mit scharfer Begränzung erhalten wird.

Die Oberfläche der Laubblätter ist mit einer sehr dünnen Haut überzogen, worunter eine Bastfaser-Schichte sich befindet, welche die Oberfläche sehr hart erscheinen macht. Der Durchschnitt eines Laubblattes ist gleichmässig grün gefärbt. Das Blatt endet mit einer nicht sehr scharfen Stachelspitze und ist am Ende gewöhnlich etwas eingebogen. Die Ränder der Blätter sind gerade und mit stachelspitzen Zähnen besetzt.

Manche Species hat Laubblätter, welche wie aus Eisenblech geschnitten erscheinen. Solche Laubblätter stehen immer eine lange schmale Röhre bildend beisammen, wesshalb nur die zwei äusseren Blätter bis auf den Grund sichtbar sind. Dieses innige Anschliessen und Umfassen der Laubblätter unter sich ist Ursache, dass diese Gewächse eine bedeutende Menge trinkbaren Wassers enthalten. Ein bemerkenswerther Umstand ist es, dass selbst kleine Wasserpflanzen (Urtricularien) zwischen den Laubblättern im Wasser vegetiren und die schönen Bromeliaceen noch durch zarte Blïmchen und überhängende Stolonen der Wasserpflanzen herrlich verziert erscheinen.

Es folgen hier die Hauptmerkmale der Blattformen einer jeden der hier angeführten Gattungen:

Merkmale:

\section{BILLBERGIA. HOPLOPHYTUM.}

Laubblätter am Grunde kelchbildend zusammenstehend, dann nach allen Richtungen abstehend, auch eine lange Röhre bildend, steif aufrecht, ungleich an Länge; einzelne Blätter lederartig überhängend (bei der Unterabtheilung Cremobotrys). 


\section{MACROCHORDIUM.}

Laubbätter gleichmässig hellgrïn, aufrecht, nur am Grunde eine kurze Röhre bildend. Blattenden eingerollt. Stachelzähne unordentlich zusammenstehend.

\section{ECHINOSTACHYS.}

Laubblätter auf beiden Flächen silberglänzend glatt, am Grunde bauchig umfassend, von halber Länge an überhängend.

\section{CHEV ALIERA.}

Laubblätter vom Grunde aus stark umfassend, tiefrinnig mit glatten Rändern; erst beim Flachwerden der Blätter erscheinen feine regelmässige Sägezähne, das Blattende wird allmälig spitz, ohne scharf bewehrt zu enden.

\section{PUYA.}

Hier ist es ein sehr bemerkenswerther Umstand, dass die Hochb]ätter am Blüthenschafte sehr hinfallig sind und auch wirklich zur Zeit der Blüthe meistens schon abfallen, aber am Schafte sichtbare Narben zuriicklassen.

Die Laubblätter, welche den Stamm krönen, sind in der Jugend gewöhnlich auf beiden Blattflächen lebhaft grün; erst nachdem die Pflanze ein gewisses Alter erreicht hat, beginnen die Laubbläter, von der Spitze angefangen, jene silberweisse, fast glänzende Unterfläche zu bilden, welche Puya so sehr von den anderen Genera auszeichnet. Desshalb ist man auch ausser Stande, über die jetzt sehr zahlreichen Sämlinge der Gärten etwas bestimmtes sagen $\mathrm{zu}$ können, indem wahrscheinlich wenigstens zehnjährige Pflanzen erst jene Gestalt entwickeln werden, welche dann erlaubt, die Species annäherungsweise zu unterscheiden.

Die ausgebildeten Laubblätter an alten Pflanzen stehen alle gleichmässig vom Stamme ab, dann hängen sie bogenförmig herab, und zwar dergestalt, dass die Blattenden gegen einwärts gekrümmt sind. Dieser Blattschwung gereicht Puya zur besonderen 
Zierde. Die Länge der Laubblitter beträgt 4 bis 5', die Breite, welche allmälig gegen die etwas bräunliche weiche Spitze abnimmt, über 1". Die Zähne an den Blatträndern stehen 1" (und weniger) entfernt von einander; sie bilden scharfe, hellbraune, gekriimmte, gerade abstehende Haken. Die weiche Spitze ist bei ausgewachsenen Pflanzen 1' lang, zahnlos und sehr schmal. Die Oberfläche der Laubblätter isi ein sehr helles, bläuliches Grün, glänzend glatt wie Seide. Die Oberhaut ist pergamentartig sehr steif und sammt der darunter liegenden Zellenschicht rein weiss. Die Unterfläche ist sehr stcif, hellgriin, wie fein linirt, mit mehr oder minder dichtem, weissem oder rostfarbigem Ueberzuge bekleidet. Auf der Blattfläche sind stets Eindriicke der Nebenblätter sichtbar, welche auf der Kehrseite oft merkliche erhabene Streifen bilden.

\section{TILLANDSIA.}

Die Pflanze bildet, auf Bäumen wachsend, ein dicht verschlungenes, aus dünnen fädlichen Verzweigungen sehr lang herabhängendes Gewirre. Die Hauptachse wächst langsam fort und entsendet eine grosse Menge von Seitenzweigen, welche wieder zahlreiche Verästelungen bilden. An den fidigen, runden, sehr dünnen Zweigen stehen die linealen, kaum $1 / 2$ “" breiten Blätter sehr entfernt von einander. Die ganze Pflanze, mit Ausnahme der Blüthe ist fein zottig, schmutzig hellbraun oder fast schwarz von Farbe. Diese zottige Bekleidung ist durch sich überlagernde Sternhaare gebildet, welche an den Ründern gezahnt sind. Die junge Samenpflanze bildet wahrscheinlich einen winzigen Büschel ganz schmaler, gleich langer Blättchen; erst später erscheinen die Seitenverzweigungen, welche dann schlaff herabhängen.

Es ist bemerkenswerth, dass man bei grossen Mengen dieser Pflanzen, wo mancher Zweig bis 4' lang sich findet, dennoch gar keine Wurzeln entdecken kann. Vielleicht sind dieselben so dünn und hinfällig, dass im trockenen Zustande der Pflanze hiervon nichts mehr zu bemerken bleibt. 


\section{ANOPLOPHYTUM. DIAPHORANTHEMA.}

Laubblätter pfriemlich, rund, oder durch eingerollte Blattrïnder rund erseheinend, ganz unbewehrt, silberglänzend oder mit weiss kleiigem, auch braun filzigem Anfluge versehen, in den seltensten Fällen glatt glänzend. Sie stehen immer steif aufrecht und variiren von $2^{\prime \prime}$ bis $1^{\prime}$ an Länge bei den verschiedenen Species.

Das Erscheinen des Blüthenstandes trennt Anoplophytum von Diaphoranthema natürlich. Erstere blüht endstündig, die zweite aber seitenständig. Beide Gattungen umfassen die kleinsten Formen dieser Pflanzenfamilie, obwohl besonders die erstere gerade hierdurch, wie nicht minder durch die lebhaft gefärbten Blüthenstïnde für Pflanzensammlungen sehr wünschenswerth ist.

\section{DYCKIA.}

Laubblätter fleischig, fast rund, gleich lang, am Ende sanft übergebogen, feiu, scharf, oft unregelmüssig sägezühnig, immer eine schön geordnete Rosette bildend. Oberfläche der Blätter glatt glänzend, Unterfläche der ganzen Länge nach mit einem stark entwickelten Mittelwulste versehen und sehr fein weiss linirt, am Grunde oft fast wollig.

\section{AECHMEA.}

Diese Form bildet kräftige aufrechte, sehr scharf stachelzühnige, rinnige Laubblätter, welche allmälig mit einer scharfen Spitze enden. Der Stamm ist, obwohl kurz, doch selır krüftig entwickelt. Die einzelnen Blätter nelımen vom Grunde aus an Länge immer mehr zu, sind sonst aber an Bewehrung u. s. w. ganz gleich. Der starke aufrechte Blüthenschaft erscheint hier am Grunde bei den untersten Laubblättern. Die verkümmernden Blüthen, deren eine Menge vorhanden sind, finden sich entweder am Anfange oder am Ende der Blüthenstands-Verzweigungen. Auch ganz verkümmernde Blüthenzweige finden sich; diese haben das Aussehen lang bestachelter Zweige. 


\section{DISTEGANTHUS.}

Laubblätter verschieden an Länge ( $1 \frac{1}{4}$ bis $\left.2^{\prime}\right)$, auf der Unterfläche weiss filzig bekleidet, mit den Enden zierlich herabgebogen. Am Grunde tiefrinnig, stark umfassend, dann deutlich gestielt, hier $1 / 2^{\prime \prime}$ breit, an den dünnen Rändern mit gerade abstehenden Stachelzähnen besetzt, dann herzförmig ausgebreitet, hier am Rande wellig, $31 / 2$ " breit, sehr verlängert und mit zurückgebogener, langer Spitze endigend, an den Rändern mit kleinen scharfen Dornenzähnen besetzt.

Die Rinne auf der Blattfläche verliert sich von der herzförmigen Ausbreitung allmälig. Der Stamm treibt am Grunde zu verschiedenen Zeiten zahlreiche bei 1' lange Stolonen, welche an den Enden junge Pflanzen bilden; nachdem derselbe aber mehrere Blüthenschäfte gebildet, treibt er zur Zeit der Fruchtreife einen starken Seitentrieb, welcher die Mutterpflanze danı günzlich ersetzt. Die Stolonen hingegen werden, nachdem sie die junge Pflanze über 1' weit von der Mutterpflanze entfernte, endlich dürr, und bei diesem Zustande hört auch die Verbindung der jungen Pflanze mit der Mutterpflanze gänzlich auf. 


\section{U e ber \\ A N A N A S S A.}

Jene Gewächse, welche reellen Nutzen schaffen, wurden am ehesten studirt und zu verbreiten gesucht. So haben die Formen der Cacteen, welche geniessbare Früchte tragen, oder deren Insekten, Holz und Faser dem Haushalte der Menschen Nutzen gewähren, eine grosse Verbreitung, selbst in den entferntesten Welttheilen erlangt, obwohl diese seltsamen Gestalten nur auf einen bestimmt begränzten Verbreitungsbezirk, nämlich $40^{\circ}$ südl. Breite und $40^{\circ}$ nördl. Breite in Amerika angewiesen sind.

Auffallend ist es, die V a nilla in Amerika im vollkommen wilden Zustande zu finden, welche wahrscheinlich eine asiatische Pflanze ist. Die Ananassa wurde auch in alle Tropenländer der Erde getragen und ist jetzt in den ihr fremden Weltheilen wie wild wachsend zu betrachten. Wenn nun nachweisbar, dass die Ananassa nach Asien und Afrika gebracht wurde und daselbst förmlich verwildert gefunden wird, - aber die e in zige Bro. meliacee ist, welche dort vorkommt, - soliegt die Ansicht nicht sehr ferne, dass jene Species der Vanilla, welche jetzt in Amerika sich wildwachsend findet und die einzige stammbildende Form der Orchideen-Familie ist, die A merika bewo h nt, - als Pflanzenformen zu betrachten sind, welche in vorgeschichtlicher Zeit von Asien nach Amerika gebracht wurden. 
Alterthümer in Central - Amerika und in den südlichen Provinzen von Mejiko stehen nun in einsamen Wildnissen in Mitte mächtiger, fast unzugänglicher Urwälder - Wahrzeichen einer längst vergangenen Zeit, an denen man Spuren eines Zusammenhanges mit asiatischer Einwanderung zu entdecken glaubte! Wenn solche Hypothesen zu begründen wären, dann stände manche Vanilla noch an dem Platze, wo der Mensch sie gepflanzt, und umrankte jetzt die Ruinen jener Wunderbaue, deren Gartenzierde sie einst waren.

Gewächse wie die Vanilla, welche in der Jugend nur wenig, im blühbaren Alter aber gar nicht mehr im Boden wurzeln, sondern nur mit ihren zahlreichen, gleichmässig am Stamme vertheilten Wurzeln an den Riesenbäumen oder über Fels und Schutt hinankriechen, konnten auch, verlassen von der Cultur, ihre jetzigen Standorte selbst gewählt haben, indem die feinen Körnchen, welche den Samen darstellen, durch die Lüfte fortgetragen, die entferntesten Plïtze an den Meeresküsten und in den Urwäldern zu erreichen vermochten, um hier - da sie sehr schnell wachsen in kurzer Zeit vollkommen eingebürgert, dem Suchenden die küstliche Vanilla-Frucht zu bieten.

So lange eine Pflanze keine Vexänderung dureh die Cultur erlitt, bleit immer die Wahrscheinlichkeit, dass unter gleichen Breitegraden eine weit hergebrachte Pflanze endlich auch in dem fremden Boden heimisch werden kann. -

In den alten Schriften wird von den Bromeliaceen nur die Ananassa beschrieben, da sie als Nutzgewächs auch vor allen die Aufmerksamkeit auf sich zog.

Die erste Beschreibung und Abbildung dürfte wohl in dem Werke von Gonzalo Hernandez de Oviedo: „La historia de las Indias," Ausgabe von 1535 und 1546 zu finden sein. Der Verfasser war Commandant in St. Domingo.

Damals kannte man schon drei Abarten der Ananassa, nämlich: Yayman, Yayagua und Boniama, welche sümmtlich von dem Spanier Pinas nach Pom me de pin genannt wurden. 
Die Versuche, die Ananassa-Früchte in nicht vollkommen reifem Zustande nach Europa zu senden, misslangen damals, denn sie verfaulten unterwegs. Erst im Jahre 1599 brachten Sehiffer die mit Zucker eingemachten Ananassa-Früchte sammt dem Blattschopfe - aber nicht aus Domingo, sondern aus Java - nach Europa.

Bemerkenswerther ist das Werk von André Thevet: „Les singularités de la France antaretique, autrement nommée Amérique, ${ }^{6}$ Ausgabe 1559.

Th evet, welcher mehrere Jahre in Brasilien gewesen, har die Ananassa unter dem Namen , Na na s" beschrieben und auch abgebildet. Er sagt, die Frũchte seien gegen mehrere Krankheiten sehr heilsam. Die Frucht ist zur Reifezeit gelb, von Geschmack und Geruch vorzüglich. Sie trägt keinen Samen und wird nur durch die Seitensprossen vermehrt. Vor der Reife der Frucht sei der Saft so scharf, dass er das Zahnfleisch angreife und dadurch Blutungen im Munde entstehen.

Der Name "Ananas" kommt zuerst bei J e an de Lery in dessen, Histoire d"un voyage faiten la terre du Brésil," Ausgabe von 1580 vor und ist olme Zweifel aus der Benennung "Nanas" entstanden.

Fernere Nachrichten finden sich bei H a r n a ndez, welcher im 16. Jahrhundert als Naturforscher in Mejiko reiste. Dieser nennt die Ananas "Matzatli"6 orer ,pinea Indica." Der Abbildung nach zu urtheilen, düfte $\mathrm{Hernandez}$ die Ananassa sagenaria gemeint haben, was aber in so ferne auffillt, da Ananassa sagenaria sauere Früchte trägt, während die anderen Autoren sich an die süssen Früchte hielten.

Eine grössere Bedeutung haben die Nachrichten von Christophori a Costa, 'Tradato de las Drogas y medicinas de las Indias orientales, Ausgabe 1578. Hier findet sich die erste Anmerkung, dass die Ananassa von Santa Crux nach West-Indien und dann nach Ost-Indien, endlich auch nach China verpflanzt wurde. 
Er sagt ferner, dass man auf den $\mathrm{C}$ a $\mathrm{n}$ a rischen. Inscln diese Frucht „Ananasa" nennt.

Plumier, - Nova plantarum Americanarum Genera, Ausgabe von 1703 - ist derErste, wcher in seinem rortrefflichen Werke die Ananassa - Bromelia benennt, zu Ehren cines schwedischen Botanikers Namens Olol "Bromelius.

In Margraw, - Historia rerum natural. Brasiliae, Ausgabe von 1648 - findet sich eine rette Abbildung der Ananassa mit Namen „A nanas," welche wahrscheinlich die Ananas conique der Franzosen ist.

Die schlechteste Abbildung der Ananassa hat - auffallend genug! - Meriani in dem Werke, ,Florum cultura," Ausgabe 1641, geliefert, da aus den Händen dieser Künstler - Familie rles 17. Jahrhunderts nur vortreflliche Arbeiten hervorgingen.

Bei Dilenius, Trew und Ehret, Kerner, Descourtzils n. s. w., wie nicht minder in den englisehen und französischen Gartenschriften, finden sich zahlreiche Abbildungen der verschiedenen Varietiten der Ananassa sativa. Von mehrfachem Interesse sind jedoch noch manche Mittheilungen aus verschiedenen Sammelwerken, welche ich hier ebenfalls im Auszuge mittheile.

L'Histoire du nouveau monde etc., par le Sieur Jean de L a et d'Anvers. Leyde 1640.

In diesem Werke findet sich eine schlechte Abbildung der Ananassa, und zwar pag. 500, mit Namen "La Nana.“"

In dem Werke von Griffith $\mathrm{Hughes:}$,The natural History of Barbados"6 findet sich pag. 231, tab. 21, die Ananassa (tueen Pine und Sugur-loaf abgebildet, welche beide aus Surinam herstammen.

Ueher die wilde Ananassa sagt der Autor: „Die wilde Ananassa ist ron allen bisher beschriebenen in der äusseren Form verschieden, ähnlich wie der Crap-Apfel ron $R$ us set und Golden Pippin sich rersehieden zeigt. Dic Laubhititer bei der wilden 
Ananassi sind alle sehr lreit, und im Verhältniss zur Pflanze ist die Frucht nur schmal und kümmerlich zu nennen.

K rünitz sagt in seiner „Oeconomischen Encyclopädie":

Ananas Pitta dictus Plum., französisch Ananas de Pitte, hat keine stacheligen Blätter. Die Gattung ist kleiner als die beiden vorhergehenden (Anan. ovatus und Anan. pyramidalis). Er ist ebenfalls sehr gut.

Wenn man den weissen Ananas aus Samen heranzieht, so gilbt es unter dessen Früchten so viele Veränderungen, als wir in Europa unter unsern Aepfeln und Bimen haben. Der Terfasser der „Agréments de la Campagne" scheint sogar zu behaupten, dass alle vorerwähnten Varietäten von der Art, wie man mit den Schösslingen verfúht, und ron dem Grade der Temperatur der Luft, in weleher sie wachsen, horrühren. Der gemeine Name war in A merika "Ananas," "Ananases Nanas," auch nach L a et in Brasilien "Panacous" genannt. Therenot benennt sie Hoyriri.

Bei den Sinesern heisst dieses Gewächs ,Ungley, "bei Pater Kircher" „Kapa 'Tsiaka." Die Mexikaner henennen die Frucht "Matzatli;" so findet man auch die Benemungen ,Yayama" oder ,Jayama, "Boniama" und „Jajagua."

Der wilde Ananas, die $\mathrm{N}$ an a brava oder Ananassa sylvestris non aculeatis, Pita dicta oder der wilde Ananas ohme Stacheln, so insgemein Pita genannt wird. Dieser giltt durch seine Blätter solehe subtile Fäserchen, die dem feinsten Flachs und Hanf Trotz bieten, daher auch dieser I'it a von L a et genannt wird. Aus diesen Fasern werden in Amerika Strümpfe angefertigt, welche an Glanz, Feinheit, Weisse und Ibauerhaftigkeit die Seidt weit übertreften.

M a ri us bemerkt in seiner ,Flora Brasiliensis, "Fas. XT, bei seiner Abhandlung üher Agaveae, dass er hinsichtlich der Bennenung „Pita" nicht vollkommen gewiss sei, ob diese Benennung den Fasern ron Agave zukomme; wohingegen Arruda da Camara bei Agave vivipera vorsetzt „Caroatá assú Pitiera.” Bei 
vielen Autoren wäre demmach die Benennung „Pita ${ }^{66}$ für alle amerikanischen Pflanzen bestimmt, deren Bastfasern nutzbringend sind, wo dagegen, wie oben angeführt, der berühmte Plumier den Namen „Pita" nur auf die Ananas sylvestris non aculeatis angewendet hat. Bei Hernandez findet sich Seite 275, Pati (s. Metl lenissimum), das als eine Art Pita Fäden zur Bereitung von Stricken liefert. Martius bemerlist bei seinen Agaveen, dass diese Pflanze vielleicht für ein Dasilirium zu betrachten sei. In dem westlichen Theile von Java wird aber die Agave R umphii "Nanas costa," d. i. "Ananas von der Küste Indiens," oder "Nanas sabrang," d. i. ,ausländische Ananas" genannt.

Philipp Millers bemerkt in seinem vortrefflichen Werke: ,Allgemeines Gärtner-Lexicon"6 - welches viele Jahre mit Recht in höcbster Achtung stand und dessen Name noch jetzt hüılig genaunt wird - über Ananassa, dass ihm sechs Sorten bekanut seien, nämlich :

1. Ananas ovatus: der eirunde Ananas mit weissem Fleische;

2. Ananas pyramidalis: der pyramidenförmige Ananas mit gelbem Fleische, der Zuckerbrot-Ananas genannt.

3. Ananas glabra: der Ananas mit glatten Blättern.

4. Ananas lucidus: der Ananas mit glänzenden grünen Blättern, welche an dem Rande kaum einige Stacheln haben.

5. Ananas serotinus: der pyramidenförmige olivenfarbene Ananas mit gelbem Fleische, und

6. Ananas viridis: der grüne Ananas.

Ausserdem bemerkt der Autor, dass ihm noch mehrere Varietiten bekannt seien, wovon wohl einige dureh Samenzucht erzielt sein können; er hält die Ananas für eine a frika $n$ is ch e Pflanze, obwohl er selbst gesteht, dass es schwer zu bestimmen sei, von wo diese Pflanze ursprünglich komme. Der Erste, welcher in Europa Ananassa-Früchte gezogen, war Herr Le Cour zı Leyden in Holland; von ihm sind die Gïrten von England 
zuerst mit diesen Pflanzen versehen worden, aber zur sellen Zeit hatte man schon viele Früchte der Ananassa ans Amerika nach Europa gebracht. Ananas ovatus sei damals die gemeinste gewesen, aber Ananas pyramidalis der ersteren bei weitem vorzuziehen, indem die Frucht nicht nur grösser, sondern auch von viel besserem Geschmacke sei. - Ananas glabra ward von einigen Liebhabern damaliger Zeit um der Verïnderung willen gezogen, aber die Frucht ist lange nicht so gut wie die vorige. - Ananas viridis war damals die seltenste in Europa. In Amerika ward sie als die beste Sorte gehalten; sie kam von B arbados und Montserrat nach Europa.

Millers berichtet weiter, dass er mehrere Pflanzen von Ananas lucidus selbst gezogen, den Samen hatte er aus Jamaica erhalten. Schliesslich bemerkt der Autor, dass er diesen Pflanzen den Namen ,Ananas" liess, weil dieser der bekannteste und gewöhnlichste sei. Er hält die genannten sechs Ananas nur für Varietüten, deren Früchte so wie bei anderen Früchten, nur in Gestalt, Farbe und Geschmack von einander a bweichen.

M'Pail, Nicol, Griffin und Baldwin nennen als die geschütztesten Varietüten der Ananassa sativa: die Königin Ananassa, ferner den braunen Zuckerhut, die schwarze Antigua und die schwarze Jamaica.

In der ,allgemeinen Encyclopädie der Wissenschaften und Künste" von Ersch und Gruber, Leipzig 1816, III, pag. 464, wird bei Ananas mit Bestimmtheit bemerkt, dass diese Pflanzenform unstreitig a us Afrika stamme und ausserdem vielleicht im Süden ron China heimisch sei; ob sie in Brasilien, Mexico u. s. w. ebenfalls heimisch sei, kann nicht genau bestimmt werden. In China heisst sie "Ungley," in Mexico "Matzatli," in England "Pine Apple," in Brasilien "Vanacous."

\section{H. G. Ritter.}

Es wäre jedenfalls von grosser Wichtigkeit, von Herrn Ritter zu crfahren, a uf welhem Wege er zu der 
Ueberzeugung gelangte, dass die Ananassa in Afrika heimisch sei?! - -

L o u d on berichtet in sciner Encyclopädie des Gartenwesens, Weimar 1823, 2. Lief., S. 616, dass die Ananas in den Tropenländern Asiens, Afrikas und Süd-Amerikas einheimisch sei und dass ihr ein kurzandauernder Kältegrad keinen Schaden zufüge. Da die Ananas ein dreijihriges Gewächs ist, welches nur ein einziges Mal Frucht trägt, so bedarf es einer Zeit von $1 \frac{1}{2}$ bis 3 Jahren, ehe man Friichte erzielt.

Herr von Martius sagt in seinem Beitrag zu den Agaveen Seite 42, Anmerkung 66:

„Es ist besonders auf dem Festlande (Amerika), wo man sich der Fasern aus den Blättern der Agave americana als einer Art „Pita" bedient. Aus den hochliegenden Thälern am GoazocoalcoFlusse und aus $\mathrm{Oxac}$ a wird diese weisse zähe Pita-Faser in die Seehäfen versendet. Man bereitet aus ihr einen sehr haltbaren Nähzwirn, Schnüre, künstliche Blumen, und sowohl in den genannten Lündern als in Brasilien spitzenartige Fleehtwerke, dessen sich besonders die Nonnen befleissigen. Um den Fasern meln $r$ Schmiegsamkeit zu ertheilen, wird der Schaum von ungekochtem. Salzfleische darüber gegossen oder eine mehrstünige Einweichung in Wasser und Oel damit vorgenommen. Der Name, "Pita“ (mit lusitanischerEndung, „Piteira ${ }^{6}$ ) st a m m t a u s der Sprache der Karaiben, womit auf den Inseln wie in Brasilien theils Agaveen, theils Bromeliaceen bezeichnet werden.

Ich erlaube mir hier anzufügen, dass "Pitta" der Name für die Bastfaser der Ananassa-Blatter (siehe Ananas Pitta Plum.), „Pitteira“ aber der Name für die Blattfaser der Agave vivipera-Blätter sei. (Siehe Arruda da Camera, p. 23.)

Als Beweis, wie behutsam man mit der Aufnahme mancher Berichte der alten Autoren sein muss, mag hier eine Stelle des berïhmten Dodoneus folgen, welche Ananassa betrifft, und 
wo sich die $\Delta$ blbildung des $A$. Costa nachgebildet findet. Der Autor sagt hierüber :

„Die wilde Ananas hat immer einen gerade aufstrebenden Stamm, so lang wie eine Lanze und so dick wie cin Orangenbaum, mit Stacheln besetzt. Die grössten Blätter liegen auf der Erde ansgebreitet; in der Form sind sie den Aloë-Blittern etwas ähnlich, jedoch viel diunner; zwischen diesen kommen die Knospen von zarter Gestalt, gelb, süss riechend; nachher folgen die Frïchte, denen der zahmen Ananas etwas ähnlich, so gross wie Melonen, blass-gelb oder weisslich grün, auch schön roth, in Theilen zusammenstehend wie Cypressenknospen (Friichte?), aher zwiebelartio, so dass sie von ferne grossen Zapfen gleichen. Die Sprossen sind so zahlreich am Grunde des Stammes, dass sie zu Spalieren oder lebenden Ziiunen verwendet werden. Aus den Wurzeln fliesst ein Saft oder Ocl, von Farbe gelb und von siissem Geruche. Die Sprossen sind auch voll Saft, wie überhaupt das ganze Gewiichs. Die Spitzen der Blätter werden, so lange sie noch weich sind, wis: auch die Bluthen, roh gegessen und schmecken wie Chardons, geben aber sehr wenig Nahrung. Die Früchte werklen sehr selten gegessen; sie sind sehr süss, jedoch dem Munde nicht sehr angenehm u. s. w.

Dieses Gewächs heisst in Arabien ,Gunuver," in Persien "Ananas," und "Angali," in Portugal "Ananas bravo" und im Lateinischen "Ananas sylvestris." Die Blumen heissen in Arabien "Chuxtacd," in Persien „Picrocbuith."

Pyrard schreibt, dass die Blätter sehr lang und schmal sind und an den Rändern stachelig; dass die Früchte, sowohl von der zahmen wie ron der wilden Pflanze, vierzehn Tage ohne zu verderben aufbewahrt werden können, aber nur in sehr feuchtem Zustande. Einige Indianer bereiten hiervon einen Wein, weleher wie französischer Cidre schmeckt, aber geistreicher und auch besser von Geschmack ist

Siehe Dodoneus Kruit Bock. Leyde, 1618. 
Unter den Arlueiten, welche über Ananassa bestehen, ist der „Bericht der Londoner Gartenbau-Gesellschaft über die Varietäten der Ananassa, " von Donald Munro daselbst am \%. December 1830 und 4. Jänner 1831 vorgetragen, der vollständigste und beste. Die englische Abhandlung trägt die Ueberschrift: ${ }_{\text {A }}$ A Report upon the Varieties of Pine Apple cultivated in the Garden of the Horticultural Society. By Mr. Donald Munro F. L. S. Gardner of the Society. Read, Decbr. 7 and 21, 1830 and January 4, 1831."

Es lässt sich bei dieser vortrefflichen Bearbeitung die Mithilfe der Feder des weltberühmten Professors L in d l e y in London nicht verkennen! Wenn auch diese treffliche Bearbeitung, welche sieben Jahre der eifrigsten Bestrebungen in Anspruch nahm, den Mangel hat, dass dieselbe nicht bis in die letzten Jahre hineinragt, so ist doch andererseits diese mühevolle sichtung bleibend im Werthe. Ich habe mich bestrebt, sämmtliche Erfahrungen und Ergebnisse der Jahre nach 1831 bis auf den heutigen Tag zu sammeln und, die Eintheilung von Munro zur Grundlage nehmend, eine umfassende Bearbeitung der Arten und Varietäten von Ananassa versucht. Uebrigens sind viele der älteren und neuen Varietäten der Ananassa sativa, welche mehr versprachen als leisteten, schon wieder aus den Sammlungen versehwunden.

Es ist nun die Frage: worin besteht die Veränderung der Formen der Ananassa sativa, im Vergleiche mit der wilden Ananassa?"

Die wilde Ananassa hat sich in ihrer Gesammtform durch die Pflege des Menschen nicht viel verändert. Die Hauptveränderung dürfte aber bei der Fruchtbildung zu suchen sein, die durch Uebernährung in allen Theilen angeschwollen erscheint. Es ist ein erheblicher Umstand, dass die Ananassa sativa nur in höchst seltenen Füllen - trotz künstlicher Befruchtung - einzelne Samen bildet, indem die mit Säften unnatürlich überfültte Frucht oft zur Zeit der Genussreife schon aufspringt und der Saft auszu- 
fliessen beginnt; hierdurch aber wird der noch nicht vollständig reife Same gewöhnlich mit der schnell eintretenden Fäulniss der Frucht gänzlich zerstört, indem er nicht gehörig abzutrocknen vermag.

Im kaiserlichen Museum zu Wien befindet sich eine gute Species der Ananassa, gesammelt von Poeppig am Amazonas in der Provinz Pará in Brasilien, mit Namen,,Bromelia Ananas Linné." Mein verehrter Freund, Herr Dr. Fenzl, hat mir diese seltene Pflanze zu untersuchen gestattet, wofür ich ihm neuerdings zu grossem Danke verpflichtet wurde. Hier hatte ich Gelegenheit, nachzuforschen, in welchem Stadium der Entwicklung sich diese Pflanzenform bei der Cultur zu verändern beginnt. Es finden sich zwei Exemplare der obigen Pflanze im kaiserlichen Museum: eines mit dem Blüthenstande, das andere mit der Frucht. Die Gestalt der Pflanze ist sehr schlank, der Stengel stielrund, mit wenigen langen, schmalen Laubblättern besetzt.

Zunächst dem Blüthenstande finden sich dieBlätter in sehr geringer Entfernung, so zwar, dass sie sich am Grunde decken. Sie sind aufrecht, abstehend, und überragen den Blüthenstand dergestalt, dass er wie zwischen die-

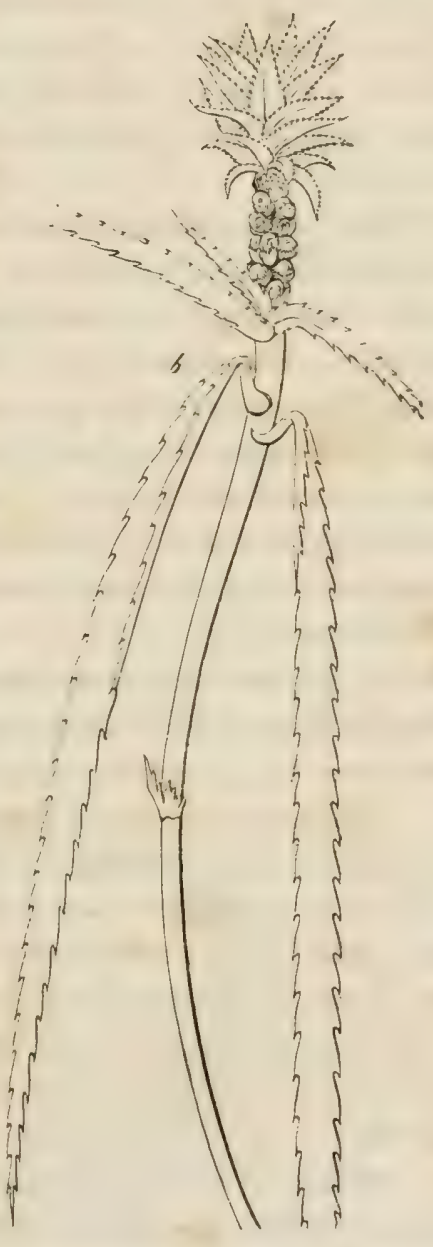

Eine wilde Aninassi. 
sen Blättern sitzend erscheint. Der Blüthenstand hat eine eiförmig runde Gestalt. Der Laubschopf ist noch unentwickelt.

Die Deckblättehen stehen dachziegelförmig; aufrecht, sind scharf gezihnt, bedecken und überragen die Blïthen um vieles. Es ist nach genauen Messungen in diesem Stadium der Entwicklung gar kein Unterschied zwischen dem Blüthenstande der guten wilden Sp. Ananassa und einer Ananasa sativa, welche nach weiteren Beobachtungen eine Frucht von zwei Wiener Pfunden lieferte.

Nun kommen wir aber zu Betrachtungen und Vergleichungen der Fruchtbildung der wilden Speeies mit jener der Ananassa sativa. Bei der wilden Ananassa ist der Laubschopf 11/2 " hoch, die Blätter desselben sind 1 bis $1 \frac{1}{2}$ " lang und am Grunde $3 / 4$ " breit; die Frucht nur um ein geringes länger als 1“; der Durchmesser derselben ist an dem getrockneten Exemplar nicht genau anzugeben, diurfte aber kaum iiber 1" erreicht haben. Es finden sich vier Reihen Beeren. Die Beeren stehen ohne sich zu drüngen. Sämmtliche Theile des Blüthenstandes scheinen wenig aufgetrieben gewesen zu sein.

Gegen den Laubschopf stehen vier Reihen sehr dicht übereinander gelegter Deckblätter, welche verkümmernde Blïthen umschliessen; die Anlage ist daher auf acht Beerenreihen vorhanden.

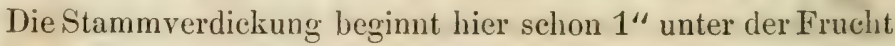
und scheint sich in derselben noch mehr ausgedehnt zu haben. Alle Theile an der Frucht sind gleichmässig eingetrocknet, was auf keine sehr saftreiche Beschaffenheit der einzelnen Theile wie auch der ganzen Frucht schliessen lïsst. Deckblätter und Kelchzipfel $3 \frac{1}{2}$ " lang, sümmtlich bis auf den Grund frei. Die Ovarien sind in die Spindel eingesenkt, wie dies überhaupt bei Ananassa der Fall ist.

Wemn wir nun die hier beschriebene wilde Ananassa und die Früchte der Ananassa sativa zusammenhalten, so findet sich nur der. Unterschied, dass bei Anan assa sativa alle Tlieile 
der Frueht samm t der Spindel übermässiganschwellen, und dass die ganze Frucht nur durch Cultur gezwungen wird, an Länge und Breite so a uffallend z uzunehmen.

Ich erlaube mir, die Wachsthumszustände der Ananassa sativa im cultivirten Zustande zu verfolgen.

\section{Ananassa sativa Lindl.}

1. Sïmmtliche Fruchtknoten in die fleischig werdende Spindel eingesenkt, - nackt.

2. Deckblatt und Kelchzipfel zur Blüthezeit ron unten auf durch Fleischigwerden erweitert, ab er na ch jener Entwicklung nicht mehr länger werdend.

3. Beim Vordrüngen der Blüthenknospen sind d i e D e ek bl ätter am Endeder Frucht und die Anlage zuden Laubblättern des Blattschopfes vollkommen gleich gestaltet.

4. Erst beim Beginnen des Anschwellens der ganzen Beerenfrucht entwickeln sich die Laubblitter und bilden die Blattkrone, aber auch diese verkümmert oft; die Frucht ist dann ganz ohne Laubkrone und bildet durch mehrere Reihen zusammengeneigter Deckblätter, die theilweise verkümmernde Blüthen umschliessen, die Frucht am oberen Ende ganz rund. Diese Erscheinung ist aber nie bleibend, indem ein Schössling jener Pflanze, welche eine blattschopflose Frucht bildete, dann doch eine Frucht mit Blattschopf liefert.

5.DieLaubkrone(d.) zeigt gleich bei der

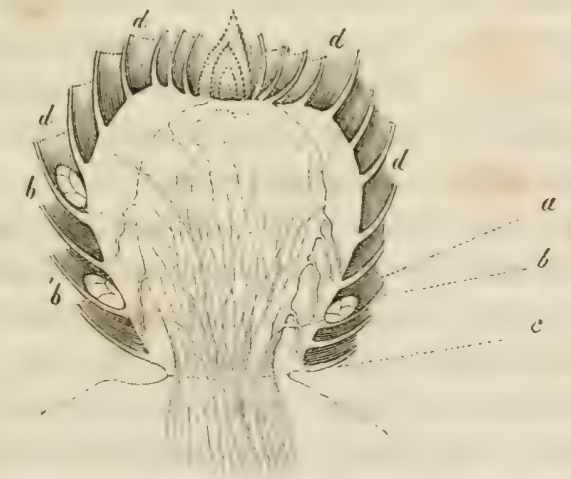

Durchschnitt der Laubkrone: 
Fruchtreife zwischen den unteren Blättern e in e $M$ enge $k l$ ein e r K n ospen (b.) die ebenso vertheilt sind, wie jene am Grunde des Hauptstammes. An dem Durchschnitte der Laubkrone zeigt sich die Wurzelbildung schon sehrentwi ckelt(a.); aber diese Wurzeln haben die fleischige Schichte, welche das Stammende umgibt, noch nicht durchbrochen. Der La u b s chopf is t daher eine vollständige Pflanze mit Knospen und Wurzeln, welche letztere nur die dünne fleischige Schichte zu durchbohren brauchen, um die Pflanze selbständig zu ernähren.

6. Erst nachdem die Blüthenknospe sich zu entwickeln beginnt, wird das Deckblatt am Grunde faltig, um seinem eigenen, sowie dem Anschwellen der Knospe nicht hinderlich zu sein.

7. Die Entwicklung der Anzahl der Blüthenknospen ist nicht durch die Anzahl der Deckblätter bedingt, indem die obersten Reihen der Deckblätter mehr oder minder zahlreich verkümmernde Blüthen umschliessen, hierdurch aber die Frucht mehr oder weniger Beeren bildet.

8. Deckblätter und Kelchzipfel werden endlich vom Grunde aus fleischig und durch das Anschwellen der Ovarien und der Spindel dergestalt vorgedrüngt, dass die sichtbare Begränzung der Basis der ersteren eine viereckige Form erhält; da aber auch, wie schon gesagt, die Deckblätter und Kelchzipfel am Grunde fleischig werden, so erscheinen diese Organe wie verwachsen und rund vorstehend. Dies beruht aber nur auf Täuschung, indem nach Messungen in den verschiedenen Stadien der Entwicklung der Frucht sich erwiesen hat, das d ie Länge der Organe si ch ganz gleich bleibt und nur das unverhältnissmässige Anschwellen aller Theile die Frucht rund bildet.

9. Die Fruchtknoten sind schon beim ersten Vordrängen des Blüthenstandes mit der Spindel scheinbar verwachsen, aber jeder derselben trägt seine $g$ ut begränzte $\mathrm{Ob}$ brhaut. Bei behutsamer Untersuchung eines augeschnittenen Theiles dieser Frucht vermag man den Fruchtknoten ganz auszulösen. 
10. Ananassa sativa trïgt trotz künstlicher Befruchtung nur iiusserst selten keimfihigen Samen; bei verkümmernden Beeren finden sich manchmal in Mitte der Reihen einzelne Samenkörner.

11. Ueberreif - platzt die Frucht, geht in Gührung über und fault schnell. Dies mag auch, wie schon früher bemerkt, mit Ursache sein, dass so selten keimfähige Samen sich finden, inclem der noch nicht ausgereifte Same gewöhnlich mit der Frucht verfault.

12. Jedes Laubblatt am Stamme zunächst der Frucht kann in der Achsel eine, obwohl gewöhnlich nur sehr kleine schopflose Beerenfrucht treiben; an häufigsten aber bilden sich hier nur Laubsprosse, welche am Grunde mehrere Reihen Niederblätter besitzen. Die Knospen in den Achseln der Laubblätter am unteren Ende des verkürzten Stammes sind auffallend zahlreich: ich habe 31 Stiick gezählt. Je mehr diese Knospen dem Lichté ausgesetzt sind, desto derber und grüner wird ihre ganze Gestalt.

13. Anan. sativa bildet manchmal drei, auch selbst fünf Blattkronen, auch ist hier zuweilen die gänzliche Verwachsung zweier Blattkronen in eine zu beobachten. Bei dieser Umwandlung zeigt der Blattschopf eine ganz regelmässige, dicht spiralige Stellung der Blätter, welche in geordneten Reihen stehend eine auffallend zierliche Erscheinung bieten. Auch verwachsen die Laubblätter manchmal dergestalt unter einander, dass sie eine hahmenkammähnliche Gestalt annehmen.

14. Zu den Seltenheiten gehört es, zwei gleich grosse, vollkommen und gleichzeitig reife Früchte an einem Stamme zu finden; aber hier steht eine Frucht immer etwas höher als die andere; dies ist erklürlich, indem die Blatt knospe zunäehst dem Blüthenstande gleichzeitig mit demselben statt in einen Laubspross, sich auch in einen Blithenstand verwandelt. 


\section{Classification}

der Arten und Varietäten der Gattung "Ananassa."

Species I. Ananassa muricata Beer. Frucht pyramidal. Bliithe purpurfarbig. Bractee in eine $3 \frac{1}{2}$ " lange scharfe Granne(Dornenfortsatz) auslaufend.

Species I1. Lnanassa sagenaria Beer. 1. Scharlachroth. (A. bract. Lindl.) Species III. Ananassa Jubilis Lindl. 2. Blätter wellenförmig.

Species IV. Ananassa lncila Lindl. 3. King. 4. Gerippte kugelförmige.

Species V. Ananassa sativa Lindl.

${ }^{*}$ Blätter dornenlos.

a) Blïthe purpurn. - 5. Havannah. 6. Smooth Havannah.

b) Blüthe lila, fast weiss. Frucht kugelförmig. 7. Green Antiqua. - Frucht pyramidal. 8. Striped smooth-leaved sugar-loaf.

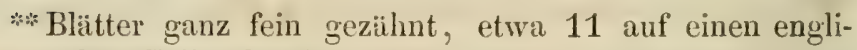
sehen Zoll gehend.

9. White Providence. 10. Green Java. 11: Black Jamaica. Frucht cylindrisch. 12. Orange sugar-loaf. 13. Downton Havannah. - Frucht pyramidal. 14. New-Jamaica. 15. New-Demerara. 16. Striped Surinam.

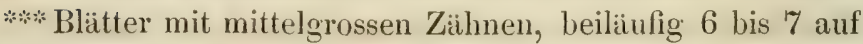
den englischen Zoll.

a) Blüthe purpurn. Frucht cylindrisch. 1\%. Sierra Leone. 18. Ansons. 19. Moutserrat. 20. Trooper's Helmet. Frucht pyramidal. 21. Green Providence. 22. St. Vincent.

b) Blüthen lila. Frucht cylindrisch. 23. Globe. 24. Lemon Queen. 25. Otahaiti. 26. Surinam. 27. Buck's seedling Globe. Frucht pyramidal. 28. Brown leaved sugar-loaf. 29. Brown sugar-loaf. 30. Mealy leaved sugar-loaf. 31. Black sug.-loaf. 32. Strip. leav. sug.-loaf. 33. Trinidad. 34. Buck's Seedl. 35. Env. 36. New-Env. 37. Spring Grove Env. 38. Lord Bagot's Seedl. 39. Bliethfield orange.

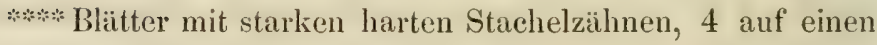
englischen Zoll gehend.

a) Blüthe purpurn. 40. Black Antiqua. 41. Welbeck Seedl. 42. Ripley.

b) Blüthe lila. Frucht kugelförmig. 43. Russia Globe. 44. Russian Cockscomb. - Frucht cylindrisch. 45. Queen. 46. Ripley Queen. 47. Green Queen. 48. Mroscorv Queen. 49. Strip. Queen. 50. Silver striped Queen. 51. Antiqua Queen und 52. Blood Red. 
ANANASSA muricata Beer.

Bromelia muricata Arruda da Camara. Dissert. Plantas que das linho etc. Rio Janeiro 1810, pag. 21. (Ananás de Agulha.) Anenas muricatus Schultes.

Arruda weist in obiger Schrift auf seine Centurie (primeira Centuria) hin; diese Arbeit ist jedoch in keiner Bibliothek zu finden. Er beschrieb in obiger Broschüre diese so ausgezeichnete Art nur flüchtig. - Er berichtet, „dass die Frucht der Form nach Aehnlichkeit mit seiner Bromelia sagenaria habe. Jedoch unterseheidet sie sichaufallend von allen ïbrigen Arten dadurch, dass siestatt der Bracteen aufrechte $3 \frac{1}{2}$ " Iange Stacheln hat, welche, anfrecht stehend, der ganzen Frucht ein fremdartiges Aussehen verleihen."

Die Bracteen bei den Beeren sind demnach $31 / 2$ "lang, starr gegrant. Dieses einzige Merkmal ist jedenfalls von so grosser Bedeutung, dass man, ohne eine ausführlichere Beschreibung, dennoch eine sehr gute Art erkennt. Dieses veranlasste mich auch, die Classification nit dieser eigenthümlichen Form zu beginnen.

\section{Anan. sagen aria Beer.}

Syn. Brazilian scarlet. - Scarlet.

Ananassa bracteata Lindl, Bot. leg. t. 1081. - Ananas sagenaria Schult. - Bromelia sagenaria Arruda da Camara Dissertat. Plantas que dao linho u. s. w. Rio Janeiro 1810, pag. 13.

Arruda beschreibt diese Pflanize:

Becren vereinigt in eine pyramidale Frucht. Bracteen $3^{\prime \prime}$ lang, sehr l:nng dachziegelförmig übereinander gelegt, die Frueht bedeckend. Blätter 3 bis !) lang und 1 $\frac{1}{2}$ " breit, an Rande mit scharfen Sitgezihnen bewehrt, rinnenartig, auf der innern Seite matt grün, auf der Aussenseite aschgrau. Schaft $1 \frac{1}{2}$ ' lang. Blüthe purpurblau. Frucht pyramidal, bedeckt mit den Bracteen, vom Geschmacke unangenehm sauer. Same von der Grösse eines Maiskornes.

Arruda.

II u n ro bemerkt über Ananassa bracteata:

Blätter lang, llach, ziemlich breit, hellgrün, oft am Grunde hellbraun bemalt, wenig mehlig bestäubt. Zühne sehr stark. Blüthe gross, dunkel-purpurn - zur Blüthezeit im schönen Gegensatze zu den prachtvollen hochrothen Deckblättern. Frucht pyramidal, vor der Reife trüb gelb gefïrbt, - zur Reifezeit blassgrïn, etwas mehlig bestïubt; voll- 
kommen ausgereift blassgelb von Farbc. Blattkrone breit. Blätter zahlreich, aufrecht.

II unro.

Planze gross und schön. Laubblätter steif aufrecht, die unteren etwas übergebogen, sehr zahlreich, bei $5^{\prime}$ lang und $2^{\prime \prime}$ breit, am Grunde wenig umfassend, desshalb bis zum Ende sichtbar.

Wenn sich der bläulich graue filzige Schaft erhebt, werden die Laubblätter, welche sich mit ihm erheben, lebhaft blutroth gefärbt; aber diese Färbung findet sich fast ausschliesslich nur auf der Aussenfläche der Laubblätter. Diese werden zunächst dem Blüthenstande bedeutend kürzer, stehen hier frei ab und verändern auch die Farbe der Unterfläche, indem selbe sehr hellgrau erscheinen; endlich umstellen sie in dichter Reihe den Blüthenstand. Dieser ist bei 4" hoch und nur um weniges schmäler. Die Bracteen desselben sind nervig, sägezähnig, mit den stachelspitzen Enden übergebogen, aussen lebhaft lila-rosa, mit hellgelb bemalt, innen feurig blutroth; am Grunde bauchig, 3/4" breit und $2^{\prime \prime}$ und darüber lang. Die Blüthen aufrecht, halb geöffnet, licht purpurblau, im Verblühen lederbraun werdend; in diesem Zustande kaum merklich gedreht, $1 / 2$ " sichtbar vorstehend. Kronenzipfel $3^{\prime \prime \prime}$ breit. Der Laubschopf erhebt sich 2 bis $3^{\prime \prime}$ hoch. Die Blätter stehen zierlich geschindelt; sie sind auf der Unterfläche lebhaft bläulich grün, mit weinroth bemalt. Oberfläche von hellroth in bläulich-roth übergehend. Frucht sauer, fast ungeniessbar, wesshalb sie auch „sauere Ananassa" in ihrem Vaterlande genannt wird.

Die kurze Beschreibung der Bromelia sagenaria von A r ru da gibt jedenfalls ein genügendes Bild des ganzen Gewächses und erlaubt, die Ananassa bracteata Lindl. mit Arruda's Pflanze für e in Gebilde zu erkennen, wesshalb ich auch die Benennung des Arruda beizubehalten mir erlaube.

\section{Anan. debilis.}

Syn. Waved-leaved.

Bot. Reg. 1068. Pomological Mag. tab. 1.

Blätter breit, dunkelgrün, wenig mehlig bestäubt, auf der Oberfläche blass purpur-licht gefärbt. Zähneklein, röthlich, gleich gross. Die ganze Pflanze nimmt 3’ im Durchmesser Raum ein. Blüthe blass purpurn. Frucht verlängert oval, vor der Reife sehr dunkelgrün, - ausgereift schmutzig gelb, mit griinlichem Antluge auf einer Seite. Blattkrone breit, ohne Sprossen.

Deutlich ausgezeichnet ist diese Pflanze durch ihre wellenförmig geschwungenen Laubblätter, welche nicht wie bei den anderen steif anfrecht sind. Sie ist demnach eine gute Species. 
3. Anan. Iucida.

Syn. King. - Gras-Green. - Common-King. - Old-King. - Havannah Nicol's. Ananas virilis inermis.

A. Incida virens, Dillenius Hort. Elth. XXII. - Trew et Ehret, Plantae selectae tab. III. Ananas lucidus Mill.

Laubblätter ziemlich lang, breit, mit entschiedenem Mittelnerv, stachellos und wellig am Rande, hell gelbgrün, gleichfarbig.

Herzblätter sehr dicht stehend. Blüthe purpurn. Frucht cylindrisch eilörnig, glänzend olivengrï̈. V'or der Reife glänzend orangenfarbig, vollkommen reif fleischroth. Ist eine gute Species. Mu un ro.

Lanbblatter ganz unbewehrt; sie erheben sich mit dem Schafte, sind hier stark überhängend oder abstehend, am Grunde nicht umfassend, nicht anliegend, anf der Unterfläche lebhaft grüu, aut der Oberfläche vom Grunde an lenchtend loch gelb-roth gefürbt, dann gegen die Spitze in hellgriu iibergehend. Sie umstellen den Blïthenstand nicht und sind sparrig, an demselben vertheilt stehend.

Blüthenstand kugelfürnig, 4" in Durchmesser, durch die in eine lange schmale Lappe endigenden, lebhaft fenerrothen, am Grunde umfassenden bracteen prachtvoll geflïbt. Beere plattgentriekt, rund, hellgelb mit roth bemalt. Blüthe als Knospe schon feurig blan von Farbe, am Grunde ins Weissliche übergehend, gerade abstehend, mit spitzen

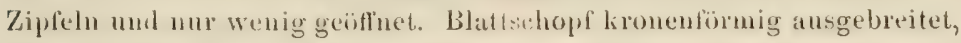
nur 1" hoch und 1 1 $\frac{2}{2}$ " breit. Die Bläter gleichtörmig iibergebogen, hellgrün mit roth-braun bemalt. Frucht lıell gelblich grün.

\section{Anan. 's ativa.}

\section{Syn. Fiseherwick Striped Globe.}

Laubblätter mit weichen unregelmässigen Zühnen an den Ründern, dunkelgrüin, gegen die Herzblatter zu sind sie auf der Unterfläche mit silberglänzenden Punkten ziemlich dicht bestrent.

Ist eine Varietät, welche aus einem Spross der Ananassa lucida gezogen wurde und welche 6 Jahre stand, ohne Frucht zu bilden.

5. Anan. sativa - Havannah.

Syn. Brown Havannah. Smooth-leaved Antiqua. Ripley - Ripley's. Old-King. - Common- King. - Ananas semi-serrata. - Lapete Pine Aple of St. Vincent.

Blätter schmal, lang und ausgebreitet, licht bläulich grün, stark mit lichtbraun angehancht, leicht mehlig bestiubt, stachellus, lennoch zuweilen wenige, nahe der Blattspitze. Blüthe purpurn.

Beer, Bromeliaceen. 
Frucht cylindriseh, zuweilen gespitzt, vor der Reife dunkelpurpurn, ziemlich dicht mehlig bestïnbt; reif tief orangefarben. Blatterkrone breit, reich, lang ansgebreitet.

\section{Anan. sativa - Smooth Havannah.}

Syn. Green Havannah, Havannah, - Ananas Antiqua aurantiaca.

Pfanze schwächlich. Blïtter ziemlich brïunlich und stark mehlig bestäubt. Frucht wie die Havammah, aber selten so gross.

\section{Anan. sativa - Green Antiqua.}

Syn. Smood-leaved Green Autiqua. - Smooth Green Havanuah. - Ananas sans epines. - Ananas Malabarica.

Bläter berlentend kïrzer als bei Havannah, anch blasser ron Farbe, breiter, mit stärker entwickeltem Mittelnerv und ganz unbewehrt. Blüthe sehr blass lila. Frucht kugelörmig, zuweilen eiförmig, vor der Reife sehmutzig matt griin, dicht mehlig bestaubt; ausgereilt - dunkelgelb. Beeren mittelmissig, rundlich, in eine scharfe Spitze verlaufend.

\section{Anan. sativa - striped-leaved suger-loaf.}

Laubblätter gänzlich unberehrt, blass-roth gestreift. Blüthe blasslila. Frucht wie beim gewöhnlichen Znckerhut.

\section{Ananassa sativ a - White Providence.}

Syn. Providence. - New-Providence. - Mealy leaved Providence. Ananas Providentia.

Laubblätter sehr robust und lang, hell bläulich grïn, zuweilen etwas tiefer grïn gefleckt, sehr mehlig bestïubt. Zähne sehr klein, dicht und ziemlich unregelmässig. Blïthe gross, dnnkel-purpurn.

Frucht eiförmig, anch tonnenförmig, oben und unten fast gleich dick, sehr dunkelgriin oler purpurfarbig, dicht bestïnbt. Bei ammähernder Reife allmälig in röthlich gelb übergehend.

\section{Anan. sativa - Green Java.}

Syn. Narrow-leaved Java.

Sehr ausgezeichnet durch sehr lange, breite, flache, mit kleinen,

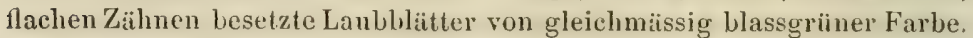
Blüthe gross, dunkel blïulich purpurn. Frucht eiförmig, zuweilen an derSpitze etwas verkïmmernd. Vor der Reife hellgriin, wenig bestäubt, im reifen Zustande rein citronengelb. 


\section{Anan. sativa - Black Jamaica.}

Syrn. Montserrat. - Jamaica. - Black Barbadoes. Copper coloured, Tawny. - St. Vincent sugar-loaf,

Lanbblatter lang und schmal, wenig ausgebreitet, mit Mitteherv, mat griin, dunkelbram angelaufen und ziemlich bestäubt. Zühne klein, sparsam. Blüthe purpurfarbig. Frucht eiformig, an den Enden stumpf, vor der Reife dunkel oliven-, zur Reifezeit dunkel orangefarben mit kupferroth bemalt.

\section{Anan. sativa - Orange sugar-loat.}

Laubblätter ziemlich lang und schmal, wenig gekielt und wenig ausgebreitet, schmutzig dunkelgriun, ins Dunkelbranne gefärbt und ziemlich mehlig bestüubt. Zähne kurz, wenig, gleichmässig vertheilt. Blüthe blass purpurn. Frucht walzenfömig, vor der Reife sehr dunkel olivengrïn, etwas glinzend und leicht bestiubt; zur Reifezeit dunkelgelb, in Orangefarbe ïbergehend. Krone mittelgross, durch zahllreiche ansgebreitete Blätter gebildet.

\section{Anan. sativa - Downton Havannah. Syn. Knight's Seedling,}

Gleicht der Smooth Havannah, mit dem Unterschiede, dass sie be wehrte Lanbblätter hat.

\section{Anan. sativa - New-Jamaica.}

Syn. Black Jamaica. - Newblack Jamaica. - St. Kitts, - Brown Antiqua. - English Globe. - Montserrat. - St. Vincent sugar loaf. W. Rae's St. Vincent.

Verschieden von Black Jamaica durch die blasseren, mit leicht umgebogenen Ründern versehenen Blitter. Frneht pyramilal, leicht mehlig bestäubt, schwarz ron Farbe, zur Reilezeit dunkel orangefarbig erscheinend. Laubkrone mittelgross.

\section{Anan. sativa - Nerv-Demerara.}

Syn. Harrison's New.

Blätter stark, sehr breit und ziemlich lang, mit Mittelrippe, dunkelgrün, auf der Oberiliche röthlich brann. Unterlläche sehr stark bestäubt. Zähne klein, gleichmässig. Bliithe lila. Frucht kugelig, oben und unten glatt, dunkelgrïn; vor der Reife und reif matt ockergelb mit roth bemalt, ziemlich mehlig an den Spitzen der weit vorspringenden Beere. Krone stark. Blätter ziemlich lang und aufrecht. 


\section{Anan. sativa - Striped!Surinam.}

Sym. Silvery striped Pine from Surinam. - Striped Silver and Pink Surinam. - Ribbon. - Prince of Wales Island. - Prince of Wales Island striped.

Blätter rein weiss gestreift, anf dnukelgrinem Grunde mit feurig roth bemalt. Frncht cylindrisch, mit gelb, roth und weiss verschiedentlich marmorirt. Krone mittelgross mit farbig gestreiften Blättern. Eine ausgezeichnete Schmuckptlanze, welche aber gegen 20 Jahre bedarf, um Friichte zu tragen.

\section{Anan. sativa - Sierra Leone.}

Blätter lang, breit, mit zurïckgebogenen wellenfürmigen Spitzen, lell bläulich griin, oft dunkler gefleckt. Zühne mitlelgross, regelmässig. Blïthe purpurn. Frncht cylindrisch, dunkelgriin, rüthlich bemalt, zur Reifezeit dunkel ockergelb clicht bestänt. Krone lang, flatterig. An der Basis der Frucht bilden sich oft eine Menge Sprossen. Die Sprossen am Stamme bilden manchmal kleine Frïchte, während die Hauptfucht noch nicht reif ist.

\section{Anan. sativa - Anson.}

\section{Syn. Anson's Queen. - Lemon Antiqua.}

Blätter lang, diinner und aufrechter als bei der ihr durch die Zähne und Blattfächen sehr ähnlichen Otahaite, Bliithe purpurn. Frucht cylindrisch, vor der Reife dunkelgrïn, ziemlich bestäubt, ... in reifem Zustande hoch citronengelb. Krone miltelgross, dnrch wenige Blätter gebildet.

\section{Anan. sativa - Montserrat.}

Syn. Copper. - Cap coast. - Bugwarp. - Red. Ripley. - New Ripley. Copper coloured Antiqua. - Cochineal. - Brazil. - Oldking. - St. Kitts. - Malacci. - Snmatra. - Ananas antiqua rubra. - Indian

Creole. - St. Vincent's Cockscomb. - Chevalier's Sierra Leone.

Blätter mit rlunkel purpurrothen kleinen unregelmässigen Zähnen bewaffnet. Bliithe purpmrn. Frucht eylindriseh, zuweilen kugelfürmig, vor der Reife dunkelgrïn und mehlig, zur Reifezeit blass orangen mit Lupferroth bemalt. Krone durch zahlreiche Blatter ziemlich gross.

\section{Anan. s a tiva - Trooper's Helmet.}

$$
\text { Syn. Cockscomb. - Hussar. - Broad leaved Java. }
$$

Blätter ziemlich lang, platt, blass gelblich grün, auf der Unterfläche bestäubt. Zühne regelmässig, mittelgross. Blüthe purpurn. Frucht stark 
cylindrisch, vor der Reife blassgriin und ziemlich lestiubt, im reifen Zustande dunkel ockerfarbig. Krone sehr stark und breit.

21. Anan. sativa - Green Providence.

Syn. Wallaton Prov. - Wall. Green Prov. - New Green olive. - Green Antiqua. - Royal Green Prov. - Royal Prov.

Blätter lang, sehr breit, etwas flach und an der Basis zusammengebogen, in eine verlängerte Spitze auslanfend. Aư der Oberfläche blassgriin, fast ohne mehlige Bestäubung. Unterfäche sehr stark bestäubt. Zähne regelmässig, mittelgross. Blïthe purpurn. Frucht pyramidal, an der Spitze breit, vor der Reife dunkelgriin, reif - blass orangen und leicht bestäubt. Krone klein, durch wenige Blätter gebildet.

22. Anan. sativa - St. Vincent.

Syn. Green St. Vincent. - Green olive. - St. Thomas.

Blätter schmäler, weniger zusammengebogen. (Ibertliiche blisser und mehr bestäubt wie bei Green Providence.

Bliithe purpur, mittelgross. Frucht stumpf pyramidal, wenig be. stanbt, matt olivengriin; zur Reifezeit gesiittigt gelb. Krone mittelgross. Blätter ziemlich zahlreich und zierlich ausgebreitet.

23. Anan. sativa - Globe.

Syn. English Globe.

Blätter starr, aufrecht, schmal, wenig zusammengebogen, Wliulich griun, sehr bestäubt, besonders aul der Unterfäche. Zïhne regelmissig, mittelgross. Bliithe lila. Frucht kugelig, zuweilen cylindrisch, dunkel olivenfurbig vor der Reife; zur Reitezeit duukelgelb, leicht bestiubt. Krone klein, durch wenige Blätter gebildet.

24. Anan. sativa - Lemon Queen.

Syn. Lemon coluured Barbadoes. - Barbadoes Qneen. -- White Barbadoes. - Ripley's new Queen.

Blätter geriffelt, an den Rändern oft umgebogen, bläulich griun, stark bestäubt. Ziihne ziemlich tief, mregelmässig. Bläthe gross. Frucht cylindrisch; mnreif glänzend hellgriun. reif blass limoniengelb, leicht bestäubt. Krone mittelgross, oft verbildet, hahnenkammiörmig.

\section{Anan. sutiva - Otahaite.}

Bläter lang, ziemlich breit, aufrecht, gleich breit bis zur Spitze, sehnell in eine Stachelspitze ibergehend, ausnehmend platt, dunkel blangriin, leicht bräunlich angellogen. Auf der Oberfläche wenig bestäubt. 
Unterfläche sehr stark bestäubt. Zähne mittelgross, auffallend unregelmässig. Bliithe lila. Frucht walzenförmig, zur Eiform sich neigend; unreif: dunkel olivengriin, dicht aschgrau bestiubt, reif: dunkel orangefarben. Die kleine Krone durch wenige aufrechte Blätter gebildet.

\section{Anan. sativa - Surinam.}

Blätter ziemlich schmal, leicht ausgebreitet, b]äulich griin, ein wenig bestäubt. Zähne ziemlich tief, nicht sehr regelmässig. Bliithe lila. Frucht cylindrisch; unreif matt griin, reif dunkel orangefarbig und ziemlich bestäubt.

\section{2\%. Anan. sativa - Buck's Seeding Globe.}

Blätter lang, ziemlich schmal, etwas zusammengebogen, ausgebreitet, bläulich grïn, licht braun-roth bemalt, dicht bestäubt. Zähne nicht selır stark, selı regelmässig. Bliithe dumbel lila. Frucht cylindrisch, zuweilen zur Kugelform sich neigend; vor der Reife dunkel schmutzig griin, etwas bestäubt, - reif lunkel orangefarben. Krone klein. Blätter kurz und gegen aussen gebogen.

\section{Anan. sativa - Brown leaved sugar-loaf.}

Syn. Striped brown leaved sugar-loaf. - Hocho. - Brown sugar-loaf. Antiqua sugar-loaf.

Blätter ziemlich stark, breit, etwas zusammengebogen und zierlich ausgebreitet, dunkelgriin, stark mit purpur-braun bemalt, ziemlich mchlig. Zähne mittelgross, regelmässig. Bliithe lila. Frucht cylindrisch, saftgriin, stark bestïubt; reif - dunkelgelb, in orangen iubergehend. Krone mittelgross. Blitter ziemlich zahlreich, ausgebreitet.

29. Anan. - sativa sugar-loaf.

Syn. Brown sugar - loaf.

Blätter wenig bestäubt, stark braun-roth bemalt. Frucht nicht bestäubt, hochgelb.

30. Anan. sativa - Mealy-leaved sugar-loaf. Syn. White sugar-loaf. - Dominica. - New Mealy leaved sugar-loat. Allen's Seedling, - Otahaite. - Brown sugar-loaf.

Blätter gerifielt, wenig bestäubt, schmutzig braun bemalt. Bliithc lila. Frucht pyramidal, matt griin, leicht bestäubt; reif blassgelb, in limoniengelb übergehend.

Krone durch kleine, zicmlich zahlreiche Blạtter gebildet. 


\section{Anan. sativa - Black sugar-loaf. Syn. Copper coloured Barbadoes.}

Frucht wic alle ,Zuckerhüte." Farbe dunkel purpurn, leicht bestäubt; vollkommen reif hell orangefurl)en. Krone ziemlich gross, durch wenige aufrechte Blätter gebildet.

\section{Anan. sativa - Striped leaved sugar-loaf.}

Syn. Green leaved with purple striped and spines on the edges. - Purple striped Queen. - Green sugar-loaf, - Green striped sugar-loaf. - Striped-leaved from Jamaicat. - Bird's Eye Bahma. Brown strip. sug.-loaf

Blätter breit, blassgriin mit dunkel purpurnen Streifen. Bliithe sehr blass lila. Frucht wie die anderen „Zuckerhüte" rein blassgriin und ziemlich mehlig; reif hochgelb.

Krone mittelgross. Blätter ziemlich zahlreich.

\section{Anan. sativa - T'rinidad.}

Syn. Pitch Lake of some.

Blatter zusammengebogen, sehr lang und hängend, breit an der Basis, regelmässig spitz zulaufend, dunkelgrïn, stark purpurbraun bemalt, besonders an den Spitzen der Herzblätter. Unterfläche selır bestäult. Zähne auffallend unregelmässig, in Büscheln angehäuft, mittelmïssig stark und zahlreich. Blithe lila. Frucht länglich kegelfürmig; nureif dunkel olivenfarbig, leicht bestiubt; reif dunkel orangefarben und roth an der Spitze der Beeren.

Krone sehr klein, sie bildet mit der Frucht zusammen einen regelmässigen Kegel. Blätter zurïckgebogen, stark rothbram bemalt.

\section{Anan. sativa - Buck's Seedling:}

Ptlanze in allen Theilen kleiner als bei Anan. Trinidad. Blätter leedeutend blasser, gleich griin, etwas bestäubt. Frucht vor der Reife stark bestäubt.

35. Anan. sativa - Enville.

Syn. Old Enville. - Cockscomb. - Enville sugar-loaf.

Blätter nicht sehr lang, aber ziemlich breit und stark, wenig genervt, etwas iibergebogen, bläulich grïn, sehr stark bestäubt. Zähne dicht, unregelmässig, mittelgross. Bliithe lili. Frucht vor der Reife pyramidal dunkel purpurn, in braunroth ïbergehend, und sehr bestänl,t; zur Reifezeit tief röthlich gelb, blass kup ferfarbig angellogen. Beeren mit langen scharfen Spitzen, Krone klein, oft hahnenkammförmig verbildet. 


\section{Anan. s ativa - New Enville.}

Blititer weniger mehlig bestaubt als bei Enville. Zahne starker und regelmässiger. Frucht eben so.

\section{Anan. sativa - Spring Grove Enville.}

Blätter lurz, breit und flach, mit zurückgebogenen Kanten, bläulich grün, stark bräunlich purpurn bemalt, ziemlich dicht mehlig bestäubt. Zähne mittelgross, ziemlich dicht und regelmässig. Bliithe lila. Frucht pyramidal, schr breit an der Basis, vor der Reife dunkelgrün und ziemlich stark melılig bestänbt, im reilen Zustande dunkelgelb. Beeren benabelt, ziemlich flach. Das Hiillblatt bedeckt die Beere bis zur Hailfte, und endet mit kurzer Spitze.

\section{Anan. sativa - Bagot's Seedling.}

\section{Syn. Lord Bagot's Seedl.}

Blätter ungewöhnlich kurz, breit und flach, bläulich grün, dicht mehlig bestäubt. Zähne ziemlich gleichmässig mittelgross. Bliithe lila. Frucht stumpr pyramidal, unreif dunkel grianlich roth, dicht bestäubt, reif blassgelb. Krone klein, mit wenigen Blättern.

\section{Anan. sativa - Blithficld Orange.}

Blätter wie bei Enville, jedoch etwas weicher und weniger melilig bestäubt. Frucht an der Spitze breiter wie bei obiger. Beeren etwas länger, zur Reife hell ockerfarbig. Kleine Krone mit wenigen Blattern.

\section{Anan. sativa - Black Antiqua.}

Syn. Brown Antiqua. - Jagged-leaf B1. Ant. - Wortley's West Indian.

Ausgezeichnet durch sehr lange, schmale, hell blau-grïne, scharf bewehrte Blatter, die Ilerzhlitter stark häunlich. Obertiiche wenig, Unterflache sehr stark bestäuht. Sehr entlomt regelmässig vertheilte scharfe Zähne an den Blatträndern. Bliithe purpurn. Frucht oval-cylindrisch, unreif trïb röthlich-grïn, dicht mehlig bestäubt, reif dunkel-ockerfarbig. Beeren sehr lang mod roragend. Das scharf gespitzte Deckblatt bedeckt die Becre ïber $1 / 3$ der Länge. Krone klein, mit wenigen aufrechten Blättern.

\section{Anan. sativa - Welbeck's Seedling:}

$$
\text { Syn. Crown. - Prickly Providence. }
$$

Blätter zierlich sich ausbreitend, am Grunde stark umfissend und sich in eine sehr scharfe Spitze ve riungend, schmutzig griin, leicht mehlig bestäubt. Zähne stark, regelmïssig stehend. Blüthe klcin, dunkel- 
purpurn. Frucht etwas cylindrisch, gewöhnlich oben breiter als unten, vor der Reife dunkel olivenfurbig, reif blass citronengelb. In Mitte der flachen Bceren stark mehlig. Deckblatt fast die halbe Beere bedeckend, mit scharfer Spitze. Krone zierlich, zuveilen hahnenkammfömig; die Blätter nicht sehr zahlreich.

42. Anan. sativa - Ripley.

Syn. Old Ripley. - Montserrat. - Brown sugar-loaf. - Indian black Pine St. Vincent.

Blätter breit, lang, zierlich iibergebogen, dunkelgriin, stark in rothbraun fallend, oben und unten melılig bestäubt. 'Zähne mittelgross, unregelmässig. Ränder umgebogen, anch wellenförmig. Blïthe purpurn. Frucht eirund, zuveilen etwas cylindrisch, an den Enden leicht eingedrückt; unreif sehr dunkelgrün, in Mitte der Beeren dicht bestänbt; reif blass liupferroth. Becren rorragend. Krome ziemlich gross. Blatter zahlreich, ausgebreitet.

\section{Anan. sativa - Russian Globe.}

(A. nervosa der Gïrten.)

Blätter ziemlich kurz und breit, etwas rinnig, ausgebreitet und ctwas gefureht, schmutzig griin, stark in braun fallend, leicht bestäubt. Stachel lang, dünn, sparsam und regelmissig. Blïthe lila. Frucht kugelförmig, zuweilen an der Spitze sich verjiingend, - unreif dunkel röthlich grün, dicht mehlig bestäubt, reif dunkel orangen, in kupferroth fallend. Beeren breit, flach, etwas eingedrückt. Krone ziemlich gross, durch abstehende Blätter gebildet.

\section{Anan. sativa - Russian Cockscomb.}

Blätter ziemlich stark, breit, kurz, etwas gefurcht, ziemlich flach, mit nongebogenen Ränlern, bianlich griun, leicht mit braun bemalt, stark mehljg hekleiłlet. Zahne regehmässig ziemlich entfernt stehend. Bläthe lila. Frucht kugelförmig, an Ende sich verjüngend, - unreif dunkelgriin, ziemlich bestäult; reif blass orangefarben. Beeren iber Mittelgrösse, zuweilen mit besonderen Auswiichsen versehen. Krone ziemlich klein, durch breite abstehende Blätter gebildet.

\section{Anan. sativa - Queen.}

Syn. Old Qucen. - Common Queen. - Narrow leaved Queen. - Broad leaved Queen. Ananas ordinaire (der Franzosen).

Blätter ziemlich steif, breit und kurz, ausgebreitet, mit Mittelrime, bäulich grän dicht bestäubt. Zälıne regelnässig, ziemlich entiernt 
stehend. Blithe lila. Frucht eylindrisch, vor der Reife hellgrïn bestäubt, reil schön dunkelgelb. Beeren ziemlich kleiı und wenig vorspringend. Krone mittelgross, Blätter zahlreich, zierlich ausgebreitet.

$$
\text { 46. Anan. sativa - Ripley's Queen. }
$$

Syn. Green Queen.

(A. nervosa der Gärten.)

Eine Varietät der Qucen.

47. Anan. sativa - Green Queen.

Blätter stälier als bei Queen, weniger bestäubt und oft ohne Zahne. Frucht im allgemeinen breiter, atuch die Beeren mehr vorstehend.

48. Anan. sativa - Moscow Queen.

Blätter gefurcht, auf der Unterfläche ohne Bestäubung, wesshalb sie hier gestreift erscheinen.

49. Anan. s ativa - Striped Queen.

Syn. Striped leaved Olive.

Blätter gelblich, selbst roth gestreift. Frucht ebenfalls buntfarbig.

50. Anan. sativa - Silver striped Queen.

Syn. Gold striped. - Silver striped.

Blattränder gestreift mit roth, im übrigen blass-grün.

51. Anan. sativa - Antiqua Queen.

Syn. Black Caraile. - Yellow Car. - Lord Effingham.

Blätter kurz, breit, mittelrinnig, wenig ansgebreitet, schmutzig griin, stark in hellbrann fallend, auf der Oberfiache sehr bestänt). Zähne regelmässig, entfernt stehend, scharf. Blïthe dunkel lila. Frucht cylindrisch, zuweilen gerundet, - unreif dunkel olivengrün, etwas bestäubt, reif' schmutzig gelb. Beeren gross, vorstehend. Krone ziemlich breit. blätter zahlreich ausgebreitet.

\section{Anan. sativa - Blood Red.} Syn. Blood. - Claret.

Blätter dunkel-purpurroth, lang, breit, anfirecht. Zalne regelmassig, breit. Blithe lila. Frucht cylindrisch, an der Spitze zuweilen sich verjüngend, - unreif dunkel purpurroth, sehr bestäubt, reif roth, chncoladefarbig. Beere mittelgross, leicht vor'suringend. Krone mëssig gross. Blätter ziemlich aufrecht, zahlreich. 
53. Anan. sativa - de Cayenne à feuilles lisses.

Laubblätter glatt, ganz unbewehrt. Frucht schr gross, pyramidal. Eine der küstlichsten Frichte, und auch hinsichtlich der Traglihigkeit sehr zu empfehlen.

54. Anan. sativa - de Cayenne à feuilles épineuses.

Laubblätter scharf bewchrt durch regelmässige starke Sägezähne. Frucht etwas gedrickt, pyramidal, sehr gross und rom köstlichsten (icschmacke, ebenfalls sehr empfehlenswerth durch Tragfähigkeit.

55. Anan. sativa - Cayenne Neumanni.

Eine gute Frucht, ohne besondere Vorzüge.

56. Anan. sativa - Cayenne Charlotte Rothschild.

Eine der grössten und besten Friichte nach den Beschreibungen.

5\%. Anan. sativa - de St. Domingue.

Eine köstliche Frucht, mit starkem Wohlgeruche. Frucht kugelig, hoch orangengelb, fast roth.

58. Anan. sativa - de Malabar.

Planze sehr stattlich. Laubblätter sehr lang und schari bewehrt. Frucht sehr gross, mit breiten Beeren, hochgelt, von vorziiglichem Geschmack und Geruch.

59. Anan. saitiva - Dumont d'Urville.

Lanbblätter auffallend kurz und steif anfrecht stehend, gänzlich unbewehrt. Frucht gross und vortrefllich.

60. Anan. sativa - de St. Lucie.

Blätter sehr lang und mit besonders langen und scharfen Ziahnen bewaffinet. Frucht sehr gross, cylindrisch, gelb. Beeren breit. Wohlgertuch und Geschmack vorzïglich.

61. Anan. sativa - de la Guadeloupe. benamnt die „Grussherzige." Vorzïgliche Frucht von gelber Farbe und gelbem Fleische.

62. Anan. sativa - Enville Pelvillain.

Frucht von ausgezeichneter Grösse und gleichem Geschmack. 
63. Anan. sativa - Enville de Gontier.

Frucht sehr verlingert walzenförmig oder pyramidal, von ausgezeichneter Gestalt und sehr feinem Geschmack.

64. Anan. sativa - Enville Reine Pomaré.

Frucht schr gross, stark und vorziiglich von Geschmack und von Geruch.

65. Anan. sativa - Reine de Français.

Eine stattliche, unbewehrte, sehr zierliche Pflanze.

Früchte prachtvoll und sehr gross, mit kugeligen, weit vorragen. den Beeren.

\section{Anan. sativa - Princesse de Russie.}

Laubblätter sehr schön blau-grün, mit braunen Streifen gezicrt. Frucht herrlich von Geschmack.

6\%. Anan. sativa - Martinique Comte de Paris.

Tracht und Form der Frucht wie bei den gewöhnlichen Pflanzen; die Frucht wird jedoch schr gross und trïgt sehr gern. Sie treibt schr wenige Sprossen.

68. Anan. Sativa - Enville Princesse royal.

Frucht pyramidal, sehr gross, nit stark vorragenden Beeren.

69. Anan. sativa - Le Roi.

Laubblätter glatt, ganz unbewehrt, sehr hellgrün. Frucht cylin. drisch. Die ganze Tracht der Pilanze ist so eigenthümlich, dass man sie lïr eine gute Species halten möchte.

\section{Anan. sativa - Martinique (oder Gemeine).}

Hat mehrere Varietäten, welche sich durch gefleck te und sehr zierlich gestreilte Laubblitter auszeichnen. Sie finden sich mit dem Namen ,) Mlartinique ${ }^{6}$ - mit weiss gestreiften Blättern, - mit gelb gestreiften Blättern und rosenfarbiger Frucht, - und mit goldgelb gestreiften Blittern. Diese Pllanzen bilden wahre Zierden in den Sammlungen und sind daher, obschon sie sehr selten Friichte liefern, nicht genug verbreitet. 


\section{Ueber die Art der Gewinnming und den Nutzen der Bastfaser aus den Blättern der Ananassa sativa.}

Es ist bekannt, dass die Bastfaser der Blitter der Ananassat und wahrscheinlich aller langhbittrigen Bromelien, in Amerika schon lange durch künstliche Mittel nutzhringend gemacht wurde. Dass nach Europa hieriber wenig bemerkenswerthes gelangt, darf nicht wundern, da nutzbringende Vegetabilien in den Tropenläuderu häulig sind und theilweise seln sorgfältig gepflegt werden, ron denen wir in Enropa selten Kunde erhalten. Es hricht sich aher mancher Pflanzenstoff auffallend schnell die Bahn, wis z. B. Lei Gut a pereh a es sich so anfliallend zeigt. Hier ist es jedoch der europaiische Speculationsgeist, welcher diesen Stuff gut erkannte und schnell zum Rivalen des Ka utschuk machte. Die Manipulation hei Gewinnung dieser Pflanzensüfte ist ganz einfach, wesshalb anch die Ausbente derselhen keine Schwierigkeiten fund, bis endlich die Bestande der Bäume, welche diese Stoffe lieferm, ausgerottet sein werden.

Anders verhält es sich aber bei Gewinnung von Pflanzenfasern; hierbei ist sehon ein mehr eomplicirtes Verfahren nüthig, anch will man gleich grosse Massen in den Handel bringen, um diesen Stoften bei der Fabrication Eingang zu verschaffen. Um dies zu erreichen, sind jedoch grosse Culturen oder oft schwierige Sammlungen der Gewïchse nöthig, welche sich aber, wem sie nutzbringend sein sollen, nur allmälig entwickeln dürfen. 
Die Bastfasern, welche die Blätter der Ananassa enthalten, niher kennen zu lernen, ist judenfills von grosser Wichtigkeit, indem es sich hier um einen edlen Pflanzenstoff handelt, der bis jetzt nur sehr wenig geachtet wurde.

Ich werde weiter unten auf die erstannliche Menge von Ananassa-Blätern hinweisen, welche nur allein in Deutschland jährlich als ganz nutzlos weggeworfen werden, und die man nicht eimmal gerne als Compost verwendet, da die Blätter oft nach Jahren noch durch ihre scharf bewehrten Blattränder dem Arbeiter sich schmerzlich fühlbar machen.

Ich erlaube mir hier auf jene Versuche hinzuweisen, welche init der Anzucht der Ananassa, - und zwar ohne besonderen Schutz - im Freien gemacht wurden.

Im Jahre 1847 hat Herr Barnes zu Picton in England die Möglichkeit gezeigt, über Sommer im Freien Ananassa-Früchte zur Reife zu bringen. Lady Rolle hat dieses Verfahren in Gardener's "Chronicle" No. 29, pag. 467 genau beschrieben. Wenn man im Stande ist, in England im Freien Ananassa-Früchte zu ziehen, so liegt es gewiss nahe, dass man ähnliche Versuche, und zwar jedenfalls mit bedeutenden Vortheilen, durch höhere Wärmegrade u. s. w. unter dem heiteren Himmel von Dalmatien und andern ähnlichen Landstrichen unserer Monarchie machen könnte. Man darf aber nicht unberiucksichtigt lassen, dass Barnes für dic Zucht im Freien Pflanzen wiblte, welche die Fruchtbildung schon zeigten; dieses setzt aber schon ein geregeltes Verfihren voraus. Auf Gewinnung von Frïchten mïsste man daher anfinglich in Dalmatien u. s. w. bei der Zucht im Freien verzichten; allein das scheint gewiss, dass ein kleiner Schössling von Ananassa sativa, im Fruhjahre dort ausgepflanzt, lis Herbst vollkommen genügende Laubbläter zur Gewinmmg der Bastfaser in Menge getrieben haben würde, und dass an dem Stamme sich genug Schösslinge gebildet haben werden, $и \mathrm{~m}$ im nächsten Jahre einen zehmmal grössern Raum damit zu bepflanzen. 
Die Ueberwinterung der Schösslinge bedarf nur eines warmen geschülzten Ortes. Es würde sich wahreheinlich schon im dritten Jahre zeigen, dass die Schösslinge, welche die Pflanze im Freien trieb, bei weitem kräftiger und ausdanernder sind als jene, welche man zum ersten Versuche aus den gewöhulichen Ananassa-Culturen entuahm. Den Standort im Freien betreflend, erlanbe ich mir darauf hinzuweisen, dass in Brasilien u. s. w. die wilde Ananassa und deren Varietuiten in Masse an freien Orten, und zwar in stark sandigem boden gefunden werden; hier stehen die Gewächse gewöhulich ganz nohe beisammen und bedecken oft bedentende Strecken, die sie allein in Anspruch nehmen.

Barnes stellte seine Ananassa-Pflanzen in einen Erdgraben, wo anf beiden Seiten die anfgehobene Erde einen Längswall bildete, damit die Hauptstrümung der Winte durch die Wälle von den Pflanzen abgehalten werden. In Dalmatien u. s. w. würden einjührige Pflanzen der Ananassa sativa ohne weitere besondere Sorgfult, und zwar in 1 1/2' Entfernung ron einander, im Anfunge des Monats Mai ausgepflanzt werden kömnen. Die Versuche werden lehren, ob solche Pflanzungen bewässert werden müssen, weun längere Zeit eine bedeutende Dürre des Bodens sich zeigt. Ich glanbe jedoch, dass eine künstliche Bewaisserung nicht erforderlich sein dürfte, indem die feuchten Luftzïge, welche von dem Meere das Land überströmen, der geniigsamen Ananassa wahrscheinlich zum Gedeihen hinreichend sind. Wenn anch bei diesen Versuchen die Spitzen der Laubblïter durch kalte Winde u. s. w. schwarz werden oder vertrocknen, so ist dieses ron keiner störenden Bedeutung, indem die Blattenden ohnehin zur Bastgewinumg am wenigsten geeignet sind. Das Hanptverdienst besteht hier in gut ausgebildeten robusten Blättern; diese zu liefern würde aber eine in freier Luft gezogene Pflanze sich jedenfalls am geeignetsten erweisen.

Die Beobachtungen an fremden Gewächsen, welche, endlich heimisch werdend, bei uns im Freien ohne Schutz zur Vollkommenheit gelangen, sind unsere besten Wegweiser. Desshalb erlaube 
ich mir, die treftliche Arbeit des Herrn ron Ma rtius im Auszuge hier anzureihen.

Herr von M a r tius berichtet in seinem , Beitrag zur N. und L. Geschichte der Agaveen, Hünchen 1855, Seite 49-50).

„In I) a I m a tie nerscheint eine Agave americana nach den brieflichen Mittheilungen des Herm de Visiani, südlich ron der Insel Arbe, sowohl auf dem Festlande als anf den Inseln, jerloch immer nur nahe an der Kïiste, im felsigen Grunde. Sie liebt siidliche Expositionen, gedeiht aber anch an anderen, so namentlich in den sïellicheren Insch Lesina, Lissa, Meleda, Calamotta, wo sie anch zur Blïthe kommt, was im nördlicheren Reviere nur iusserst selten der Fall ist."

Diese Mittheilungen des Herm ron Martus sind ron Wichtigkeit, weil sie bewcisen, dass das Klima ron Lalmatien, indem die Agave americana hier ganz frei, ohne allen sichutz fortkommt, gewiss auch fïr die Cultur der Ananassa sich tamglich crweisen wird. Es war für mich sehr erfreulich, bei den Forschungen, welche ich in dieser Angelegenheit anstellte, zu finden, dass in Wien schom im Jahre $18: 36$ Versuche gemacht wurden, die Bastfasern ans den Ananassa-Blittern geterinigt darzustellen.

Herr Ritter von Kees machte im Jahre 1836 im Augarten in Wien, die Gewinnung der Bastfasern aus deu Blättern der Ananassia betrefiend, mehrere Versuche; diese wurden unter seiner Aufsicht durch den Iterm Ilofgärtner Scheierma nu, welcher noch jetzt dem Augirten rorsteht, ausgefuihrt. Herr Scheierman $n$ hatte die Guite, mir das Terfihren hei Gewinnung dieser Blattfaser mitzutheilen. Die Blitter wurden nach der Fruchtreife von der Pflanze abgerissen und damn mit Holzschligel auf einem Holzstucke so lange geschlagen, bis die Faser von der Plattsubstanz sich endlich trennte. In Zwischenzeiten wurden die geschlagenen Blitter in weichem Wasser ausgeschwemmt. Diese Behandlung wurde so lange fortgesetzt, bis die Faser ron den andern Blattstoffen gereinigt war. Wenn die Faser durch Ueber- 
reste der Blattsubstanz noch verunreinigt sich zeigte, dann wurde eine Auflösung von gewöhnlicher Seife angewendet, die Fasern unter beständigem Klopfen mit dem Holzschlïgel bearbeitet und hierdurch endlich gänzlich gereinigt; d:ann liess man dic gewonnene gereinigte Faser einige Stunden im Vasser liegen und breitete sie zuletzt an einem geschützten schattigen Orte zum Abtrocknen aus. Nach diesem Verfahren wurde die Faser aufbewahrt. Die Proben, welche im Cabinete des k. k. polytechnischen Instituts hier in Wien sich befinden, sind clie Resultate der Bestrebungen des Herrn ron Kees; sie bestehen aus einem Büschel gereinigter und aus einem Büschel vollständig reiner Blattfasern.

Die Industrie-Ausstellung, welche im Jahre 185 zu Paris stattfand, zeigte mehrere Proben dieser Bastfaser aus den Blättern der Ananassa, welche die allgemeine Aufmerksamkeit der Kenner erregten, indem dieser Faserstoff, vollkommen gereinigt und sorgsam präparirt, alle andern Pflanzenfasern, selbst jene der Boehmeria utilis, an Feinheit, Glanz, Haltbarkeit und Weisse bei weitem übertrifft.

In Brasilien werden hiervon Strümpfe für Damen verfertigt, welche die seidenen übertreffen, nebst diesen rorragenden Eigenschaften aber noch den Vorzug bieten, dass die Erzeugnisse dieser Pflanzenfaser die gewöhnliche Wäsche sehr gut vertragen und hierdurch weder spröde werden, noch an ihrem Glanze verlieren.

Das Zusammenbringen der Laubblätter an einem Orte, wo überhaupt mit Lein oder Hanf manipulirt wird, bietet gar keine Schwierigkeiten, indem das Blatt lange Zeit liegen kann, ohne zu verderben. Die Versendung derselben an einen Sammelort bedarf ebenfalls gar keiner Sorgfalt, da die Blütter, in dichte Bündel zusammengebunden, ohne sonstigen Schutz verfrachtet werden können.

August, September und October sind die Nonate, in welchen die meisten Ananassa - Früchte geschnitten werden und desshalb auch zur Uebersendung der Blätter an einen Manipulationsort an geeignetsten; hicrdurch würden grosse Massen dieser B eer, Bromeliaceen. 
Blätter in kurzem Zeitraume anlangen und die Gewvinnung der Fasern auf einmal bewerkstelligt werden können. Jene vereinzelten Fülle, wo diese Gewüchse in den Wintermonaten Früchte tragen, sind nicht zu berüeksichtigen, indem es Hauptsache ist, das ganze Verfahren des Sammelns und der Versendung dieser Blätter so einfach und wenig zeitraubend als müglich zu machen. Da diese Blätter bis jetzt ganz werthlos sind, so ist auch gewiss anzunehmen, dass sie unter sehr billigen Bedingnissen zu erlangen sein werden.

Jedenfalls wird es förderlich sein, wenn man Versuche an versehiedenen Or:en mit diesen Bliittern anstellt und diese Proben dann an einem beliebigen Sammelorte zur Ansicht und Beurtheilung auflegt. Um über die Gewinnung dieser Bastfaser wo möglich gewichtige Quellen aus Amerika aufzufinden, war ich dureh die gesammte botanische Literatur, die sich auf die Familie der Bromeliaceen bezieht und die ieh zu diesem Zwecke benützte, immer aufmerksam.

Es erschien einekleine Broschüre in Rio-Janciro in Jahre 1830 von A rruda da Camara, welche aussehliesslich nur jene Pflanzen behandelt, deren Bastfasern in Brasilien für feine Gewebe, Seilerarbeiten u. s. w. gewonnen werden. Diese seltene Sehrift findet sich in den Bibliotheken Wiens nicht; ich erhielt es von Berlin ans der königlichen Hofbibliothek durch meinen verehrten Freund, Herm Dr. Pritzl. Diese wichtige Arbeit, welche auf Befehl des Prinz - Regenten von Brasilien erschien, beschreibt sehr ausführlich das Verfahren bei Gewinnung der Bastfasern aus verschiedenen Pflanzen.

Ich erlaube mir nun, das auf Ananassa u. s. w. Bezuigliche, aus der portugiesisehen Sprache übersetzt, wörtlich mitzutheilen.

Ob das hier mitgetheilte Verfahren bei Gewinnung der Bastfaser aus Ananassa-Blittern, wie es in Brasilien geschieht, auch bei uns gleiche und volle Anwendung finden kann, vermag ich nicht zu beurtheilen; jedenfalls bleibt es aber von hohem Interesse, genau 
zu wissen, auf welche einfache Weise man dort die Fasern von verschiedenen Gewächsen gewinnt.

\section{CAROA'。}

Bromelia variegata Arruda.

Die Blätter dieser Pflanze sind aus zwei Schichten zusammengesetzt. Die äussere ist convex, die innere concav; jene ist dicker und rauher, diese zarter; zwisehen der einen und der andern befinden sich lüngliche Bastfasern, welche beim Pressen der Blitter in saftiges Fleisch gehüllt sind. Diese Bastfaser ist fest, und es werden daraus, indem man sie künstlich behandelt, allerlei Strickwerk und grobes Tuch bereitet.

Die Einwohner von Rio de St. Francisco verfertigen ihre feinsten Fischernetze von den Fïden dieser Fasern. Man gewinnt auf zweierlei Art die Bastfaser der Caroa':

1. Man reisst die Blätter von dem Stamme, wozu nur wenig Kraft erforderlich ist, beschneidet die Blattränder mit dem Messer und reisst mit Gewalt die Bastfisem heraus; man nemnt desshalb diese Art, die Bastfaser herauszuziehen, die "Caroa'." Die auf diese Weise gewonnene Bastfaser ist grün und man muss sie durch Waschen reinigen.

2. Man reisst die Blätter vom Stamme, bindet sie in Bündel und wirft sie ins Wasser, wo man dieselben durch vier oder fünf Tage einweichen muss; dann klopft man die Bündel, jedoch ohne die Fuser mit dem Schlïgel stark zu bearbeiten. Diese Operation ist aber noch nicht genügend, die Fasern von dem Fleische oder den fremdartigen Theilen zu trennen. Man muss sie neuerdings in Bündel binden und dureh zwei Tage einweichen lassen, wie auch die Operation des Klopfens wiederholen; wenn nöthig, muss dieser Vorgang noch einmal wiederholt werden, dann tritt gewöhnlich die reine Faser heraus, welche man daun, damit sie sich nicht verwirre, zusammenflicht. In diesem Zustande wird die Bastfaser bündelweise in den Handel gebracht. 
Ich habe beobachtet, dass man die ganze Operation abkürzt, wenn man die noch frischen Blätter klopft, wodurch sie vor der ersten Einweichung schon zerquetscht werden. Faules oder stehendes Wasser ist hierzu besser geeignet als fliessendes und frisches. Wenn wir die auf die eine oder die andere Art gewonnene Faser vergleichen, so finden wir, dass die auf die erste Art gewonnene Bastfaser fester, aber auch kostspieliger ist.

Bei der Erzeugung dieser Bastfaser sind sechs verschiedene Operationen zu beobachten: 1. die Blütter von dem Stamme zu reissen; 2. die Dornen von den Blatträndern zu entfernen; 3. die Bastfaser mit den Hünden auszuziehen; 4. diese in einen Bach oder Brumnen zu legen; 5. die Fasern zu klopfen und 6. dieselben in der Somne zum Trocknen auszubreiten und zu sammeln.

\section{CRAUATA' de Rede.}

Bromelia sagenaria Arruda.

Man nennt diese Pflanze gewöhnlich „Crauatá de Rede" (Netz), weil die Eingebornen aus der hiervon gewonnenen Faser ihre Netze stricken und ihre Müntel weben. Die Bastfuser dieser Pflanze ist 3 bis S' lang, je nach der Fruchtbarkeit des Bodens. Auf einem dürren trockenen Boden ist die Bastfaser kürzer, feiner und glatter; auf einem fruchtbaren Boden hingegen wird diese Faser bedeutend länger, ist aber auch gröber und rauh anzufühlen.

Diese Faser erlangt schwer die Weisse durch gewöhnliche Waschungen, indem ihre Oberfläche mit einem natürlichen Firnisse bekleidet ist; aber gerade dieser Umstand ist schuld, dass sie in Wasser und Luft sich sehr haltbar beweist.

Stoffe, aus dieser Blattfaser gewebt, und ein Paar Strümpfe, welche man dem Ministerium sandte, zeigten zur Genüge, dass diese Faser bei einiger Verbesserung der Zubereitung jedenfalls zu den feinsten Geweben zu verwenden sei.

Die Blätter dieser Pflanze sind genau so wie bei der Bromelia 
variegata, nur mit dem Unterschiede, dass sich hier die Bastfasel schwerer von der Blattsubstanz entfernen lässt; dies verursacht auch eine Aenderung in der Behandlung. Die Blätter werden 12 bis 15 Tage in Wasser eingeweicht; ob die Einweichung rollkommen gelungen sei, erkennt man, wenn sich die Hälfte der Blattsubstanz mit den Nägeln trennen lässt. Alsdann zieht man die Blätter, eines nach dem andern, aus dem Wasser und schabt das Blatt, bis sich die Bastfasern blosslegen, und zieht dieselben behutsam heraus. Um sie gänzlich zu reinigen, flicht man sie zusammen und weicht sie nochmals einen 'Tag in Wasser, dann klopft man sie mit Schlaigehn auf einer Bank und wiederholt diese Einweichung und Klopfung so lange, bis die Faser ganz rein erscheint.

\section{ANANA'S Manso.}

\section{Bromelia Ananas Linné.}

Als ich mich im königlichen Auftrage mit der Erforschung der Bastfasern aus einheimischen Pflanzen beschäftigte, entdeckte ich im Jahre 1801 auch die Bastfasern in den Blättern der Bromelia Ananas.

Damals fand ich bei Vergleichung mit allen übrigen Pflanzenfasern, welche ich untersuchte, dass sie die festeste und feinste ist welche irgend eine Pflanze liefert.

Die erste Erfahrung, welche ich hieriber machte, war folgende: Ich nahm die Blätter von zwei Ananaspflanzen, welche zusammen 14 Pfund wogen, klopfte sie mit Schlïgeln, wusch die geklopften Theile und erreichte ron diesen beiden Pflanzen ein wenig mehr als ein riertel Pfund Bastfasern. Was die berührte Qualität dieser Faser betrifft, wiederhole ich noch einmal, dass sie selbst feiner als der emropäische Flachs ist und den grossen Vortheil bietet, dass die Fasern aus den Ananas-Blättern in einem Tage vollkommen gereinigt zubereitet werden können. 


\section{CAROATA' ASSU' ou PITEIRA.}

Agave vivipara Linné.

Die Methode, aus dieser Pflanze die Faser zu gewinnen, ist wie bei der Caroata, mit dem einzigen Unterschiede; dass man die Blïtter vor der Einweichung klopfen muss; dann nach 10 Tagen klopft man sie abermals, flicht sie zusammen und lässt sie wieder 3 Tage weichen, und wechselt so lange mit Klopfen und Einweichen (jedoch immer geflochten, damit sie sich nicht verwirren) bis die Faser rein ist.

\section{COQUEIRO.}

Cocos nucifera Linné.

Das Mittel, die Faser ron der Cocos zu gewinnen, ist nur: klopfen und einweichen. Vor der Einweichung muss man sie klopfen, da die ïussere Oberfläche sehr verstrickt und dicht ist, das Wasser aber hierdurch leichter eindringen kann; hierauf lässt man sie 2 bis 3 Tage im Wasser weichen, worauf man sie klopft und so abwcehselnd fortfährt, bis sich die Faser gereinigt darstellt. An frisch abgezogener Rinde ron Cocos ist die Blattfaser am leichtesten zu gewinnen.

\section{ANINGA.}

\section{Arum liniferum Arruda.}

Die Substanz des Stammes dieser Pflanze ist schwammig, gesättigt mit einem herben Safte, der die Metalle angreift. Einige Landleute bedienen sich dieser Eigenschaft, um ihre eisernen Geräthe damit zu putzen.

Die Lüngsfasern dieser Pflanze in dem Fleische derselben sind nicht sehr fest sitzend; es genügt daher das blosse Klopfen, wonach man sie auswïscht.

Die Leichtigkeit der Bereitung der Bastfaser und die ausserordentliche Menge dieser Pflanzen gehen ihr einen grossen Vorzug vor jeder andern Ṕflanzenfaser. Arruda da Camara. 
Ich erlaube mir hier schliesslich auf die Mengen der Laubblätter der Ananassa sativa hinzuweisen, welche in Oesterreich und Preussen jührlich erzeugi werden, wie auch deren Nutzen in Zahlen darzustellen.

Ein ausgebildetes Blatt der Ananassa sativa wiegt cirea . . . . . .

Eine Pflanze hat nach der Fruchtreife $3 \frac{1}{2}$ Loth. gewöhnlich 23 Blätter; diese wiegen zusammen

Eine Pflanze oder 23 Blätter liefern durchschnittlich 2 Pfund 16 ganz gereinigte Bastfasern.

In Oesterreich werden jührlich circa . . 15,000 Früchte, in Preussen ebenfalls jährlich eirca . . . 32,000, gezogen, also zusammen circa . . . . 47,000 Früchte.

Diese Pflanzen liefern demnach . . 1175 Ctr. Blätter, welche bisher als ganz nutzlos entweder verbrannt oder ganz weggeworfen wurden.

Sie enthalten vollkommen gereinigte Bastfusern 1838 Pfund.

Wemn auch die hier angeführten Zahlenverhältnisse noch manches zu wünschen iibrig lassen, so diurften dennoch Versuche mit hedeutenden Massen dieser Blitter recht bald den Beweis liefern, dass ein beachtenswerther Gewinn hierbei in Aussicht stehe, indem die gewonnenen Bastfasern in einem sehr günstigen Verhältnisse zu dem bis jetzt werthlosen Rohproducte steht und zu einem neuen Zweige der Industrie Veranlassung geben kann. 


\section{Repertorium der Bromeliaceen.}

ACANTHOSTACHYS.

Acanth. strobilacea Kl.

Jeones pl. Berol. tab. 9.

Paxton, Flower Garden III, 256. (Siehe Hohenbergia strobilacea Schult.)

\section{AECHMEA.}

Aechm. paniculata $R$, et Pav.

- angustifolia Poepp. et Endlicher. Nova Gen. Plant. t. 159.

(Siehe Hoplopliy tum angustifolium Beer.)

- corallina Brong. (Siehe Lamprococcus cor. Beer.)

- fulgens Brong. Paxton Mag. of Botany $X$, pag. 176. - Annales de Flore et de Pomonne, dann Aechmea fulgens discolor Brong. Bot. Mag. tab. 4293. - Annales de Gand. III.

(Siehe Lamprococcus fulgens und L, fulg, discolor Beer.)

- glomerata und A. glomer. disc. Hort.

(Siehe Lamprococcus glomeratus und L. glom, discolor Beer.)
Aechm. latifolia K1. Berl. Mus.

(Hoplophytum latif. Beer.)

- Mertensis Hook. Bot. Mag. tab. 3186.

(Siehe Hoplophy tum Mert. Beer.)

- miniata Hort, und Aechm. min. discolor.

(Siehe Lamprococcus miniat. $u$. Lampr, min. discolor Beer.)

- mucroniflora Hook. Bot. Mag. tab. 4832

(Siehe Hoplophytum mucroniflorium Beer.)

- spicata Martius. Nova Gen. Plant. Poeppig und Endlicher, pag. 43.

(Hoplophytum. spicatum Beer.)

- suaveolens. Floral-Cabinet III, tab. 134.

(Siehe Hoplophytum suaveolens Beer.)

- distichantha Lemaire. Jardin Fleuriste tab. 269.

Paxton, Flower Garden III, t. 80.

(Siehe Hoplophy tum distichanth. Beer.) 


\section{AGALLOSTACHYS.}

Agall. sylvestris Beer.

- fastuosa Beer.

- Pinquin Beer.

- antiacantha Beer.

- Commeliniana Beer.

- chrysantha Beer.

- variegata Beer.

\section{ANANASSA.}

Ananas muricatus Schult.

(Siehe Ananassa muricata Beer.)

- sagenaria Schult. (Siehe Ananassa sagenaria Beer.)

- Allen's Seedling. Syn. A. sat. Mealy leaved sugarloaf.

- Anson's Queen. Syn. A. sat. Anson's.

- sat. Anson's. (Siehe Ananassa.)

- Anson. Syn. A. sat. Mealy leaved sugarloaf.

- Antiqua aurantiaca. Syn. A sat. Smooth Havannah.

- sat. Antiqua Queen. (Siehe Ananassa.)

- Antiqua sugar-loaf. Syn. A. sativa brown leaved sugar-loaf.

- Antiqua rubra. Syn. A. sat. Montserrat.

- Barbadoes Queen. Syn. A. sat. Lemon Queen.

- black Barbadoes. Syn. A. sat. black Jamaica.
Anan. black Caraile. Syn. A. sat. Antiqua Queen.

- sat. black Jamaica. (Siehe Ananassa.)

- sat. Black sugar-loaf. (Siehe Ananassa.)

- sat. Black Antiqua. (Siehe Ananassa.)

- sat. Blithfield Orange. (Siehe Ananassa.)

- sat. Blood, Red. (Siehe Ananassa.

- blood. Syn. A. sat. blood. red.

- Brazil. Syn. A. sat. Montserrat.

- bracteata (Species). (Siehe Ananassa.)

- bracteata Lindl.

Bromelia sagenaria Arruda. (Arruda da Camara Disser-taçao. Plantas que dao linho u. p. Rio, 1810.j

Siehe Anan. sagenaria Beer.

- bracteata scarlet. (Siehe Ananassa.)

- Brazilian scarlet. Syn. Anan. bracteata.

- sagenaria Beer.

- Brid's Eye Bahma. Syn. Anan. sat. striped-leaved sugar-loaf.

- Bogwarp. Syn. Anan. sat. Montserrat.

- broad-leaved Queen. Syn. Anan. sat. Queen.

- brown sugar-loaf. Syn. Anan. sat. Mealy-leaved sugar-loaf.

- brown Havannah. Syn. Anan. sat. Havannah. 
Anan. Green olive.

Syn. Anan. sat. St. Vincent's.

- Green Antiqua. Syn. Anan. sativa Green Providence.

- Green St. Vincent's. Syn. Anan. sat. St. Vincent's.

- sat. Green Providence. (Siehe Ananassa.)

- sat. Green Java. (Siehe Ananassa.)

- sat. de la Guadeloupe.

- Heaton House Montserrat. Syn. Anan. sat. Ripley.

- Harrison's new. Syn. Anan. sat. new Demerara.

- Green Havannah. Syn. Anan. sativa smooth Havannah.

- sat. Havannah. (Siehe Ananassa.)

- Hussar. Syn. Anan. sativa Trooper's Helmet.

- Jagged leaf black Antiqua. Syn. Anar. sat. black Antiqua.

- Jamaica. Syn. Anan. sat. Black Jamaica.

- Indian black. Syn. Anan. sat. Ripley.

- Knight's Seedling. Syn. Anan. sat. Downton Havannah.

- Lemon Antiqua. Syn. Anan. sat. Anson's.

- Lemon coloured Barbadoes. Syn. Anan. sat. Lemon Queen.

- sat. Le Roi.

- Iucida Fisherwick striped Globe.

(Siehe Ananassa.)
Anan. lucida King. (Siehe Ananassa.)

- lucida (Species). (Siehe Ananassa.)

- sativa Lemon Queen. (Siehe Ananassa.)

- Lord Effingham. Syn. Anan. sat. Antiqua Queen.

- sat. Lord Bagot's Seedling. (Siehe Ananassa.)

- Macho. Syn. Anan. sat. brown leaved sugar-loaf.

- sat. de Malabar.

- Malacca. Syn. Anan. sat. Montserrat.

- Malabarica.

Syn. Anan. sut. Green Antiqua. - sat. Martinique Comte de Paris.

- mealy leaved Providence. Syn. Anan. sat. white Providence.

- sat. Mealy leaved sugar-loaf. (Siehe Ananassa.)

- sat. Moscow Queen. (Siehe Ananassa.)

- Montserrat. Syn, Anan, sat. new Jamaica.

- sat. Montserrat. (Siehe Ananassa.)

- Montserrat. Syn. Anan. sat. black Jamaica.

- muricata Beer.

- narrow-leaved Queen. Syn. Anan. sat, Queen.

- narrow-leaved Java. Syn. Anan. sat. Green Java.

- sat. nervosa Hort. und

- sat. nervosa maxima. (Siehe Russian Globe, Ripley.) 


\section{1}

Anan. brown Antiqua.

Syn. Anan. sat. New Jamaica.

-- brown striped-sugar-loaf.

Syn. Anan. sat. striped-leaved sugar-loaf.

- sat. Brown sugar-loaf. (Siehe Ananassa.)

- sat. Brown leaved sugar-loaf. (Siehe Ananassa.)

- brown Antiqua. Syn. Anan. sat. black. Antiqua.

- broad leaved Java. Syn. An. sat. Trooper's Helmet.

- sat. Buck's Seedling Globe. (Siehe Ananassa.)

- sat. Buck's Seedling. (Siehe Ananassa.)

- Cape coast. Syn. Anan. sat. Montserrat.

- sat. de Cayenne à feuilles épineuse.

- sat. de Cayenne à feuilles lisses.

- sat. Cayenne Charlotte Rothschild.

- sat. Cayenne Neumanni.

- Chevalier's Sierra Leone. Syn. Anan, sat. Montserrat.

- Claret. Syn. Anan. sat. blood red.

- Cochineal. Syn. Anan. sat. Montserrat.

- Cockscomb. Syn. Anan. sat. Frooper's Helmet.

- Cockscomb. Syn. Anan. sat. Enville.

- Copper-coloured Antiqua. Syn. Anan. sat. Montserrat.

- Copper.

Syn. Anan. sat. Montserrat.
Anan. Copper coloured Barbadoes. Syn. Anan. sat. Black sugar-loaf. - Copper-coloured. Syn. Anan. sat. black Jamaica.

- Commen King. Syn. Anan. luc. King.

- Commen Queen.

- Syn. Anan. sat. Queen.

- Crown. Syn. Anan. sat. Welbeck's Seedling.

- Indian Creole. Syn. A. sat. Montserrat.

- sat. Dawnton Havannah. (Siehe Ananassa.)

- debilis Waved leaved. (Siehe Ananassa.)

- debilis (Species). (Siehe Ananassa.

- Dominica. Syn. Anan. sat. Mealy leaved sugar-loaf.

- sat. Dumont-d'Urville. Syn. Anan. sat. New-Jamaica.

- English Globe. Syn. Anan. sat. Globe.

- sat. Enville. (Siehe Ananassa.)

- sat. Enville de Gontier.

- sat. Enville Prince Royal.

- sat. Enville Reine Pomaré.

- sat. Globe. (Siehe Ananassa.)

- Gras green King. Syn. Anan. luc. King.

- smooth green Havannah. Syn. Anan. sat. green Antiqua.

- sat. Green Queen.

(Siehe Ananassa.)

- sat. Green Antiqua. (Siehe Ananassa.) 
Anan. new Providence. Syn. Anan. sat. white Providence.

- sat. new Enville. (Siehe Ananassa.)

- sat. New Jamaica. (Siehe Ananassa.)

- sat. New Demerara. (Siehe Ananassa.)

- new green olive. Syn. Anan. sat. Green Providence.

- new ripley. Syn. Anan. sat. Montserrat.

- new black Jamaica. Syn. Anan. sat. new Jamaica.

- old-king. Common King. Syn. Anan. sat. Havannah.

- Old-king. Syn. Anan luc. King.

- old Enville. Syn. Anan. sat. Enville.

- old ripley. Syn. A. sat. Ripley.

- old Queen. Syn. Anan. sat. Queen.

-- Old King. Syn. Anan. sat. Montserrat.

- sat. Orange sugar-loaf. (Siehe Ananassa.)

- Otahaite. Syn. Anan. sat. Mealy - leaved sugar-loaf.

- sat. Otahaiti. (Siehe Ananassa.)

- Pitch Lake. Syn. Anan. sat. Trinidad.

- prickly striped sugar-loaf. Syn. Anan. sat. striped-leaved sugar-loaf.

- Prince of Wales' Island. Syn. Anan. sat. striped Surinam.
Anan. sat. Princesse de Russie.

- Providentia. Syn.Anan. sat. white Providence.

- Prickly Providence. Syn. Anan. sat. Welbeck's Seedling.

- purple striped Queen.

Syn. Anan. sat. striped-leaved sugar-loaf.

- sat. Queen.

(Siehe Ananassa.)

- Queen sugar-loaf. Syn. Anan. sat. striped-leaved sugar-loaf-

- Mr. Rae's St. Vincent. Syn. Anan. sat. new Jamaica.

- red ripley. Syn. Anan. sat. Montserrat.

- Rippon Grass. Syn. Anan. sat. striped Surinam.

- Ripley's new Queen. Syn. Anan. sat. Lemon Queen.

- sat. Ripley. (Siehe Ananassa.)

- Ripley. Syn. Anan. sat. Havannah.

- sat. Reine de Français.

- sat. Ripley's Queen. (Siehe Ananassa.)

- sat. Russian Cockscomb. (Siehe Ananassa.)

- sat. Russian Globe. (Siehe Ananassa.)

- Royal green Providence. Syn. An. sat. Green Providence.

- sativa (Species). (Siehe Ananassa.)

- sans épines. Syn. Anan. sat. Green Antiqua.

- sat. Sierra Leone. (Siehe Ananassa.) 
Anan. semi serrata.

Syn. Anan. sat. Havannah.

- silvery striped Pine from Surinam.

Syn. Anan. sat. striped Surinam.

- sat. Silver striped Queen. (Siehe Ananassa.)

- silver striped.

Syn. Anan. sat. striped Surinam.

- Smooth Antiqua.

Syn. Anan. sat. Havannah.

- sat. Smooth Havannah.

(Siehe Ananassa.)

- smooth leaved Green Antiqua.

- Smooth leaved Antiqua. Syn. Anan. sat. Havannah.

- sat. Spring Grove Enville.

(Siehe Ananassa..)

- Striped Silver and Pink Surinam.

Syn. Anan. sativa striped Surinam.

- sat. Striped Queen. (Siehe Ananassa.)

- sat. Striped-leaved sugar-loaf. (Siehe Ananassa.)

-- sat. Striped Surinam. (Siehe Ananassa.)

- sat. striped smooth leaved sugarloaf.

(Siehe Ananassa.)

- striped leaved olive. Syn. Anan. sat. striped Queen.

- sat. de St. Domingue.

- srt. St. Lucie.

- St. Kitt's. Syn. Anan. sat. new Jamaica.

- sat. St. Vincent. (Siehe Ananassa.)

- St. Vincent's Cockscomb. Syn. Anan, sat. MIo ${ }^{\text {ntserrat. }}$
Anan. St. Vincent's sugar-loaf. Syn. Anan. sat. black Jamaica. - sat. Surinam. (Siehe Ananassa.)

- Sumatra. Syn. Anan. sat. Montserrat.

- Tawny. Syn. Anan. sat. black Jamaica.

- sat. Trinidad. (Siehe Ananassa.)

- sat. Trooper's Helmet. (Siehe Ananassa.)

- St. Thomas?. Syn. Anan. sat. St. Vincent's.

- viridis inermis. Syn. Anan. Iuc. King.

- Wallaton Providence. Syn Anan. sat. Green. Providence.

- sat. Welbeck's Seedling. (Siehe Ananassa.)

- sat. White Providence. (Siehe Ananassa.)

- white sugar-loaf. Syn. Anan, sat. Mealy leaved sugar-loaf.

- white Barbadoes. Syn. Anan, sat. Lemon Queen.

- Wortley's West-Indian. Syn. Anan, sat. black Antiqua.

- yellow Caraile.

Syn. Anan. sat. Antiqua Queen.

\section{ANOPLOPHYTUM.}

Anopl. strictum Beer.

- rubidum Beer.

- roseum Beer.

- aëranthos Beer.

- dianthoideum Beer.

- bicolor Beer.

- pulchellum Beer. 
Anopl, lineare Beer.

- Duratii Beer.

- strobilanthum Beer.

- flexuosum var. pallidum Beer.

- vittatum Beer.

- Guianense Beer.

- xyphyoides Beer.

\section{BILLBERGIA.}

Billb. amabilis Beer.

- amoenn LindI.

- bicolor Lood.

- Croyiana Lem.

- cruenta Hook, Botanical - Mag. tab. 2892.

(Siehe Bromelia cruenta Graham.)

- Carolinae van Houtte. (Siehe Bromelia Carolinae Beer.)

- decora Poepp. et Endl.

- decora Linden (?) (Siehe Billb. pyramidalis var. minor Antoine et Beer.)

- discolor Beer.

- dubia van Houtte. (Siehe Billb. Wetherellii Hook.)

- fascista Lindl. Bot. Register tab. 1130 .

(Siehe Hoplophytum fasciatum Beer.)

- farinosa, Bot. Mag. tab. 2686. Sertum botanicum van Geel. (Siehe Billb. zebrina Lindl.)

- fasciata splendens Hort. (Siehe Billb. punicea Beer.)

- fastuosa Beer.

- (?) gracilis Poepp. Wiener MIus. Platystachys gracilis Beer.

- incarnata Beer.

- iridifolia Nees et Mart.

- lanuginosa Hort.
(Siehe Hoplophytum lanuginosum Beer.)

Billb. Liboniana de Jonghe (?).

Loddigesii Steudl.

(Siehe Billb. bicolor Lodd.)

- marmorata Lem.

- Moreliana Hort.

- Moreliana Hort. Jardin fleuriste II, tab. 138. - Gardener's Mag. of Botany III, 33 .

(Siehe Billb, amabilis Beer.)

- nudicaulis Beer.

- pallida Beer.

- Paxtonii Beer.

- polystachya. Paxton, Flower Garden tab. 80.

(Siehe Hoplophytum distichanthum Beer.)

- Porteana Brong. (?)

- purpurea Beer.

- purpurea van Houtte. (Siehe Bromelia tristis Beer.)

- purpureo rosea Lindl. Bot. Mag. tab. 3304.

(Siehe Hoplophytum purpureoroseum Beer.)

- punicea Beer.

- pyramidalis Lindl.

- pyramidalis var. bicolor Lindl. Bot. Reg, tab, 1181.

- pyramidalis var. minor Antoine et Beer.

- pyramidata Beer.

- rhodo-cyanea Lemaire. Flora van Houtte III, tab. 20\% - Bot. Mag. tab. 4883.

(Siehe Hoplopyhtum fasciatum Beer.)

- rosea Hort.

- saxatilis Beer.

- splendida Lem. 
Billb. tetrantha Beer.

- thyrsoidea Mart.

- thyrsoidea Mart. Paxton, Flower Garden III, tab. 74.

(Siehe Billb Paxtonii Beer.

- tinctoria Mart. Annales de Gand. III, tab. 56.

(Siehe Macrochordium tinctorium de Vriese.)

- variegata Beer.

- violacea Beer.

- viridiflora $\mathrm{H}$. Wendl.

- vittata Morel.

- Wetherelli Hook.

- Quesneliana Brong. Flora van Houtte tab. 1028.

(Siehe Quesnelia rufa Gaudich.) - zebrina Lindl.

\section{BONAPABTEA.}

Bonap.strobilantha R. et Pav. Flora Per, et Chil. tab. 263.

(Siehe Anoplophytum strobilanthum Beer.)

- juncea R. et Pav. Flora Per. et Chil. tab. 262.

(Siehe Platystachys.juncea Beer.)

Broch. paniculata Mart. in Röm. et Schult.

$\mathrm{Zu}$ Tussaciae Beer.

\section{BROMELIA.}

Brom, acange, Herb. Willd. No. 6315. Berl. Museum, Brasilien. Agallostachys acanga Beer.

- antiacantha Bertolini. Novi Com. Acad. sc. Just. Bononiensis tom VII, tab. XII.
(Siehe Agallostachys antiacantha Beer.)

Brom. Ananas Linné.

(Siehe Ananassa.)

- arvensis Arrab.

-- bicolor Philipi No. 204. Wiener Museum.

Bromelia carnea Beer.

- bracteata Sw. Kerner Hort. semperv. tab. 401.

(Siehe Hoplophytum paniculatum Beer.)

- blanda Schott. Brasilien. Wien. Museum.

Anoplophytum strobilanthum Beer.

- carnea Hort.

- Carolinae Beer.

- chrysantha Jacquin. Hortus Schönbrunn, tab. 55.

(Siehe Agallostachys chrysanthus Beer.)

- comata Beer.

- Commeliniana de Vriese. Descript. et Fug. des Plantes nouv. et rares. 1847.

(Siehe Agallostachys Commeliniana Beer.)

- concentrica Beer.

- cruenta Graham.

- exsudens Loddiges. Bot, Cabinet tab. 801.

(Siehe Hoplophytum paniculatum Beer.)

- fastuosa Lindl. Kerner, Hortus sempervirens tab. $\mathbf{7 4 5 .}$

(Siehe Agallost. fastuosa Beer.)

- fastuosa Lindl. Collectanea

tab. 1.

(Siehe Agallostachys fastuosa Beer.) 
Brom. Gaudini Beer. (Fossil.) Puya (?) Beer.

- grassa Steudl Wiener Mus. Brom. longifolia Rudge.

- humilis Linné.

- ignea Beer.

- incarnata R. et Pav. Fl. Per. et Chil. tab. 255.

(Siehe Billbergia incarnataBeer.)

- Karatas Jacquin.

- lanuginosa Beer.

- lasiantha. Herb. Willd. No.6312, Berl. Museum. Cumana. Agallostachys lasiantha Beer.

- latifolia Willd. No. 6316. Berl. Museum.

Hoplophytum latifolium Beer.

- lingulata Linné. (Siehe Hoplophy tum lingulatum Beer.)

- longifolia Rudge.

- longifolia Rudge (?). Paxton Flower Garden II, tab. 65.

(Siehe Brom. carnea Beer.)

- melanantha Bot. Reg. tab. "766. (Siehe Bacroc hordium melananthum Beer.)

- meridionalis (?) Berl. Museum. Billbergia meridionalis Beer.

- muricata Arruda. (Siehe Ananassa muricata.)

- nudicaulis Linné. Billbergia nudicaulis Beer.

- nudicaulis Ker. Exotic Flora tab. 143.

(Siehe Hoplophy tum uni-spicatum Beer.)

- Pinguin Linné.

Jacquin, Hist. select, pag. 91.

Redouter, Liliacees tab. 396.

Tussac, Flore des Antilles t. 22,
Dictionnaire des Sciences naturelles tab. 49.

(Siehe Agallostachys Pinguin Beer.)

Brom. pumila Schott.

(Siehe Cryptanthus acaulis? n-a

- pallida. Reichenbach, Miag. der Aest. Botanik tab. 94.

(Siehe Billbergia pallida Beer.)

- paniculigera Sw. Reichenbach, Hortus tab. 139, 140.

(Siehe Hoplophytum paniculatum Beer,)

- pyramidata Beer.

- pyramidalis Reichent. Hortus botanicus pag. 22, tab. 156 . (Siehe Billbergia fastuosa Beer.)

- pyramidata Plumier Pl. american. tab. 62 .

(Siehe Billbergia pyramidata Beer.)

- pyramidata purpurea Plumier Pl. american. tab. 63.

(Siehe Billb. purpurea Beer.)

- ramosa et racemosa etc. Plum. Plant. american. tab. 64 .

(Siehe Lamprococcus ramosus Beer.)

- sagenaria Arruda.

(Siehe Ananassa sagenaria Beer.)

- sylvestris Arrab.

- trietis Beer.

- sp. Philipi. Chili. No. 165.

Brom. Pinguin Jacquin.

- sceptrum Fenzl. Paradisus Vindobonensis.

(Siehe Agall. antiacantha Beer.)

- sylvestris Willd. Botan. Magaz. tab. 2392.

(Siehe Agallostachys sylvestris Beer.) 
Brom. sylvestris IVilld. Sertum botanicum van Geel.

(Siehe Agallostachys sylvestris Beer.)

-rsiflora Willd. No. 6313. Berl. Mnseum.

Hu -uphytum thyl'siflorum Beer.

- tinctoria Hort.

(SieheMacrochordium pulchrum Beer.)

- sp. Pohl. Bras. No. 3436. Mus. Wien.

(Woltersdorfia Kl.)

(Zu Agallostachys Beer.)

- sp. Sellow. Bras. No. 79. Mus.

Berlin.

Billb. pallida.

- variegata Arruda.

(Siehe Agallostachys variegata Beer.)

\section{CARAGUATA.}

Carag. Plumier.

(Siehe Carag. Lindl.)

- latifolia, clavata etc. Plumier. Pl. american. tab. 74 .

(Siehe Carag. latifolia Beer.)

- clavata et spicata etc. Plumier. Plant. american. tab. 75.

(Siehe Platystachys Plumierii Beer.)

- latifolia Beer.

- lingulata Lindl.

- splendens Bouché. Flore des Serres van Houttes tab. 1091.

\section{CHEVALIERA.}

Cheval. ornata Gaud.

- sphaerocepliala Gaud.

\section{CRYPTANTHUS.}

Crypt. acaulis

Beer.

- acaulis var. argenteus "

- $"$ ruber Beer. $"$

- diversifolius Beer. "

- zonatus.

- $\quad$ var. fuscus Visiani.
- $\quad$ viridis Beer.

\section{COCHLIOPETALUH.}

Cochl. albiflos Beer.

- flavescens

- Schüichii .

- stamineum .

\section{COTTENDORFIA.}

Cottend. Guianensis Kl. R. Schomb. 1564. Mus. Berlin.

(Zu Anoplophytae Beer.)

\section{DIAPHORANTHEMA.}

Diaph. recurvata Beer.

- capillaris

- virescens

- uniflora

- versicolor

- subulata

- triflora

- biflora

$n$
$n$
$n$
$n$
$n$
$n$

Dillenius Hort. Elth. II, tab. 211.

(Siehe Agallost. Pinguin Beer.)

\section{DISTEGANTHUS.}

Dist. basilateralis Lem.

\section{DYCKIA.}

Dyck. rariflora Schult.

- princeps Lem.

- tuberosa Beer. 
ECHINOSTACHYS.

Echin. Pineliana Brong.?

- rosea Beer.

- ? cylindrica Brong.

-? oblonga Brongn.

- Pinelianus van Houtte's Garten (Siehe Echinost. rosea Beer.

\section{ENCHOLIRIUM.}

Enchol. Augustae R. Schomb.

- Garrelii Beer.

GARRELIA.
Garr. encholirioides Gaudichaud.

Bonite, Atlas botanique tab.115. (Siehe Enchol. Garrelii Beer.

\section{GUZMIANIA.}

Guzm. erythrolepis Ad. Brongn. Flore des Serres van Houtte, tab. 1089.

- sympaganthera Beer.

- tricolor R. et Pav.

- pieta Hort. (Siehe Nidularium fulgens Hort.)

- tricolor. Exotic Flora tab. 163. (Siehe Guzmania sympagan thera Beer.)

\section{HOHENBERGIA.}

Hohenb. strobilacea Schult. fil.

- cyanthiformis Beer.

- terminalis

- bracteata

- brachystachys Poepp. W. Mus. No. 2399.

Platyst. brachystachys Beer.

- flexuosa Poepp. Wiener Museum No. 2716.

Platyst. flexuosa Beer.

\section{HOPLOPHYTUN.}

Hopl. fasciatum Beer.

- paniculatum n

- mucroniflorum

- cyaneum n

- angustifolium n

- spicatum

- Mertensis

- suaveolens

-- purpureo-roseum n

- distichanthum n

- augustum .n

- polystachium

- tetrastachium n

- uni-spicatum

- lanuginosum n

- platynema n

- lingulatum n

- spicatum n

- comatum n

Lamarque Encyclopedie t. 223.

(Siehe Bromelia ignea Beer.

\section{LAMPROCOCCUS.}

Lampr. fulgens Beer.

- fulgens diseolor n

- miniatus

- $"$ discolor $\pi$

- glomeratus . n

- $"$ discolor

- ramosus n

- Corallinus n

\section{MACROCHORDIUII.}

Macr. tinctorium de Vriese.

- melananthum Beer.

- bromeliaefolium

- pulchrum n

- strictum Beer. $\quad$ " 
Margrav. Pl. Brasil. III. tab. 37. (Siehe Billbergia? Beer.)

Mexocotl. Hernandez, Rerum med. n. Hisp. XV.

(Siehe Bromel. Karatas Jacquin.)

\section{NAVIA.}

Navia acaulis Mart. in Röm. et Schult.

(Zu Niduleriae Beer.)

(Cryptanthus?)

- caulescens Mart, in Römer et Schultes.

(Zu Anoplophytae Beer.) (Cottendorfia?)

NEUMANNIA.

Neum. Gigantea Brongn.

(Siehe Phlomostachys gigantea Beer.)

- imbricata Brongn.

(Siehe Phlomostachys imbricata Beer.)

\section{NIDULARIUM.}

Nidul. fulgens Hort.

- discolor Beer.

- purpureum "

- splendens Hort.

(Siehe Carag. splendens Bouché.)

- cyanea. Berl. bot. Garten.

(Siehe Hoplophytum cyaneum) Beer.)

\section{ORTHOPETALUM.}

Orthop. lanuginosum Beer.

- pulverulentum

- inerme
PALAEOXYRIS.

Palaeoxyris regularis Brongn.

(Fossil.)

Phlomostachys? regularis Beer.

\section{PHYTARRHIZA.}

Phytarrhiza Duratii Visiani. Memoire de Visiani, 1854.

(Siehe Anoplophytum Duratii Beer.)

\section{PITCAIRNIA.}

Pitcairn. albiflos Herb. Bot. Mag. tab. 2642.

(S. Cochliopetalum albiflos Beer.)

- albucaefolia Schrad.

- angustifolia Willd.

- angustifolia R. Aiton. Bot. Mag. tab. 1547.

(Siehe Pitc. tomentosa Dietrich.)

- asterotricha Poepp. et Endl.

- Beycalema. Hort.

- bracteata Ait.

- bract. var. Gireaudiana Beer.

- bract. var. sulphurea Hort. Bot. Mag. tab. 1416.

(Siehe Pitc. sulphureaAndrews.)

- bromeliaefolia l'Heret.

- densiflora A. Brongn.

(Siehe Phlomostachys densiflora Beer.)

- discolor. - Herbier général des amateurs V, tab. 345.

(Siehe Billbergia discolor Beer.)

- distacilia Beer.

- echinata Hook.

- exscapa Hook.

- fastuosa Morren. Annales de Gand. III, tab. 412.

(Siehe Billbergia fastuosa Beer. 
Pitc. ferruginea R. et Pav.

- flammea Lindl.

- flavescens Hort. (SieheCochliopetalum flavescens Beer.)

- fulgens Decsne.

- furfuracea Jacquin.

- furfuracea. Annales de Flore et de Pomone. - Blumenbachia, Schrader.

(Siehe Pitc. integrifolia Gawl.)

- heterophylla Beer.

- Jacksonii Hook.

- integrifolia Garvl.

- iridiflora Hort. Land.

- Karwinskyana Schult.

- laevis Beer.

- lanuginosa R. et Pav. Fl. Per. et Chil. tab. 258.

Kerner, Hort. semperv. tab. $24 \%$. Salvi Flora Italica III, tab. 99. (Siehe Orthopetalum lannginosum Beer.)

- latifolia Jacquin.

- latifolia. Bot. Mag. tab. 856. Bot. Mag. tab. 265\%.

(Siehe Pitc. furfuracea Hort.)

- latifolia. Herbier général des amateurs IV, tab. 223. Redouté Liliacees II, tab. 73. (Siche Pitc. bracteata Ait.)

- latifolia Ait. Hortus Herrenhusanus tab. 3 ist

Pitc. ringens KI.

- leiolema Hort. (Siehe Pitc. muscosa.)

- longifolia Hook.

- macrocalyx Hook.

- monstrosa Beer.

- muscosa Mart.

- nubigena $\mathrm{Pl}$. et Lindn.
Pitc. paniculata R. et Pav. Flora Per. et Chil. t. 260 ist

Pitc. longifolia Hook. Bot.Mag. t. $47 \% 5$.

- pulverulenta R. et Pav. Flora Per. et Chil. t. 259.

(SieheOrthopetalum pulverulentum Beer.)

- punicea Hort.

- Redoutéana Hort.

- ringens $\mathrm{Kl}$.

- staminea Lodd. Botan. Magaz. tab. 2411.

Loddiges, Bot. Cabinet tab. 723. Pertum botanicum van Geel.

(Siehe Cochliopetalum stamineum Beer.)

- suaveolens Lindl.

- sulphurea Andrews.

- tomentosa Dietrich.

- undulata Hort.

- undulatifolia Hook. Bot. Mag. tab. 4241.

(Siehe Phlomostachys Altensteinii Beer.)

- Warszewitziana KI.

\section{PIRONNEAVA.}

Pironneava glomerata. Gaudichaud. Bonite. Voyage. Atlas botanique tab. 63.

(Siehe Hoplophytum augustum Beer.)

- platynema. Gaudichand, Atlas botanique tab. 64 .

(Siehe Hoplophytum platinema Beer.)

\section{PITYROPHYLLUM.}

Pitiroph. erubescens Beer.

- gracile Beer. 
PHLOMOSTACHYS.

Phlom. Altensteinii Beer.

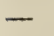

Beer.

- densiflora Beer.

- sulphurea "

- gigantea "

- imbricata "

- atrorubens "

- Funkiana "

—? regularis "

\section{PHOLIDOPHYLLUM.}

Pholidophyllum Visiani.

(S. Cryptanthus zonat. Visiani.)

\section{PLATYSTACHYS}

Plat. setacea Beer.

$\begin{array}{ll}\text { - anceps } & \\ \text { - heptantha } & " \\ \text { - viridiflora } & " \\ \text { - glaucophylla } & " \\ \text { - inanis } & " \\ \text { - bulbosa } & " \\ \text { - erythraea } & " \\ \text { - juncea } & " \\ \text { - degitata } & " \\ \text { - havanensis } & " \\ \text { - polystachia } & " \\ \text { - parviflora } & " \\ \text { - purpurea } & " \\ \text { - Kunthiana } & " \\ \text { - azurea } & " \\ \text { - Plumierii } & "\end{array}$

\section{POTHUAVA.}

Pothuava comata Gaudichand.

Bonite. Atlas botan. tab. 116.

(S. Hoplophytum comat. Beer.)

Pothuava spicata. Gaudichand.

Bonite. Atlas botan, tab. 117.)

(S. Hoplophytum spicatum Beer.)

\section{POURRETIA.}

Pourr. alpestris, Poeppig ct Endl. Nov, Gen, Plant, tal, 156.

(Siehe Puya alpestris Beer.)

- aeranthos. Rossi.

Cat. Motoetiensis tab. II. -

Herbier général des amateurs

V. tab. 304.

(Siehe Anoplophytum aeranthos. Beer.)

- coarctata, $R$, et Pav.

Fl, Peru, et Chil. III, 34, auch

Prodromus. - Bonite Gaudichand.Atlas botanique tab.41.Nov, Gen. Plantar. Poeppig et Endl. pag. 41.

(Siehe Puya coarctata Beer.)

- caerulea Mirs.

Puya caerulea Lind!.

Bot, Reg, tab. 11. (1840.)

- inermis Pressl.

Reliquae Haenkiana tab. 23.

(Siehe Orthopetal, inerme Beer.)

- lanata. Herb. Humboldt.

Berl. Museum.

Puya lanata Beer.

- lanuginosa. $R$, et Pav.

Fl. Pera, et Chil, tab. 256.

(S. Bromelia lanuginosa Beer.)

- magnispatlia.

Accad. Re di 'Torino. Tom, 31. tab. 19.

(S. Billbergia amoena. Lindl.)

- pyramidata. R, et Pav.

Fl. Peru, et Chil, tab. 57.

(Siehe Bromelia pyramidata.

Beer.)

- stricta Hort.

(S. Pityrophyllum gracile. Beer.)

- sympaganthera. R. et, Par. 
(Siehe Guzmania sympaganthera. Beer.)

\section{PUYA.}

Puya Altensteinii. L, Kl, et Otto. Jc. pl. Berol. tab. 1. - Annales de Gand. II. tab. 59. - Flore van Houtte II. 1846.

(Siehe Phlomostachys Altensteinii Beer.)

- Altensteinii var. gigantea Hook. Bot. Mag. tab. 4309. Flore van Houtte Il, tab. 253, 254.

(Siehe Plomostachys Alt.v. gigantea. Beer.)

- alpestris. Beer.

- chilensis Molina.

- coarctata. Beer.

- caerulea. Mirs.

- _ Lindley.

Botanical Register t. 11.(1840.)

- densiflora Hort.

(Siehe Phlomostachys densiflora Beer.)

- maëdifolia. Hort.

(Siehe Phlomostachys densiflora Beer.)

- Funkiana. Lindley.

(Siehe Phlomostachys. Funkiana. Beer.)

- ? Gaudini. Beer.

- Guianensis. Kl. Berl. Museum. Agallostachys Guianensis, Beer.

- heterophylla. Hort. Bot. Register tab. 71. (1840.) Dietrich bot. Zeitschrift.

(Siehe Pitcairnia heterophylla. Beer.)

- longifolia. Hort. Annales de Gand.II. - Paxtons Flower Garden III, tab. 86.
(Siehe Pitcairnia longifolia. Beer.)

Puya mäidifolia. Pl. et Lind.Flora van Houtte tab. 915. - Annales de Gand. V. tab. 289.

(Siehe Phlomostachys densiflora, Beer.)

- sulphurea. Hort. Herrenh. Bot. Mag. tab. 4696.

(Siehe Phlomostachys sulphurea. Beer.)

\section{QUESNELIA.}

Quesnelia rufa. Gaud.

\section{RENEALMIA.}

Renealmia ramosa lutea etc. Pater Feuillé. Amerikan. Pflanzen. tab. 39.

(Siehe Puya chilensis, Molina.)

- polystachia Jacquin. Historia select, pag. 93.

(Siehe Platystachys polystachia Beer.)

\section{STREPTOCALYX.}

Streptocalyx Poeppigii. Beer.

Tabernaemontanus, Kräuter-Buch pag. $13 \%$.

(Siehe Platystachys digitata. Beer.)

\section{TILLANDSIA.}

Tillandsia acaulis. Lindley. Bot. Register tab. 11\%,)

(Siehe Cryptanthus acaulis. Beer.)

- aloifolia Hook. Exotic Flora tab. 205. - Kerner Hort. Semperv. 822.

(Siehe Vriesea aloefolia Beer.) 
Tillandsia. aloides. Schiede. n. sp. 1009. Mus. Wien. (Siehe Tussacia aloides. Kl.)

- amoena. Loddiges. Bot. Cabinet tab. '76.

(Siehe Billbergia amoena Lindl.)

- anceps. Loddiges. Bot. Cabinet tab. 771.

(Siehe Platystachys anceps Beer.)

- augusta Arrab. Fl. Flum. t. 135. (Siehe Hoplophytum augustum Beer.)

- apicroides. Schiede. Jalarpa. Berl. Museum.

Tussacia apicroides Beer.

- azurea. Pressl. Reliquae Haenkiana tab. 24.

(Siehe Platystachys azurea Beer.)

- Benthamiana Kl. Berl. Museum Hartweg Mex.

Anoplophytum Benthamianum Beer.

- biflora. R. et Pav. Flor. Peru. et Chil. tab. 268.

(Siehe Diaphoranthema biflora Beer.)

- bicolor. Brong. La Coquille, Voyage par Duperrey. tab. 36. (S.Anoplophy tum bicolor.Beer.)

- bracteosa. Kl. Berl. Museum. Ehrenb. Haiti.

Vriesea bracteosa Beer.

- bracteata. Arrab. Fl.Flum. t.125. (S. Hohenbergia bracteata Beer.)

- bromeliaefolia Rudge. Plantarum Guianae. tab. 50. (Siehe Macrochordium bromeliaefolium Beer.)

- bulbosa Hook. Exotic Flora tab. 173.

(S. Platystachys bulbosa Beer.)
Tillandsia bulbosa var. pieta Hook. Bot.Mrag, tab. 4288. - Annales de Gand. III. tab. 255 .

(S.Platystachys ery thraea Beer.)

- calothyrsus. Poepp. Wiener Museum. Peru Nr. 1224.

Anoplophytum calothyrs. Beer.

- caespitosa. Schiede et Deppe. Wiener Museum Nr. 1007.

Vriesea caespitosa Beer.

- capillaris. R. et Pav. Fl. Peru. et Chil. tab. 271.

(Siehe Diaphoranthema capillaris Beer.)

- cinerascens Willd. Berl. MIuseum Nr. 6330 .

Platystachys cinerascens Beer.

- caerulea Knth. Berl. IIuseum. Herb. Humboldt et Bonpl. Platystachys caerulea Beer.

- comata Arrab. Fl. Flum. III. tab. 140.

(Siehe Bromelia comata Becr:)

- concentrica, Arrab. Fl. Flum. III. tab. 133.

(Siehe Bromelia concentr. Beer.)

- crinita.

Pluckenet Oper't omnia tab. 26. Fig. 6. - Sloane Nat. History of Jamaica tab. 122. Fig. 3. - cyanthiformis Arrab. Fl. Flum. tab. 144.

(Siehe Hohenbergia cyanthif. Beer.)

- dianthoidea, Rossi.

Cat. Motoetiensis tab. 1.

Herbier Général d. amat. t. 304 . Garten-Flora v. Regel, Mai 1854. Academia Neapolitana 5. t. 1. (Siehe Anoplophytum dianthoideum Beer.) 
Tillandsia auch Billbergia discolor und rubra. Hort.

(Siehe Nidularium, discolor unel N. purpureum Beer.)

- disticha Willd. Nr. 632\%. Berl. Museum.

Platystachys disticha Beer.

- distacaia Arrab. Fl. Flum. tab. 141.

(S. Piteairnia distacaia Beer.)

- Ehrenbergii Kl. Berl. MIuseum. Ehrenb. Hex.

Platystachys Ehrenbergii Becr.

- ensiformis Arrab. Fl. Flum. tab. 129.

(Siehe Vriesea ensiformis Beer.)

- erubescens. Hort. Herren.

(Siche Pityrophyllum erubescens Beer.)

- erythraea Lindley.

(Siche Platystachys erythraea Beer.)

— filifolia. Schiede. Nr. 1005. Berl. Museum.

Platystachys filifolia Beer.

- flexuosa var. pallida. Bot. Mag. tab. 749 .

(Siehe Anoplophytum flex. v. pallidum Beer.)

- flexuosa. Sw.? (Siehe Vriesea aloefolia Beer.)

- floribus violac. G. Andrieux. Wiener Mus. Nr. 60.

Platystachys violaceus Beer.

- floribunda. Humboldt Knth. Berl. Museum.

Platystachys floribunda Beer.

- fulgens. KItsch. (Siehe 'Tussacia fulg. Klotzsch.)

- Havanensis. Jacquin. Select. crip. america, hist, tab, 183.
(Siehe Platystachys havanensis Beer.)

Tillandsia heptantha $R$. et Pav.

Flora Peru, et Chil. III. pag. 41.

(Siche Platystachys heptantha Beer.)

- imbricata Arrab. Fl. Flum. tab. 131.

(Siehe Vriesea imbricata Beer.) - inanis Hort. Paxton Flower Garden I. tab, 210.

(Siehe Platystachys inanis Beer.) - incarnata? Berlin. Mus. Herb. Humboldt et Bonpl.

Platystachys incarnata Beer.

- ionantha Blanch. Flore van Houtte. tab. 1006.

(Siche Pityrophyllum erubescens Beer.)

- Kunthiana Gaud, Bonite, Atlas botanique tab. 53.

(S. Platystachys Kunthiana Beer.) -. laevis Arrab. Fl. Flum, t. 126. (Siehe Pitcairnia laevis Beer.)

- linearis. Arrab. Fl. Flum. t. 128. (S. Anoplophytum lineare Beer.) - lingulata Linné. Sloane Nat. Hist. of Jamaica. tab. 120.

(S. Caragua ta lingulata Lindley.) - longibracteata Meyen. Berl, Mus. Anoplophytum longebracteatum Beer.

- longifolia Mayen, Mus, Berlin. (S. Platystachys longifol, Beer.)

- maculata R. et Pav. Wiener Mus. Poepp. Nr. 1528.

Platystachys cyanea C. Koch. (Allardtia cyanea Ditrich.)

- macrostacliya Kl. Berlin. Mus. Ehrenb. Haiti.

Platystachys macrostach, Beer. 
Tillandsia maculata $R$. et Pav. Flora Peru. et Chil.tab. 268, - Kerner Hortus semperv, tab. 515. (Siehe Vriesea maculata Beer.)

- Moritziana, Kl. Berl. Museum. Moritz Columbia Nr. 449.

Platystachys Moritziana Beer.

- nitida Hook. Exotic. Fl. tab. 218. (Siehe Tussacia nitida Beer.)

- plachystachis Kl. Berlin. Mus. Ehrenb. Haiti.

Platystachys pachystachis? Beer.

- paniculata. Schiede. Berl. Mus. Nr. 1108.

Platystachys paniculata Bcer.

- polystachia Arrab. Fl. Flum. tab. 138.

(Siehe Hoplophytum polystachium Beer.)

- pruinosa. Sw. Wiener Mus. Platystachys pruinosa Beer.

- psittacina Hook. Botan. Mag. tab. 2841.

(S. Vriesea psittacina. Lindl.)

- punctulata Schiede Nr. 1006. Berlin. Museum.

Platystachys punctulata Beer.

- pulchella Lindl. Exotic Flora. tab. 154 .

(Siehe Anoplophytum pulchellum Beer.)

- purpurea. R. et Pav. Fl. Peru. et Chil. tab, $2 \%$.

(S. Platystachys purpurea Beer.)

- parviflora R. et Pav. Fl. Peru. et Chil. tab. 269.

(Sielie Platystachys parviflora Beer.)

- Quesneliana Hort. (Siehe Pityrophylum gracile Beer.)
Tillandsia ramosaSw.Berl.Museum.

Vriesea ramosa Beer.

- recurvata R. et Pav. Fl. Peru. et Chil, tab, 271.

(Siehe Diaphoranthema recurvata Beer.)

- regina Arrab. Fl. Flum. t. 142. (Siehe Vriesea regina Beer.)

- rosea Lindley. Bot. Register. tab. $135 \%$.

(S. Anoplophyt. roseum Beer.)

- rubida Lindley. Bot. Register tab. 63. (1842.)

(Siehe Anoplophytum rubidum Beer.)

- rubra $R$, et Pav. Fl. Peru, et Chil. tab. 266.

(Siehe Vriesea rubra Beer.)

- saxatilis Arrab. Fl, Flum, t. 139. (Siehe Billbergia saxatilis Beer.)

- scapo ramosa Mikan Nr. 3. Mus. Wien.

Vriesea ramosa Beer.

- Schüchii Beer.

(Siehe Cochliopetalum Schitchii Beer.)

- scoparia. Willd. Nr. 6332. Berl. Mlus.

Platystachys scoparia Beer.

- simplex Arrab. Flor. Flum. tab. 130 .

(Siehe Vriesea simplex Beer.)

- serrata. Lamarque Encyclopedie tab. 224.

(Siehe Platystachys Plumierii Beer.)

- setacea Sw. Bot. Mag. tab. 3275. (S. Platystachys setacea Beer.)

- setacea. Otto. Cuba. Berliner MIuseum.

Anoplophytum setaceum Beer. 
Tillandsia sessiliflora R, et Pav.FI. Peru. et Chil, tab, 271. (Siehe Tussacia sessiliflora Bcer.) - subulata. Arrab. Flor. Flum. tab. 127.

(Siche Diaphoranthema subulata Beer.)

- Sprengeliana Kl. Mus. Berlin. Anoplophytum Sprengelianum Beer.

- sp. Nr. 86. Schiede et Deppe. Wien. Museum.

Platystachys latifolia Beer.

- splendens. Brong. (Siehe Vriesea speciosa Hook.)

- stricta. Bot. Mag. tab. 1529. Sertum botanicum van Geel. Rossi. Cat. Modaetiensis. tab. 3. (Siehe Anoplophytum strictum Beer.)

- squamulosa. Willd. Nr. 6329. Berl. Museum.

Diaphoranthema squamul, Beer.

- tenuifolia? Röm. Schult. pag. 1215. - Sloane Jamaica tab. 122, Fig. 1.

(Siehe Diaphoranthema versicolor Beer.)

- tenuifolia. Jacquin. Select, america. Hist, tab. 63.

Kerner Hortus sempervirens. tab. 388.

(Siehe Vriesea tenuifolia Beer.)

— trichoides. Willd.

- tricolor. Schiede Nr. 1006. Ja= lapa. Berl. Museum.

Platystachys tricolor Beer.

- triflora. Arrab. Flor. Flum. tab. 134 .

(Siehe Diaphoranthema triflora Beer.)
Tillandsia tetrantha. R. et Pav. Fl. Peru, et Chil. tab. 265. (S. Billbergia tetrantha Beer.)

- tetrastachia Arrab. Fl. Flum. tab. $13 \%$.

(Siehe Hoplophytum tetrastachium Beer.)

- terminalis. Arrab. Fl. Flum. tab. 143.

(Siehe Hohenbergia terminalis Beer.)

- tortilis. Kl, Berl. Museum. Platystachys tortile Beer.

- tuberosa Arrab. Flor. Flum. tab. $15 \%$.

(Siehe Dyckia tuberosa Beer.

- uniflora Kunth. - Sloane. Jamaica tab. 221. Fig. 1.

(Siehe Diaphoranthema uniflora Beer.)

- unispicata. Arrab. Fl. Flum. tab. 124.

(Siehe Hoplophytum unispicatum Beer.)

- utriculatae. L. Wien. Museum.

Platystachys utriculatae Beer.

- usneoides. Lamarque Encyclopedie I. tab. 226. Fig. 12. Pluckenetii Opera omnia t. 25. Sloane Nat. History of Jamaica I. tab.122. Fig. 2. Petiverii Gazophylaceum I. tab. 62. Fig.12.(?) - vestita. Cham. etSchlecht.Wien. Mu.s. Hartweg Nr. 223.

Ist Anoplophytum vestit. Beer.

— vestita. Willd. Nr. 6326. Berl. Museum.

Macrochordium vestit. Beer.

- violacea Kl. Berl. Museum. Anoplophytum violaceum Beer, 
Tillandsia vitellina. Kltsch. (Siehe Tussacia vittelina $\mathrm{Kl}$.)

- variegata Arrab. Fl. Flum. tab. 132.

(Siehe Billbergia variegata. Beer.)

- virescens. R. et Pav, Fl. Peru. et Chil, tab. 270.

(Siehe Diaphoranthema virescens Beer.)

- vittata. Linden.

(Siehe Anoplophytum vittatum Beer.)

- zonata. Hort. Till. Zebrina Hort. Billbergia acaulis zebrina Hort. Till. acaulis zonata Hort.

(Siehe Cryptanthus zonatus Visiani.)

- sp. Sellow, Bras. Nr. $85-89$. Iruseum Berlin.

Anoplophytum bicolor Beer.

- sp. Sellow. Cras. Nr. \&8. Mus. Berlin.

Anoplophytum dianthoideum Beer.

- sp. Sellow. Bras. Nr. 86. Mus. Berlin.

Anoplophytum rubidum. Beer.

- sp. Sellow. Bras. Nr. 90. Musenm Berlin.

Anoplophy tum pulchellumBeer. Trew et Ehret. Pl. selectae tab, 51. (Siehe Bromelia ignea Beer.

\section{TUSSACIA.}

Tussacia vitellina $\mathrm{Kl}$.

- fulgens Kl.

- nitida Beer.

- sessiliflora
Tussacia Cornucopia Dr. Bertero. (Siehe Tussacia sessiliflora. Beer.)

\section{VRIESEA.}

Vriesea aloefolia Beer.

- aloifolia.

(Siehe Vriesea aloefolia Beer.)

- conferta Gaud.

- ensiformis Beer.

- gigantea Gaud.

- gracilis Gaud.

- imbricata Beer.

- incurvata Gaud.

- maculata Beer.

- platynema Gaud.

- psittacina Lindley.

- recurvata Gaud.

- regina Beer.

- rubra "

- simplex

- speciosa Lindl.

- tenuifolia Beer.

\section{VRIESIA.}

Vriesia (Vriesea!) glaucophylla Hook. Bot. Mag. tab. 4415. Flora van Hontte tab. 432.

(Siehe Platystachys glaucophylla Beer.

Viscum coriophylloides. Catesby's Nat. Hist. II. tab. 86.

(Siehe Platystachys digitata Beer.)

Billbergia marmorata Thibeaud et Keteler Paris.

Bromelia marmorata Beer. 


\section{Register}

\section{der beschriebenen Gattungen und Arten.}

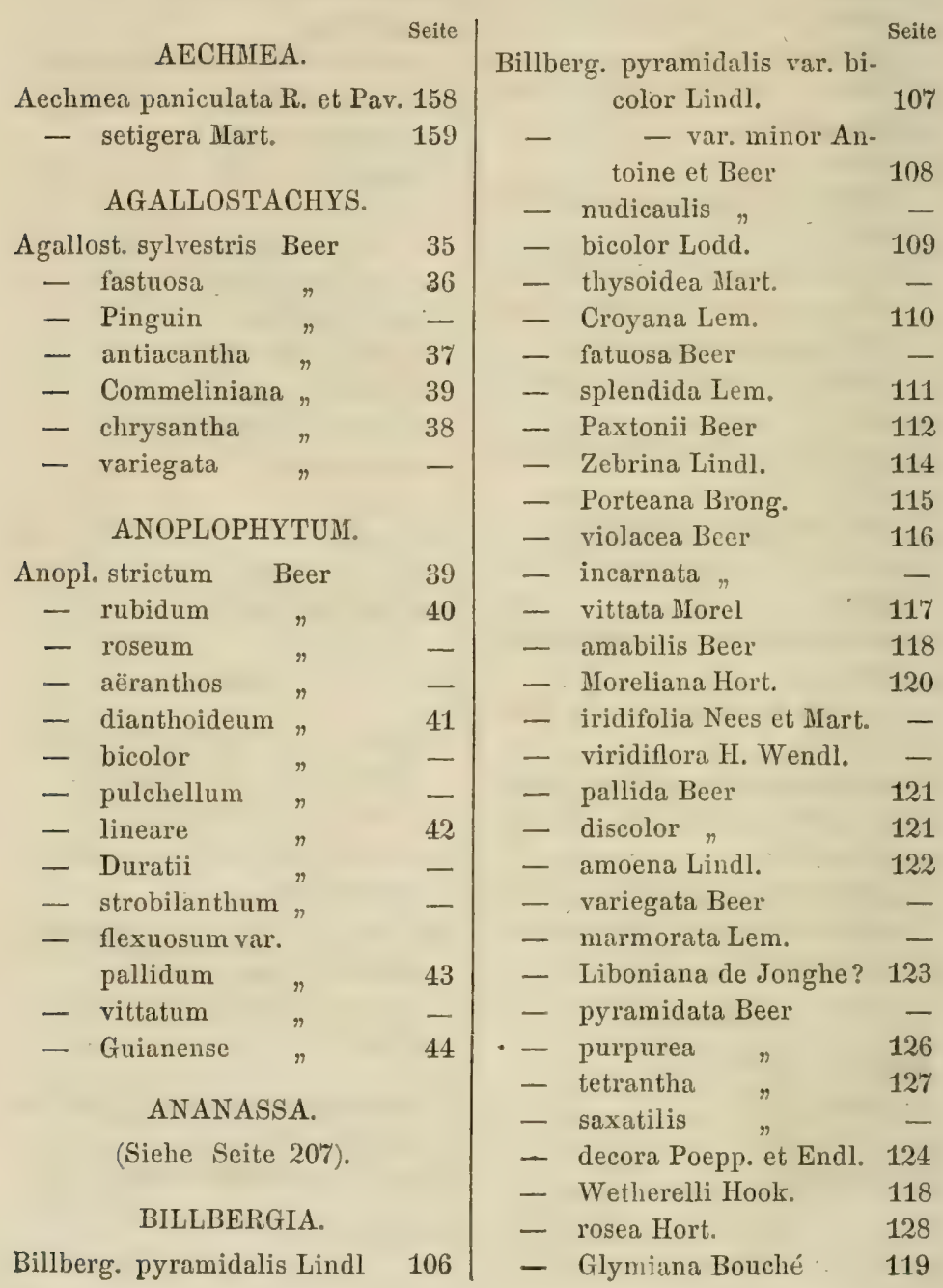




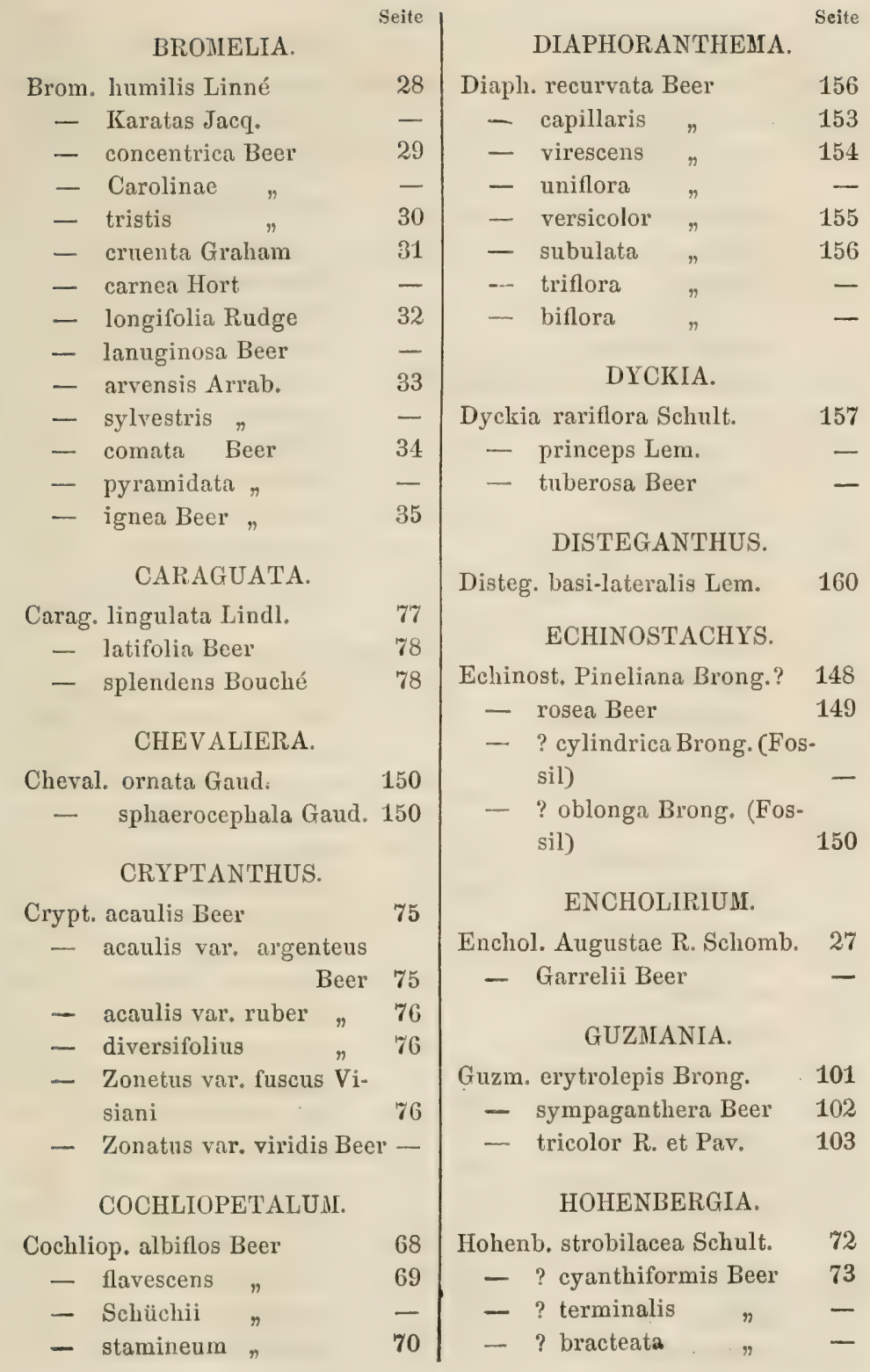




\section{HOPLOPHYTUM.}

$\begin{array}{lc}\text { Hoploph. fasciatum } & \text { Beer } \\ \text { - paniculatum } & " \\ \text { - mucroniflorum } & n \\ \text { - cyaneum } & " \\ \text { - angustifolium } & " \\ \text { - spicatum } & " \\ \text { - Mertensis } & " \\ \text { - suaveolens } & " \\ \text { - purpureo-roseum } & " \\ \text { - distichanthum } & " \\ \text { - augustum } & " \\ \text { - polystachium } & " \\ \text { - tetrastachium } & " \\ \text { - lani-spicatum } & " \\ \text { - platinema } & " \\ \text { - lingulatum } & " \\ \text { - spicatum } & " \\ \text { - comatum } & " \\ & \text { LAMPROCOCCUS. }\end{array}$

Lampr. fulgens

Beer 103

- - v. discolor.

- miniatus

- - v. discolor "

- glomeratus

- - v. discolor "

- ramosus "

- corallinus

MACROCHORDIUM.

Macr. tinctorium de Vriese

- melananthum Beer

- bromeliaefolium.

- pulchrum

- strictum

NIDULARIUM.

Nidul. fulgens Hort.

- discolor Beer

- purpureum
Seite

129

130

131

-

134

-

135

-

136

-

137

-

$-$

139

-

140

-

-

105

100

--

145

146

-

147

-

74

$\frac{74}{75}$
ORTHOPETALUNI.

Seite

Orthop. lanuginosum Beer $\quad 70$

- pulverulentum

- inerme $\$ 72$

PHLOMOSTACHYS.

Phlom. Altensteinii Beer 45

- Altensteinii var. gigantea

- densiflora

- sulphurea

- gigantea

- imbricata

- Funkiana

- atrorubens

- ? regularis (fossil),

\section{PITCAIRNIA.}

Pitcair. bracteata Ait.

- - var. Gireaudina Beer 51

- iridiflora Hort. Lond. -

- sulphurea Andrews 52

- macrocalyx Hook --

- asterotrichaPoepp. etE. 53

- ferruginea R. et Pavon. 54

- fulgens Decsne. 55

- ringens Kltsch. -

- punicea Hort. 56

- albucaefolia Schrad. $\quad 56$

- bromeliaefolia l'Heret. 57

- Redouteana Hort. $\quad 57$

- distacaia Beer 58

- echinata Hook.

- flammea Lindl.

- furfuracea Jacq.

- integrifolia Gawl.

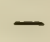

- Jacksonii Hook.

- laevis Beer

- latifolia Jacq.

- longifolia Hook. 
Pitcair. paniculata R. et Pav, $\quad 62$

- muscosa Mart.

- Beycalema Hort.

- nubigena Pl. et Linden. -

- angustifolia Willd.

- tomentosa Dietrich

- suaveolens Lindl.

- undulata Hort.

- Karwinskiana Schult. 161

- Warszewitziana Kltsch. 66

- Morenii Lem.

- exscapa Hook.

- longifolia Beer

- heterophylla,

- monstrosa

PITYROPHILLUMI.

Pityroph. erubescens Beer

- gracile

PLATYSTACHYS.

Platyst. setacea Beer

- anceps

-

- heptantha ,

- viridiflora

- glaucophylla

- inanis

- bulbosa

- erythraea

- juncea

- digitata

- havanensis

- polystachya

- parviflora

- purpurea $\quad$

- Kunthiana "

- azurea

- Plumierii

PUYA.

Puya coarctata Beer

80

82
Puya chilensis Molina

Seite

- alpestris Beer

144

143

144

- ? Gaudinii Beer (Fossil) 145

QUESNELIA.

Quesn. rufa Gaud.

STREPTOCALYX.

Strept. Poeppigii Beer

141

TILLANDSIA.

Tillan. usneoides Linné

151

- trichoides Willd.

153

- crinita Willd.

152

TUSSACIA.

Tussac. vitellina Kltsch.

99

- fulgens Kltsch.

100

- nitida Beer

- sessiliflora $r$

101

VRIESEA.

Vries. speciosa Lindl.

91

- incurvata Gaud.

81 - recurvata Gaud.

- conferta Gaud.

83 - gigantea Gaud.

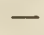

- - platynema Gaud. 93

86 - aloëfolia Beer 95

84 - tenuifolia Beer 96

85 - psittacina Lindl. -

87 - simplex Beer 97

88 - - gracilis Gaud. -

89 - regina Beer -

90 - maculata $n \quad 98$

- - rubra n -

Bromelia marmorata Beer.

(Eine Form wie Bromelia tristis 141 Beer.) 


\section{I n h a I t.}

Einleitung.

Seite

Begränzung und Ordnung der Bromeliaceen . . . . . . . 5

Schema der Haupt- und Unterabtheilungen . . . . . . 13

Schema der Sippen . . . . . . . . . . . . 14, 19. 23

Schema der Gattungen . . . . . . . . 16. 21. 24

Repräsentanten der Gattungen . . . . . . . . 25

Beschreibung der Arten . . . . . . . . . . . 27

Bemerkungen ülser die Gattungen bei den Bromeliaceen . . . . 163

Bemerkungen ïber die Blattorgane bei den Bromeliaceen und bei anderen Pflanzenfamilien . . . . . . . . . 190

Ueber Ananassa . . . . . . . . . . . . . . . 207

Classification der Arten und Varietäten der Gattung Ananassa . 222

Ueber die Art der Gewinnung und den Nutzen der Bastfaser ans den Blättern der Ananassa sativa u. m. a. . . . . . . . . 237

Repertorium der Bromeliaceen . . . . . . . . . . 248

Register der beschriebenen Gattungen und Arter . . . . . . 265 

Bei TEXI)LER \& COMP. int frner orschienen:

Lorinser, Dr. Gust.,

\title{
botanisches Excursionsbuch
}

fiir s'is

\author{
Intsch-östepretchischen Kronlämler \\ und das angrenzende Geliet.
}

12. 1854. hr. H. 2 -- in Leinwand geb. fl. $2.30 \mathrm{kr}$. C. Mr.

J)ruck von L. C. Zamarski in Wien. 




Beer, J. G./Die Familie der Bromelia

3518500072881 
